LEANDRO GOMES DE CARVALHO

UM ESTUDO CINÉTICO DA PRECIPITAÇÃO DE COMPOSTOS INTERMETÁLICOS E DA REVERSÃO DA MARTENSITA EM AÇOS MARAGING 300 E 350 


\title{
UM ESTUDO CINÉTICO DA PRECIPITAÇÃO DE COMPOSTOS INTERMETÁLICOS E DA REVERSÃO DA MARTENSITA EM AÇOS MARAGING 300 E 350
}

\author{
Tese apresentada à Escola Politécnica \\ da Universidade de São Paulo para a \\ obtenção do título de doutor em Ciências \\ no Programa de Engenharia Metalúrgica \\ e Materiais da Universidade de São \\ Paulo. \\ Área de concentração: \\ Engenharia Metalúrgica e Materiais \\ Orientador: \\ Prof. Dr. Angelo Fernando Padilha
}


Este exemplar foi revisado e corrigido em relação à versão original, sob responsabilidade única do autor e com a anuência de seu orientador.
São Paulo, 09
de hovembros
de 2016

Assinatura do autor:

deconero Gomes de Conwho

Assinatura do orientador:

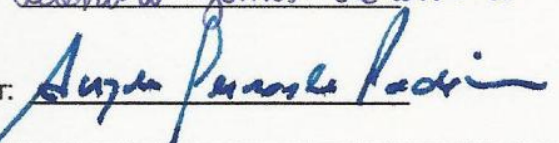

Catalogação-na-publicação

Gomes de Carvalho, Leandro

Um estudo cinético da precipitação de compostos intermetálicos e da reversão da martensita em aços maraging 300 e 350 / L. Gomes de Carvalho -- versão corr. -- São Paulo, 2016.187 p.

Tese (Doutorado) - Escola Politécnica da Universidade de São Paulo.

Departamento de Engenharia Metalúrgica e de Materiais.

1.Aços maraging 2.Cinética de transformações de fase 3.Precipitação de compostos intermetálicos 4.Reversão da martensita 5.Mecanismos de endurecimento I.Universidade de São Paulo. Escola Politécnica.

Departamento de Engenharia Metalúrgica e de Materiais II.t. 


\section{DEDICATÓRIA}

Dedico esse trabalho à minha querida esposa Liliane, aos meus pais Silvia e Manoel

e à minha sogra Estelita. 


\section{AGRADECIMENTOS}

A realização de trabalho como esse depende diretamente da confluência do esforço de diversas pessoas que, doaram parte de seus talentos individuais, bem como do apoio de várias instituições que tornaram possível a conclusão dessa tese.

Primeiramente, gostaria de agradecer ao meu orientador, Prof. Dr. Angelo Fernando Padilha, pela orientação dedicada, por seu apoio incondicional e pela paciência, pelos conselhos e motivações ao longo de todos os anos de trabalho, assim como pela mobilização dos recursos necessários para a realização dessa tese.

Agradeço igualmente ao Conselho Nacional de Desenvolvimento Científico e Tecnológico (CNPq) pela bolsa de doutorado concedida (Processo n 141675/20128) e pelo apoio financeiro para realização dessa pesquisa.

Ao Departamento de Engenharia Metalúrgica e de Materiais da Escola Politécnica da USP (PMT-USP) pela oportunidade de cursar o doutorado e pelos recursos experimentais usados nessa tese.

Ao Centro Tecnológico da Marinha pelos materiais fornecidos e pelas facilidades experimentais oferecidas, especialmente ao almirante Luciano Pagano Junior pelo incentivo para a realização desse trabalho.

Ao Prof. Dr. Marcelo de Aquino Martorano pelas suas críticas e sugestões na etapa de qualificação e de defesa do doutorado, que ajudaram a melhorar este trabalho. Gostaria também de agradecer pela sua participação no trabalho do congresso TMS 2015:144th Anual Meeting and Exhibition. Ademais, sou muito agradecido pela oportunidade de atuar como monitor PAE nas disciplinas de Fenômenos de Transporte e de Modelos Matemáticos e Simulação.

Ao Prof Dr. Ronald Lesley Plaut pela colaboração na publicação de trabalhos em periódicos e anais de congresso e a sua atuação como docente na disciplina de Metalurgia Física da Transformação Mecânica. Além da sua participação nesses trabalhos, ele alertou também a respeito dos limites da validade da equação JMAK para algumas situações, o que inspirou a parte da tese relativa à análise comparativa dos modelos JMAK e Austin-Rickett. 
Aos membros da banca de defesa, Dra. Margareth Spangler Andrade do SENAI-CETEC, Prof. Dr. Paulo Rangel Rios da UFF, Dr. Nelson Batista de Lima do IPEN, que contribuíram para o aperfeiçoamento da versão da final da tese.

À Prof. Dra. Izabel Fernanda Machado pelas críticas e sugestões durante a qualificação que contribuíram para o aperfeiçoamento da tese.

Aos colaboradores da Amazul que doaram parte de seus talentos na realização de alguns experimentos dessa tese. Em especial, Ricardo Gomide, Selma Luiza, Marcelo Soares, Marco Aurélio, Darlene Kobayashi, Odair Diná Rigo e Maurício.

A todos os colaboradores do PMT-USP, em especial aqueles que me ajudaram diretamente no trabalho experimental Danilo, José Gomes Veríssimo, Lívio Nunes, Rafael Rocha Maia.

À Profa. Cristina Borba dos cursos de redação acadêmica e de apresentação em inglês da Escola Politécnica.

Aos pesquisadores que tiveram a gentileza de permitir alguns experimentos em seus laboratórios, porém os resultados obtidos não foram aproveitados nessa tese. Dessa forma, agradeço ao Prof. Dr. Hugo Ricardo Zschommler Sandim e à Prof. Dra. Maria José Ramos Sandim, ambos pesquisadores atuantes junto à Escola de Engenharia de Lorena - USP; ao Prof. Dr. Antonio Domingues dos Santos do IFUSP; ao Dr. Lalgudi Venkataraman Ramanathan e ao Olandir Vercino Correa do IPEN.

Aos colegas do grupo liderado pelo Prof. Dr. Angelo Fernando Padilha: Angelo José de Oliveira Zimmermann, Daniel Sierra Yoshikawa, Denilson José Marcolino de Aguiar, Denise Adorno Lopes, Fabrício Mendes Souza, Litzy Choquechambi Cartoceno, Maysa Terada, Saul Hissaci de Souza, Tiago Evangelista Gomes e Wei Tsu Jinan.

Aos professores do Departamento de Engenharia e de Materiais com os quais tive a oportunidade de conviver nas disciplinas de pós-graduação e que me ajudaram na adaptação a uma linguagem que não era comum à minha graduação (Bacharelado em Física). Agradeço especialmente aos professores doutores André Paulo Tschiptschin, Cláudio Geraldo Schön, Douglas Gouvêa, Hélio Goldenstein, Marcelo Breda Mourão, Sérgio Duarte Brandi e Thomaz Augusto Guisard Restivo.

Aos demais colegas de pós-graduação de outros grupos de pesquisa no PMT que me ajudaram em diversos momentos e que permitiram uma rica troca de ideias. 
Às outras pessoas que contribuíram indiretamente para essa tese.

Por fim, gostaria de agradecer à minha esposa pela revisão final desse trabalho e pela sua paciência durante o meu processo de escrita dessa tese, bem como aos meus familiares por compreenderem os meus períodos de ausência para a finalização desse trabalho.

Soli Deo Gloria 
"É um erro comum supor que a esperança é a causa da ação.

A esperança é a consequência da ação: você age e então, como resultado, você começa a acreditar" 


\section{RESUMO}

O objetivo dessa tese é contribuir para 0 entendimento da precipitação de compostos intermetálicos e da reversão da martensita por meio de modelos cinéticos, tanto em experimentos isotérmicos no aço maraging 350 (350B) como em estudos não-isotérmicos nos aços maraging 300 (300A), maraging 350 (350C). Além da cinética das transformações de fase, foram estudadas também as mudanças da microestrutura e dos mecanismos de endurecimento decorrentes de tratamentos térmicos de envelhecimento para o aço maraging 350B. Para estas finalidades, foram usadas diversas técnicas complementares de caracterização microestrutural, como microscopia ótica (MO), microscopia eletrônica de varredura (MEV) com espectroscopia por dispersão de energia de raios X (EDS), microdureza Vickers, difração de raios $X(D R X)$ e ferritoscopia. Já a calorimetria exploratória diferencial (DSC) foi usada para estudar a precipitação de compostos intermetálicos e reversão da martensita em experimentos não-isotérmicos. Os resultados dos experimentos não-isotérmicos de DSC com os aços maraging 300 e 350 evidenciaram que a precipitação ocorre em duas etapas. A primeira relacionada à difusão de soluto no volume com energia de ativação próxima da difusão do níquel e molibdênio na ferrita, enquanto a segunda acontece por meio da difusão de soluto ao longo das discordâncias com energia de ativação menor que a difusão do níquel e do molibdênio na ferrita. Observou-se também que a reversão da martensita pode ocorrer em duas etapas. A primeira etapa foi associada à difusão de soluto, enquanto a segunda foi relacionada ao mecanismo de cisalhamento. Já as observações microestruturais, por meio de microscopia óptica e de microscopia eletrônica de varredura, evidenciaram que a austenita revertida formou-se nas regiões de interface, como os contornos de grão, contornos de pacote e contornos de ripas da estrutura martensítica para temperaturas a partir de $520^{\circ} \mathrm{C}$, enquanto a austenita revertida encontrada no interior das ripas da martensita formou-se a partir de $560^{\circ} \mathrm{C}$. O estudo da cinética de precipitação e do comportamento da curva de envelhecimento em um aço maraging 350 (350B), para tratamentos isotérmicos entre 440 e $600{ }^{\circ} \mathrm{C}$, mostrou que as medidas de microdureza podem ser muito úteis para estudos dessa natureza nesses aços. A análise cinética da precipitação, realizada por meio do ajuste dos dados experimentais aos modelos JMAK e Austin- 
Rickett, mostrou que eles se ajustam bem a esses modelos com coeficiente de correlação próximo de 1. Entretanto, a interpretação dos valores de $\mathrm{n}$, obtidos pela equação Austin-Rickett, mostrou que eles têm maior concordância com as mudanças microestruturais observadas nos aços maraging, em estudos anteriores, se comparados com aqueles estimados por meio da equação JMAK. A interpretação das constantes $\mathrm{n}$, usando a equação Austin-Rickett, permitiu estabelecer diversas etapas para a precipitação. Na primeira ocorre a precipitação nas discordâncias para $440^{\circ} \mathrm{C}$, seguida pelo crescimento de cilindros longos e finitos em comparação com a distância de separação deles para $480^{\circ} \mathrm{C}$ e, por fim, o crescimento de precipitados partindo de dimensões pequenas com taxa de nucleação zero para 520 e $560^{\circ} \mathrm{C}$. Já o estudo do comportamento da curva de envelhecimento para diversos tempos entre 440 e $600{ }^{\circ} \mathrm{C}$ em aço maraging 350 (350B) mostrou que esse aço apresenta uma etapa de endurecimento e outra de amolecimento. Essa etapa de endurecimento, comumente atribuída à formação de fases intermetálicas coerentes e semicoerentes, pode subdividir-se em dois estágios para as temperaturas de envelhecimento de 440 e $480{ }^{\circ} \mathrm{C}$ ou apresentar um único estágio para 520 e $560 \stackrel{\circ}{\circ} \mathrm{C}$. Já a etapa de amolecimento é associada não somente ao mecanismo clássico de superenvelhecimento em que a queda na resistência mecânica ocorre em virtude da perda de coerência e do engrossamento de precipitados, mas também como consequência da formação de austenita revertida a partir da martensita, especialmente, para temperaturas entre 520 e $600^{\circ} \mathrm{C}$.

Palavras-chave: Aços maraging. Cinética de transformações de fase. Precipitação de compostos intermetálicos. Reversão da martensita. Mecanismos de endurecimento. 


\section{ABSTRACT}

The purpose of this thesis is to contribute to the understanding of precipitation of intermetallic compounds and reversion of martensite through kinetic models, as in isothermal experiments in maraging 350 steel (350B) as in non-isothermal studies in maraging steels $300(300 \mathrm{~A})$ maraging $350(350 \mathrm{C})$. In addition to kinetics of phase transformation, they were also investigated both the changes of the microstructure and the mechanisms of hardening due to aging heat treatments for the maraging steel 350B. For these purposes, we used several complementary techniques for microstructural characterization, such as optical microscopy (OM), scanning electron microscopy (SEM) with energy dispersive X-ray spectroscopy (EDS), Vickers hardness, X-ray diffraction (XRD) and feritscope, while differential scanning calorimetry (DSC) was used to study the precipitation of intermetallic compounds and reversion of martensite in non-isothermal experiments. The results of the nonisothermal DSC experiments with the maraging steel 300 and 350 showed that precipitation occurs in two steps. First stage related to the diffusion of solute in bulk with activation energy next to nickel diffusion and molybdenum in the ferrite, while second stage occurs through the solute diffusion along dislocations with lower activation energy than the diffusion of nickel and molybdenum in ferrite. It was also observed that the reversion of the martensite can occur in two steps. First stage was associated with the solute diffusion, while the second stage is related to the shear mechanism. Microstructural observations by optical microscopy and scanning electron microscopy showed that austenite reverted was formed in the interface regions, such as grain boundaries, packet boundaries and lath boundaries of martensitic structure for temperatures from the $520^{\circ} \mathrm{C}$, while the reverted austenite found within the martensite laths formed from $560^{\circ} \mathrm{C}$. Study of the kinetics of precipitation and aging hardening behavior in a 350 maraging steel (350B), by isothermal treatments between 440 and $600{ }^{\circ} \mathrm{C}$, showed that the microhardness measurements can be very useful for such studies in these steels. Kinetics of precipitation analysis was carried out by adjusting the experimental data to JMAK and Austin-Rickett models. It showed that they fit well to these models with a correlation coefficient close to 1 . However, the interpretation of the $n$ values, obtained by Austin-Rickett equation, they have showed higher agreement with the observed 
microstructural changes in the maraging steel, in previous studies, when compared with those estimated by JMAK equation. The interpretation of the constants, using the Austin-Rickett equation, revealed several steps to precipitation. In the first precipitates on dislocations for $440^{\circ} \mathrm{C}$ followed by growth of long and finite cylinders in comparison with the distance their separation for $480^{\circ} \mathrm{C}$ and, finally, the growth of precipitates starting from small dimensions with nucleation rate zero for 520 and 560 ${ }^{\circ} \mathrm{C}$. Study of aging hardening behavior curve for various times between 440 and 600 ${ }^{\circ} \mathrm{C}$ in maraging steel 350 (350B) showed that the steel has a hardening step and another softening. This step of hardening, commonly attributed to the formation of intermetallic phases coherent and semicoerentes, it can be divided into two stages to the aging temperatures of 440 and $480^{\circ} \mathrm{C}$ or present a single stage 520 and $560^{\circ}$ C. Since the softening stage is associated not only to classic overaging mechanism in which a drop in mechanical strength occurs due to loss of coherence and precipitate coarsening, but also as a consequence of austenite formation reverted from the martensite especially to temperatures between 520 and $600^{\circ} \mathrm{C}$.

Keywords: Maraging steels. Kinetics of phase transformations. Precipitation of intermetallic compounds. Martensite reversion. Hardening mechanisms. 


\section{LISTA DE ILUSTRAÇÕES}

Figura 1: Relação entre tenacidade e resistência de diversos aços de alta resistência (SCHMIDT; ROHRBACH, 1991; RAO, 2006). .36

Figura 2: Diagramas de fase das ligas ferro-níquel: (a) metaestável e (b) equilíbrio (FLOREEN, 1978; SCHMIDT; ROHRBACH, 1990). 45

Figura 3: Microestrutura típica da martensita em ripas (TAMURA; TSUZAKI; MAKI, 1982)

Figura 4: Mapa de orientação usando EBSD de uma amostra usada em dilatometria com uma taxa de resfriamento de $1,5 \mathrm{~K} \cdot \mathrm{min}^{-1}$ (LOWEY et al., 2014).

Figura 5: Fração transformada como função da temperatura obtida por medidas dilatométricas usando as taxas de resfriamento de 2,5, 1,5, 1,0,0,5 e 0,2 K/min. As linhas tracejadas indicam a faixa de temperatura onde as modulações são mais significativas (ver Figura 6) (LOWEY et al., 2014)....

Figura 6: Taxa de transformação versus temperatura, obtidas por meio de medidas dilatométricas com taxas de resfriamento de 2,5, 1,5, 1,0,0,5 e 0,2 K/min. As curvas mostram múltiplos picos levando a um serrilhado da máxima taxa de transformação (LOWEY et al., 2014).

Figura 7: Taxa de transformação como função da temperatura para uma taxa de resfriamento de 0,2 K.min ${ }^{-1}$ usando DTA (LOWEY et al., 2014). 53

Figura 8: Taxa de transformação versus temperatura obtida por meio de medidas dilatométricas, variando os tempos de recozimento em $1323 \mathrm{~K}$ (a) 1 hora, (b) 60 horas e (c) sobreposição dos dados da amostra recozida por 60 horas deslocada em $\Delta \mathrm{T}=6,5 \mathrm{~K}$ e aquela recozida por $1 \mathrm{~h}$ (LOWEY et al., 2014). .54

Figura 9: Variação da temperatura $\mathrm{M}_{S}$ com o tempo de envelhecimento do ausaging em uma liga Fe-29,7\%Ni-6\%Al em 600 e $700{ }^{\circ} \mathrm{C}$ (FLOREEN, 1968). .57

Figura 10: Micrografia no campo escuro mostrando a fase $\omega$ observada por Lecomte e coautores na liga Fe-18,5Ni-8,9Co-4,8Mo após tratamento a $420{ }^{\circ} \mathrm{C}$ por 48 horas (LECOMTE; SERVANT; CIZERON, 1985). 
Figura 11: Micrografia de campo iônico de uma amostra de maraging 300 envelhecida em $414 \stackrel{\circ}{\circ} \mathrm{C}$ por 15,8 horas, mostrando a ocorrência de dois tipos de precipitados (SHA; CEREZO; SMITH, 1993c).

Figura 12: Padrões de difração ao longo dos eixos (a), (b) $<110>_{M}$ e (c), (d) $<111>_{M}$ em uma amostra da liga Fe-18,5Ni-8,9Co-4,8Mo após tratamento a $420{ }^{\circ} \mathrm{C}$ por 48 horas (LECOMTE; SERVANT; CIZERON, 1985).

Figura 13: Micrografia de uma amostra de aço maraging 300 envelhecida a $510^{\circ} \mathrm{C}$ por 1 hora mostrando precipitados esferoidais (SHA et. al., 1993c).

Figura 14: Imagens em campo claro de amostras envelhecidas a $510{ }^{\circ} \mathrm{C}$ por (a) 0,3 h, (b) $1 \mathrm{~h}$, (c) $3 \mathrm{~h} \mathrm{e} \mathrm{(d)} 1200 \mathrm{~h}$ para um aço maraging 250. Também é mostrada uma micrografia em campo escuro na amostra tratada por $1 \mathrm{~h}$ (figura 14b) (MOSHKA et al., 2015).

Figura 15: Crescimento dos precipitados em um aço maraging 350: (a) tamanho médio da fase $\omega$ em função do tempo de envelhecimento para amostras tratadas por até 72 horas em $430{ }^{\circ} \mathrm{C}(703 \mathrm{~K})$ (b) tamanho médio da fase $\mathrm{Ni}_{3} \mathrm{Ti}$ com o tempo de envelhecimento para amostras envelhecidas por até 18 horas em $510{ }^{\circ} \mathrm{C}(783 \mathrm{~K})$. Tamanho estimado por SAXS (TEWARI et al., 2000). 65

Figura 16: Diagrama TTT esquemático correspondente à precipitação de compostos intermetálicos em aços maraging (TEWARI et al., 2000). .66

Figura 17: Fração volumétrica da austenita formada durante tratamentos térmicos em $480{ }^{\circ} \mathrm{C}$ para: (a) diversas ligas $\mathrm{Fe}-\mathrm{Ni}$, (b) diversas ligas $\mathrm{Fe}-18 \mathrm{Ni}$ contendo diferentes teores de cobalto, (c) diversas ligas $\mathrm{Fe}-18 \mathrm{Ni}$ contendo diferentes teores de molibdênio e (d) diversas ligas $\mathrm{Fe}-18 \mathrm{Ni}$ contendo diferentes teores de molibdênio (PETERS, 1968).

Figura 18: Micrografia da austenita formada entre as ripas da martensita para uma amostra de aço maraging 350 tratada a $640^{\circ} \mathrm{C}$ por 2 horas: (a) imagem em campo claro, (b) imagem em campo escuro (VISWANATHAN, DEY, SETHUMANDHAVAN, 2005).

Figura 19: Morfologias da austenita formada em uma amostra de aço maraging 350 tratada a $640{ }^{\circ} \mathrm{C}$ por 8 horas: (a) austenita de Widmanstätten (b) austenita 
recristalizada e (c) austenita globular (VISWANATHAN, DEY, SETHUMANDHAVAN, 2005).

Figura 20: Crescimento da austenita revertida em placas dentro das ripas de martensita (ATSMON, ROSEN, 1981). .72

Figura 21: Variação da resistividade (a) e da dureza (b) em função do tempo de envelhecimento entre $357^{\circ} \mathrm{C}$ e $593^{\circ} \mathrm{C}$ para um aço maraging 250 (PETERS; CUPP, 1966) .74

Figura 22: Variação da resistividade (a) e da dureza (b) em função do tempo de envelhecimento entre $427^{\circ} \mathrm{C}$ e $538^{\circ} \mathrm{C}$ para um aço maraging 250 sem cobalto (VASUDEVAN; KIM; WAYMAN,1990). .75

Figura 23: Variação da microdureza como função do tempo e da temperatura de envelhecimento para um aço maraging 300 (a) e um aço maraging 350 sem cobalto (b) (PARDAL et al.; 2005, VISWANATHAN; DEY; ASUNDI, 1993a). .76

Figura 24: Variação do In t como função de $1 / T$ para a obtenção da energia de ativação aparente para um aço maraging 300 (a) e um aço maraging 350 sem cobalto (b) usando o tempo necessário para alcançar o pico de microdureza (PARDAL et al.; 2005, VISWANATHAN; DEY; ASUNDI, 1993a). .77

Figura 25: Variação do log $t_{50 \%}$ como função de 1/T para a obtenção da energia de ativação aparente para um aço maraging 250 com cobalto (C-250) e um aço maraging 250 sem cobalto (T-250) (VASUDEVAN; KIM; WAYMAN, 1990) .78

Figura 26: Percentagem transformada $(P)$ como função do tempo em temperatura constante (AUSTIN, RICKETT,1939).

Figura 27: Fração transformada durante o envelhecimento de uma liga de alumínio Al-10,3 \%at. Si como função do tempo de envelhecimento. Análise comparativa do ajuste dos dados experimentais aos modelos JMAK e Austin-Rickett (STARINK,1997).

Figura 28: Aplicação do modelo JMAK linearizado aos dados de fração transformada de precipitação para um aço maraging T250 (SINHA et al.,1998).

Figura 29: Difratograma de raios $X$ de amostras envelhecidas em $600{ }^{\circ} \mathrm{C}$ por 1 hora que foram lixadas e não lixadas de um aço maraging 300 obtido usando radiação CoKa (PARDAL et al.,2006). 
Figura 30: Evolução da fração volumétrica da austenita em função do tempo e da temperatura de envelhecimento para um aço maraging 300 (PARDAL et al.,2006). 85 Figura 31: Comparação da curva do modelo empírico ajustado com os dados experimentais de fração volumétrica da austenita para amostras tratadas a $560 \mathrm{e}$ $600^{\circ} \mathrm{C}$ em um aço maraging 300 (PARDAL et al.,2006).

Figura 32: Curvas de histerese magnética de amostras antes e depois da imersão em nitrogênio líquido por 15 min: (a) amostra solubilizada e envelhecida a $650{ }^{\circ} \mathrm{C}$ por $1 \mathrm{~h}$; (b) amostra solubilizada, laminada a frio e envelhecida por $1 \mathrm{~h}$ em um aço maraging 350 (TAVARES et al., 2004a).

Figura 33: Relação entre a fração volumétrica da austenita e a saturação magnética em (a) um aço maraging 300 e (b) um aço maraging 350 (AHMED et al.,1994; PARDAL et al., 2007).

Figura 34: Variação do campo coercivo $\mathrm{H}_{\mathrm{C}}$ (a) e da fração volumétrica da austenita (b) em função do tempo de envelhecimento um aço maraging 300 (PARDAL et al., 2007). .89

Figura 35: Variação da fração volumétrica da austenita e da corrente parasita em função da temperatura de envelhecimento em um aço maraging 350 (HABIBY et al..,1992b).

Figura 36: Relação entre a fração volumétrica da austenita e a corrente parasita em um aço maraging 350 (HABIBY et al..,1992b). 91

Figura 37: Variação da magnetização com o aumento da temperatura para uma taxa de aquecimento e resfriamento de $10{ }^{\circ} \mathrm{C} / \mathrm{min}$ em um aço maraging 350 (TAVARES et al..,1993).

Figura 38: Variação do comprimento da amostra com relação ao seu tamanho inicial para o ciclo de aquecimento e resfriamento de $10^{\circ} \mathrm{C} / \mathrm{s}$ em um aço maraging 350 (CARVALHO et al..,2013).

Figura 39: Variação da derivada do comprimento da amostra durante o experimento de dilatometria com relação à temperatura para diversas taxas de aquecimento em um aço maraging 350 (KAPOOR; KUMAR; BATRA, 2003).

Figura 40: Variação do fluxo de calor com aumento da temperatura no DSC para diversas taxas de aquecimento em um aço maraging 250 (GUO; SHA, 2004). 
Figura 41: Variação do fluxo de calor com aumento da temperatura no DSC para diversas taxas de aquecimento em um aço maraging 250 (GUO; SHA, 2004)

Figura 42: Variação do fluxo de calor com aumento da temperatura no DSC para diversas taxas de aquecimento em um aço maraging 350 (KAPOOR; BATRA, 2004).

Figura 43: Método de Kissinger usado para a determinação da energia de ativação da precipitação (a) e da reversão da martensita (b) em um aço maraging 350 a partir de dados de dilatometria (VISWANATHAN; KUTTY; GANGULY, 1993). 100

Figura 44: Curva de endurecimento em função do tempo de envelhecimento (GUO; SHA, 2002).

Figura 45: Movimentação das discordâncias através do cisalhamento de precipitados (GLADMAN,1999).

Figura 46: Formação dos anéis de discordâncias pela passagem das discordâncias em precipitados incoerentes por meio do mecanismo de Orowan (GLADMAN,1999).

Figura 47: Ajuste do modelo da precipitação em estágios iniciais aos dados experimentais da curva de envelhecimento para um aço maraging 300 (PARDAL et al.,2005) 105

Figura 48: Ajuste do modelo da curva de envelhecimento para o amolecimento devido ao engrossamento dos precipitados em um aço maraging 300 (PARDAL et al.,2005) 106

Figura 49: Ajuste do modelo empírico de Pardal e coautores (2005) aos dados de microdureza Vickers em amostras superenvelhecidas em um aço maraging 300 (PARDAL et al.,2005). 107

Figura 50: Organograma dos experimentos realizados e das técnicas utilizadas na tese. 110

Figura 51: Desenho esquemático da medida de indução magnética realizada por um ferritoscópio (MARÉCHAL, 2011). 
Figura 52: Micrografia obtida com microscopia óptica e revelada pelo uso dos reagentes Vilella (a) e 4\% Nital (b) para o aço maraging 300A no estado como recebido.

Figura 53: Micrografia obtida com microscopia óptica e revelada pelo uso dos reagentes Vilella (a) e 4\% Nital (b) para o aço maraging 350B no estado como recebido.

Figura 54: Micrografia obtida com microscopia óptica e revelada pelo uso dos reagentes Vilella (a) e 4\% Nital (b) para o aço maraging 350C no estado como recebido

Figura 55: Valores médios das medidas de microdureza, usando carga de $1 \mathrm{kgf}$, para diversas regiões dos discos de aços maraging 300A, 350B e 350C no estado como recebido.

Figura 56: Difratograma de raios $X$ das barras pesquisadas no estado como recebido usando radiação CuKa.

Figura 57: Extrapolação do parâmetro de rede da martensita usando regressão linear como função de $\cos ^{2} \theta$ para os aços maraging pesquisados no estado como recebido. 122

Figura 58: Comparação dos valores do parâmetro de rede estimados com os valores de Habiby e de Ball (BALL,1984; HABIBY et. al.,1996). 123

Figura 59: Variação do fluxo de calor em função da temperatura para diversas taxas de aquecimento no aço maraging $300 \mathrm{~A}$.

Figura 60: Variação do fluxo de calor em função da temperatura para diversas taxas de aquecimento no aço maraging $350 \mathrm{C}$. 125

Figura 61: Variação do fluxo de calor corrigida em função da temperatura para diversas taxas de aquecimento no aço maraging 300A. 126

Figura 62: Variação do fluxo de calor corrigida em função da temperatura para diversas taxas de aquecimento no aço maraging $350 \mathrm{C}$ 126

Figura 63: Variação das temperaturas de precipitação para diversas taxas de aquecimento nos aços maraging $300 \mathrm{~A}$ e $350 \mathrm{C}$ 
Figura 64: Variação das temperaturas de reversão da martensita para diversas taxas de aquecimento nos aços maraging 300A e 350C.

Figura 65: Diagrama CHT das transformações de fase no aço maraging 300A ....130

Figura 66: Diagrama CHT das transformações de fase no aço maraging 350C. ....130 Figura 67: Variação de In $\left(T^{2} / \beta\right)$ em função de $1 / T$ para a obtenção das energias de ativação da precipitação de compostos intermetálicos e da reversão da martensita por meio do método de Kissinger para o aço maraging 300A 132

Figura 68: Variação de In $\left(T^{2} / \beta\right)$ em função de $1 / T$ para a obtenção das energias de ativação da precipitação de compostos intermetálicos e da reversão da martensita por meio do método de Kissinger para o aço maraging 350C. 132

Figura 69: Microestrutura do aço maraging 350B revelada pelo uso do reagente Marble e obtida por meio do microscópio óptico para amostras envelhecidas em 600 ${ }^{\circ} \mathrm{C}$ para $45 \mathrm{~min}(\mathrm{a}), 2 \mathrm{~h}$ (b), $6 \mathrm{~h}$ (c) e $18 \mathrm{~h}$ (d).

Figura 70: Imagens por elétrons secundários da microestrutura do aço maraging 350B revelada pelo uso do reagente Marble em amostras envelhecidas a: $560{ }^{\circ} \mathrm{C}$ por 2 horas (a), $600^{\circ} \mathrm{C}$ por 2 horas (b), $560^{\circ} \mathrm{C}$ por 6 horas (c), $600{ }^{\circ} \mathrm{C}$ por 6 horas (d), $560{ }^{\circ} \mathrm{C}$ por 18 horas (e) e $600^{\circ} \mathrm{C}$ por 18 horas (f). 138

Figura 71: Micrografias da microestrutura do aço maraging 350B revelada pelo uso do reagente $2 \%$ Nital e obtida por microscopia eletrônica de varredura em uma amostra envelhecida a $520^{\circ} \mathrm{C}$ por 18 horas.

Figura 72: Imagem por elétrons secundários da microestrutura do aço maraging $350 \mathrm{~B}$ revelada pelo uso do reagente $2 \%$ Nital em uma amostra envelhecida a $520{ }^{\circ} \mathrm{C}$ por 18 horas para um aumento de $60000 \mathrm{X}$ 140

Figura 73: Imagem por elétrons retroespalhados da microestrutura do aço maraging $350 \mathrm{~B}$ revelada pelo uso do reagente $2 \%$ Nital em uma amostra envelhecida a $520{ }^{\circ} \mathrm{C}$ por 18 horas para um aumento de $100000 \mathrm{X}$ 141

Figura 74: Micrografias da microestrutura do aço maraging 350B revelada pelo uso do reagente $2 \%$ Nital e obtida por microscopia eletrônica de varredura em uma amostra tratada a $560{ }^{\circ} \mathrm{C}$ por 18 horas. 
Figura 75: Micrografias da microestrutura do aço maraging 350B revelada pelo uso do reagente $2 \%$ Nital e obtida por microscopia eletrônica de varredura em uma amostra tratada a $600{ }^{\circ} \mathrm{C}$ por 18 horas.

Figura 76: Difratograma de raios $X$ de amostras no estado como recebido e envelhecidas a 520,560 e $600{ }^{\circ} \mathrm{C}$ por 1 e 18 horas para o aço maraging 350B. ...144 Figura 77: Variação das medidas magnéticas como função do tempo de envelhecimento para as temperaturas 520,560 e $600^{\circ} \mathrm{C}$ no aço maraging 350B. 147 Figura 78: Relação entre medidas magnéticas feitas com o ferritoscópio e a fração volumétrica para o aço maraging 350B. 147

Figura 79: Variação da fração volumétrica da austenita como função do tempo e da temperatura de envelhecimento para o aço maraging 350B.

Figura 80: Variação da microdureza Vickers (carga $1 \mathrm{~kg}$ ) de amostras envelhecidas do aço maraging 350B como função do tempo em 440, 480, 520, 560 e $600{ }^{\circ} \mathrm{C}$...150 Figura 81: Fração transformada como função do tempo em 440, 480, 520 e $560{ }^{\circ} \mathrm{C}$ para o aço maraging 350B. 152

Figura 82: Regressão linear da equação JMAK linearizada a partir dos dados de fração transformada para o aço maraging 350B nas temperaturas 440, 480, 520 e $560^{\circ} \mathrm{C}$. 153

Figura 83: Regressão linear da equação Austin-Rickett linearizada a partir dos dados de fração transformada para o aço maraging 350B nas temperaturas 440, 480, $520 \mathrm{e}$ $560^{\circ} \mathrm{C}$.

Figura 84: In t como função de 1/T para a estimar a energia de ativação por meio do método do tempo necessário para alcançar o pico de dureza, bem como o tempo para atingir uma determinada fração transformada de 0,70 ou 0,90 para 0 aço maraging 350B. 162

Figura 85: In k como função de 1/T para os modelos Austin-Rickett e JMAK no aço maraging $350 \mathrm{~B}$. 163

Figura 86: Ajuste do modelo de endurecimento baseado no mecanismo de cisalhamento de precipitados aos pontos experimentais para as amostras envelhecidas em $440,480,520$ e $560^{\circ} \mathrm{C}$. 
Figura 87: Ajuste do modelo baseado no mecanismo de Orowan aos dados experimentais, $\Delta \mathrm{H}^{-3}$ como função do tempo, para o amolecimento durante o superenvelhecimento a 520,560 e $600{ }^{\circ} \mathrm{C}$ para o aço maraging 350B. Os pontos abertos não foram usados no ajuste. 170

Figura 88: In $\mathrm{H}$ em função de In t para a equação de Pardal linearizada para 520, 560 e $600^{\circ} \mathrm{C}$ 173

Figura 89: Dureza como função da fração volumétrica de austenita para o aço maraging 350B. 174 


\section{LISTA DE TABELAS}

Tabela 1: Composição química nominal (\% massa) os aços maraging comerciais com cobalto (SCHMIDT; ROHRBACH, 1990; INCO, 1979; GARRISON Jr., 2008). . 34

Tabela 2: Propriedades mecânicas dos aços maraging (INCO, 1979).

Tabela 3: Composição nominal (\%massa) e tensão de escoamento das primeiras ligas de aços maraging $\mathrm{Ni}-\mathrm{Ti}$ (DECKER; FLOREEN, 1988).

Tabela 4: Composição nominal (\%massa) das ligas desenvolvidas após a descoberta do efeito sinérgico entre o cobalto e o molibdênio (DECKER; FLOREEN, 1988)

Tabela 5: Composição nominal dos aços maraging sem cobalto (FLOREEN; BAYER, 1988; RAO, 2006).

Tabela 6: Fases observadas nos aços maraging Ni-Co-Mo-Ti (TEWARI et al., 2000; MOSHKA et al., 2015).

Tabela 7: Valores da constante $\mathrm{n}$ para diversas reações controladas por difusão (Starink, 1997; RIOS, PADILHA, 2007).

Tabela 8: Valores da constante $\mathrm{n}$ para mudanças polimórficas, recristalização, precipitação descontínua, reações eutectóides ou crescimento controlado pela interface (Starink, 1997; RIOS, PADILHA, 2007).

Tabela 9: Valores das constantes $\mathrm{Y}_{\mathrm{MAX}} \mathrm{e}$ b das curvas ajustadas do modelo empírico de Pardal et al. (2006) para 560 e $600{ }^{\circ} \mathrm{C}$ em um aço maraging 300. O valor do coeficiente de correlação $\mathrm{R}$ também é apresentado.

Tabela 10: Interpretação dos resultados de DSC em uma curva de DSC para uma taxa de aquecimento de $50^{\circ} \mathrm{C} / \mathrm{min}$ (GUO; SHA, 2004)

Tabela 11: Composição química (\% em massa) das barras pesquisadas. 108

Tabela 12: Reagentes utilizados nas barras pesquisadas (FAROOQ et al., 1987). 111 Tabela 13: Cálculos para a estimativa do parâmetro de rede do aço maraging 300A no estado como recebido.

Tabela 14: Cálculos para a estimativa do parâmetro de rede do aço maraging 350B no estado como recebido. 
Tabela 15: Cálculos para estimativa do parâmetro de rede do aço maraging 350C no estado como recebido.

Tabela 16: Temperaturas de pico para a precipitação e a reversão da martensita para os aços maraging $300 \mathrm{~A}$ e $350 \mathrm{C}$ em função da taxa de aquecimento.

Tabela 17: Valores da energia de ativação obtidos para a reação de precipitação $E_{p}$ por meio da análise de Kissinger os aços maraging 300A e 350C em comparação com os estudos anteriores. 133

Tabela 18: Valores de energia de ativação obtidos da reversão da martensita $E_{A}$ por meio da análise de Kissinger para os aços maraging 300A e 350C em comparação com os estudos anteriores.

Tabela 19: Valores da fração volumétrica da austenita, parâmetro de rede da austenita e da martensita do aço maraging 350B.

Tabela 20: Valores dos coeficientes das regressões linear e polinomial de $2^{\circ}$ grau das medidas magnéticas como função da fração volumétrica da austenita para o aço maraging 350B.

Tabela 21: Valores das constantes da equação JMAK obtidas diversos autores e por regressão linear para o aço maraging 350B (VASUDEVAN et al, 1990; SINHA et al,1998) 154

Tabela 22: Valores das constantes cinéticas n e In k para o modelo Austin-Rickett e o modelo JMAK para diversas temperaturas de envelhecimento no aço maraging 350B, bem como as suas possíveis interpretações com base nos trabalhos de Rios e Padilha (2007), Starink (1997) e Christian (1975). 158

Tabela 23: Intepretação da constante cinética n para o modelo Austin-Rickett no aço maraging $350 \mathrm{~B}$ entre 440 e $560{ }^{\circ} \mathrm{C}$, tendo como base a evolução microestrutural local dos precipitados analisada por outros autores 161

Tabela 24: Comparação dos valores de energia de ativação aparente obtido pelo pico de dureza, bem como pelos modelos JMAK e Austin-Rickett. 164

Tabela 25: Valores das constantes $\mathrm{m}$ e $\mathrm{K}$ para o modelo de endurecimento baseado no mecanismo de cisalhamento de precipitados obtidos no presente trabalho para o aço maraging 350B e daqueles apresentados por Pardal et al. (2005) e Sha (2000) (aço maraging 300). O coeficiente de ajuste $\mathrm{R}$ também é dado 
Tabela 26: Comparação dos valores de $\Delta \mathrm{H}_{0}$, $\mathrm{t}_{0}$, e $\mathrm{M}$ do modelo de amolecimento baseado no mecanismo de Orowan obtido no presente trabalho (aço maraging 350B) e aqueles apresentados por Pardal et al. (2005) em um aço maraging $300 \mathrm{e}$ Carvalho et al. (2015) no aço maraging 350B em 520, 560 e $600^{\circ} \mathrm{C}$. O coeficiente de ajuste $R$ também é dado. 170

Tabela 27: Comparação de $\mathrm{H}_{1}$ e $\mathrm{p}$ do modelo de Pardal et al. para a para diferentes aços maraging em $520,560,600$ e $650^{\circ} \mathrm{C}$ 173 


\section{LISTA DE ABREVIATURAS E SIGLAS}

$\begin{array}{ll}\text { CCC } & \text { Estrutura cúbica de corpo centrado } \\ \text { CFC } & \text { Estrutura cúbica de face centrada } \\ \text { CHT } & \text { Continuous heating transformation, ou seja, transformação por } \\ & \text { aquecimento contínuo } \\ \text { CTMSP } & \text { Centro Tecnológico da Marinha em São Paulo } \\ \text { CRSS } & \text { Critical resolved shear stress, isto é, tensão crítica de cisalhamento } \\ \text { CVT } & \text { Continuous variable transmission, ou seja, transmissão por variação } \\ & \text { contínua } \\ \text { DRX } & \text { Difração de raios X } \\ \text { DSC } & \text { Differential scanning calorimetry, isto é, calorimetria exploratória } \\ & \text { diferencial } \\ \text { DTA } & \text { Differential thermal analysis, ou seja, análise térmica diferencial } \\ \text { EBSD } & \text { Electron backscatter diffraction } \\ \text { EDS } & \text { Energy-dispersive } X \text {-ray spectroscopy, isto é, espectroscopia por } \\ & \text { dispersão de energia de raios } X \\ \text { ESR } & \text { Electroslag remelting furnace, ou seja, refusão em forno de escória } \\ & \text { eletrocondura } \\ \text { INCO } & \text { International Nickel Company Ltd. } \\ \text { MET } & \text { Microscopia eletrônica de transmissão } \\ \text { MEV } & \text { Microscopia eletrônica de varredura } \\ \text { MO } & \text { Microscopia ótica } \\ \text { NASA } & \text { National Aeronautics and Space Administration } \\ \text { SANS } & \text { Small angle neutron scattering, isto é, espalhamento de nêutrons em } \\ \text { VIM } & \text { baixo ângulo } \\ \text { VAXS } & \text { Small angle } x \text {-ray scattering, ou seja, espalhamento de nêutrons em } \\ \text { baixo ângulo }\end{array}$


VSM

Vibrating sample magnetometer, isto é, magnetômetro de amostra vibrante 


\section{LISTA DE SÍMBOLOS}

\begin{tabular}{|c|c|}
\hline $300 \mathrm{~A}$ & Aço maraging 300 barra $A$ \\
\hline $350 \mathrm{~B}$ & Aço maraging 350 barra $B$ \\
\hline $350 \mathrm{C}$ & Aço maraging 350 barra $\mathrm{C}$ \\
\hline$A_{f}$ & Temperatura final da reversão da martensita \\
\hline As & Temperatura de início da reversão da martensita \\
\hline b & Módulo do vetor de Burgers \\
\hline$D_{A B}$ & Coeficiente de autodifusão \\
\hline$d_{h k l}$ & Distância interplanar dos planos cristalinos hkl \\
\hline $\mathrm{E}$ & Energia de ativação \\
\hline f & fração transformada \\
\hline g & $\begin{array}{l}\text { Constante negativa dependente da temperatura e relacionada à fração } \\
\text { volumétrica da austenita }\end{array}$ \\
\hline $\mathrm{H}_{0}$ & Valor da microdureza no estado solubilizado \\
\hline $\mathrm{H}_{1}$ & $\begin{array}{l}\text { Valor de dureza quando o tempo de envelhecimento é } 1 \mathrm{~h} \text { no modelo } \\
\text { de Pardal e coautores (2006) }\end{array}$ \\
\hline $\mathrm{H}_{\mathrm{C}}$ & Campo coercivo \\
\hline $\mathrm{H}_{\text {MAX }}$ & $\begin{array}{l}\text { Valor máximo da microdureza para uma temperatura de } \\
\text { envelhecimento fixa } T\end{array}$ \\
\hline $\mathrm{H}_{\mathrm{t}}$ & $\begin{array}{l}\text { Microdureza no tempo de envelhecimento t para uma dada temperatura } \\
\text { fixa } T\end{array}$ \\
\hline $\mathrm{k}$ & $\begin{array}{l}\text { Constante dependente da temperatura para o modelo do } \\
\text { endurecimento. }\end{array}$ \\
\hline $\mathrm{k}(\mathrm{T})$ & Constante cinética de velocidade para uma dada temperatura fixa $T$ \\
\hline $\mathrm{k}_{0}$ & Fator pré-exponencial da lei de Arrhenius para a velocidade da reação \\
\hline L.R. & Limite de resistência mecânica \\
\hline $\mathrm{m}$ & $\begin{array}{l}\text { Constante dependente da temperatura para o modelo de } \\
\text { endurecimento devido ao cisalhamento de precipitados. }\end{array}$ \\
\hline M & $\begin{array}{l}\text { Constante dependente da temperatura para o modelo de amolecimento } \\
\text { devido ao mecanismo de Orowan }\end{array}$ \\
\hline$M_{f}$ & Temperatura final da transformação martensítica \\
\hline $\mathrm{m}_{\mathrm{s}}$ & Saturação magnética \\
\hline$M_{S}$ & Temperatura de início da transformação martensítica \\
\hline
\end{tabular}


Constante da equação JMAK ou Austin-Rickett

Constante exponencial no modelo de Pardal e coautores (2006)

Fator pré-exponencial da lei de Arrhenius para o tempo para o pico de dureza

Th Tensão de linha da discordância;

$\mathrm{T}_{\mathrm{f}} \quad$ Temperatura de fusão

$\mathrm{T}_{\mathrm{H}} \quad$ Temperatura homóloga

$\mathrm{T}_{\mathrm{M}}$

Temperatura em que há a máxima taxa de transformação de fase para experimentos não-isotérmicos

Tempo para alcançar o pico de dureza

\section{$\gamma_{a p b}$}

Fração volumétrica do precipitado.

Taxa de aquecimento para experimentos não-isotérmicos

Fração volumétrica de austenita em um dado tempo de envelhecimento Energia do contorno de antifase

Fração volumétrica máxima de austenita em uma dada temperatura

Distorção na matriz

Diferença entre o valor da microdureza da amostra envelhecida e a solubilizada

Variação da dureza no tempo de início do engrossamento $t_{p}$ Comprimento de onda dos raios $X$

Espaçamento médio dos precipitados.

Módulo de cisalhamento da matriz

$\rho_{t}$

Resistividade da amostra no estado solubilizado

Resistividade para um dado tempo de envelhecimento t em uma temperatura de envelhecimento fixa $\mathrm{T}$ 


\section{SUMÁRIO}

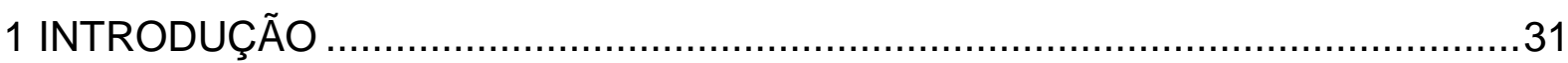

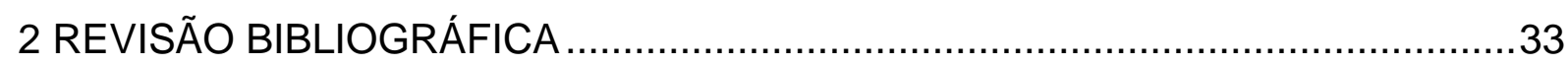

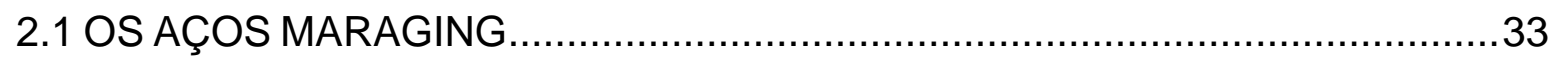

2.2 DESENVOLVIMENTO HISTÓRICO E APLICAÇÕES DOS AÇOS MARAGING

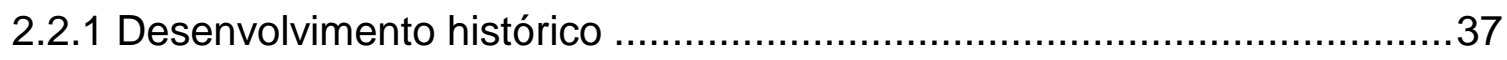

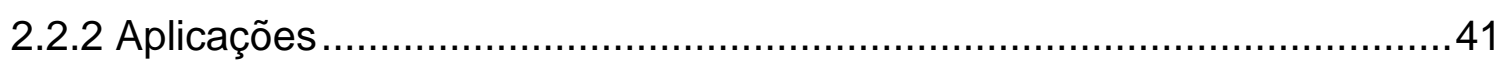

2.3 METALURGIA FÍSICA DOS AÇOS MARAGING......................................4 44

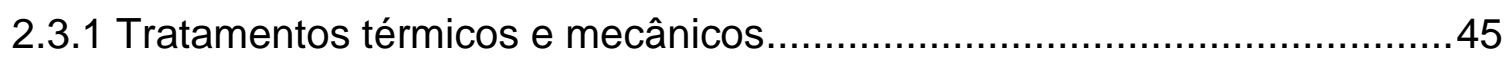

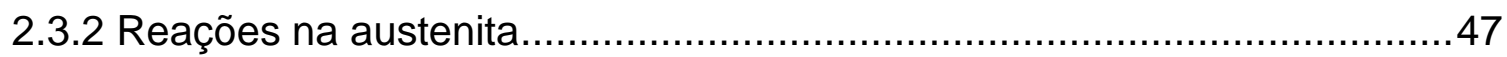

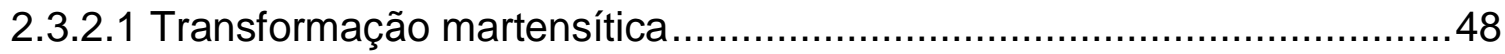

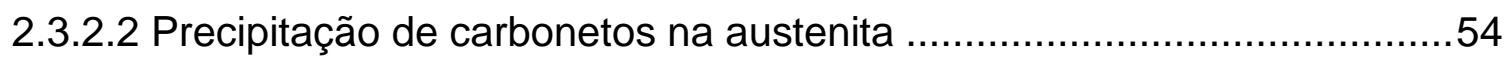

2.3.2.3 Precipitação de compostos intermetálicos na austenita.........................56

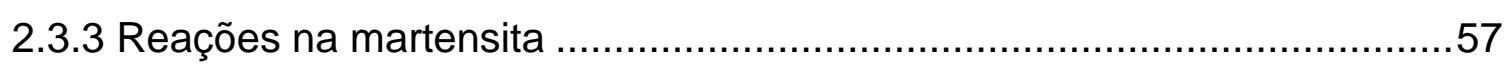

2.3.3.1 Precipitação de compostos intermetálicos na martensita.......................57

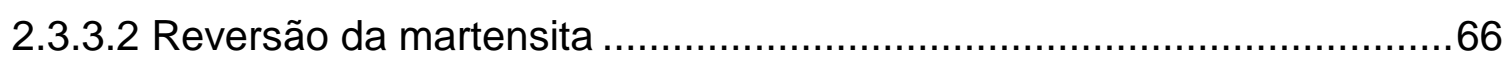

2.4 CINÉTICA DE TRANSFORMAÇÕES DE FASE NOS AÇOS MARAGING .......72

2.4.1 Estudos da cinética isotérmica de precipitação e de reversão da martensita

2.4.1.1 Uso de medidas de microdureza e de resistividade para o estudo da cinética de precipitação. .73

2.4.1.2 Análise cinética isotérmica JMAK e Austin-Rickett para amostras

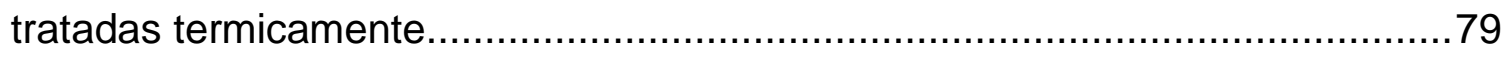

2.4.1.3 Cinética isotérmica de reversão da martensita ..................................84

2.4.2 Estudos de cinética não-isotérmica de precipitação e reversão da

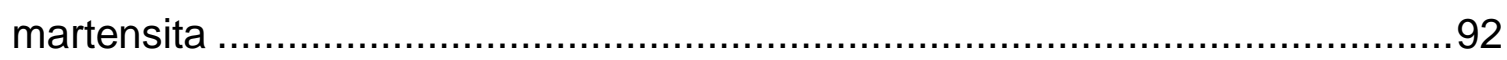

2.4.2.1 Uso de medidas físicas para o estudo da cinética não-isotérmica de precipitação e de reversão da martensita ....................................................92

2.4.2.2 Análise cinética pelo método de Kissinger ...........................................98

2.5 MECANISMOS DE ENDURECIMENTO NA MARTENSITA E O COMPORTAMENTO DA CURVA DE ENVELHECIMENTO .............................101

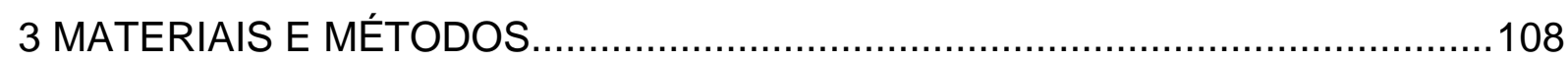


3.1 MATERIAIS 108

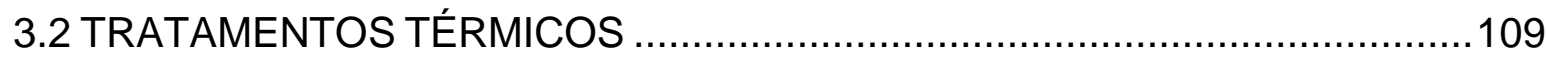

3.3 TÉCNICAS DE ANÁLISE MICROESTRUTURAL........................................109

3.3.1 Microscopias óptica e eletrônica de varredura ........................................111

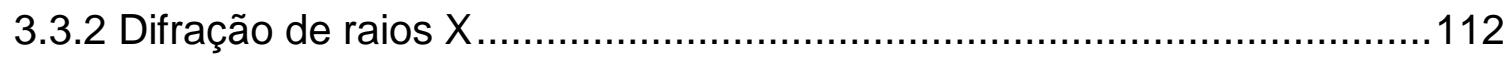

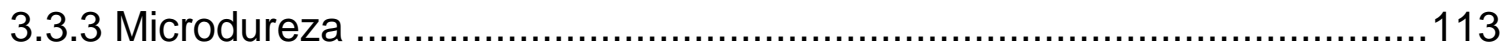

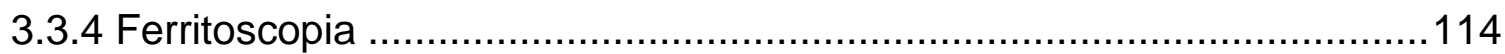

3.3.5 Calorimetria exploratória diferencial ...............................................116

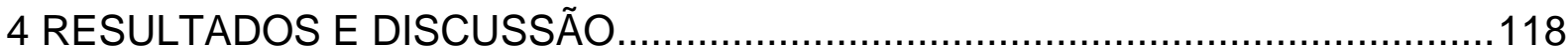

4.1 CARACTERIZAÇÃO MICROESTRUTURAL NO ESTADO COMO RECEBIDO

4.2 ANÁLISE CINÉTICA DA PRECIPITAÇÃO DE COMPOSTOS INTERMETÁLICOS E DA REVERSÃO DA MARTENSITA NOS AÇOS MARAGING

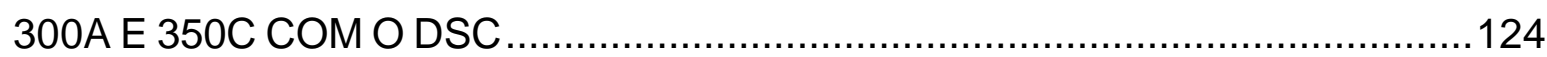

4.2.1 Temperaturas de transformação e diagramas $\mathrm{CHT}$..............................124

4.2.2 Análise cinética por meio do método de Kissinger pela máxima taxa de transformação 131

4.3 AVALIAÇÂO DAS MUDANÇAS MICROESTRURAIS APÓS O ENVELHECIMENTO PARA O AÇO MARAGING 350B 136

4.3.1 Análise da microestrutura após o envelhecimento para o aço maraging $350 \mathrm{~B}$ 136

4.3.2 Medidas ferromagnéticas e de difração de raios $X$ para 0 aço maraging $350 \mathrm{~B}$ 144

4.3.3 Estudo da cinética de precipitação e do comportamento da curva de envelhecimento para o aço maraging 350B 149

4.3.3.1 Estudo da cinética de precipitação para o aço maraging 350B 151

4.3.3.2 Estudo do comportamento da curva de envelhecimento 166 5 CONCLUSÕES 175 REFERÊNCIAS 178 


\section{INTRODUÇÃO}

Os aços maraging são aços de alto valor agregado e de aplicação ampla que podem ser usados nas indústrias aeroespacial, nuclear, óleo e gás (ASSUNÇÃO, 2010), além de sua utilização tradicional na fabricação de moldes para injeção de plásticos (PINEDO, 2004). Especialmente, nos setores aeroespacial e nuclear, os aços maraging são de fundamental relevância devido à elevada resistência mecânica e boa tenacidade, características que proporcionam conceber estruturas com baixo peso e aumento de segurança (ASSUNÇÃO, 2010).

O Brasil já possui alguma experiência na fabricação de aços maraging, porém tem pouca experiência na produção de ligas de resistência mais elevada, tais como os aços maraging 350, 400 e 450. Portanto, um esforço tanto acadêmico quanto industrial deve ser realizado para que os setores aeroespacial e nuclear fiquem menos dependentes da importação desses materiais, pois a produção desses aços é controlada pelos países produtores (ASSUNÇÃO, 2010). Esses aços são martensíticos de baixo teor de carbono, altamente ligados, endurecidos por envelhecimento da martensita (ASSUNÇÃO, 2010). Ao contrário de outros aços de alta resistência mecânica, os aços maraging têm uma pequena distorção dimensional durante tratamentos térmicos, boa soldabilidade, assim como boa combinação entre resistência mecânica e tenacidade (ASSUNÇÃO, 2010).

De acordo com o estudo Materiais Avançados 2010-2022, o conhecimento dos aços maraging precisa ser aprofundado para que novas ligas sejam produzidas no país, visando um melhor desempenho, em especial os aços maraging 350 e 400 (ASSUNÇÃO, 2010).

Sabe-se que a precipitação de compostos intermetálicos e a reversão da martensita têm uma influência nas mudanças das propriedades mecânicas e magnéticas dos aços maraging (PARDAL et al., 2005). Dessa maneira, o estudo da cinética dessas transformações permite entender os possíveis mecanismos que regem a ocorrência dessas transformações e prever a evolução do comportamento dessas propriedades. Assim, o objetivo dessa tese de doutorado é contribuir para o entendimento dos mecanismos de precipitação de compostos intermetálicos e da reversão da martensita por meio de modelos cinéticos tanto em experimentos 
isotérmicos para uma barra de aço maraging 350 (350B) quanto em estudos nãoisotérmicos para um aço maraging 300 (300A) e um maraging 350 (350C). Além da cinética das transformações de fase, foram estudadas também as mudanças da microestrutura e dos mecanismos de endurecimento decorrentes de tratamentos térmicos de envelhecimento para o aço maraging 350B.

Dessa maneira, as contribuições inéditas dessa tese são: a análise da cinética de precipitação em amostras envelhecidas de um aço maraging 350 por meio das equações JMAK e Austin-Rickett; o estudo do comportamento da curva de envelhecimento com relação aos mecanismos de endurecimento e de amolecimento; o acompanhamento da cinética de reversão da martensita mediante o uso do ferritoscópio para um aço maraging 350; análise cinética não-isotérmica comparativa da precipitação e da reversão da martensita em aços maraging 300 e 350 mediante o uso de calorimetria exploratória diferencial (DSC).

A tese foi estrutura em diversos capítulos. No segundo capítulo do presente texto é apresentada uma revisão bibliográfica das aplicações dos aços maraging, de sua metalurgia física e dos tratamentos térmicos nesses materiais, enquanto no terceiro capítulo são explicitados os materiais e os métodos utilizados, tais como as microscopias óptica e eletrônica de varredura com análise dispersiva de energia, difração de raios $\mathrm{X}$, microdureza, calorimetria exploratória diferencial e ferritoscopia. Já o quarto capítulo é referente aos resultados e à discussão da cinética de envelhecimento e das transformações de fase dos aços maraging estudados. Por fim, a sumarização dos resultados nessa tese é apresentada no quinto capítulo. 


\section{REVISÃO BIBLIOGRÁFICA}

\subsection{OS AÇOS MARAGING}

Os aços maraging são uma classe especial de aços de alta resistência que difere dos aços convencionais, pois eles não são endurecidos por reações que envolvem a precipitação de carbonetos (SHA, GUO, 2009). Esses materiais são endurecidos por reações de precipitação induzidas por elementos de liga que promovem a formação de fases intermetálicas em uma matriz martensítica, durante o tratamento térmico de envelhecimento (SCHMIDT, ROHRBACH, 1990; SHA, GUO, 2009). O próprio termo maraging deriva de martensite age hardening, de forma a denotar o endurecimento de uma matriz martensítica em ripas com baixo teor de carbono devido ao envelhecimento (SCHMIDT; ROHRBACH, 1990).

A ausência do carbono e a presença de fases intermetálicas nesses aços também proporcionam uma melhor combinação entre a conformabilidade, a tenacidade e a resistência mecânica, quando comparados aos aços convencionais de alta resistência (INCO,1979; SCHMIDT; ROHRBACH, 1990; SHA, GUO, 2009).

$\mathrm{Na}$ tabela 1 pode-se observar que a nomenclatura estabelecida para os aços maraging comerciais desenvolvidos pela International Nickel Company Ltd. (Inco) é o limite de resistência no estado envelhecido em ksi (SHA, GUO, 2009; SCHMIDT; ROHRBACH, 1990; RAO, 2006; INCO, 1979). Por exemplo, o aço 18Ni (200) é normalmente envelhecido para um limite de resistência de $1380 \mathrm{Mpa}(200 \mathrm{ksi})^{1}$ (SCHMIDT; ROHRBACH, 1990).

Vale ressaltar que os aços maraging $18 \mathrm{Ni}(200), 18 \mathrm{Ni}(250)$ e $18 \mathrm{Ni}(300)$ são os mais usados, sendo também os mais disponíveis no mercado, enquanto a série 18Ni (350) é mais empregada em aplicações especiais que requerem maior nível de resistência (SCHMIDT; ROHRBACH, 1990). Como pode ser visto na tabela 1, estes aços possuem altos teores de níquel, de cobalto e de molibdênio, porém eles apresentam baixos teores de carbono, de nitrogênio e de enxofre (INCO, 1979; SHA, GUO, 2009). Pequenas adições de titânio e alumínio também são feitas devido ao efeito suplementar no endurecimento desses aços durante o tratamento de

\footnotetext{
${ }^{1}$ Para aços maraging contendo o cobalto é comum também a notação em que o valor do limite de resistência é precedido da letra C. Por exemplo, o aço maraging $350 \mathrm{com}$ cobalto pode ser denotado por maraging C350. Outra notação usada adotada em países provenientes da fragmentação da União Soviética consiste na abreviação da composição química em proporção mássica. Nessa notação o maraging 350 é representado por N18K12M5T, em que N18 representa 18\% de níquel; K12, $12 \%$ de cobalto; M5, 5\% de molibdênio; T, $1 \%$ de titânio.
} 
envelhecimento (INCO, 1979). Sua composição química nominal e suas propriedades mecânicas estão sumarizadas nas tabelas 1 e 2 .

Tabela 1: Composição química nominal (\% massa) os aços maraging comerciais com cobalto (SCHMIDT; ROHRBACH, 1990; INCO, 1979; GARRISON Jr., 2008).

\begin{tabular}{ccccc}
\hline Elemento & $18 \mathrm{Ni}(200)^{*}$ & $18 \mathrm{Ni}(250)^{*}$ & $18 \mathrm{Ni}(300){ }^{*}$ & $18 \mathrm{Ni}(350)$ \\
\hline $\mathrm{Ni}$ & 18 & 18 & 18 & 18 \\
$\mathrm{Co}$ & 8,5 & 8,5 & 9,0 & 12,5 \\
$\mathrm{Mo}$ & 3,3 & 5,0 & 5,0 & $4,2^{(\mathrm{a})}$ \\
$\mathrm{Ti}$ & 0,2 & 0,4 & 0,7 & $1,6^{(\mathrm{a})}$ \\
$\mathrm{Al}$ & 0,1 & 0,1 & 0,1 & 0,1 \\
$\mathrm{C}$ max & 0,03 & 0,03 & 0,03 & 0,03 \\
$\mathrm{Si}$ max & 0,10 & 0,10 & 0,10 & 0,10 \\
Mn max & 0,10 & 0,10 & 0,10 & 0,10 \\
$\mathrm{Si}+$ Mn max & 0,20 & 0,20 & 0,20 & 0,20 \\
S max & 0,010 & 0,010 & 0,010 & 0,005 \\
P max & 0,010 & 0,010 & 0,010 & 0,005
\end{tabular}

* Podem ocorrer algumas mudanças de composição química devido às diversas especificações nacionais e internacionais; (a) alguns produtores usam uma combinação de 4,8\% Mo e 1,4\% Ti.

Tabela 2: Propriedades mecânicas dos aços maraging (INCO, 1979).

\begin{tabular}{|c|c|c|c|c|c|}
\hline Propriedade & Condição* & $18 \mathrm{Ni}(200)$ & $18 \mathrm{Ni}(250)$ & $18 \mathrm{Ni}(300)$ & $18 \mathrm{Ni}(350)$ \\
\hline \multirow{2}{*}{$\begin{array}{l}\text { Limite de } \\
\text { escoamento } \\
\text { (MPa) }\end{array}$} & Solubilizada & 800 & 800 & 790 & 830 \\
\hline & $\begin{array}{l}\text { Solubilizada e } \\
\text { envelhecida }\end{array}$ & $1310-1550$ & $1650-1830$ & $1790-2070$ & 2390 \\
\hline \multirow{2}{*}{$\begin{array}{l}\text { Limite de } \\
\text { resistência (MPa) }\end{array}$} & Solubilizada & 1000 & 1010 & 1010 & 1150 \\
\hline & $\begin{array}{l}\text { Solubilizada e } \\
\text { envelhecida }\end{array}$ & $1340-1590$ & $1690-1860$ & $1830-2100$ & 2460 \\
\hline \multirow[b]{2}{*}{ Alongamento (\%) } & Solubilizada & 17 & 19 & 17 & 18 \\
\hline & $\begin{array}{l}\text { Solubilizada e } \\
\text { envelhecida }\end{array}$ & $6-12$ & $6-10$ & $5-10$ & 8 \\
\hline \multirow{2}{*}{$\begin{array}{l}\text { Redução em área } \\
(\%)\end{array}$} & Solubilizada & 79 & 72 & 76 & 70 \\
\hline & $\begin{array}{l}\text { Solubilizada e } \\
\text { envelhecida }\end{array}$ & $35-67$ & $35-60$ & $30-50$ & 36 \\
\hline
\end{tabular}

* solubilização por $1 \mathrm{~h}$ a $820{ }^{\circ} \mathrm{C}$; envelhecimento por $3 \mathrm{~h} \mathrm{e} 480{ }^{\circ} \mathrm{C}$ nas séries 200,250 e 300; envelhecimento por $12 \mathrm{~h}$ e $480^{\circ} \mathrm{C}$ na série 350 . 
Tradicionalmente, os aços maraging são produzidos usando duas técnicas de fundição: os constituintes são fundidos primeiramente em forno de indução a vácuo (vacuum induction melting - VIM); em seguida, os lingotes produzidos serão refundidos em forno a vácuo (vacuum arc remelting - VAR) (SCHMIDT; ROHRBACH, 1990; AHMED, NASIM; HUSAIN, 1994); já as séries premium de aços maraging, comumente usadas em aplicações aeronáuticas e aeroespaciais, são submetidas à tripla fusão usando $V A R, V I M$ e a refusão em forno de escória eletrocondutora (electroslag remelting furnace - ESR) (SCHMIDT; ROHRBACH, 1990; AHMED, NASIM; HUSAIN, 1994).

A utilização de tais processos tem como objetivo manter uma composição química que minimize a presença de elementos residuais, tais como carbono, manganês e enxofre, bem como de gases $\mathrm{H}_{2}, \mathrm{~N}_{2}$ e $\mathrm{O}_{2}$ até o nível exigido (INCO,1979; SCHMIDT; ROHRBACH, 1990). Dos elementos residuais mencionados, o carbono e o enxofre são os elementos mais prejudiciais, pois tendem a formar carbonetos, sulfetos, carbonitretos e carbosulfetos que fragilizam esses aços (INCO,1979; SCHMIDT; ROHRBACH, 1990). Outro objetivo desses processos é diminuir a microssegregação dos lingotes (INCO, 1979).

Apesar dos aços maraging demandarem processos especiais de produção, os tratamentos térmicos desses materiais são relativamente simples (SHA, GUO, 2009; SCHMIDT; ROHRBACH, 1990). O tratamento térmico final desses aços geralmente envolve duas etapas principais. A primeira consiste na solubilização (austenitização) a $820{ }^{\circ} \mathrm{C}$ por $1 \mathrm{~h}$ por $25 \mathrm{~mm}$ de espessura seguida por resfriamento ao ar. Posteriormente, na segunda etapa é realizado o envelhecimento com tratamento térmico em torno de $480{ }^{\circ} \mathrm{C}$. O tempo de tratamento térmico em $480{ }^{\circ} \mathrm{C}$ varia de acordo com a série: nas séries 200, 250 e 300, na faixa de 3 a 8 horas, enquanto na série 350 ele é realizado entre 6 e 12 horas (SCHMIDT; ROHRBACH, 1990; INCO, 1979).

Dependendo do tipo de aplicação, o aço maraging pode ser submetido aos tratamentos superficiais, visando melhorar as propriedades como resistência ao desgaste e à corrosão. Se o objetivo é incrementar a resistência à corrosão, o envelhecimento pode ser combinado com uma etapa de tratamento de superfície em vapor de água superaquecido (REZEK; KLEIN; YAHALOM, 1997a; REZEK; KLEIN; YAHALOM, 1997b); enquanto a melhoria da resistência ao desgaste pode ser 
atingida realizando-se tratamentos de nitretação simultaneamente com 0 envelhecimento (SCHMIDT; ROHRBACH, 1990; SHETTY; KUMAR; RAO; 2009).

Em virtude da natureza das aplicações que exigem o uso de materiais de alta resistência, por exemplo, as indústrias nuclear e aeroespacial, a tenacidade à fratura torna-se um importante parâmetro, pois define a resistência de um material a propagação de trincas (MEYERS, CHAWLA, 2009; SCHMIDT; ROHRBACH, 1990; ASSUNÇÃO, 2010). No caso dos aços maraging, os níveis de tenacidade à fratura $e$ de limite de resistência são superiores aos outros aços de alto limite de resistência mecânica, conforme pode ser visto na figura 1 (SCHMIDT; ROHRBACH, 1990; RAO, 2006).

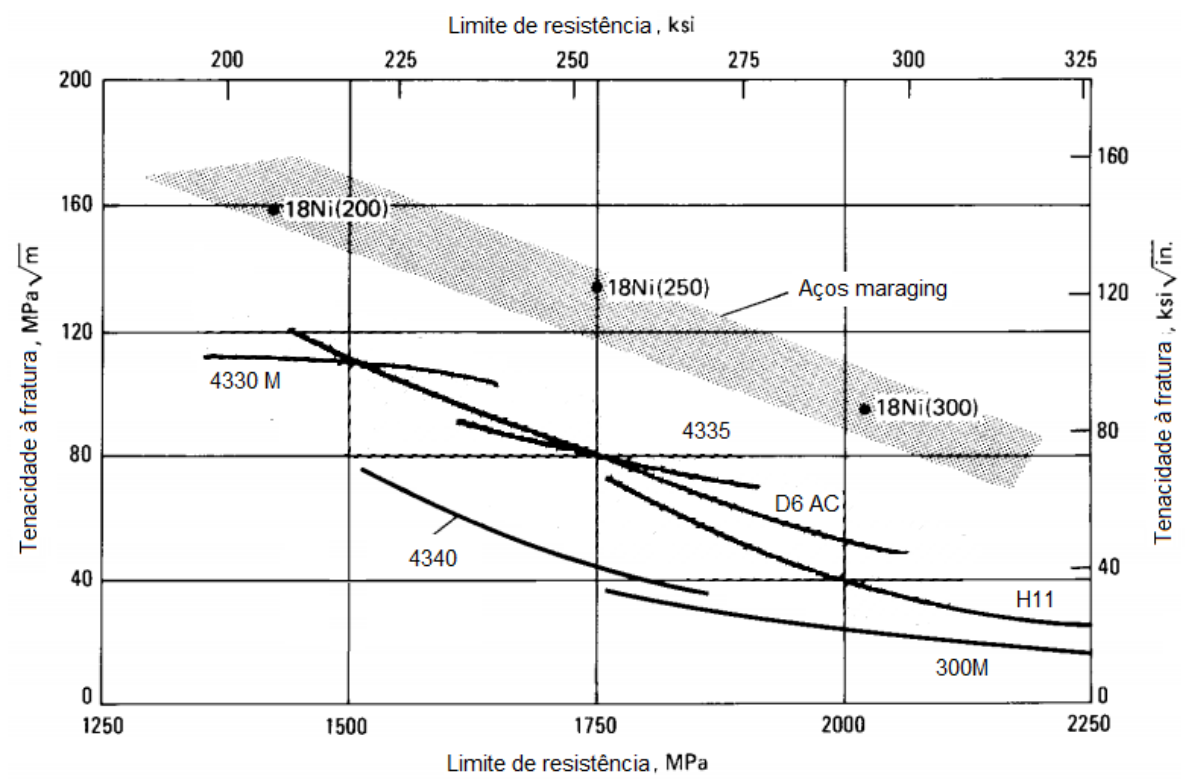

Figura 1: Relação entre tenacidade e resistência de diversos aços de alta resistência (SCHMIDT; ROHRBACH, 1991; RAO, 2006).

Além da série de aços maraging mencionados, outras séries com composições diferentes foram desenvolvidas nos últimos anos, incluindo séries inoxidáveis, outras séries fundidas, séries com outros níveis de resistência, uma variedade sem cobalto para aplicação nuclear e uma série com propriedades magnéticas superiores (SCHMIDT; ROHRBACH, 1990). Apesar desses aços serem processados e usados comercialmente, eles são feitos em uma limitada quantidade para aplicações específicas (SCHMIDT; ROHRBACH, 1990).

No próximo item são discutidos o desenvolvimento histórico e as aplicações dos aços maraging. 


\subsection{DESENVOLVIMENTO HISTÓRICO E APLICAÇÕES DOS AÇOS MARAGING}

Nesse tópico são discutidos os principais fatores que levaram ao desenvolvimento e às aplicações dos aços maraging.

\subsubsection{Desenvolvimento histórico}

O início do desenvolvimento dos aços maraging remonta a década de 1940, quando Clarence Bieber pesquisava as propriedades magnéticas de uma liga ferroníquel e atuava como metalurgista-chefe da Inco's Huntington Alloys. Clarence observou que a liga Fe-28Ni-4Ti-4Al poderia ser endurecida significativamente por tratamento térmico. Contudo, essa era uma observação secundária em vista do objetivo inicial, que era estudar as propriedades magnéticas dessas ligas (DECKER; FLOREEN, 1988).

Na década de 50, mais precisamente em 1954, Clarence foi transferido para a Inco's Bayonne, onde aplicou o endurecimento pela formação da fase Y' em superligas, o que resultou no desenvolvimento da liga de níquel Inconel 713C. Inspirado pelo desenvolvimento das superligas, em uma conferência sobre esses materiais em 1958, Clarence sugeriu a criação de um novo campo da metalurgia a partir das pesquisas realizadas na época em que trabalhara na Inco's Huntington, o que resultou no desenvolvimento dos aços maraging (DECKER; FLOREEN, 1988).

Os primeiros estudos focaram na maneira como o envelhecimento da austenita desencadeava a transformação martensítica. Foi observado que as ligas Fe-28Ni-4T-4 Al podiam ser endurecidas até a dureza Rockwell HRC 67, mas elas eram pouco dúcteis. Em seguida, foi descoberto que um "segundo" envelhecimento na martensita que poderia aumentar o limite de resistência (DECKER; FLOREEN, 1988).

A partir dessas observações, Clarence reduziu os níveis de titânio e alumínio para alcançar uma razoável ductlidade, focando inicialmente nas ligas com 25\% de níquel. Contudo, essa liga ainda era complexa, pois o teor de níquel continuava relativamente alto, o que resultava numa temperatura de início da transformação martensítica $M_{S}$ abaixo da temperatura ambiente. Dessa forma, um primeiro envelhecimento da austenita era necessário para remover parte dos elementos de liga em solução sólida e, em seguida, a austenita transformar-se em martensita 
durante o resfriamento. Por fim, um segundo envelhecimento era aplicado para um endurecimento final (DECKER, 1979; DECKER; FLOREEN, 1988).

O passo seguinte de Clarence foi reduzir o teor de níquel a fim de que o envelhecimento da austenita tornasse desnecessário, o que resultou no desenvolvimento do aço maraging com $20 \%$ de níquel. Essa liga transformava-se totalmente em martensita após o resfriamento a partir do tratamento de austenitização (DECKER, 1979; DECKER; FLOREEN, 1988).

Posteriormente, Decker propôs a criação de acrônimos para identificar os possíveis tipos de envelhecimento que poderiam ser aplicados a essas ligas. $O$ envelhecimento da austenita passou a ser denominado ausaging, enquanto o envelhecimento da martensita foi designado por maraging. Esse último nome passou a ser amplamente usado para se referir a esses aços, tornando-se uma palavra consagrada pelo uso dos pesquisadores. A composição dessas ligas iniciais de aços maraging é mostrada na tabela 3 (DECKER, 1979; DECKER; FLOREEN, 1988).

Tabela 3: Composição nominal (\%massa) e tensão de escoamento das primeiras ligas de aços maraging Ni-Ti (DECKER; FLOREEN, 1988).

\begin{tabular}{cccccc}
\hline Liga & $\mathrm{Ni}$ & $\mathrm{Ti}$ & $\mathrm{Nb}^{2}$ & $\mathrm{Al}$ & $\begin{array}{c}\text { Tensão de } \\
\text { escoamento (MPa) }\end{array}$ \\
\hline $20 \mathrm{Ni}$ & 20 & 1,7 & 0,4 & 0,2 & 1750 \\
$25 \mathrm{Ni}$ & 25 & 1,6 & 0,4 & 0,2 & 1700 \\
\hline
\end{tabular}

O desafio dos pesquisadores do centro de pesquisa e desenvolvimento da Inco até 1960 era superar diversas barreiras relacionadas à tenacidade, à soldagem e à corrosão sob tensão devido à precipitação de compostos contendo titânio nos contornos de grão, que limitavam sobremaneira o uso comercial desses aços (DECKER, 1979; DECKER; FLOREEN, 1988). Nesse mesmo ano, foi observado que o molibdênio aumentava a tenacidade e melhorava a soldagem, enquanto o cobalto poderia suplementar o endurecimento da liga em conjunto com o molibdênio (DECKER; FLOREEN, 1988).

Estudos complementares foram realizados para explorar variados teores de cobalto e molibdênio. Foi observado que uma combinação de cobalto e de

\footnotetext{
${ }^{2}$ Na referência citada, o nióbio é denominado como colúmbio $(\mathrm{Cb})$.
} 
molibdênio poderia produzir um endurecimento mais significativo do que as contribuições individuais de cada elemento (DECKER; FLOREEN, 1988).

A descoberta desse efeito sinérgico entre o cobalto e o molibdênio foi a base dos aços maraging comercialmente usado na atualidade, cujas composições já foram apresentadas na tabela 1. Além desses elementos, o titânio foi adicionado a esses aços como um endurecedor por solução sólida e por precipitação suplementar. As propriedades mecânicas dessas ligas eram superiores em relação às ligas $20 \mathrm{Ni}$ e $25 \mathrm{Ni}$, o que levou a substituição delas pela série $18 \mathrm{Ni}$ (250) (DECKER; FLOREEN, 1988).

Muitos pesquisadores envolvidos no início do desenvolvimento dos aços maraging tinham um conhecimento em ligas à base de níquel, especialmente superligas. Já a seção metalurgia dos ferrosos no centro de pesquisa e desenvolvimento da Inco não estava diretamente envolvida no projeto de desenvolvimento dos aços maraging (DECKER; FLOREEN, 1988).

Após a descoberta do efeito sinérgico, uma quantidade significativa de pesquisadores passou a estudar os aços maraging contendo molibdênio e cobalto. As pesquisas acerca dos maraging teve uma expansão mundial na década de 60, mais especificamente, em 1963 na Rússia e na Europa e, posteriormente, no Japão. O objetivo dessas pesquisas era padronizar os processos de fusão, o controle da composição química, o processamento dos lingotes, bem como definir o procedimento para a conformação a quente e a frio desses materiais (DECKER, 1979; DECKER; FLOREEN, 1988).

Com o prosseguimento das pesquisas, as principais limitações desses materiais ficaram evidenciadas. Os aços maraging são sensíveis a fragilização por hidrogênio e a corrosão sob tensão em meios aquosos. Além disso, esses aços apresentam baixas taxas de endurecimento por encruamento e os limites de escoamento e de resistência mecânica são próximos entre si (DECKER; FLOREEN, 1988).

Além dessas pesquisas, outras ligas inoxidáveis, séries com feitas a partir de metalurgia do pó e de resistência extremamente elevada foram desenvolvidas, conforme mostrado na tabela 4 (DECKER; FLOREEN, 1988). 
Tabela 4: Composição nominal (\%massa) das ligas desenvolvidas após a descoberta do efeito sinérgico entre o cobalto e o molibdênio (DECKER; FLOREEN, 1988).

$\begin{array}{rrrrrrrrr}\text { Liga } & \mathrm{Ni} & \mathrm{Co} & \mathrm{Mo} & \mathrm{Ti} & \mathrm{Cr} & \mathrm{Al} & \text { Outros } & \begin{array}{r}\text { Tensão de escoame } \\ (\mathrm{ksi})\end{array}\end{array}$

\begin{tabular}{|c|c|c|c|c|c|c|c|c|}
\hline \multicolumn{9}{|l|}{ Ligas Ni-Co-Mo } \\
\hline Liga 400 & 13 & 15 & 10 & 0,2 & - & 0,2 & - & $2800(400)$ \\
\hline Liga 500 & 8 & 18 & 14 & 0,2 & - & 0,2 & - & $3500(500)$ \\
\hline \multicolumn{9}{|l|}{ Ligas Ni-Cr } \\
\hline $12-5-3$ & 12 & - & 3 & 0,2 & 5 & 0,3 & - & $1250(180)$ \\
\hline IN 736 & 10 & - & 2 & 0,2 & 10 & 0,3 & - & $1250(180)$ \\
\hline IN 833 (Cast) & 7 & - & - & - & 12 & - & $1 \mathrm{Si}$ & $900(130)$ \\
\hline \multicolumn{9}{|l|}{ Baixa-ligas } \\
\hline IN 787 & 0,8 & - & 0,2 & - & 0,6 & - & $\begin{array}{c}0,3 \mathrm{Si}, 1,1 \mathrm{Cu} \\
0,03 \mathrm{Nb}\end{array}$ & $620(90)$ \\
\hline IN 866 (Cast) & 1 & - & 0,2 & - & 0,5 & - & $\begin{array}{c}\text { 0,4 Si, } 1,3 \mathrm{Cu} \\
1,8 \mathrm{Mn}\end{array}$ & $620(90)$ \\
\hline
\end{tabular}

Nos anos 70, as vantagens e as limitações desses materiais já estavam bem estabelecidas. Contudo, a escalada de preços do cobalto, entre 1978 e 1980, devido a uma crise no fornecimento desse elemento motivou uma busca pelo desenvolvimento de novas ligas de aços maraging isentas de cobalto ou contendo um baixo teor desse elemento (DECKER; FLOREEN, 1988; FLOREEN; BAYER, 1988; SCHMIDT; ROHRBACH, 1990). O desenvolvimento de ligas sem cobalto envolveu a pesquisa de ligas ferro-níquel com adições de molibdênio, titânio, alumínio, tungstênio ou vanádio. A pesquisa realizada nos laboratórios de pesquisa da Inco e da Teledyne Vasco mostrou que o vanádio e o tungstênio causam um aumento na resistência mecânica, porém esses elementos acarretam a diminuição da ductilidade em comparação com o molibdênio (FLOREEN; BAYER, 1988).

A partir dessas considerações ficou estabelecido que as ligas comerciais dos aços maraging sem cobalto deveriam ser ligas ferro-níquel com adições de 
molibdênio, titânio e alumínio (FLOREEN; BAYER, 1988). Como consequência do teor de cobalto reduzido, o teor de molibdênio foi reduzido e o teor de titânio foi aumentado para que fosse obtida uma estrutura totalmente martensítica e níveis de limite de resistência mecânica similares aos aços maraging com cobalto (PADIAL, 1994; SCHMIDT; ROHRBACH, 1990). A composição química desses aços está na tabela 5.

Tabela 5: Composição nominal dos aços maraging sem cobalto (FLOREEN; BAYER, 1988; RAO, 2006).

\begin{tabular}{cccc}
\hline Elemento & T200 & T250 & T300 \\
& & & \\
\hline $\mathrm{Ni}$ & 18,5 & 18,5 & 18,5 \\
$\mathrm{Mo}$ & 3,00 & 3,00 & 4,00 \\
$\mathrm{Ti}$ & 0,70 & 1,40 & 1,85 \\
$\mathrm{Al}$ & 0,10 & 0,10 & 0,00 \\
Si max & 0,10 & 0,10 & 0,10 \\
Mn max & 0,10 & 0,10 & 0,10 \\
$\mathrm{C}$ max & 0,03 & 0,03 & 0,03 \\
S max & 0,01 & 0,01 & 0,01 \\
$\mathrm{P}$ max & 0,01 & 0,01 & 0,01 \\
\hline
\end{tabular}

Essas ligas tinham algumas propriedades inferiores como a tenacidade à fratura e ductibilidade em relação às séries que continham cobalto, mas como o custo era inferior compensava as possíveis desvantagens (DECKER; FLOREEN, 1988).

Além dos aços maraging sem cobalto, recentemente foram desenvolvidos aços maraging com efeito TRIP, que apresentam um alongamento mais elevado após o envelhecimento do que os aços maraging tradicionais (RAABE et al.; 2009).

No próximo tópico são abordados diversos aspectos relacionados às aplicações dos aços maraging.

\subsubsection{Aplicações}

Para iniciar as vendas das ligas desenvolvidas, o grupo de marketing da Inco identificou que seria possível usar os aços maraging desenvolvidos na época em placas do casco de submarinos (DECKER, 1979; DECKER; FLOREEN, 1988). 
Dessa forma, foi construído o submarino de pesquisa Deep Quest para testar a viabilidade de uso dos aços maraging nessas aplicações nos anos 60. Contudo, a maior parte do tempo esse submarino ficava fora da água e armazenado em um navio, o que não permitiu avaliar o comportamento desses materiais para tempos prolongados de exposição em meio corrosivo (DECKER; FLOREEN, 1988).

A concepção de aplicação dos aços maraging na construção de submarinos nos anos 60 é devido à possibilidade de operação deles em águas mais profundas do que aqueles construídos com aços HY-80 e HY-100, pois estes aços têm o limite de resistência mecânica inferior ao aço maraging da série 200 (GERMERAAD, 1970). Porém, a descoberta da fragilização por hidrogênio e de fratura devido à corrosão sob tensão em meios aquosos já citada antes impediu a aplicação ampla desses materiais na indústria naval de defesa (DECKER; FLOREEN, 1988).

Nos anos 60, basicamente dois tipos de mercados para os aços maraging ficaram bem estabelecidos. O primeiro mercado foi relativo às aplicações aeroespaciais e militares devido às boas combinações de resistência mecânica e tenacidade fornecida por esses materiais. Já o segundo mercado formado consistia em aplicações na indústria metalomecânica de ferramentas e criação de moldes para injeção de plásticos e de alumínio, pois os aços maraging podem ser usinados em formas complexas na condição não envelhecida e, posteriormente, após o envelhecimento apresentavam apenas uma pequena distorção nas dimensões após o endurecimento (HAMAKER, BAYER, 1968; DECKER; FLOREEN, 1988).

$O$ desenvolvimento dessas ligas foi enormemente acelerado em virtude da corrida espacial iniciada no final da década de 50 , tendo como grande incentivadora a NASA, devido ao uso desses aços em dispositivos com aplicações espaciais (GUIMARÃES, 2003). A aplicação dos aços maraging nas partes estruturais de veículos espaciais, em consequência de sua alta razão entre limite de resistência mecânica e seu peso, foi muito importante para a fabricação de foguetes com partes estruturais leves, bem como para a fabricação de componentes altamente resistentes do jipe lunar (Lunar Roving Vehicle) e do módulo lunar (Lunar Excursion Module) (PADIAL, 1994; AVADHANI, 2003). Recentemente Babu e coautores (2015) também simularam diversos aços e ligas de alumínio de alta resistência em motores foguete com propelente sólido. O material que apresentou a menor distorção foi o aço maraging, sendo o material recomendado para o uso de tal aplicação. 
A substituição do aço $300 \mathrm{M}$ pelo aço maraging 300 na construção do Veículo Lançador de Satélites (VLS) tem sido avaliada nos últimos anos por diversos estudos (FIGUEIREDO, 2015; PALAU, 2011). Por razões históricas, o Programa Espacial Brasileiro adotou o aço 300M como material para a construção do envelope motor foguete do VLS. Isso ocorreu devido a um tempo menos prolongado de desenvolvimento que seria necessário para o aço maraging 300, visando uma redução da dependência externa desse programa de pesquisa. Com a fabricação local dos aços maraging, as restrições para a sua aplicação não existem mais (LOMBARDO, 2015; FIGUEIREDO, 2015; PALAU, 2011).

Os aços maraging 300 têm melhor estabilidade dimensional durante tratamentos térmicos, menor susceptibilidade a trincas por solda, melhor tenacidade à fratura da junta soldada e à zona termicamente afetada, menores custos dos processos de soldagem e dos ciclos de tratamento térmico em relação ao aço $300 \mathrm{M}$. Além disso, os sais usados no tratamento térmico de martêmpera do $300 \mathrm{M}$ e os resíduos resultantes desse processo atualmente são classificados como resíduos perigosos. Tendo em vista tais considerações, a pesquisa em aços maraging tem sido incentivada a fim de aperfeiçoar o programa aeroespacial brasileiro (PALAU, 2011; LOMBARDO, 2015).

A aplicação de aços maraging não está restrita somente as indústrias militar, aeroespacial e de ferramentas. Novos processos de refino das inclusões TiN em aços maraging 250 possibilitaram a disseminação desse aço na tecnologia de transmissão por variação contínua (CVT - continuous variable transmission) na indústria automotiva, pois o refino das inclusões TiN proporcionam o aumento da resistência à fadiga $e$, consequentemente, eleva-se a durabilidade desse componente mecânico. A vantagem do CVT em relação às transmissões automáticas é a redução do consumo de combustível (HITACHI, 2013).

Com relação ao uso dos aços maraging em experimentos científicos, esses materiais não se restringem apenas aos dispositivos aeroespaciais. Os aços maraging também são materiais muito usados em sistemas de atenuação sísmica, os quais são empregados em detectores de ondas gravitacionais na área de Física Nuclear Experimental, devido ao endurecimento após o envelhecimento. $O$ endurecimento inibe a movimentação das discordâncias, o que aumenta de forma significativa a dissipação de energia em movimentos oscilatórios até mesmo em condições de vibração mecânica de baixa frequência. Tal condição é essencial para 
esses detectores, uma vez que reduz o ruído do transdutor, o qual detecta as ondas gravitacionais (DESALVO et al., 2005).

Recentemente, foi proposta a construção de casas com estrutura feita com aços maraging em áreas vulneráveis à ocorrência de tornados. Apesar do aumento do custo de construção ser $25 \%$ a $30 \%$ maior em relação aos processos de construção tradicional, as construções feitas com aços maraging são mais seguras e resistentes a tornados (KANTAMANENI; ALRASHED; PHILLIPS, 2015).

Além das aplicações citadas, os aços maraging têm uma aplicação relevante na indústria nuclear, especificamente, na construção de ultracentrífugas para enriquecimento isotópico de urânio (KRASS, 1983; DECKER; FLOREEN, 1988; ZETNER COLES, TALBERT, 2005; WOOD, GLASER, KEMP, 2008; KEMP, 2009; CARVALHO, 2012).

A seguir são mostrados os principais aspectos da metalurgia física dos aços maraging.

\subsection{METALURGIA FÍSICA DOS AÇOS MARAGING}

A boa resistência e a excelente tenacidade dos aços maraging são alcançadas pelo envelhecimento de uma estrutura martensítica com baixo carbono. Com o envelhecimento da estrutura martensítica objetiva-se obter uma distribuição uniforme de precipitados intermetálicos que promova um endurecimento significativo da matriz martensítica. Outro objetivo do tratamento térmico de envelhecimento é minimizar ou eliminar a reversão da martensita metaestável em austenita e ferrita (SCHMIDT; ROHRBACH, 1990).

As transformações de fase nesses aços são geralmente explicadas com base nos diagramas de fase metaestável e de equilíbrio de ligas Fe-Ni. (SCHMIDT; ROHRBACH, 1990). A Figura 2a mostra o diagrama metaestável da transformação da austenita durante o resfriamento para martensita e a reversão da martensita para austenita quando submetido ao aquecimento. Enquanto a Figura 2b, que consiste no diagrama de equilíbrio, evidencia que em altas quantidades de níquel as fases de equilíbrio em baixas temperaturas são austenita e ferrita (FLOREEN, 1978; SCHMIDT; ROHRBACH, 1990). 


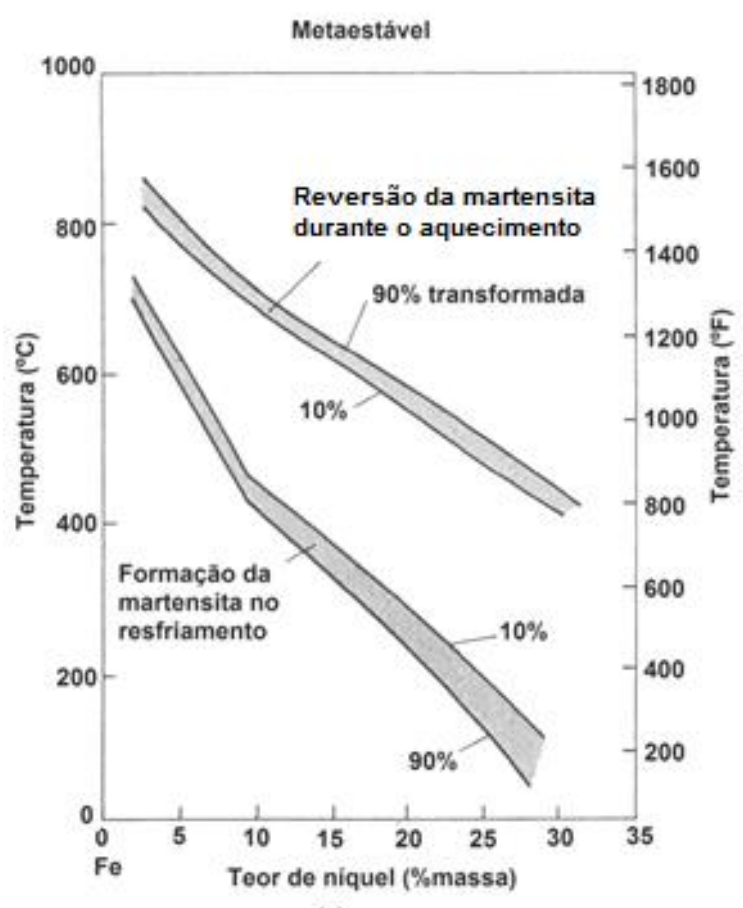

(a)

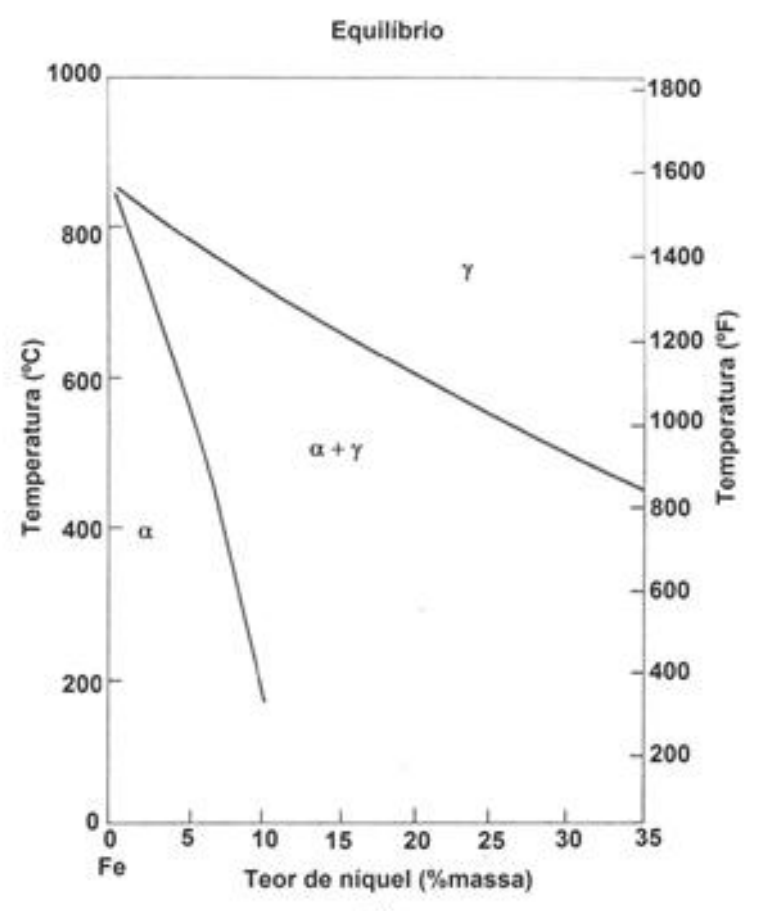

(b)

Figura 2: Diagramas de fase das ligas ferro-níquel: (a) metaestável e (b) equilíbrio (FLOREEN, 1978; SCHMIDT; ROHRBACH, 1990).

A cinética de reação de precipitação que causa o endurecimento dos aços maraging ocorre antes do início da reversão que produz austenita e ferrita (SCHMIDT; ROHRBACH, 1990). Os aços maraging também exibem uma histerese térmica nas transformações de fase, ou seja, uma diferença entre a temperatura de término da reversão da martensita e a temperatura de início da transformação martensítica. (SCHMIDT; ROHRBACH, 1990).

A seguir são discutidos os tratamentos térmicos aplicados nos aços maraging.

\subsubsection{Tratamentos térmicos e mecânicos}

Os tratamentos térmicos e mecânicos têm um papel central nas propriedades mecânicas dos aços maraging. Os principais tratamentos realizados nesses aços são a solubilização e o envelhecimento, que podem ser complementados por etapas de conformação no campo da martensita, bem como no campo da austenita (DECKER, FLOREEN, 1988).

Os lingotes dos aços maraging no estado bruto de fundição, após os processos VAR e VIM, apresentam uma microestrutura com uma alta 
microssegregação, que pode influenciar de maneira significativa nos constituintes microestruturais do lingote. Dessa forma, deve ser realizado um tratamento de solubilização a fim de reduzir a microssegregação, garantindo uma homogeneidade de composição química no lingote com o objetivo de obter uma microestrutura martensítica com a ausência de austenita retida (DECKER, FLOREEN, 1988). Por definição, a solubilização é feita de forma a induzir os elementos em solução sólida. Esse tratamento geralmente é realizado a $820^{\circ} \mathrm{C}$ por $1 \mathrm{~h}$ por $25 \mathrm{~mm}$ de espessura, seguido por resfriamento ao ar (SCHMIDT; ROHRBACH, 1990; SCHMIDT; ROHRBACH, 1991; INCO, 1979).

Já refino de grão da microestrutura pode ser obtido por meio de ciclagem térmica que é feita entre a temperatura final da transformação martensítica $\left(M_{f}\right)$ e uma temperatura maior do que aquela usada na solubilização, usualmente acima da temperatura final da reversão da martensita $\left(A_{f}\right)$. As deformações induzidas pelas transformações não-difusionais da martensita para a austenita e da austenita para a martensita fornecem a força motriz para a recristalização durante os ciclos térmicos (SCHMIDT; ROHRBACH, 1991).

O tratamento térmico de envelhecimento da estrutura martensítica, realizado após a solubilização, é tradicionalmente feito a temperatura de $480{ }^{\circ} \mathrm{C}$. O objetivo desse tratamento é obter uma distribuição muito fina de precipitados, que propicie um limite de resistência muito elevado, a partir de uma matriz supersaturada em elementos de liga. $O$ tempo de tratamento térmico varia de acordo com a série: nas séries 200, 250 e 300 na faixa de 3 a 8 horas e na série 350 entre 6 e 12 horas. A série 350 pode ser envelhecida também por 3 a 6 horas entre 495 e $510{ }^{\circ} \mathrm{C}$. $\mathrm{Na}$ fabricação de moldes, as peças devem ser envelhecidas em $530{ }^{\circ} \mathrm{C}$, pois $\mathrm{O}$ superenvelhecimento proporciona maior estabilidade térmica. Durante $\mathrm{O}$ envelhecimento ocorre uma contração de até $0,02 \%$ para a série $18 \mathrm{Ni}(200)$, de 0,04\% para a série $18 \mathrm{Ni}(250)$ e de 0,08\%, para as séries $18 \mathrm{Ni}(300)$ e $18 \mathrm{Ni} \mathrm{(350)}$ (SCHMIDT; ROHRBACH, 1990; SCHMIDT; ROHRBACH, 1991).

Além dos tratamentos térmicos de solubilização e envelhecimento, os aços maraging podem ser conformados mecanicamente no campo austenítico, o que é também conhecido como ausforming. Esse processamento tem diversas finalidades. A primeira é reduzir o tamanho de grão na austenita primária. Já a segunda é evitar a formação de compostos do tipo $\mathrm{M}(\mathrm{C}, \mathrm{S}, \mathrm{N}, \mathrm{O})$ nos contornos de grão. A terceira é assegurar uma microestrutura martensítica fina, contendo uma alta densidade de 
discordâncias. Por fim, a quarta finalidade visa dispersar os carbonitretos na microestrutura e garantir que os precipitados intermetálicos tenham tamanhos menores que 1,0 um (DECKER, FLOREEN, 1988).

Já a conformação da martensita, também conhecida como marforming, pode ser interposta entre os tratamentos térmicos de solubilização e envelhecimento com o objetivo de adicionar mais discordâncias, bem como de aumentar o nível de resistência mecânica. Além disso, o marforming antes do tratamento de solubilização induz um refino de grão da austenita (DECKER, FLOREEN, 1988).

É importante mencionar que outro tratamento térmico era necessário antes do envelhecimento da martensita no início do desenvolvimento das ligas de aços maraging. Esse tratamento consistia em induzir a precipitação de compostos intermetálicos no campo austenítico a fim de diminuir o teor de elementos em solução sólida, uma vez que as ligas baseadas em aços com $25 \%$ de níquel desenvolvidas na época tinham uma temperatura $M_{S}$ menor do que a temperatura ambiente. O tratamento mencionado ficou conhecido ausaging, ou seja, envelhecimento da austenita. Contudo, essa abordagem tornou-se obsoleta quando ligas com teores menores ou iguais a $20 \%$ de níquel foram desenvolvidas, pois nessas ligas a austenita transformava-se totalmente em martensita durante 0 resfriamento a partir da temperatura de solubilização (DECKER, FLOREEN, 1988).

A fim de simplificar a discussão acerca das transformações de fase em aços maraging decorrentes de tratamentos térmicos, elas foram divididas em duas partes. A primeira parte referente às reações na austenita, que será discutida no próximo tópico, enquanto a segunda parte, no tópico 2.3.3, discute as transformações de fase na martensita.

\subsubsection{Reações na austenita}

As principais reações no campo austenítico são a transformação martensítica que ocorre durante o resfriamento da austenita, discutido no item 2.3.2.1 e a formação de precipitados contendo carbono e de precipitados intermetálicos, ocorridas em temperaturas mais altas do que a transformação martensítica, serão discutidos, respectivamente, nos itens 2.3.2.2 e 2.3.2.3. 


\subsubsection{Transformação martensítica}

A microestrutura destes aços, após o tratamento de solubilização e antes do tratamento de precipitação, é caracterizada habitualmente pela martensita em ripas com estrutura cúbica de corpo centrado (CCC), com alta densidade de discordâncias e praticamente isenta de maclas (SCHMIDT; ROHRBACH, 1990). Durante o resfriamento após o tratamento térmico de solubilização, a austenita (CFC) transforma-se em uma estrutura martensítica de corpo centrado (CCC) por meio de uma transformação de fase não-difusional sem a decomposição nas fases de equilíbrio (SCHMIDT; ROHRBACH, 1990). Esta transformação não ocorre até que seja atingida a temperatura de início de formação da martensita $\left(M_{s}\right)$. Dessa maneira, a temperatura $M_{s}$ deve ser alta para que se obtenha uma estrutura totalmente martensítica à temperatura ambiente (FLOREEN, 1978).

$O$ tipo de fase formada em ligas ferro-níquel depende da quantidade de níquel. A ferrita equiaxial é formada para teores de níquel entre 0 e $6 \%$ em massa. A estrutura totalmente martensitíca em ripas é estável em teores de níquel na faixa de 10 e $26 \%$ em massa. Teores maiores que $26 \%$ propiciam a formação de martensita lenticular (martensita maclada) (SERVANT; LACOMBE, 1977; SCHMIDT; ROHRBACH, 1991). Geralmente, a martensita na forma de ripas é preferível em aços maraging, pois após o envelhecimento esta estrutura tem maior tenacidade do que a martensita maclada (SCHMIDT; ROHRBACH, 1990). Um diagrama esquemático da microestrutura da martensita em ripas é apresentada na figura 3 (TAMURA; TSUZAKI; MAKI, 1982).

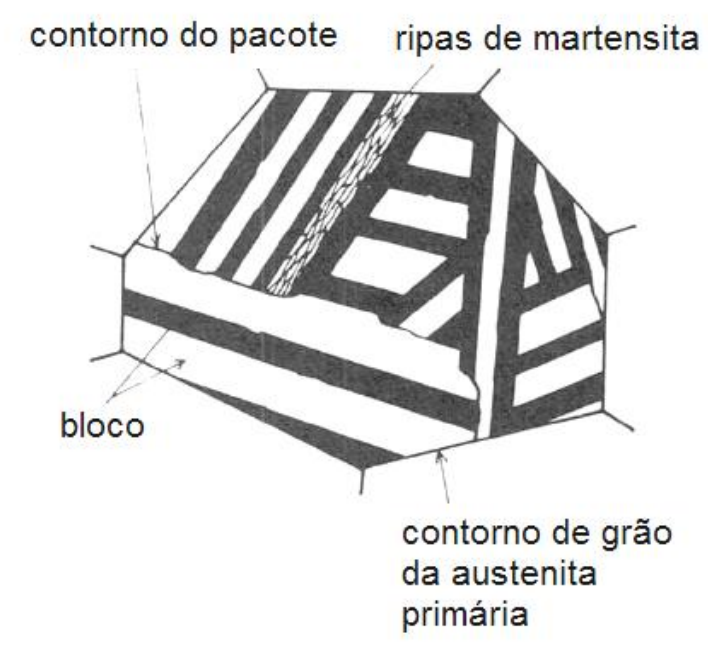

Figura 3: Microestrutura típica da martensita em ripas (TAMURA; TSUZAKI; MAKI, 1982). 
Como pode ser observado na figura 3, a microestrutura da martensita em ripas consiste de diversos pacotes dentro de cada grão da austenita primária e numerosos blocos dentro de cada pacote. Geralmente, os pacotes e blocos são planares, ao longo de uma direção, e paralelos um ao outro. Os pacotes são a estrutura predominante da martensita em ripas. Já a estrutura dos blocos aparece como áreas discretas dentro de cada pacote (SCHMIDT; ROHRBACH, 1990). A estrutura de cada bloco da martensita em ripas consiste de uma série de ripas finas e paralelas. Estas ripas da martensita são caracterizadas por uma alta densidade de discordâncias emaranhadas (FLOREEN, 1978; SCHMIDT; ROHRBACH, 1990). A relação de orientação entre as ripas de martensita e a austenita primária foi identificada como do tipo Kurdjumov-Sachs: $(111)_{\mathrm{Y}} / /(011)_{\alpha^{\prime}},[110]_{\mathrm{\gamma}} / /[111]_{\alpha^{\prime}}$ (SCHMIDT; ROHRBACH, 1990).

Lowey e coautores (2014) também observaram a microestrutura de amostras submetidas aos testes dilatométricos com taxa de resfriamento de $1,5 \mathrm{~K} \cdot \mathrm{min}^{-1}$, conforme mostrado na figura 4. A microestrutura da martensita em ripas analisada por EBSD apresentou regiões alongadas e arranjadas na forma de pacotes, como já foi ilustrado anteriormente na figura 3. Além disso, cada bloco da martensita em ripas formada consiste de dois tipos de sub-blocos com orientações ligeiramente diferentes em relação à orientação de Kurdjumov-Sachs, indicada pelas variações de cor e contraste.

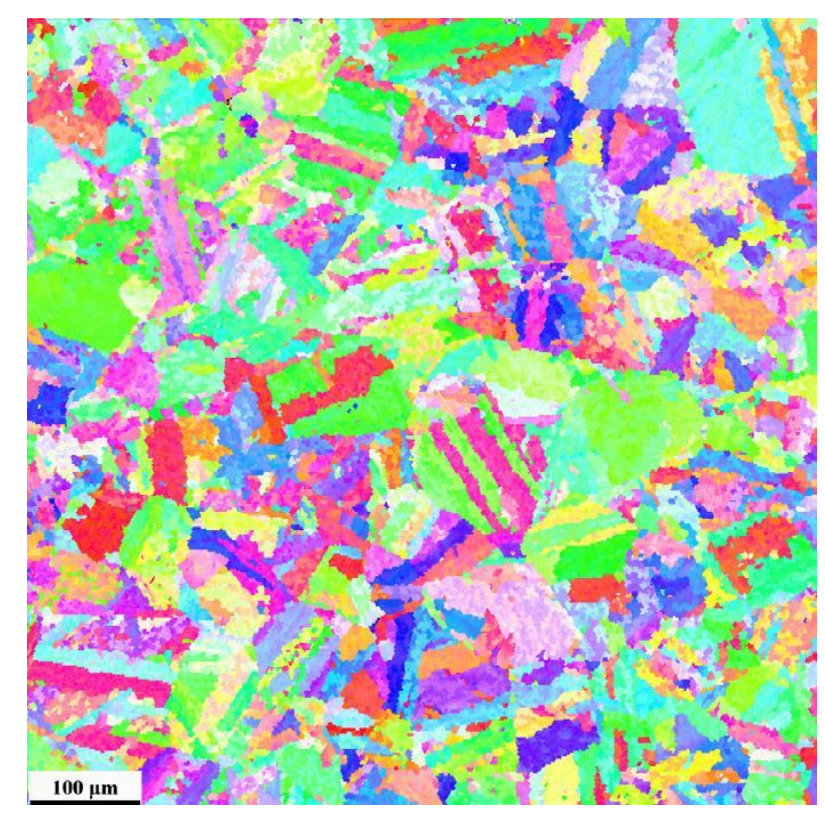

Figura 4: Mapa de orientação usando EBSD de uma amostra usada em dilatometria com uma taxa de resfriamento de $1,5 \mathrm{~K} \cdot \mathrm{min}^{-1}$ (LOWEY et al., 2014). 
Além dessas características, a alta densidade e a distribuição uniforme de discordâncias dentro das ripas da martensita promovem um aumento na resposta ao tratamento térmico de envelhecimento devido ao grande número de locais preferenciais para a nucleação de compostos intermetálicos (FLOREEN, 1978; SCHMIDT; ROHRBACH, 1990). A taxa de difusão de soluto também é aumentada pela difusão ao longo das discordâncias, pois elas proveem caminhos preferenciais em relação à difusão por meio da rede cristalina (VASUDEVAN; KIM; WAYMAN,1990).

Sabe-se que em aços, a morfologia da martensita é dependente da temperatura $M_{s}$. Altas temperaturas $M_{s}$ favorecem a formação da martensita em ripas (lath-martensite), enquanto baixas temperaturas $M_{s}$ induzem a formação da martensita maclada ou lenticular (twinned martensite). Dessa forma, a adição de elementos nos aços maraging que diminuem a temperatura $M_{s}$ (níquel, titânio e molibdênio) deve ser cuidadosa, pois favorece a formação de martensita maclada. Entretanto, esses elementos são responsáveis pelos mecanismos de envelhecimento (SCHMIDT; ROHRBACH, 1990).

$A$ adição de cobalto tem um papel relevante, pois aumenta a temperatura $M_{s}$ permitindo a adição de maiores teores de elementos de liga (FLOREEN, 1978; SCHMIDT; ROHRBACH, 1990). Assim, na ausência de cobalto, os níveis de níquel, molibdênio e titânio devem ser alterados para assegurar uma alta temperatura $M_{s}$. $O$ molibdênio diminui de forma significativa a temperatura $M_{s}$ e o cromo também tem um efeito negativo sobre a temperatura $M_{s}$. Contudo, o efeito do cromo não é tão forte quanto do molibdênio e do níquel (SCHMIDT; ROHRBACH, 1990; VICENTE; GIUSEPONE Jr; PADILHA, 2000). O titânio também reduz a temperatura $M_{s}$, em todos os teores. Além de contribuir para o endurecimento por precipitação, adições de alumínio de até 0,2\% aumentam ligeiramente a temperatura $M_{\mathrm{s}}$. Esse efeito, aliado à capacidade de desoxidação do alumínio, é responsável pela adição de 0,1\% deste elemento nos aços maraging comerciais (SCHMIDT; ROHRBACH, 1990). A diferença de composição química das diversas séries de aços maraging influencia também de maneira significativa a temperatura $M_{S}$. As séries 250,300 e 350 têm, respectivamente, uma temperatura $M_{S}$ de 175,155 e $200{ }^{\circ} \mathrm{C}$ (AHMED et al., 1988).

Além do estudo da influência da composição química, estudos recentes da cinética da transformação da austenita para a martensita foram realizados por Lowey 
e coautores (2014). Essas pesquisas buscaram evidências da existência de energia de ativação usando dilatometria e análise térmica diferencial (DTA), em um aço maraging experimental com a composição $18,8 \% \mathrm{Ni}-9,0 \% \mathrm{Co}-5,0 \% \mathrm{Mo}$, próxima do aço maraging 250. Nesses experimentos, as amostras foram resfriadas a uma taxa de $5 \mathrm{~K} /$ min entre $1323 \mathrm{~K}$ e $600 \mathrm{~K}$ para garantir que elas tivessem a mesma história térmica. A partir de $600 \mathrm{~K}$, as amostras foram submetidas às taxas de resfriamento variáveis de 2,5, 1,5, 1,0,0,5 e 0,2 K/min. Na figura 5 , é mostrado um gráfico da fração transformada como função da taxa de resfriamento (LOWEY et al., 2014).

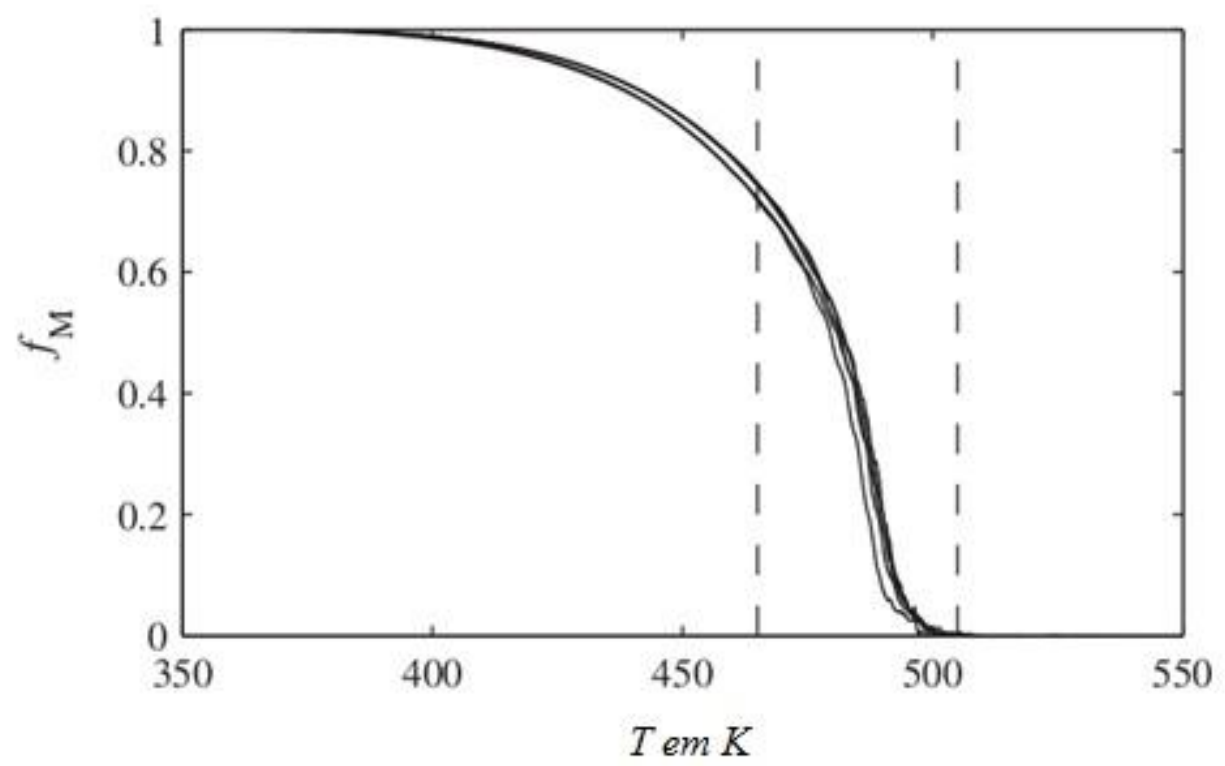

Figura 5: Fração transformada como função da temperatura obtida por medidas dilatométricas usando as taxas de resfriamento de 2,5, 1,5, 1,0, 0,5 e 0,2 K/min. As linhas tracejadas indicam a faixa de temperatura onde as modulações são mais significativas (ver Figura 6) (LOWEY et al., 2014).

Como pode ser visto na figura 5, Lowey e coautores (2014) não observaram diferenças significativas entre as curvas de fração transformadas para as diversas taxas de resfriamento, evidenciando que a energia de ativação deve ser muito pequena. $O$ comportamento das curvas da figura 5 sugere também uma diminuição da taxa de transformação a partir da fração transformada 0,7 , o que sugere um processo autocatalítico devido ao encontro de diferentes pacotes da martensita (LOWEY et al., 2014).

Tendo em vista tais considerações, Lowey e coautores (2014) também analisaram o comportamento da taxa de transformação da martensita de transformação com a temperatura, que é dada pela derivada da fração transformada com relação ao tempo, conforme mostrado na figura 6 . 


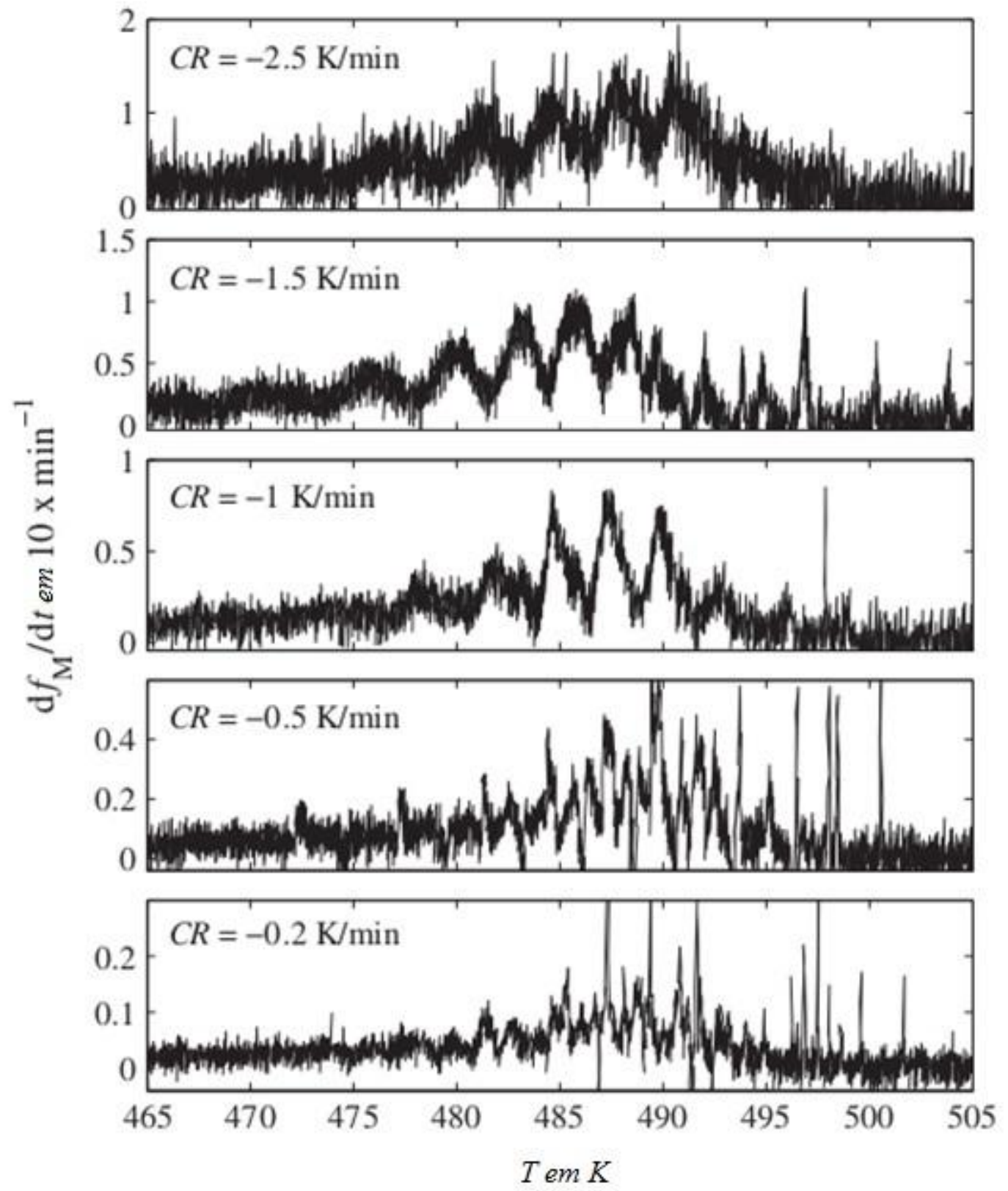

Figura 6: Taxa de transformação versus temperatura, obtidas por meio de medidas dilatométricas com taxas de resfriamento de 2,5, 1,5, 1,0, 0,5 e 0,2 K/min. As curvas mostram múltiplos picos levando a um serrilhado da máxima taxa de transformação (LOWEY et al., 2014).

$\mathrm{Na}$ figura 6, pode ser visto que há ocorrência de diversos picos da taxa de transformação para temperaturas próximas, na qual a fração transformada é 0,7 . As taxas de transformação apresentaram um comportamento "abnormal" para fração transformada acima de 0,7, o que corresponde às temperaturas de 485 a $500 \mathrm{~K}$. Normalmente, as transformações martensíticas apresentam uma única taxa máxima de transformação. Observa-se que esses picos são mais bem definidos na medida em a taxa de resfriamento aumenta (LOWEY et al., 2014). 
Medidas de DTA também foram realizadas por Lowey e coautores (2014) com uma taxa de $0,2 \mathrm{~K} / \mathrm{min}$ para verificar se era um comportamento exclusivo das curvas dilatométricas. Os resultados dessa medida são mostrados na figura 7 , que também apresentam um comportamento similar ao obtido por meio da análise térmica diferencial.

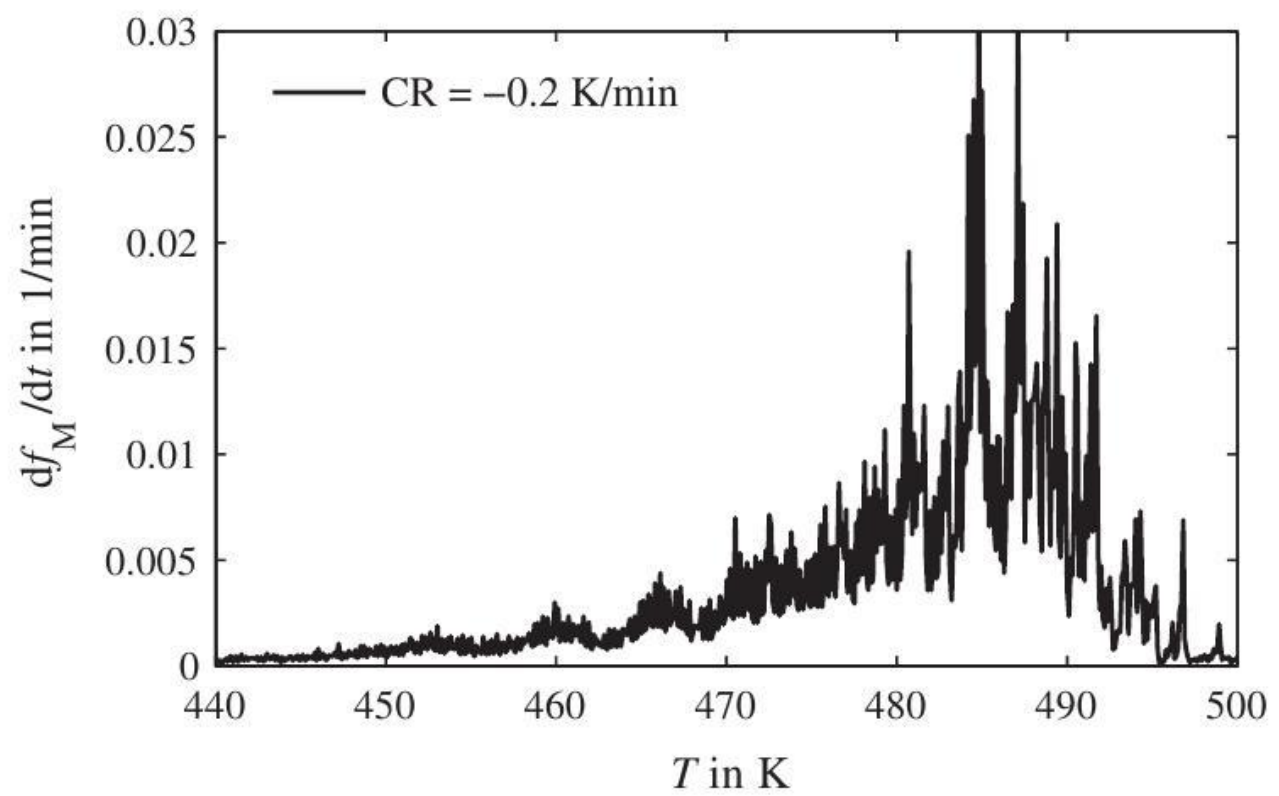

Figura 7: Taxa de transformação como função da temperatura para uma taxa de resfriamento de 0,2 K. min $^{-1}$ usando DTA (LOWEY et al., 2014).

Recozimentos prolongados a $1323 \mathrm{~K}$ por 60 horas, bem como a $1323 \mathrm{~K}$ por 1 hora, também foram realizados para verificar o efeito do tamanho de grão na cinética da transformação martensítica. Após esses tratamentos térmicos, a amostra tratada por 1 hora apresentou tamanho de grão aproximado de $90 \mu \mathrm{m}$, enquanto a amostra recozida por 60 horas teve tamanho de grão em torno de $180 \mu \mathrm{m}$; ambas resfriadas a uma taxa de $2,5 \mathrm{~K} / \mathrm{min}$ no dilatômetro.

A figura 8 mostra a influência desses tratamentos na derivada da fração transformada com relação ao tempo. 


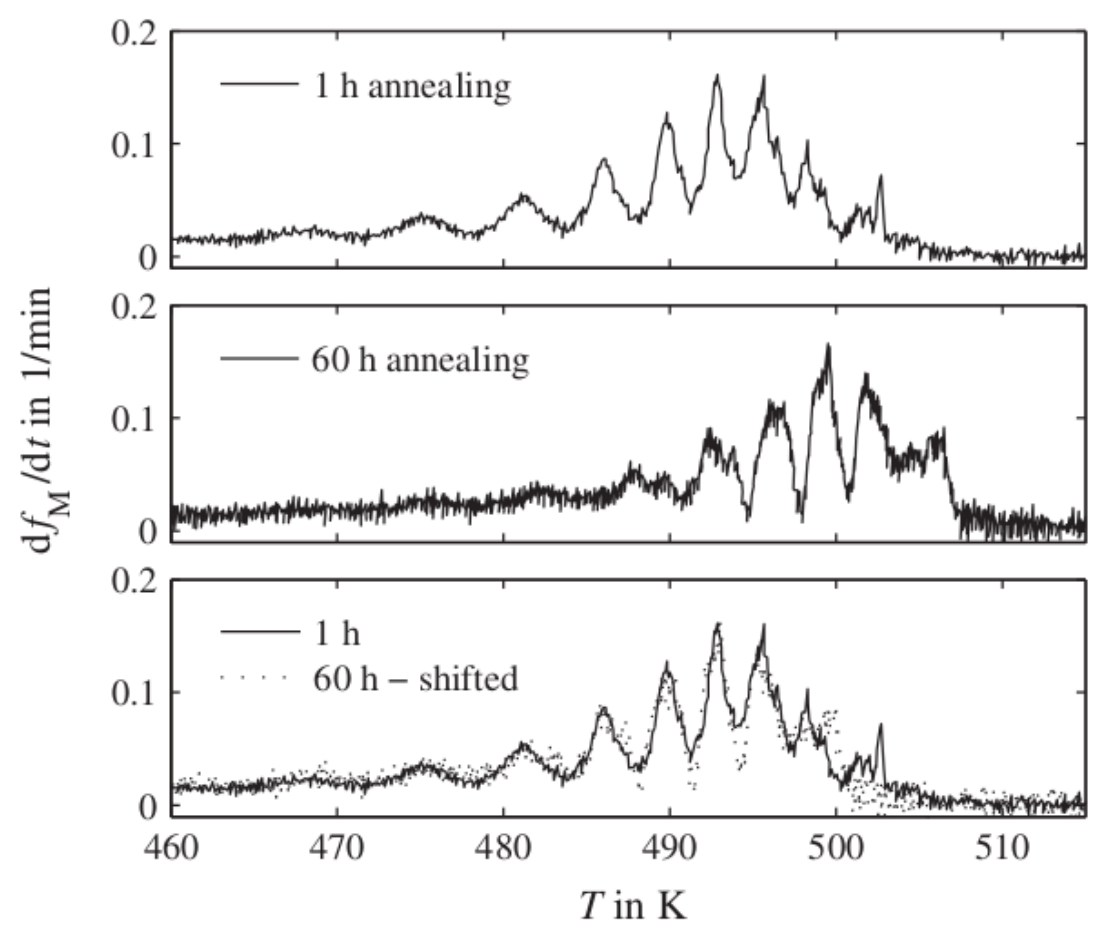

Figura 8: Taxa de transformação versus temperatura obtida por meio de medidas dilatométricas, variando os tempos de recozimento em $1323 \mathrm{~K}$ (a) 1 hora, (b) 60 horas e (c) sobreposição dos dados da amostra recozida por 60 horas deslocada em $\Delta T=6,5 \mathrm{~K}$ e aquela recozida por $1 \mathrm{~h}$ (LOWEY et al., 2014).

$\mathrm{Na}$ figura 8, observa-se um pequeno desvio de $\Delta \mathrm{T}=6,5 \mathrm{~K}$ em virtude do tamanho de grão ser maior para amostra recozida em $1323 \mathrm{~K}$ por $60 \mathrm{~h}$, em comparação àquela tratada por $1 \mathrm{~h}$ à mesma temperatura. De acordo com Lowey $\mathrm{e}$ coautores (2014), a menor temperatura $M_{S}$ na amostra recozida por 1 hora ocorre devido ao menor tamanho de grão, o que dificulta a movimentação das discordâncias em virtude do empilhamento delas próxima aos contornos de grão. Dessa maneira, esse empilhamento de discordâncias retarda a transformação martensítica.

A seguir são discutidas as reações envolvendo a formação de precipitados de carbono nos aços maraging.

\subsubsection{Precipitação de carbonetos na austenita}

Além da transformação martensítica durante o resfriamento da austenita, há a ocorrência também da precipitação de carbono em alta temperatura no campo austenítico. A caracterização e a distribuição desses precipitados na microestrutura dos aços maraging são muito relevantes, pois são locais preferenciais nos quais 
ocorre a nucleação de trincas que fragilizam os aços maraging (FLOREEN, HAYDEN, 1970).

Durante as décadas de 60 e 70, muitos pesquisadores estudaram formas de evitar que fossem formados precipitados nos contornos de grão (KALISH, RACK, 1971; CAIRNS, NOVAK, 1971; JOHNSON, STEIN, 1974; NES, THOMAS, 1976; RACK, HOLLOWAY, 1977). A precipitação de carbonetos nos contornos de grão, conhecida também como fragilização térmica, ocorre quando o aço maraging é submetido a baixas taxas de resfriamento ou mantido em temperaturas de recozimento entre 780 e $1010{ }^{\circ} \mathrm{C}$ (CAIRNS, NOVAK, 1971; NES, THOMAS, 1976). Kalish e Rack (1971) e Rack e Holloway (1977) propuseram que essa precipitação é decorrente da segregação de carbono e do nitrogênio na austenita primária. Johnson e Stein (1974) sugeriram também a formação de TiC como resultado da segregação do titânio no contorno de grão da austenita primária, enquanto Nes e Thomas (1976) propuseram que a formação de carbonetos é devido aos fenômenos de nucleação heterogênea e crescimento, ocorrendo em uma solução sólida supersaturada de Fe-Ti-C.

As inclusões nos aços maraging têm tamanhos superiores ao dos compostos intermetálicos após o envelhecimento. Foram identificadas nos aços maraging três tipos de inclusões: $\mathrm{Ti}(\mathrm{C}, \mathrm{N})$, (Ti,Mo)C e $\mathrm{Ti}_{2} \mathrm{CS}$ ou $\mathrm{Ti}_{4} \mathrm{C}_{2} \mathrm{~S}_{2}$, que são suficientemente grandes para serem observadas com auxílio do microscópio óptico. As inclusões $\mathrm{Ti}(\mathrm{C}, \mathrm{N})$ são partículas cúbicas com tamanho médio de 3,3 $\mu \mathrm{m}$ nos aços maraging (PSIODA, LOW, 1974; BONISZEWSKI, BONISZEWSKI, 1966).

Além da presença das inclusões $\mathrm{Ti}(\mathrm{C}, \mathrm{N})$, diversos pesquisadores identificaram a presença de partículas de sulfeto nos aços maraging. Essas inclusões tinham a forma de partículas alongadas tendo um tamanho médio da ordem de $4 \mu \mathrm{m}$, sendo identificadas como $\mathrm{Ti}_{2} \mathrm{~S}$ (BONISZEWSKI, BONISZEWSKI, 1966; PSIODA, LOW, 1974). Ball também mostrou que as partículas identificadas anteriormente como $\mathrm{Ti}_{2} \mathrm{~S}$ eram na verdade $\mathrm{Ti}_{2} \mathrm{CS}$ (BALL, 1984b).

Um terceiro tipo de inclusão foi observado nos aços maraging. Essa inclusão foi identificada como (Ti,Mo)C , que possui uma morfologia de partículas globulares com diâmetro de 0,4 $\mu \mathrm{m}$, bem como na forma de partículas alongadas (BONISZEWSKI, BONISZEWSKI, 1966; PSIODA, LOW, 1974). Psioda mostrou que essas inclusões tinham uma fração volumétrica menor do que as partículas de 
$\mathrm{Ti}(\mathrm{C}, \mathrm{N})$ e $\mathrm{Ti}_{2} \mathrm{CS}$. Psioda constatou ainda que vazios foram primeiro nucleados em partículas de sulfeto e partículas Ti(C,N) (PSIODA, LOW, 1974).

Além da formação de precipitados com titânio, Psioda e Low (1974) observaram que a região no centro de uma fase $\mathrm{Ti}(\mathrm{C}, \mathrm{N})$ continha zircônio, sugerindo que o $\operatorname{Zr}(\mathrm{C}, \mathrm{N})$ formado em temperaturas de fundição mais elevadas pode favorecer a nucleação heterogênea. Carvalho (2012) também observou a presença de fase $\mathrm{Ti}(\mathrm{C}, \mathrm{N})$ com zircônio em um aço maraging 350. Além disso, Carvalho (2012) verificou que a alumina $\left(\mathrm{Al}_{2} \mathrm{O}_{3}\right)$ pode facilitar a nucleação heterogênea de precipitados de carbonetos de titânio.

No item 2.3.2.3 é discutida a formação de precipitados na austenita.

\subsubsection{Precipitação de compostos intermetálicos na austenita}

Como dito anteriormente na seção 2.3.1 sobre tratamentos térmicos, o envelhecimento da austenita, conhecido como ausaging, está atualmente em desuso nos aços maraging comerciais devido ao equilíbrio na proporção dos elementos de liga que não permite a formação de austenita retida ou martensita maclada (DECKER, FLOREEN, 1988).

Estudos em uma liga Fe-25\%Ni com altos teores de níquel, alumínio e nióbio mostraram a formação de precipitados em tratamentos térmicos em $705{ }^{\circ} \mathrm{C}$ no campo austenítico. Foi observada a formação de precipitados $\mathrm{y}^{\prime}-\mathrm{Ni}_{3}(\mathrm{Ti}, \mathrm{Al}) \mathrm{com}$ morfologia esférica com diâmetro de $250 \mathrm{~nm}$ para amostras tratadas por 64 horas (FLOREEN, 1968).

Além da formação de precipitados, as variações da temperatura $M_{S}$ também foram medidas em virtude do envelhecimento da austenita. Em $600{ }^{\circ} \mathrm{C}$, observou-se uma diminuição da temperatura $\mathrm{M}_{\mathrm{S}}$ para tempos curtos devido ao excesso de energia requerido para a formação dos precipitados, enquanto tempos de tratamentos mais prolongados aumentam a temperatura $\mathrm{M}_{\mathrm{S}}$. Já para tratamentos em $700{ }^{\circ} \mathrm{C}$ há um aumento contínuo da temperatura $\mathrm{M}_{\mathrm{S}}$ com o incremento do tempo de tratamento, conforme pode ser visto na figura 9 (FLOREEN, 1968). 


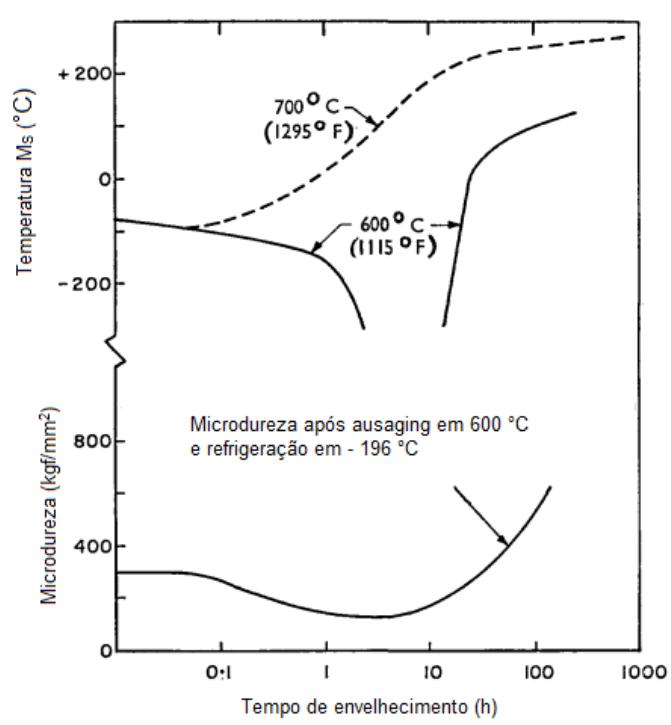

Figura 9: Variação da temperatura $\mathrm{M}_{\mathrm{S}}$ com o tempo de envelhecimento do ausaging em uma liga $\mathrm{Fe}$ $29,7 \% \mathrm{Ni}-6 \% \mathrm{Al} \mathrm{em} 600$ e $700{ }^{\circ} \mathrm{C}$ (FLOREEN, 1968).

$\mathrm{O}$ aumento da temperatura $\mathrm{M}_{\mathrm{S}}$ para ligas de aços maraging em virtude do ausaging favorece a formação da martensita em ripas, ou seja, desfavorece a formação da martensita maclada (FLOREEN, 1968).

No próximo item é discutida a precipitação de compostos intermetálicos na martensita.

\subsubsection{Reações na martensita}

\subsubsection{Precipitação de compostos intermetálicos na martensita}

O estudo da precipitação no campo martensítico é muito importante nos aços maraging, pois essa reação induz a formação de fases que são responsáveis pelo principal mecanismo de endurecimento após o tratamento de envelhecimento nesse material, cujo objetivo é obter uma distribuição muito fina de precipitados, que propicie um limite de resistência muito elevado (SCHMIDT; ROHRBACH, 1990).

A precipitação nos aços maraging é uma transformação de fase complexa, uma vez que diversas fases são formadas durante o envelhecimento da martensita, tais como X, S, $\omega, \mu, \mathrm{Fe}_{2} \mathrm{Mo}, \mathrm{Ni}_{3}\left(\mathrm{Ti}, \mathrm{Mo}\right.$ ) e $\mathrm{Ni}_{3} \mathrm{Mo}$ (TEWARl et al., 2000; SHA; CEREZO; SMITH, 1993c, 1993d; FLOREEN, 1968). Sabe-se que nos estágios 
iniciais de envelhecimento entre 400 e $450{ }^{\circ} \mathrm{C}$ as formadas as fases $\mathrm{X}, \mathrm{S}, \omega$ e $\mu$; enquanto em temperaturas em torno de $500 \stackrel{\circ}{\circ}$ e em tempos prolongados de envelhecimento são formadas as fases $\mathrm{Ni}_{3} \mathrm{Ti}, \mathrm{Ni}_{3} \mathrm{Mo}$, $\mathrm{Fe}_{2} \mathrm{Mo}$ e $\mathrm{Fe}_{7} \mathrm{Mo}_{6}$ (TEWARI et al., 2000; SHA; CEREZO; SMITH, 1993c; MOSHKA et al., 2015).

Pesquisas realizadas por diversos pesquisadores usando SAXS, SANS, MET e espectroscopia Mössbauer mostraram que a evolução microestrutural dos precipitados envolve a formação de aglomerados ricos em molibdênio, nos quais posteriormente há a formação da fase $\omega$ durante tratamentos térmicos em baixas temperaturas ou tempos curtos de envelhecimento em aços maraging (SERVANT, LACOMBE, 1977; LECOMTE; SERVANT; CIZERON, 1985; SHA; CEREZO; SMITH, 1993a; LI; YIN, 1995a; TEWARI et al., 2000).

A fase $\omega$ é uma fase de não-equilíbrio e nanométrica que possui uma estrutura cristalina hexagonal com dimensões $a=0,4058 \mathrm{~nm}$ e $c=0,2485 \mathrm{~nm}$. Trabalhos anteriores evidenciaram por meio de SAXS que, nos estágios iniciais de envelhecimento, eram formados pequenos aglomerados (clusters) ricos em molibdênio com diâmetro médio de 5 a $6 \AA$ (SERVANT, LACOMBE, 1977). Experimentos posteriores com MET mostraram que, na verdade, é formada a fase $\omega$ com morfologia esferoidal (SHA; CEREZO; SMITH, 1993c).

Em estágios posteriores de envelhecimento são formadas fases estáveis FeMo, que podem ocorrer de forma simultânea ou separadamente com a fase $\omega$. Isso depende se a temperatura de envelhecimento é suficientemente alta ou se os tempos de tratamento térmico são longos (SHA; CEREZO; SMITH, 1993c). O tamanho e a proporção relativa desses precipitados também variam de acordo com o tempo e a temperatura de envelhecimento (LECOMTE; SERVANT; CIZERON, 1985). Lecomte e coautores observaram a presença da fase $\omega$ com diâmetro médio de $5 \mathrm{~nm}$ após tratamentos térmicos a $420{ }^{\circ} \mathrm{C}$ por 48 horas, como pode ser visto na figura 10 (LECOMTE; SERVANT; CIZERON, 1985). 


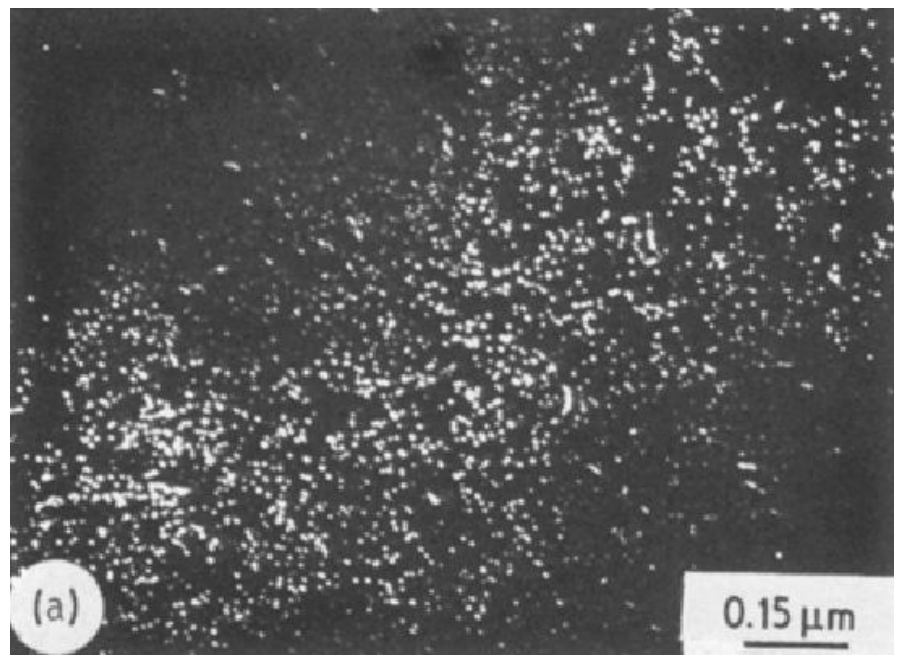

Figura 10: Micrografia no campo escuro mostrando a fase $\omega$ observada por Lecomte e coautores na liga $\mathrm{Fe}-18,5 \mathrm{Ni}-8,9 \mathrm{Co}-4,8 \mathrm{Mo}$ após tratamento a $420{ }^{\circ} \mathrm{C}$ por 48 horas (LECOMTE; SERVANT; CIZERON, 1985).

A alta densidade de precipitados formados nos aços maraging geralmente é atribuída à alta densidade de discordâncias (da ordem de $10^{12} \mathrm{~cm} / \mathrm{cm}^{3}$ ) da estrutura martensítica em ripas (SERVANT; MAEDER; CIZERON, 1975).

Sha e coautores também observaram que, em um aço maraging 300 , tanto a fase $\omega$ quanto a fase $\mu\left(\mathrm{Fe}_{7} \mathrm{Mo}_{6}\right)$ estão presentes em $414^{\circ} \mathrm{C}$ e 15,8 horas, com a fase $\omega$ predominante. $A$ fase $\omega$ teve uma estequiometria média de $\mathrm{Fe}_{12} \mathrm{Ni}_{47} \mathrm{Co}_{1} \mathrm{Mo}_{40}$ e fração volumétrica aproximada de $3 \%$, enquanto a fase $\mu$ teve fração de $1 \%$. Além disso, foi observado em uma micrografia de campo iônico que estas duas famílias de precipitados têm morfologia esferoidal, como pode ser visto na figura 11 (SHA; CEREZO; SMITH, 1993c).

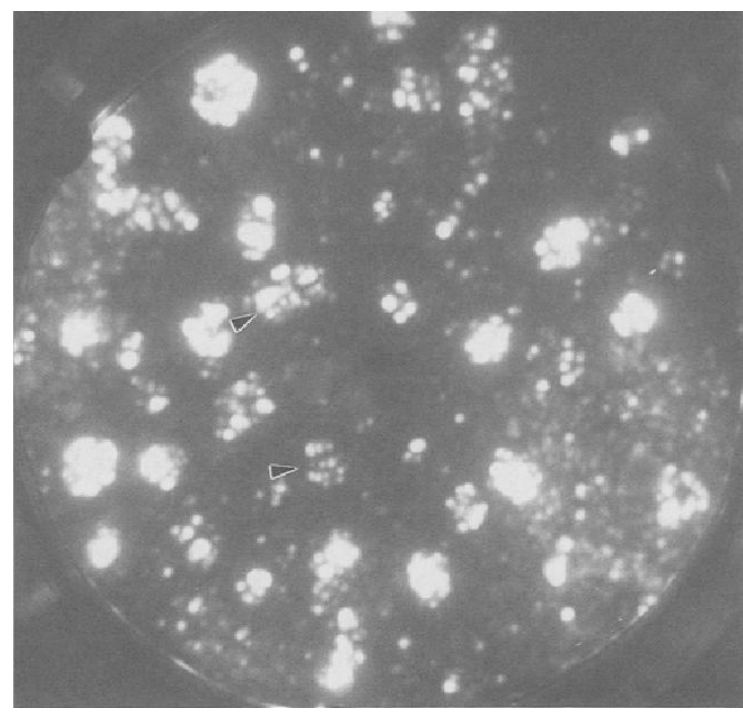

Figura 11: Micrografia de campo iônico de uma amostra de maraging 300 envelhecida em $414 \stackrel{\circ}{\mathrm{C}}$ por 15,8 horas, mostrando a ocorrência de dois tipos de precipitados (SHA; CEREZO; SMITH, 1993C). 
A primeira família é composta de precipitados da fase $\omega$, enquanto os pequenos precipitados indicados na figura 11 são pequenos núcleos da fase $\mu$ $\left(\mathrm{Fe}_{7} \mathrm{Mo}_{6}\right)$. Foi observado também por Sha e coautores que as fases $\omega$ e $\mu$ coexistem na temperatura de $510^{\circ} \mathrm{C}$ e 1 hora, enquanto para 4 horas somente a fase $\mu$ foi encontrada (SHA; CEREZO; SMITH, 1993c).

Lecomte e coautores também analisaram os padrões de difração de elétrons em área selecionada e concluíram que a fase $\omega$ é uma fase ordenada, pois há um spot de difração extra dos tipos $\{1010\}_{\omega}$ e $\{2020\}_{\omega}$, ao longo tanto do eixo do padrão de difração $<110>_{M}$ quanto do $<111>_{M}$ - proibidos para a fase $\omega$ desordenada, conforme a figura 12 (LECOMTE; SERVANT; CIZERON, 1985).
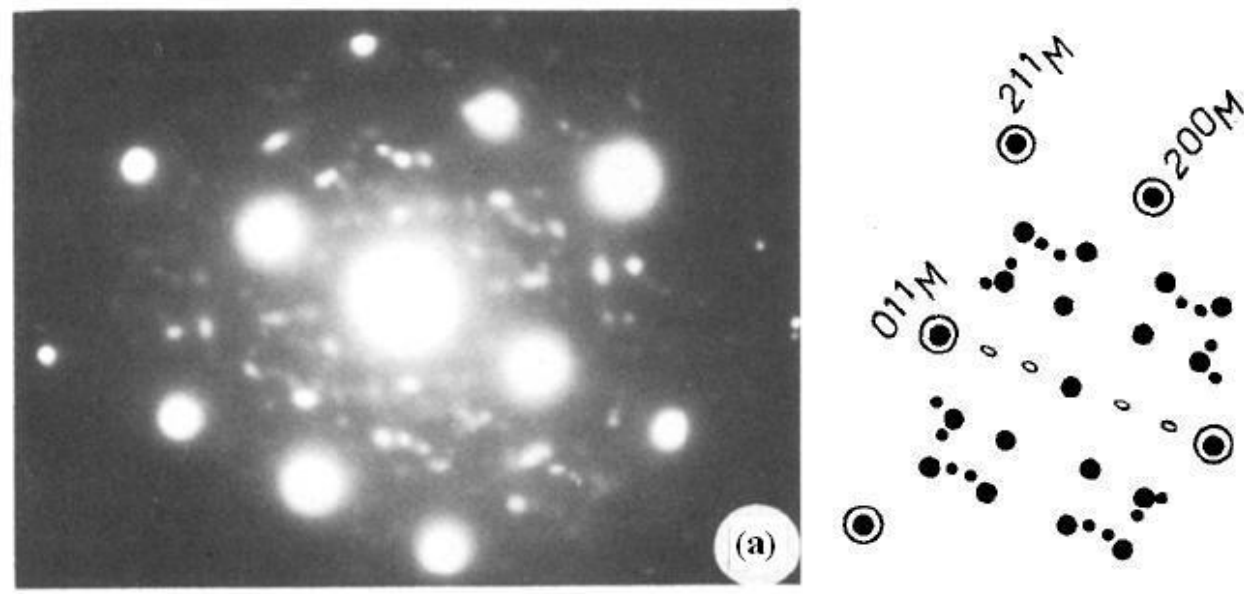

○
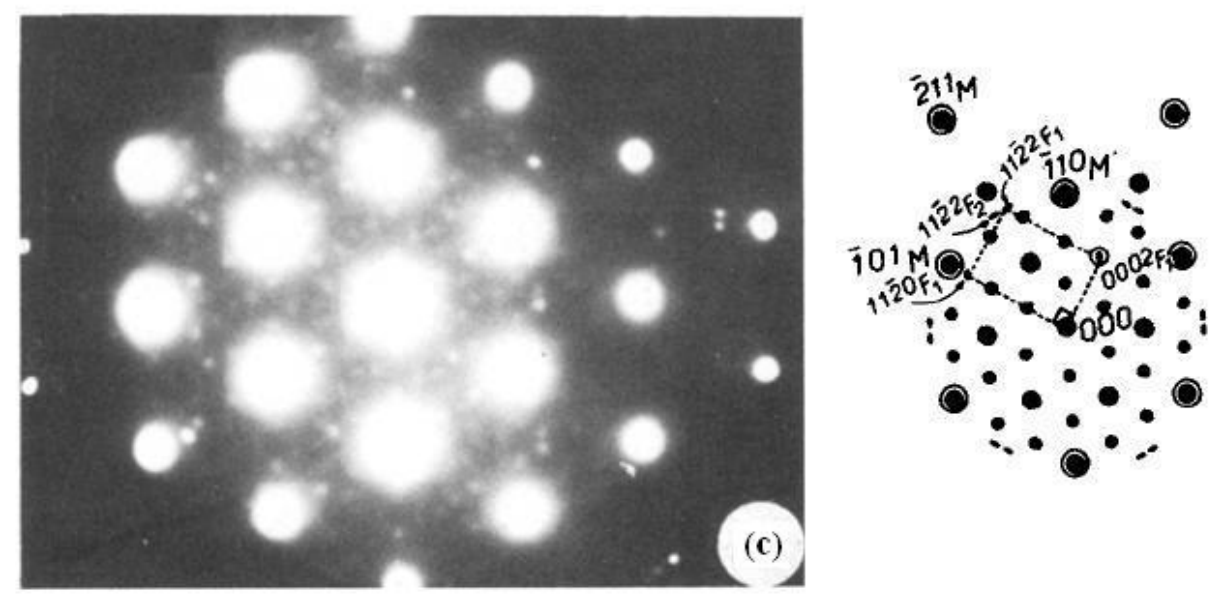

(b)

(d)

Figura 12: Padrões de difração ao longo dos eixos (a), (b) $<110\rangle_{M}$ e (c), (d) $\left.<111\right\rangle_{M}$ em uma amostra da liga Fe-18,5Ni-8,9Co-4,8Mo após tratamento a $420^{\circ} \mathrm{C}$ por 48 horas (LECOMTE; SERVANT; CIZERON, 1985).

Lecomte e coautores sugeriram que a formação da fase $\omega$ ordenada, partindo da fase $\mathrm{S}$, ocorre com uma mudança contínua na composição química partindo de 
$A_{8} B$ (fase $S$ ) para $A_{7} B_{2}$ e, em seguida, pela fase $A_{6} B_{3}$ (LECOMTE; SERVANT; CIZERON, 1985).

Tewari e coautores (2000) sugeriram que, em temperaturas de envelhecimento abaixo de $450 \stackrel{\circ}{\circ}$, os precipitados $\omega$ são formados por meio do mecanismo de ordenamento. Enquanto para temperaturas de envelhecimento maiores que $450 \stackrel{\circ}{\circ}$, há a nucleação e crescimento de compostos intermetálicos do tipo $A_{3} B$.

As discordâncias têm um papel relevante na reação de precipitação em aços maraging. Vasudevan e coautores (1990) sugeriram que a precipitação inicial ocorre nas discordâncias, seguida por uma etapa de crescimento dos precipitados pelo mecanismo de difusão ao longo das discordâncias. Sha e coautores (1993c) também observaram que além dos pequenos precipitados isolados, os precipitados podem se concentrar ao longo de uma linha contínua de precipitados, indicando que há uma precipitação preferencial nos contornos de ripas da martensita ou nos contornos de grão da austenita primária, conforme pode ser visto na figura 13.

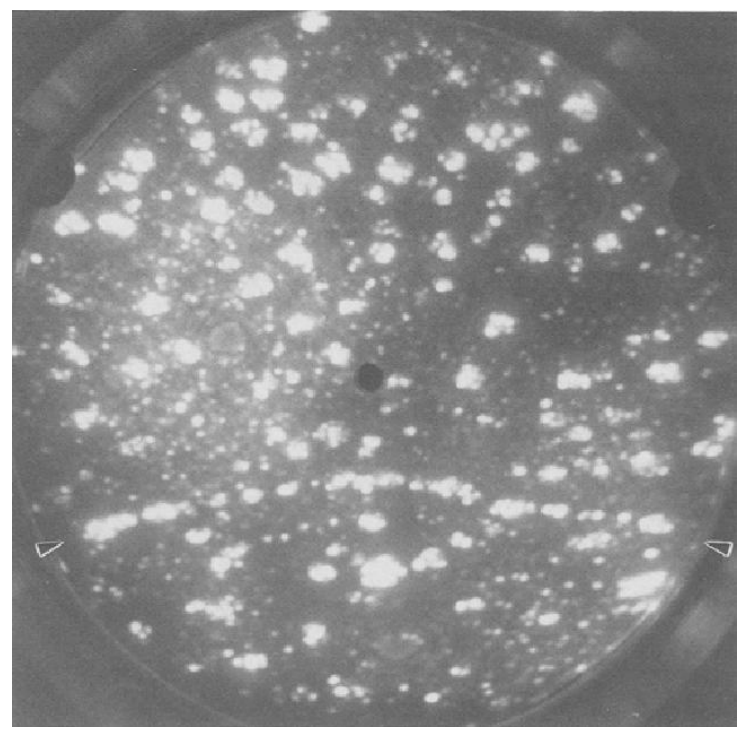

Figura 13: Micrografia de uma amostra de aço maraging 300 envelhecida a $510{ }^{\circ} \mathrm{C}$ por 1 hora mostrando precipitados esferoidais (SHA et. al., 1993c).

Li e Yin (1995a) observaram também, usando medidas de espectroscopia Mössbauer, que nos estágios iniciais há uma rápida distribuição de soluto, formando zonas ricas em Ni-Ti-Mo e Fe-Co, favorecendo a criação de fases mais estáveis como $\mathrm{Ni}_{3} \mathrm{X}$ (X=Ti,Mo) e Fe-Mo (LI; YIN, 1995a).

Há certa diversidade de opiniões sobre a natureza ou estequiometria dos precipitados endurecedores mais estáveis formados durante o tratamento térmico de 
envelhecimento em aços maraging Fe-Ni-Co-Mo-Ti em virtude de dificuldades experimentais. Dentre elas, as principais se relacionam com o comprometimento da resolução das imagens dos precipitados por meio de MET, em virtude do campo magnético gerado pela matriz martensítica ferromagnética; além disso, a similaridade da distância interplanar e das relações de orientação com a matriz dos diversos precipitados encontrados em aços maraging impõe dificuldades adicionais na sua identificação (MOSHKA et al., 2015). Tewari e coautores (2000) sumarizaram os precipitados encontrados na literatura dos aços maraging, como pode ser visto na tabela 6. Também foram adicionadas as relações de orientação entre a matriz martensítica e o precipitado $\mathrm{Ni}_{3} \mathrm{Mo}$, que foram determinadas por Moshka e coautores (2015).

Tabela 6: Fases observadas nos aços maraging Ni-Co-Mo-Ti (TEWARI et al., 2000; MOSHKA et al., 2015).

\begin{tabular}{|c|c|c|c|c|}
\hline Fases & Estequiometria & $\begin{array}{l}\text { Estrutura } \\
\text { cristalina }\end{array}$ & $\begin{array}{l}\text { Parâmetros de } \\
\text { rede }\end{array}$ & $\begin{array}{c}\text { Relações de } \\
\text { Orientação }\end{array}$ \\
\hline$\mu$ & $A_{7} B_{6}$ & Romboédrica & $\begin{array}{l}a=4,751 \AA \\
a=30,38^{\circ}\end{array}$ & - \\
\hline$\omega$ & $\mathrm{A}_{2} \mathrm{~B}$ & Hexagonal & $\begin{array}{l}a=3,9-4,05 \AA \\
c=2,39-2,48 \AA\end{array}$ & $\begin{array}{c}(0001)_{\omega} \| \mid\{111\}_{\alpha} \\
1120_{\omega} \| 110_{\alpha}\end{array}$ \\
\hline$S$ & $A_{8} B$ & Hexagonal & $\begin{array}{l}a=7,04 \AA \\
c=2,48 \AA\end{array}$ & - \\
\hline $\mathrm{x}$ & $A_{3} B$ & Hexagonal & $\begin{array}{l}a=2,55 \AA \\
c=8,30 \AA\end{array}$ & $\begin{array}{l}(0001)_{X} \|\{111\}_{\alpha} \\
2110_{X} \| 110_{\alpha}\end{array}$ \\
\hline $\mathrm{Fe}_{2} \mathrm{Mo}$ & $\mathrm{A}_{2} \mathrm{~B}$ & Hexagonal & $\begin{array}{l}a=4,745 \AA \\
c=7,754 \AA\end{array}$ & $\begin{array}{l}(0001)_{\mathrm{Fe}_{2} \mathrm{Mo}} \|\{111\}_{\alpha} \\
2110_{\mathrm{Fe}_{2} \mathrm{Mo}} \| 110_{\alpha}\end{array}$ \\
\hline $\mathrm{Ni}_{3} \mathrm{Ti}$ & $\mathrm{A}_{3} \mathrm{~B}$ & Hexagonal & $\begin{array}{l}a=5,101 \AA \\
c=8,307 \AA\end{array}$ & $\begin{array}{c}(0001)_{N i_{3} T i} \|\{111\}_{\alpha} \\
1120_{N i_{3} T i} \| 110_{\alpha}\end{array}$ \\
\hline $\mathrm{Ni}_{3} \mathrm{Mo}$ & $A_{3} B$ & Ortorrômbica & $\begin{array}{l}\mathrm{a}=5,064 \AA \\
\mathrm{b}=4,224 \AA \\
\mathrm{c}=4,448 \AA\end{array}$ & $\begin{array}{c}(010)_{N i_{3} M o} \|\{011\}_{\alpha} \\
100_{N i_{3} M o} \| 111_{\alpha}\end{array}$ \\
\hline
\end{tabular}

A maioria das pesquisas indica que a formação de precipitados $\mathrm{Ni}_{3} \mathrm{Ti}_{\text {e }} \mathrm{Ni}_{3} \mathrm{Mo}$ ocorre durante o envelhecimento, enquanto fases mais estáveis $\mathrm{Fe}-\mathrm{Mo}$ ( $\mathrm{Fe}_{2} \mathrm{Mo}$ ou 
$\mathrm{Fe}_{7} \mathrm{Mo}_{6}$ ) são formadas após um longo tempo de exposição (SHA; CEREZO; SMITH, 1993d; SPITZIG; CHILTON; BARTON, 1979; VASUDEVAN; KIM; WAYMAN, 1990; VISWANATHAN; DEY; ASUNDI, 1993a; MOSHKA et al, 2015).

As pesquisas também sugerem que os precipitados dos aços maraging apresentam mudanças de morfologia e de tamanho com o aumento do tempo de envelhecimento. As fases $S$ e $\omega$ têm morfologia esferoidal, enquanto a fase $\mathrm{Ni}_{3} \mathrm{Ti}$ possui morfologia elipsoidal e a fase $\mathrm{Ni}_{3} \mathrm{Mo}$ apresenta morfologia na forma de agulhas. Por fim, as fases $\mathrm{Fe}_{2} \mathrm{Mo}$ e $\mathrm{Fe}_{7} \mathrm{Mo}_{6}$ possuem também morfologia esferoidal (VASUDEVAN; KIM; WAYMAN, 1990; SHA; CEREZO; SMITH, 1993a; TEWARI et al., 2000; MOSHKA et al., 2015).

Até recentemente, havia dúvidas quanto à existência da fase $\mathrm{Ni}_{3} \mathrm{Mo}$, pois estudos realizados por Sha e coautores (1993a) haviam sugerido que as fases $\mathrm{Ni}_{3} \mathrm{Ti}$ eram enriquecidas com molibdênio. Além disso, eles mostraram por meio de cálculos termodinâmicos que a fase $\mathrm{Ni}_{3} \mathrm{Mo}$ tem força motriz negativa, indicando que ela é uma fase metaestável termodinamicamente e seria pouco provável nos aços maraging.

Moshka e coautores (2015) fizeram um estudo sistemático das mudanças de morfologia dos precipitados formados durante o envelhecimento em $510{ }^{\circ} \mathrm{C}$ de três ligas de aços maraging: um aço maraging 250 com cobalto, uma liga com composição similar ao aço maraging 250 sem adição de titânio (15\%Ni-9,3\%Co$4,2 \% \mathrm{Mo})$ e outra também com composição próxima ao aço maraging 250 sem adição de molibdênio (15,3\%Ni-9,2\%Co-2,1\%Ti). Eles observaram que o precipitado formado durante o envelhecimento da liga 15,3\%Ni-9,2\%Co-2,1\%Ti em $510{ }^{\circ} \mathrm{C}$ tinha a composição química $\mathrm{Ni}_{3} \mathrm{Ti}$ e morfologia elipsoidal; enquanto o precipitado formado durante o envelhecimento da liga $15 \% \mathrm{Ni}-9,3 \% \mathrm{Co}-4,2 \% \mathrm{Mo}$, na mesma temperatura, tinha a composição química $\mathrm{Ni}_{3} \mathrm{Mo}$ e a forma de agulhas.

A partir de tais considerações, foi possível Moshka e coautores (2015) identificar a morfologia das fases formadas em amostras de aço maraging 250 envelhecidas em $510^{\circ} \mathrm{C}$ por 0,3, 1, 3 e 1200 horas, conforme apresentado na figura 14. 

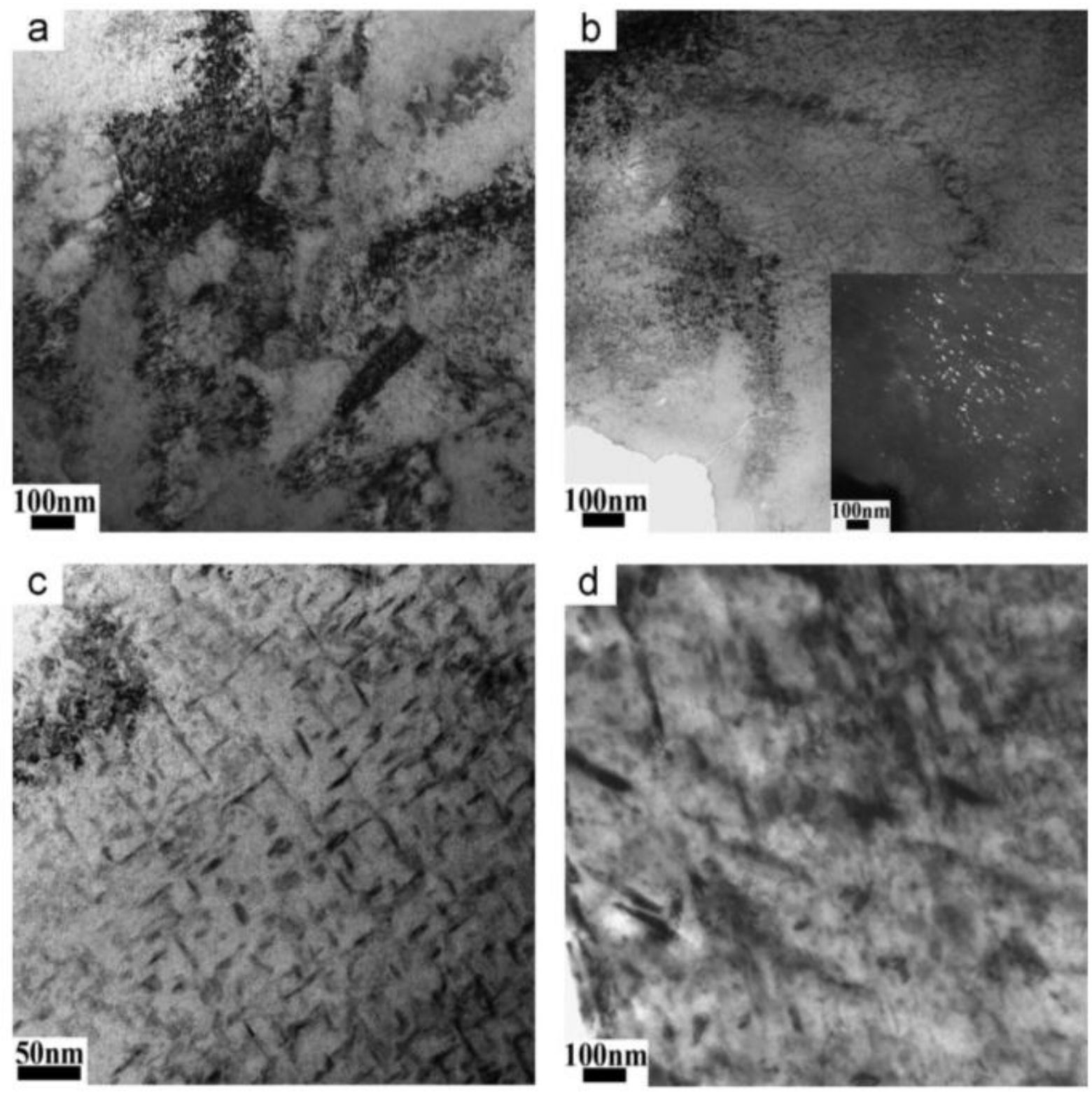

Figura 14: Imagens em campo claro de amostras envelhecidas a $510^{\circ} \mathrm{C}$ por (a) $0,3 \mathrm{~h}$, (b) $1 \mathrm{~h}$, (c) $3 \mathrm{~h}$ e (d) $1200 \mathrm{~h}$ para um aço maraging 250. Também é mostrada uma micrografia em campo escuro na amostra tratada por $1 \mathrm{~h}$ (figura 14b) (MOSHKA et al., 2015).

A figura 14a apresenta os precipitados finos formados para a amostra tratada por 0,3 h. Já a figura 14b mostra que os precipitados se tornam alongados para a amostra envelhecida por $1 \mathrm{~h}$ em relação àqueles encontrados na amostra tratada por 0,3 h. Na figura 14c, são observadas duas populações de precipitados com morfologia elipsoidal e na forma de agulhas. Os precipitados na forma de agulhas foram identificados como $\mathrm{Ni}_{3} \mathrm{Mo}$, enquanto aqueles com morfologia elipsoidal foram determinados como $\mathrm{Ni}_{3} \mathrm{Ti}$. Por fim, a figura $14 \mathrm{~d}$ mostra os precipitados grossos formados durante o superenvelhecimento a $510{ }^{\circ} \mathrm{C}$ por $1200 \mathrm{~h}$ (MOSHKA et al., 2015). 
Shmulevitsh e coautores (2015) mostraram que a energia elástica associada à presença do precipitado $\mathrm{Ni}_{3} \mathrm{Mo}$ é aproximadamente 3 vezes menor do que aquela relacionada ao precipitado $\mathrm{Ni}_{3} \mathrm{Ti}$, o que explica a menor energia de ativação para a formação da fase $\mathrm{Ni}_{3} \mathrm{Mo}$, apesar de sua instabilidade termodinâmica. O precipitado $\mathrm{Ni}_{3} \mathrm{Mo}$ tem menor desajuste com a matriz do que o $\mathrm{Ni}_{3} \mathrm{Ti}$. Esse estudo também simulou o crescimento na forma de partículas alongadas durante o envelhecimento que minimiza o campo elástico associado à presença desses precipitados.

Além das mudanças de morfologia, os precipitados apresentam um crescimento em função do tempo e da temperatura de envelhecimento devido à natureza difusional desta reação (SHA; CEREZO; SMITH, 1993a; VASUDEVAN; KIM; WAYMAN, 1990; TEWARI et al., 2000). Tewari e coautores (2000) observaram um aumento tanto no tamanho médio da fase $\omega$ em $430{ }^{\circ} \mathrm{C}(703 \mathrm{~K})$ quanto no incremento do tamanho médio da fase $\mathrm{Ni}_{3} \mathrm{Ti}$ em $510^{\circ} \mathrm{C}(783 \mathrm{~K})$ com aumento do tempo de envelhecimento, conforme mostrado na figura 15.

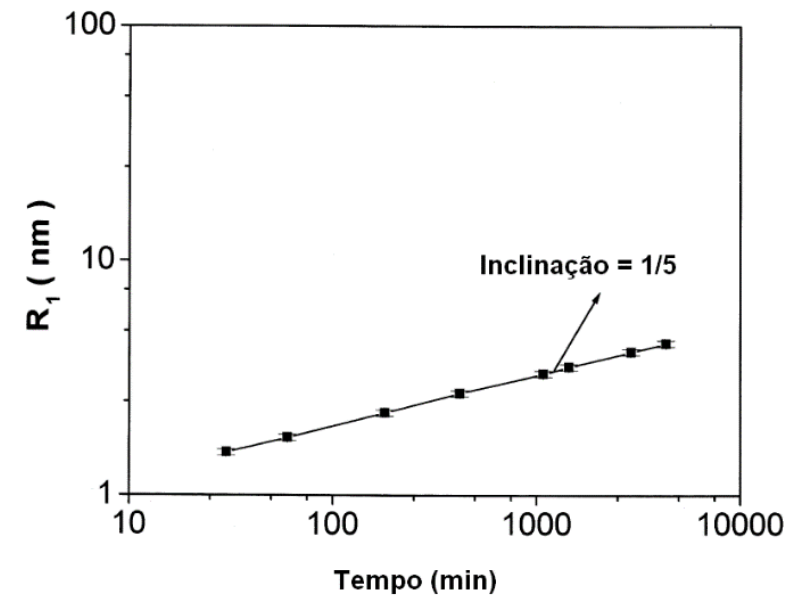

(a)

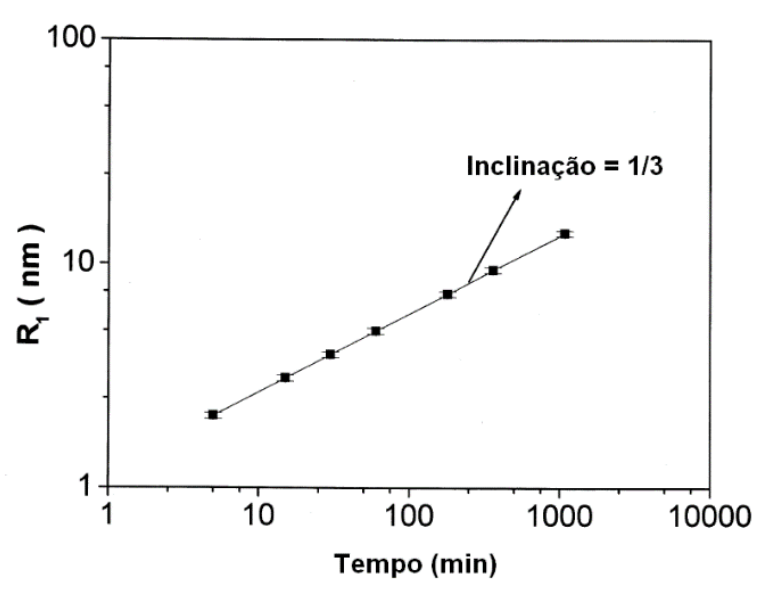

(b)

Figura 15: Crescimento dos precipitados em um aço maraging 350: (a) tamanho médio da fase $\omega$ em função do tempo de envelhecimento para amostras tratadas por até 72 horas em $430{ }^{\circ} \mathrm{C}(703 \mathrm{~K})(\mathrm{b})$ tamanho médio da fase $\mathrm{Ni}_{3} \mathrm{Ti}$ com o tempo de envelhecimento para amostras envelhecidas por até 18 horas em $510^{\circ} \mathrm{C}(783 \mathrm{~K})$. Tamanho estimado por SAXS (TEWARI et al., 2000).

A partir de suas análises microestruturais e de estudos anteriores, Tewari e coautores propuseram um diagrama temperatura-tempo-transformação (TTT), que apresenta duas curvas separadas. A primeira curva mostra a evolução da fase $\omega$ e a segunda mostra a nucleação e o crescimento de precipitados do tipo $\mathrm{Ni}_{3}(\mathrm{Ti}, \mathrm{Mo})$, conforme visto na figura 16 (TEWARI et al., 2000). 


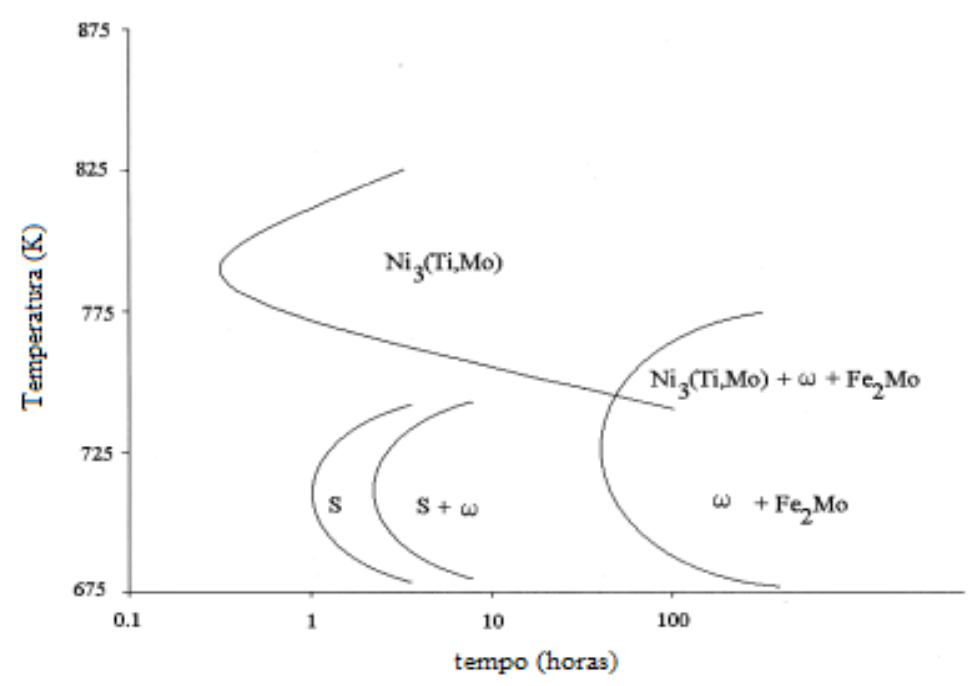

Figura 16: Diagrama TTT esquemático correspondente à precipitação de compostos intermetálicos em aços maraging (TEWARI et al., 2000).

A comparação do diagrama TTT, proposto por Tewari e coautores (2000), com os estudos feitos por Moshka et al. (2015) mostra que esse diagrama está incompleto, pois não há a presença da fase $\mathrm{Ni}_{3}$ Mo. Além disso, também não apresenta a formação da austenita revertida que ocorre em tempos prolongados de exposição ou em temperaturas a partir de $520^{\circ} \mathrm{C}$.

No item 2.3.3.2 são discutidos os mecanismos de reversão da martensita para a austenita.

\subsubsection{Reversão da martensita}

O interesse da pesquisa pela reversão está associado às mudanças que esta transformação de fase pode acarretar as propriedades mecânicas dos aços maraging, após tempos prolongados de tratamento térmico de envelhecimento, também conhecida como superenvelhecimento (RAO, 2006).

A taxa em que esta reação de reversão ocorre é fortemente dependente da composição da liga de aço maraging (RAO, 2006). Peters (1968) estudou a influência do níquel, do cobalto, do molibdênio e do titânio na reversão da martensita em ligas binárias $\mathrm{Fe}-\mathrm{Ni}$, bem como em ligas ternárias baseadas na liga $\mathrm{Fe}-18 \mathrm{Ni}$, conforme mostrado na figura 17. 


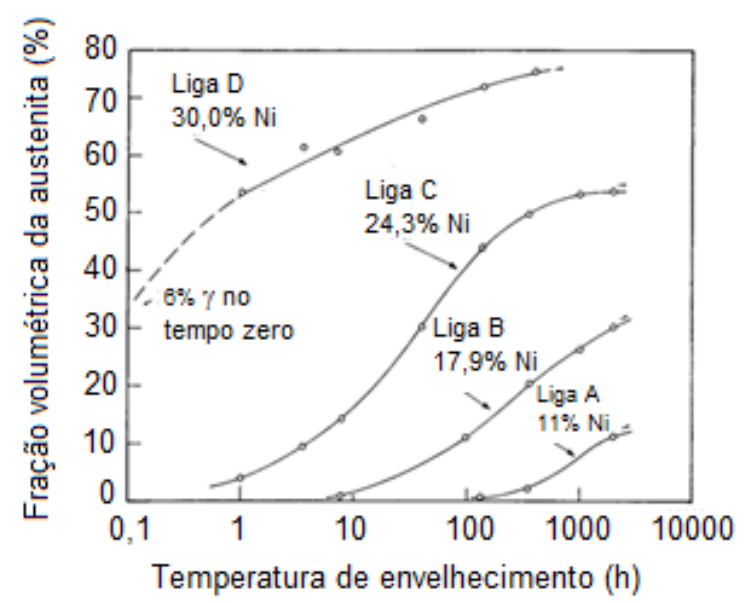

(a)

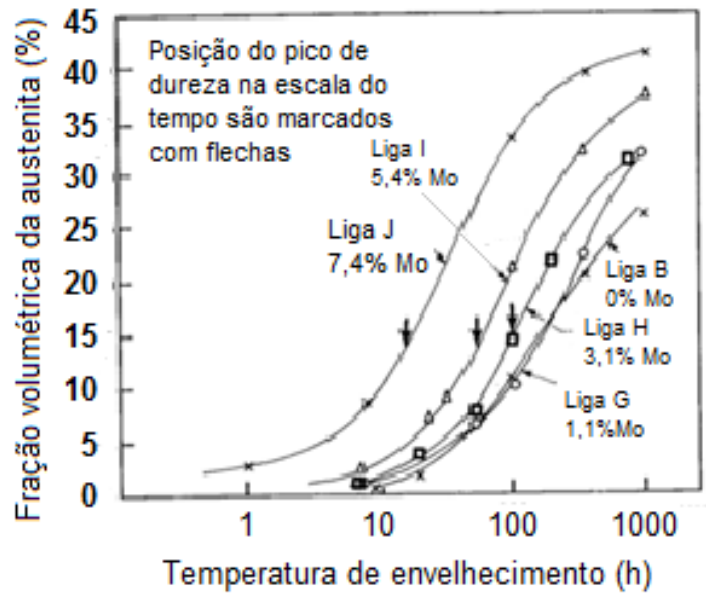

(c)

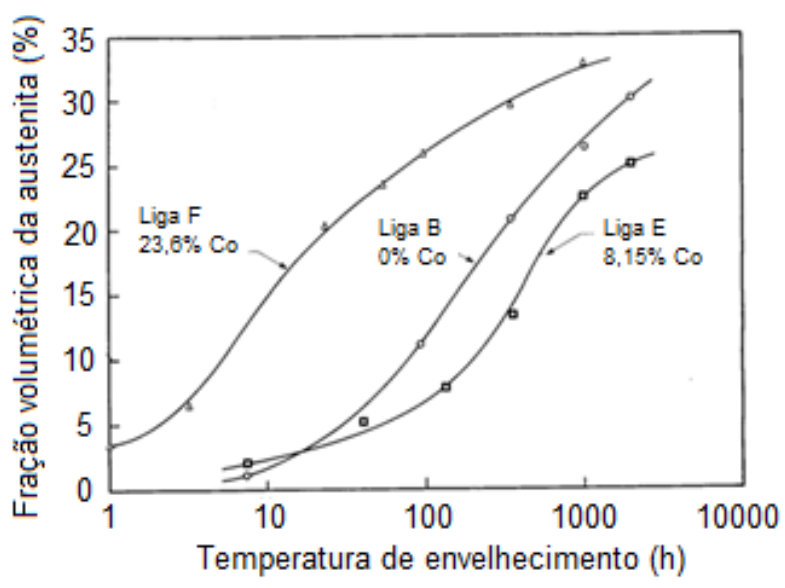

(b)

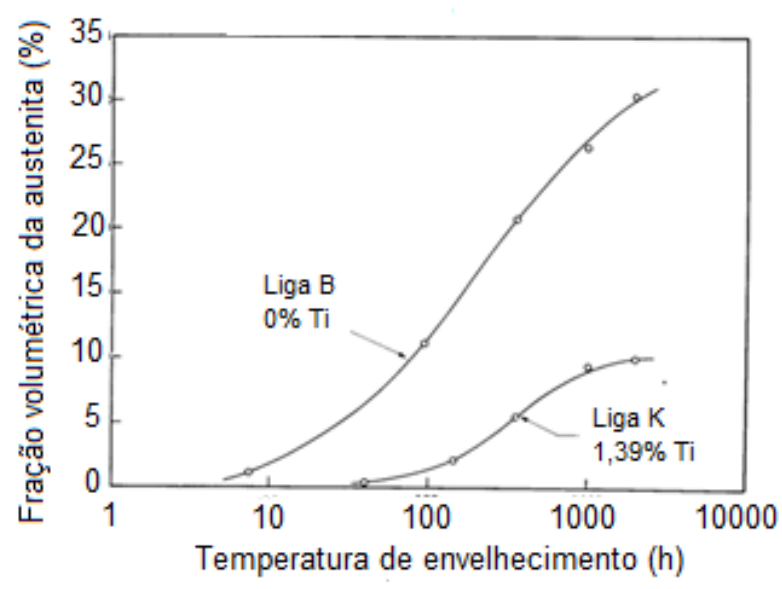

(d)

Figura 17: Fração volumétrica da austenita formada durante tratamentos térmicos em $480{ }^{\circ} \mathrm{C}$ para: (a) diversas ligas $\mathrm{Fe}-\mathrm{Ni}$, (b) diversas ligas $\mathrm{Fe}-18 \mathrm{Ni}$ contendo diferentes teores de cobalto, (c) diversas ligas $\mathrm{Fe}-18 \mathrm{Ni}$ contendo diferentes teores de molibdênio e (d) diversas ligas Fe-18Ni contendo diferentes teores de molibdênio (PETERS, 1968).

Estudos realizados por Peters (1968) mostraram que as adições de níquel, de cobalto, de molibdênio e de titânio influenciam de forma significativa a cinética de reversão da martensita. Na figura 17a, pode-se observar que o aumento do teor de níquel acelera a cinética de reversão, enquanto adições de $24 \%$ de cobalto aceleram a reversão e adições de $8 \%$ desse elemento retardam ligeiramente a formação de austenita (figura 17b). Se de um lado, o aumento do teor de molibdênio incrementa a fração volumétrica de austenita revertida como função do tempo (figura 17c), por outro lado, adições de 1,4\% de titânio diminuem consideravelmente a formação dessa fase (figura 17d) (PETERS, 1968).

Tendo como base a composição do aço maraging 350, Ahmed et al. (1994a) também analisaram a influência da variação de níquel entre 18\% e 24 \%, bem como da variação de molibdênio na faixa de 3,5\% a 7,5\%. Desses estudos, esses autores 
também concluíram que o níquel e molibdênio atuam como fortes estabilizadores da austenita.

A reversão da austenita nos aços maraging é comumente atribuída ao enriquecimento de níquel da matriz cúbica de corpo centrado. Esse enriquecimento geralmente está associado à dissolução de precipitados do tipo $\mathrm{Ni}_{3} \mathrm{X}(\mathrm{X}=\mathrm{Mo}, \mathrm{Ti})$ e à formação de compostos intermetálicos Fe-Mo durante 0 superenvelhecimento ( $\mathrm{Fe}_{7} \mathrm{Mo}_{6}$ ou $\mathrm{Fe}_{2} \mathrm{Mo}$ ) (DECKER; FLOREEN, 1988; VISWANATHAN, DEY, ASUNDI, 1993a; LI, YIN, 1995b; VISWANATHAN, DEY, SETHUMANDHAVAN, 2005). Diversos pesquisadores observaram que a formação da austenita e dos precipitados $\mathrm{Fe}_{2} \mathrm{Mo}$ ocorre aproximadamente ao mesmo tempo e sugeriram que o níquel proveniente da dissolução do $\mathrm{Ni}_{3}(\mathrm{Mo}, \mathrm{Ti})$ seria usado para formar a austenita revertida e o molibdênio, usado para formar Fe 2 Mo (LI, YIN, 1995; VISWANATHAN, DEY, SETHUMANDHAVAN, 2005; FAROOQUE, AYUB, UL HAQ, KHAN, 1998). Contudo, Moshka e coautores (2015) mostraram que o precipitado $\mathrm{Ni}_{3} \mathrm{Mo}$ é mais instável termodinamicamente que o precipitado $\mathrm{Ni}_{3} \mathrm{Ti}$. Dessa forma, é mais provável que a dissolução do precipitado $\mathrm{Ni}_{3} \mathrm{Mo}$ dê origem à austenita revertida e aos precipitados Fe-Mo simultaneamente.

Além da presença de precipitados grossos com tempos prolongados de envelhecimento ou temperatura mais alta, a austenita revertida pode apresentar mudanças de morfologia com o aumento da temperatura e do tempo de superenvelhecimento (LI, YIN, 1995; VISWANATHAN, DEY, SETHUMANDHAVAN, 2005; FAROOQUE, AYUB, UL HAQ, KHAN, 1998).

Uma delas é a austenita inter-ripas que nucleia nos contornos das ripas da martensita, conforme mostrado na figura 18. Enquanto o outro tipo de austenita, conhecida como austenita revertida intra-ripas, cresce dentro das ripas da martensita na forma de placas de Widmanstätten com maclas, como mostra a figura 19 (LI, YIN, 1995; VISWANATHAN, DEY, SETHUMANDHAVAN, 2005; FAROOQUE, AYUB, UL HAQ, KHAN, 1998; ATSMON, ROSEN, 1981). 

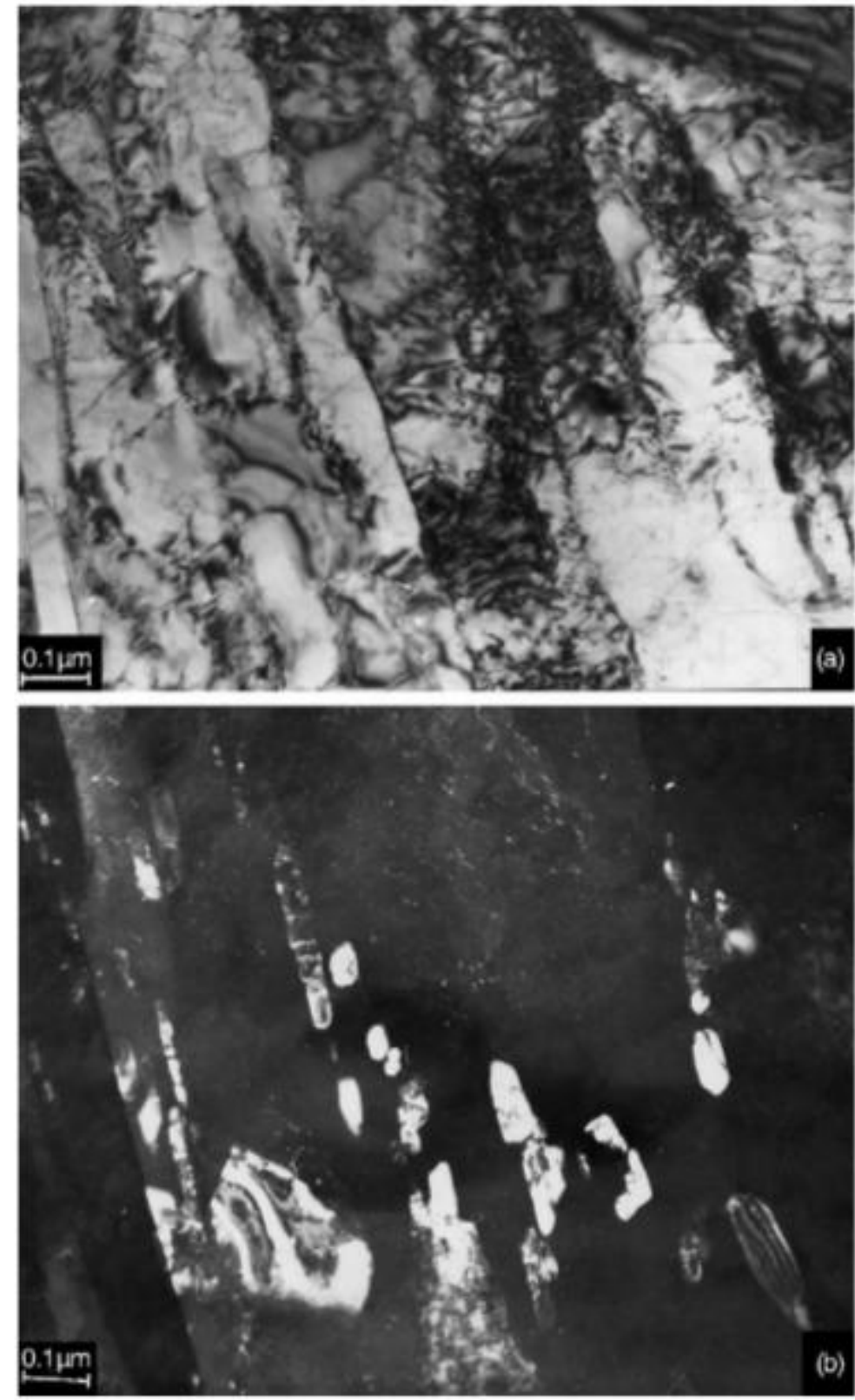

Figura 18: Micrografia da austenita formada entre as ripas da martensita para uma amostra de aço maraging 350 tratada a $640{ }^{\circ} \mathrm{C}$ por 2 horas: (a) imagem em campo claro, (b) imagem em campo escuro (VISWANATHAN, DEY, SETHUMANDHAVAN, 2005). 

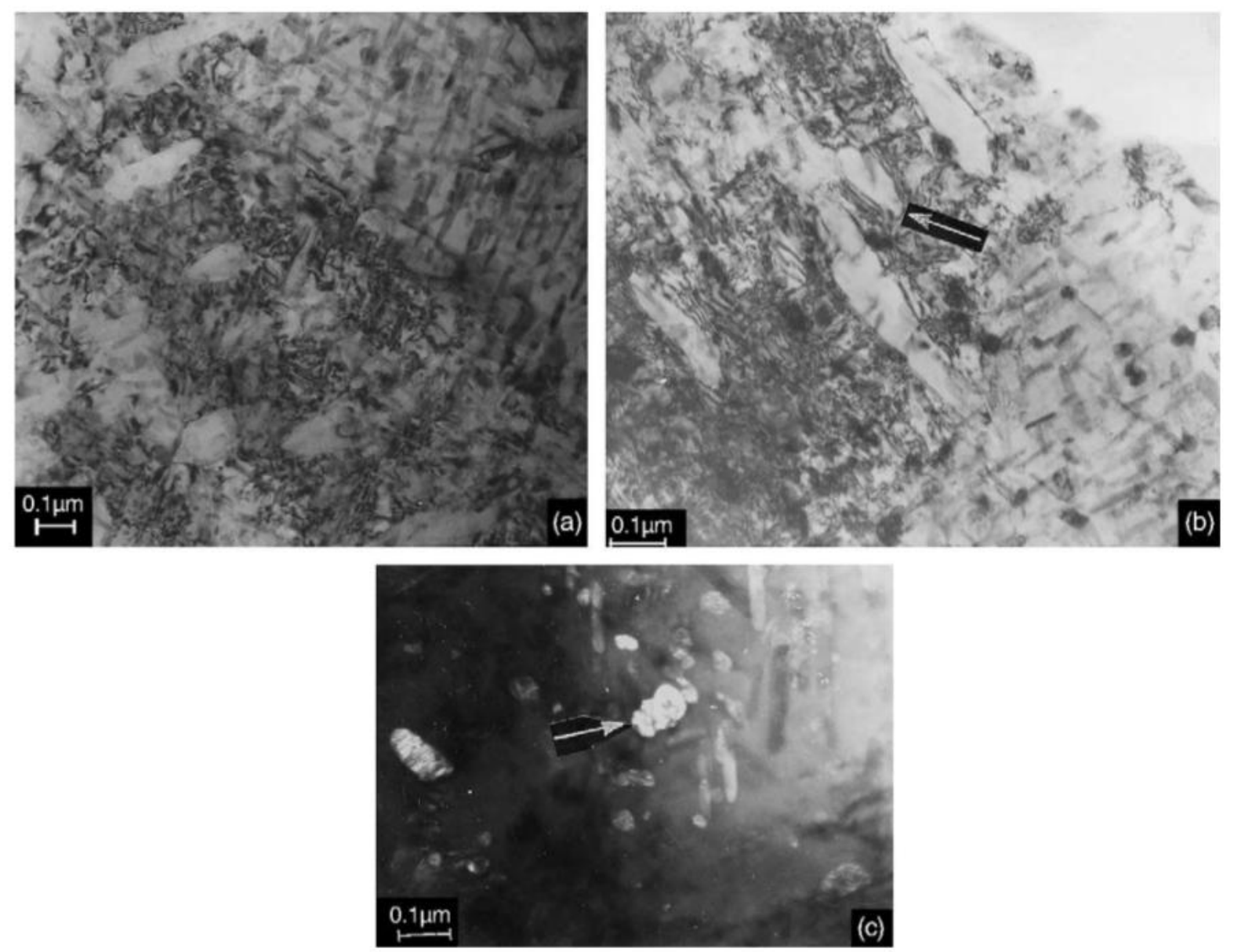

Figura 19: Morfologias da austenita formada em uma amostra de aço maraging 350 tratada a $640{ }^{\circ} \mathrm{C}$ por 8 horas: (a) austenita de Widmanstätten (b) austenita recristalizada e (c) austenita globular (VISWANATHAN, DEY, SETHUMANDHAVAN, 2005).

$\mathrm{Na}$ figura 19 pode-se observar que diversas morfologias de austenita estão presentes em uma amostra de aço maraging 350, envelhecida a $640{ }^{\circ} \mathrm{C}$ por 8 horas. A figura 19a mostra placas de austenita de Widmanstätten. Enquanto a figura 19b apresenta a austenita recristalizada formada no interior das ripas de martensita, cuja formação nessa temperatura é esperada devido à temperatura de recristalização ser aproximadamente $630{ }^{\circ} \mathrm{C}$ nos aços maraging, usando dados da temperatura de fusão de $1530{ }^{\circ} \mathrm{C}(\mathrm{INCO}, 1979)^{3}$. A figura 19c apresenta a austenita com morfologia globular (LI, YIN, 1995; VISWANATHAN, DEY, SETHUMANDHAVAN, 2005).

Li e Yin (1995b) observaram também que a austenita localizada entre as ripas da martensita forma-se em temperaturas mais baixas ou tempos menores de envelhecimento, para uma mesma temperatura, em comparação à austenita

\footnotetext{
${ }^{3}$ A temperatura de recristalização pode ser estimada por meio da relação com a temperatura homóloga igual 0,5 (PADILHA; SICILIANO Jr, 2007):

$$
T_{H}=\frac{T}{T_{f}}=0,5(1)
$$
}


formada dentro das ripas, o que também é mostrado nas figuras 18 e 19a. Outra consequência do aumento da temperatura de superenvelhecimento é a diminuição do teor de níquel necessário para formar os dois tipos de austenita, devido à natureza difusional desta reação (LI, YIN, 1995; VISWANATHAN, DEY, SETHUMANDHAVAN, 2005).

A reversão da martensita também pode envolver um movimento de cisalhamento em altas temperaturas. Li e Yin (1995) observaram que a austenita na forma de ripas e placas possuíam maclas após tratamento térmico a $640{ }^{\circ} \mathrm{C}$, indicando que esta reação pode ser dominada por cisalhamento, mas ocorre por um anterior ou simultâneo processo de difusão controlada.

Não há um consenso acerca das relações de orientações entre a martensita e a austenita revertida nos aços maraging. Se de um lado, Li e Yin (1995) observaram apenas a relação de orientação de Kurdjumov-Sachs (K-S), tanto na austenita na forma de ripas quanto na austenita na forma de placas (austenita do tipo Widmanstätten), ou seja, relações do tipo $\{111\}_{Y} / /\{011\}_{\alpha^{\prime}}$ e $[110]_{Y} / /[111]_{\alpha^{\prime}}$. Por outro lado, trabalhos publicados tanto por Farooque e coautores (1998) quanto por Astmon e Rosen (1981) sugeriram que as relações de orientação entre a martensita e a austenita revertida podem ser dos tipos Kurdjumov-Sachs (K-S) e NishyamaWassermann (N-W) (relações de orientação $\{011\}_{\alpha^{\prime}} / /\{111\}_{Y}$ e $\left.[100]_{\alpha^{\prime}} / /[110]_{Y}\right)$. Astmon e Rosen (1981) propuseram que o crescimento da austenita, na forma de placas formadas no interior das ripas de martensita, obedece a essas relações de orientação simultaneamente, conforme pode ser visto na figura 20 (ATSMON, ROSEN, 1981). 


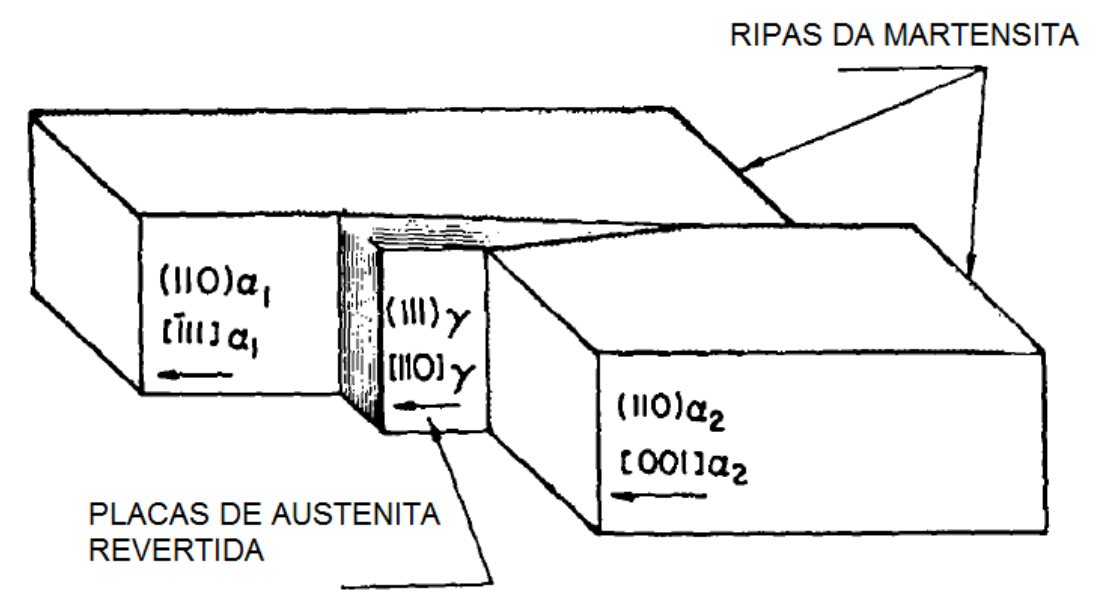

Figura 20: Crescimento da austenita revertida em placas dentro das ripas de martensita (ATSMON, ROSEN, 1981).

No próximo item são discutidos os principais aspectos relativos ao estudo da cinética de transformações de fase em aços maraging.

\subsection{CINÉTICA DE TRANSFORMAÇÕES DE FASE NOS AÇOS MARAGING}

Até o presente momento, foi analisada a influência do tratamento térmico de envelhecimento na evolução dos constituintes microestruturais dos aços maraging de acordo com a temperatura e o tempo de envelhecimento. Nessa abordagem são estudados os mecanismos e a evolução local das transformações de fase nos aços maraging.

Um enfoque alternativo e complementar é estudar como essas transformações de fase ocorrem por meio da influência delas em propriedades físicas. Diversas técnicas têm sido usadas para estudar a cinética de forma global, por exemplo, medidas de microdureza, resistividade elétrica, dilatometria, calorimetria exploratória diferencial (DSC), análise térmica diferencial (DTA), com auxílio do magnetômetro de amostra vibrante (VSM) e difração de raios $X$ (DRX).

Basicamente, há duas maneiras para estudar a cinética global de transformações de fase. A primeira consiste em medir as propriedades físicas após tratamentos térmicos, conhecidas como medidas "post mortem". Exemplos de medidas desse tipo são as feitas com o auxílio de microdurômetro, condutivímetro e magnetômetro de amostra vibrante (VSM). Enquanto a segunda consiste em acompanhar diretamente as mudanças nas propriedades físicas, quando as 
amostras submetidas a uma taxa de aquecimento/resfriamento constante ou tratamentos térmicos isotérmicos, conhecidas como medidas "in situ". Exemplos dessa abordagem são as medidas por dilatometria, DSC e DTA.

A seguir são analisados os estudos anteriores que usam medidas "post mortem" para avaliar a cinética isotérmica da precipitação e da reversão da martensita em aços maraging. No item 2.4.2 são analisadas as técnicas que acompanham as transformações de fase de maneira "in situ".

\subsubsection{Estudos da cinética isotérmica de precipitação e de reversão da martensita}

A cinética isotérmica em aços maraging é um tema estudado desde os primórdios do desenvolvimento dos aços maraging na década de 60 e continua a ser abordado por diversos autores recentemente. No item 2.4.1.1, é discutido o uso de medidas de microdureza e de resistividade para o acompanhamento da cinética de precipitação.

\subsubsection{Uso de medidas de microdureza e de resistividade para o estudo da cinética de precipitação}

Os primeiros estudos dos aços maraging que estabeleceram a composição química base dos aços maraging comerciais atuais utilizaram medidas de microdureza e de resistividade. Por exemplo, o efeito sinérgico entre o molibdênio e o cobalto durante a precipitação foi descoberto por Decker et al. (1962) e, posteriormente, confirmado por Floreen e Speich (1964) e Peters e Cupp (1966) mediante o uso da microdureza e da resistividade em diversas amostras de aços maraging tratadas termicamente.

As medidas de resistividade indicam a variação da quantidade de soluto em solução sólida de amostras tratadas termicamente. Se a resistividade diminui a quantidade de soluto em solução sólida também decresce, o que indica a precipitação de soluto. Enquanto a microdureza quantifica razoavelmente o aumento de resistência mecânica em virtude da presença de precipitados (PETERS; CUPP, 1966). A figura 21 mostra a evolução da resistividade elétrica e da dureza para um aço maraging 250 durante o envelhecimento. 

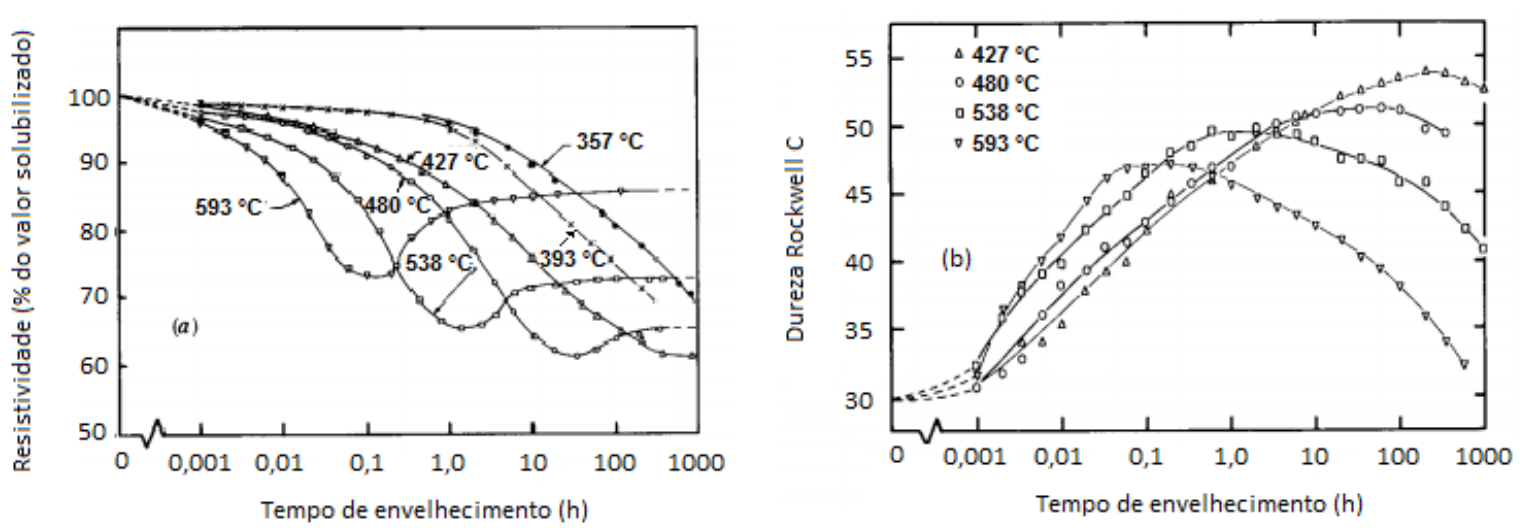

Figura 21: Variação da resistividade (a) e da dureza (b) em função do tempo de envelhecimento entre $357^{\circ} \mathrm{C}$ e $593^{\circ} \mathrm{C}$ para um aço maraging 250 (PETERS; CUPP, 1966).

Peters e Cupp (1966) observaram que o comportamento da resistividade em um aço maraging 250 contendo cobalto (C250) segue três etapas. Na primeira etapa, a resistividade tem uma pequena queda para tempos curtos de envelhecimento. Já na segunda etapa, há um grande decréscimo da resistividade que coincide com o aumento de resistência. Por fim, na terceira etapa, ocorre um aumento na resistividade seguido por um comportamento constante para longos tempos de envelhecimento, atribuído à formação da austenita controlada por difusão (PETERS; CUPP, 1966).

Vasudevan et al. (1990) também observaram o mesmo comportamento da resistividade para um aço maraging 250 contendo cobalto. Eles atribuíram à primeira etapa, principalmente, ao acúmulo de soluto nas discordâncias. Como visto na seção 2.2.3.1, as primeiras fases formadas durante o envelhecimento são por mecanismos de aglomeração e ordenamento de espécies químicas que propiciam a formação das fases S, X e w. (TEWARI et al., 2000; LECOMTE; SERVANT; CIZERON, 1985). Já a segunda etapa, em que há grande queda na resistividade e aumento na dureza, foi associada por eles à precipitação de elementos que estavam em solução sólida. Vasudevan e coautores (1990) também observaram que o pico de dureza coincidiu com o menor valor na resistividade para o aço maraging 250 com cobalto. Finalmente, à terceira etapa, em que há o aumento na resistividade, foi também atribuído a redistribuição de soluto que propicia a formação de austenita (VASUDEVAN; KIM; WAYMAN,1990).

De modo geral, o comportamento da resistividade e da microdureza do aço maraging 250 sem cobalto (T250) também segue o comportamento observado para 
o aço maraging 250 com cobalto (C250), conforme pode ser visto na figura 22 (VASUDEVAN; KIM; WAYMAN,1990).

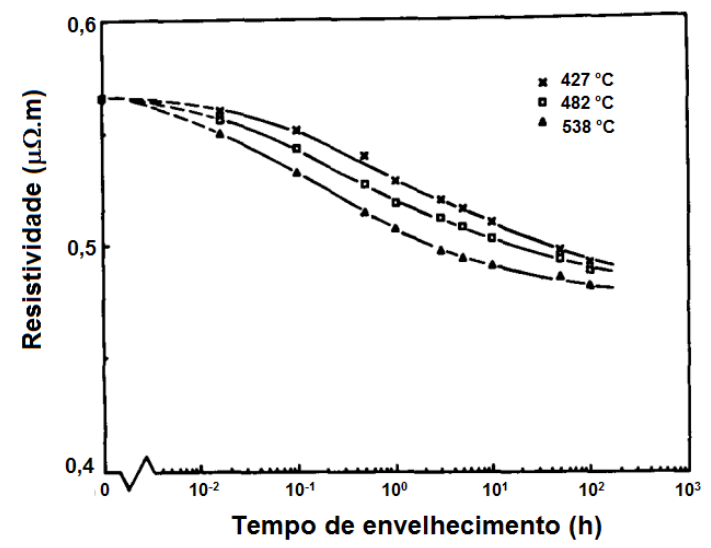

(a)

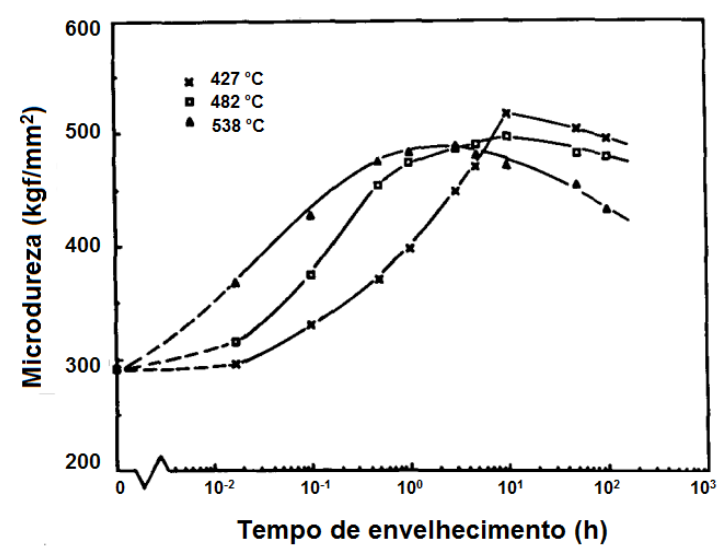

(b)

Figura 22: Variação da resistividade (a) e da dureza (b) em função do tempo de envelhecimento entre $427^{\circ} \mathrm{C}$ e $538^{\circ} \mathrm{C}$ para um aço maraging 250 sem cobalto (VASUDEVAN; KIM; WAYMAN,1990).

A figura 22 mostra que o aço maraging 250 sem cobalto (T250) também possui as duas primeiras etapas presentes na curva de resistividade do aço maraging 250 com cobalto (C250). Porém, há uma diferença com relação à diminuição da resistividade com o tempo. Os aços maraging C250 têm uma queda de resistividade mais acentuada em relação ao valor do estado solubilizado, em relação ao aço maraging T250. Observou-se que a diferença relativa entre a resistividade do estado solubilizado e o valor mínimo de resistividade em $538{ }^{\circ} \mathrm{C}$ foi de $15 \%$ para o aço maraging T250, enquanto a diferença relativa foi de $40 \%$ para o aço maraging C250 (VASUDEVAN; KIM; WAYMAN,1990). Esse comportamento se deve ao fato do aço maraging C250 possuir cobalto, causando uma aceleração da precipitação do molidênio, enquanto o aço maraging T250 não tem esse elemento em sua composição química nominal (PETERS; CUPP, 1966).

Viswanathan et al. (1993a) e Pardal et al. (2005) também analisaram a evolução da microdureza como função do tempo e da temperatura de envelhecimento nos aços maraging 300 e 350 com cobalto, conforme mostrado na figura 23. 


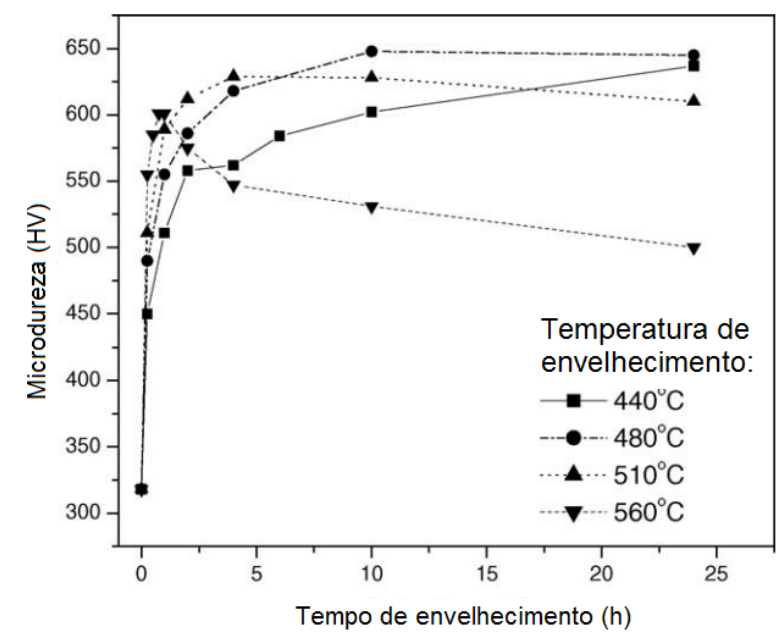

(a)

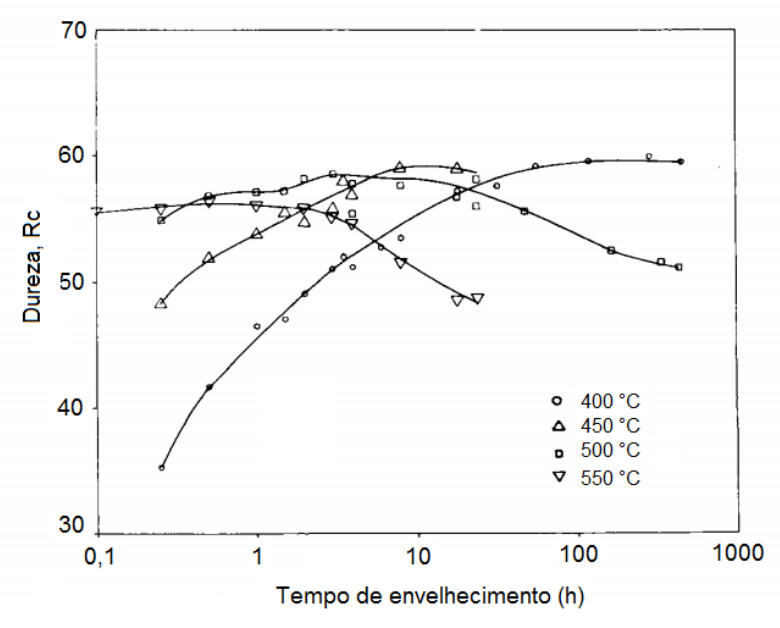

(b)

Figura 23: Variação da microdureza como função do tempo e da temperatura de envelhecimento para um aço maraging 300 (a) e um aço maraging 350 sem cobalto (b) (PARDAL et al.; 2005, VISWANATHAN; DEY; ASUNDI, 1993a).

Pardal e coautores (2005) notaram que as curvas de envelhecimento em 440 e $480^{\circ} \mathrm{C}$ não tiveram um amolecimento em tratamentos térmicos até 24 horas para um aço maraging 300 , enquanto as amostras envelhecidas em 510 e $560{ }^{\circ} \mathrm{C}$ apresentaram um amolecimento em virtude do superenvelhecimento. Viswanathan e coautores (1993) também observaram uma queda na dureza nas temperaturas de 500 e $550^{\circ} \mathrm{C}$ devido ao superenvelhecimento.

A partir do tempo necessário para atingir o pico dureza para cada temperatura de envelhecimento é possível obter a energia de ativação aparente, o que pode ser feito a partir de uma equação deduzida da lei de Arrhenius, como mostra a seguinte equação 2 (PARDAL et al.; 2005, VISWANATHAN; DEY; ASUNDI, 1993a):

$$
t=t_{0} \cdot \exp \frac{Q}{R . T}
$$

$\mathrm{Na}$ equação acima, $\mathrm{Q}$ é a energia de ativação para a precipitação, $\mathrm{R}$ é a constante universal dos gases, t e T são, respectivamente, o tempo e a temperatura em que ocorre o pico de dureza durante o envelhecimento. Pardal et al. (2005) e Viswanathan et al. (1993a) aplicaram a equação 2 aos dados experimentais de pico de dureza, como pode ser visto na figura 24 . 


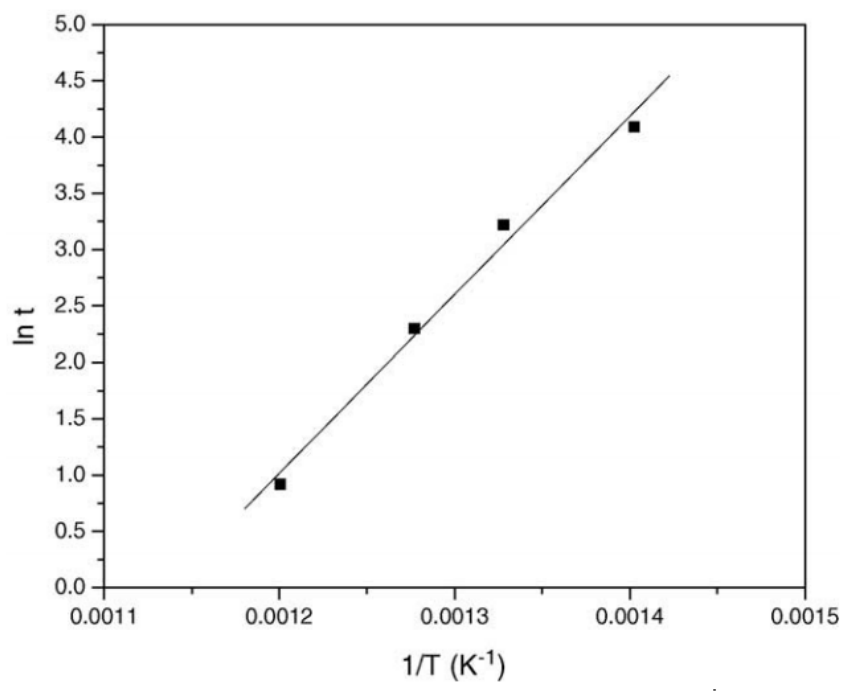

(a)

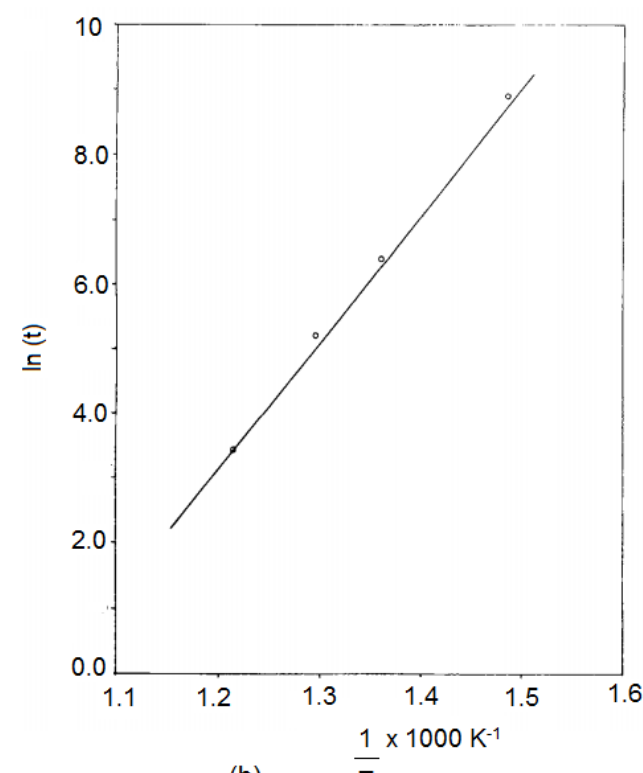

(b) $\quad \bar{T}$

Figura 24: Variação do In t como função de 1/T para a obtenção da energia de ativação aparente para um aço maraging 300 (a) e um aço maraging 350 sem cobalto (b) usando o tempo necessário para alcançar o pico de microdureza (PARDAL et al.; 2005, VISWANATHAN; DEY; ASUNDI, 1993a).

Além da obtenção da energia de ativação aparente para a precipitação por meio do pico de microdureza, os dados de microdureza e de resistividade permitem a estimativa da fração transformada. A fração transformada f estimada por meio da resistividade elétrica é dada pela equação 3 (VASUDEVAN; KIM; WAYMAN,1990):

$$
f=\frac{\rho_{0}-\rho_{t}}{\rho_{0}-\rho_{f}}(3)
$$

Em que $\rho_{0}$ é a resistividade da amostra no estado solubilizado, $\rho_{t}$ é a resistividade para um dado tempo de envelhecimento $t$ em uma temperatura de envelhecimento fixa $T$ e $\rho_{f}$ é a resistividade antes do início da reversão da martensita. Já a fração transformada por dados de microdureza é descrita pela equação 4 (SINHA et al., 1998):

$$
f=\frac{H_{t}-H_{0}}{H_{M A X}-H_{0}}(4)
$$

Em que $\mathrm{H}_{0}, \mathrm{H}_{\mathrm{t}}$ e $\mathrm{H}_{\text {MAX }}$ são, respectivamente, a microdureza da amostra no estado solubilizado, a microdureza para um dado tempo de envelhecimento $t$ em uma temperatura de envelhecimento fixa $T$ e o pico de microdureza de temperatura de envelhecimento fixa $T$.

Tanto Vasudevan et al. (1990) como Sinha et al. (1998) concluíram que a obtenção da fração transformada da precipitação, a partir de medidas de resistividade e de microdureza, devem ser consideradas de modo semiquantitativo 
devido à complexidade microestrutural dos aços maraging. Diversos fenômenos ocorrem durante o envelhecimento e podem influenciar nos valores das medidas de resistividade e de microdureza, como a presença de precipitados diferentes, o início do engrossamento de precipitados e também a presença da austenita revertida próxima à região do pico de dureza.

Considerando essas limitações, Sinha et al. (1998) e Vasudevan et al. (1990) estimaram a energia de ativação aparente de forma similar ao que foi realizado por Pardal et al. (2005) e Viswanathan et al. (1993a), mediante o uso da equação 2. Porém, no cálculo da energia de ativação aparente, foi utilizado o tempo necessário para atingir uma fração transformada fixa para cada temperatura de envelhecimento. A figura 25 ilustra como foram obtidas a energia de ativação aparente para um aço maraging 250 com cobalto e outro aço maraging 250 sem cobalto.

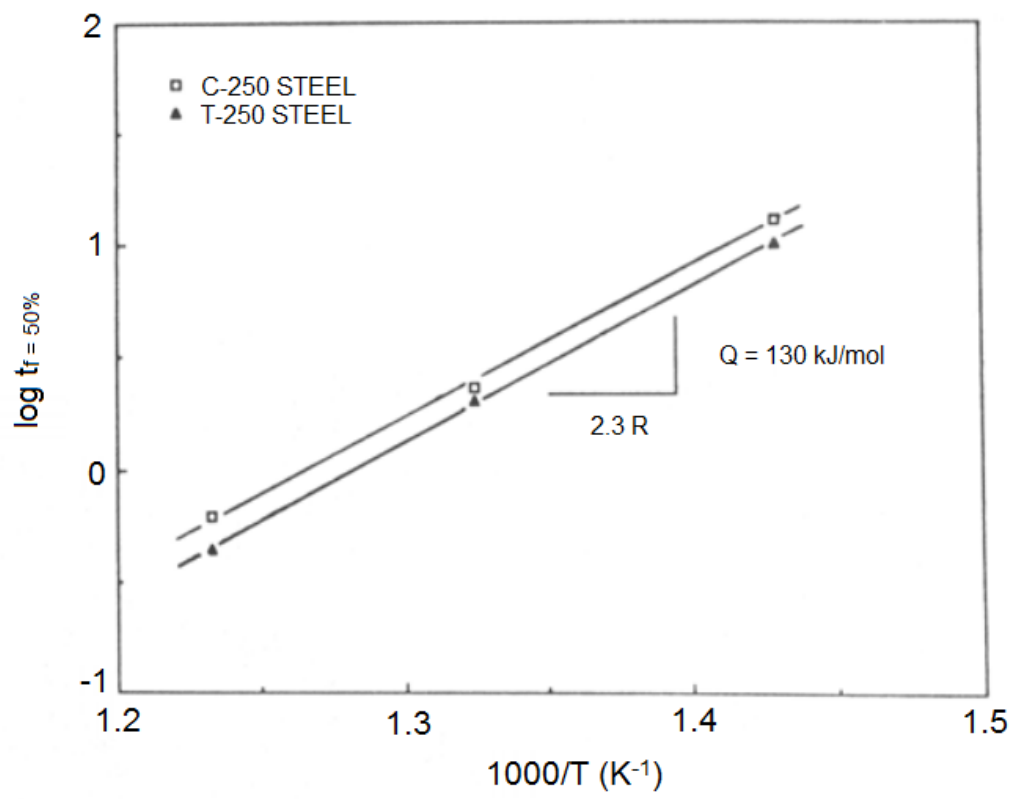

Figura 25: Variação do $\log t_{50 \%}$ como função de 1/T para a obtenção da energia de ativação aparente para um aço maraging 250 com cobalto (C-250) e um aço maraging 250 sem cobalto (T-250) (VASUDEVAN; KIM; WAYMAN,1990).

Uma análise comparativa dos valores de energia de ativação obtidos por diversos pesquisadores e, nessa tese, para diversos tipos de aços maraging, obtidos por meio dos métodos mencionados, foi realizada na seção de resultados sobre cinética isotérmica relativa à precipitação (item 4.3.3.1).

No item 2.4.1.2 são discutidos os usos da equação JMAK e Austin-Rickett para a análise cinética de transformações de fase. 


\subsubsection{Análise cinética isotérmica JMAK e Austin-Rickett para amostras tratadas termicamente}

Além da estimativa da energia ativação aparente, a fração transformada também permite correlacionar mudanças em propriedades globais com mudanças microestruturais por meio do uso de modelo cinéticos como o JMAK e o AustinRickett (STARINK, 1997).

O modelo JMAK tem sido muito usado para a análise cinética de transformações de fase em metais puros e ligas metálicas (CHRISTIAN, 1975; STARINK, 1997; RIOS, PADILHA, 2007). Esse modelo foi deduzido por Johnson e Mehl (1939), Avrami (1939, 1940,1941) e Kolmogorov (1937) em trabalhos independentes entre as décadas de 30 e de 40.

Atualmente, a equação JMAK é comumente representada por (CHRISTIAN, 1975; RIOS, PADILHA, 2007):

$$
f=1-\exp \left[k(T) \cdot t^{n}\right](5)
$$

No qual $f$ representa a fração transformada, $k(T)$ a constante cinética de velocidade para uma dada temperatura fixa e $\mathrm{n}$ uma constante.

A equação do modelo JMAK também pode ser representada na forma generalizada, conforme mostrado na equação 6 (STARINK, 1997):

$$
f=1-\exp \left\{[k(T) \cdot t]^{n}\right\}(6)
$$

O valor de $\mathrm{k}(\mathrm{T})$ na equação JMAK permite a obtenção da energia de ativação de uma transformação de fase, pois $\mathrm{k}(\mathrm{T})$ segue uma relação do tipo Arrhenius, como mostrado na equação 7:

$$
k T=k_{0} . \exp \frac{-E}{R . T}(7)
$$

A interpretação dos valores da constante $\mathrm{n}$ do modelo JMAK permite a identificação dos mecanismos de transformações de fase predominantes, conforme apresentado nas tabelas 7 e 8. 
Tabela 7: Valores da constante $\mathrm{n}$ para diversas reações controladas por difusão (Starink, 1997; RIOS, PADILHA, 2007).

\begin{tabular}{ccc}
\hline Condições e geometrias & \multicolumn{2}{c}{ Taxas de nucleação } \\
\cline { 2 - 3 } & Zero & Constante \\
\hline $\begin{array}{c}\text { Todas as partículas crescendo a partir de } \\
\text { pequenas dimensões }\end{array}$ & 1,5 & 2,5 \\
$\quad \begin{array}{c}\text { Crescimento de cilindros longos com } \quad \text { comprimento constante } \\
\quad \text { Crescimento de grandes placas com área } \\
\quad \text { superficial constante }\end{array}$ & 1 & 1,5 \\
$\begin{array}{c}\text { Crescimento de partículas nos contornos de } \\
\text { grão, alta difusividade no contorno de grão } \\
\text { Crescimento de partículas de tamanho inicial } \\
\text { grande quando comparadas com as } \\
\text { mudanças devido ao crescimento }\end{array}$ & 0,5 & 0,5 \\
Crescimento de partículas nas discordâncias & 0,5 & - \\
\hline
\end{tabular}

Tabela 8: Valores da constante $\mathrm{n}$ para mudanças polimórficas, recristalização, precipitação descontínua, reações eutectóides ou crescimento controlado pela interface (Starink, 1997; RIOS, PADILHA, 2007).

\begin{tabular}{|c|c|c|}
\hline \multirow{2}{*}{ Condições e geometrias } & \multicolumn{2}{|c|}{ Taxas de nucleação } \\
\hline & Zero $(n=m)$ & Constante \\
\hline $\begin{array}{c}\text { Todas as partículas crescendo em três } \\
\text { dimensões a partir de pequenas dimensões }\end{array}$ & 3 & 4 \\
\hline $\begin{array}{l}\text { Todas as partículas crescendo em duas } \\
\text { dimensões a partir de pequenas dimensões }\end{array}$ & 2 & 3 \\
\hline $\begin{array}{l}\text { Todas as partículas crescendo em uma } \\
\text { dimensão a partir de pequenas dimensões }\end{array}$ & 1 & 2 \\
\hline $\begin{array}{c}\text { Nucleação no contorno de grão após } \\
\text { saturação }\end{array}$ & - & 1 \\
\hline
\end{tabular}

Uma outra equação cinética também foi proposta de forma empírica por Austin-Rickett (1939) para analisar a cinética de decomposição da austenita em aços. Ele considerou que a fração transformada dada em porcentagem $\mathrm{P}$ seguiria um comportamento dado pela equação 8 :

$$
\log \frac{P}{100-P}=k^{\prime} \cdot \log t+\frac{a}{T}+b(8)
$$


Em que $k^{\prime}$, a e b são constantes, $P$ é a fração transformada dada em percentagem e té o tempo de transformação. Para uma dada temperatura fixa $T$, a equação 8 pode ser simplicada por:

$$
\log \frac{P}{100-P}=k^{\prime} \cdot \log t+C^{\prime}(9)
$$

Na qual C' é uma constante. A partir da equação 9, Austin e Rickett (1939) ajustaram o modelo proposto aos dados experimentais de dilatometria de decomposição da austenita obtidos por Davenport e Bain em 1930, conforme mostrado na figura 26. Observa-se que o modelo sugerido por eles descreve bem o comportamento da fração transformada P obtida a partir de dados experimentais.

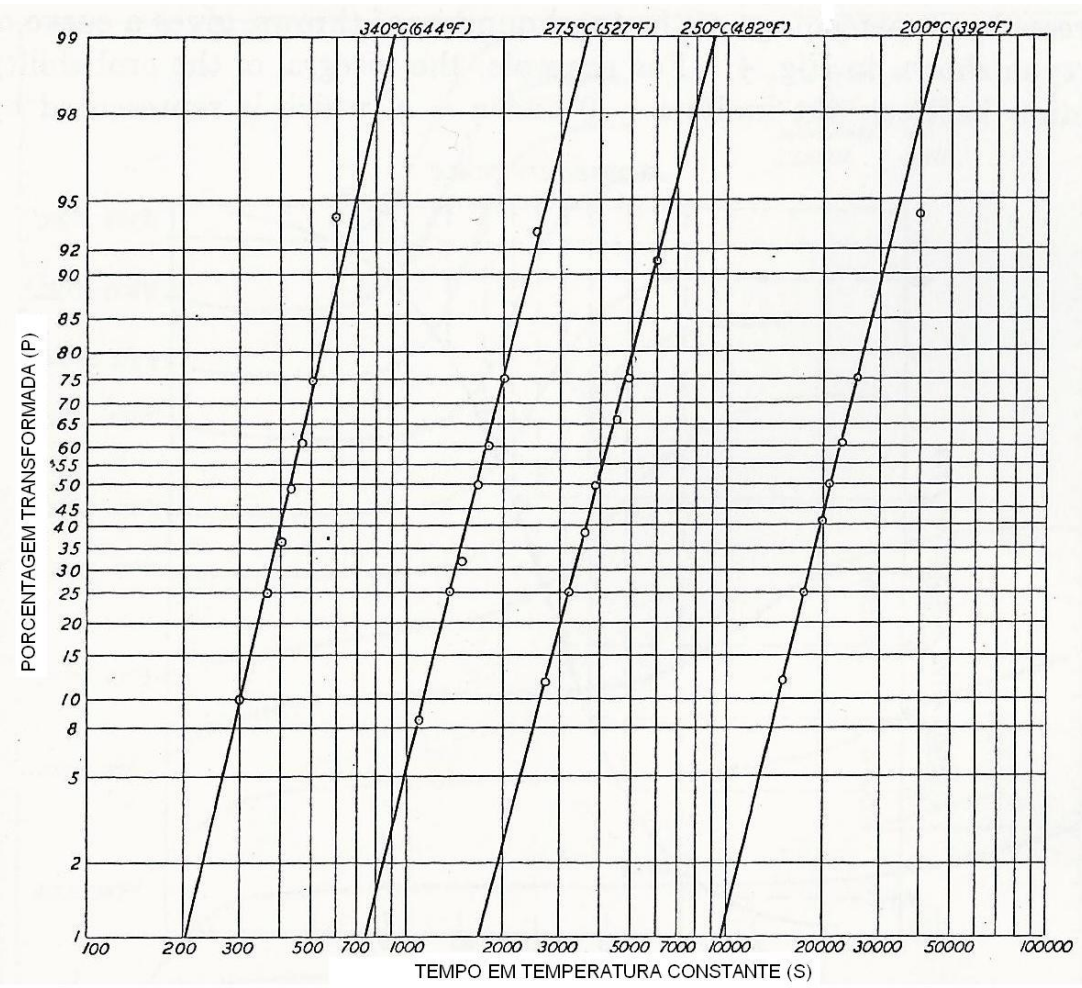

Figura 26: Percentagem transformada $(\mathrm{P})$ como função do tempo em temperatura constante (AUSTIN, RICKETT,1939).

Lee e Kim (1990) e Starink (1997) mostraram de forma quantitativa que a introdução de um fator de encontro c (impingement factor) igual a 1 na relação entre o volume extendido e o volume transformado implica que a fração transformada segue o comportamento dado pela equação Austin-Rickett. Enquanto, no fator de 
encontro c igual a 0, o modelo deduzido continuaria a seguir o comportamento descrito pela equação JMAK.

A equação de Austin-Rickett na forma generalizada é expressa pela equação 10 (STARINK,1997).

$$
f=1-k(T) \cdot t^{n}+1^{-1}(10)
$$

No qual $f, k(T)$ e $n$ têm o mesmo significado daquele apresentado na equação JMAK. Os valores da constante $\mathrm{n}$ da equação Austin-Rickett pode ser também interpretada com base nas tabelas 7 e 8 apresentadas nessa seção (STARINK, 1997).

Starink (1997) observou que o ajuste do modelo JMAK à fração transformada, obtida por meio de dados experimentais em algumas ligas ferrosas e de alumínio, têm algumas limitações. De acordo com esse autor, os valores da constante $n$ estimados pela equação de Austin-Rickett pode ter uma correlação melhor com as mudanças microestruturais devido à precipitação em materiais metálicos. Na figura 27, é mostrado um exemplo no qual o modelo AR tem um melhor ajuste do que o modelo JMAK.

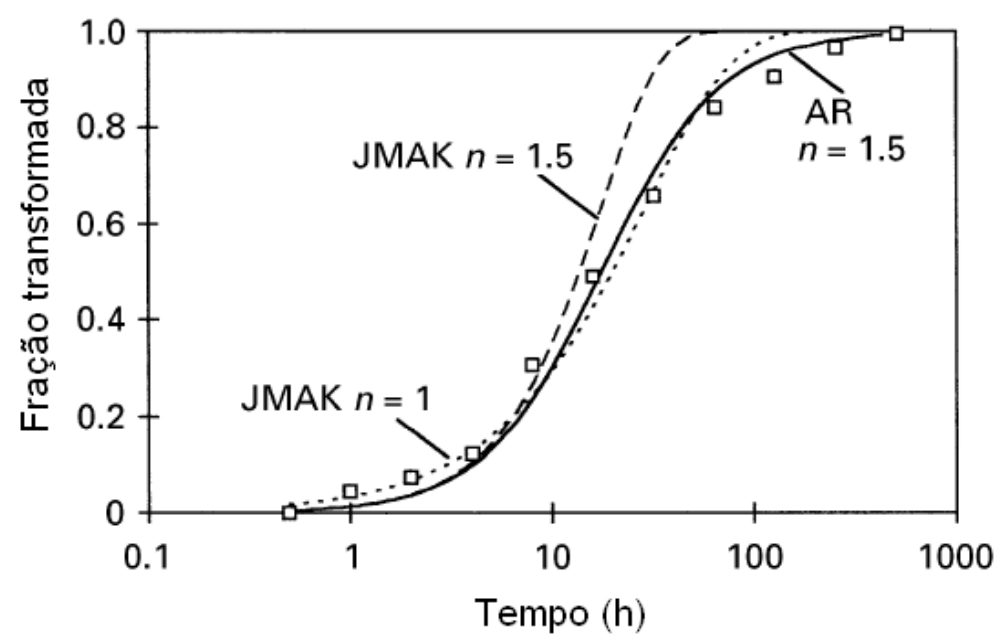

Figura 27: Fração transformada durante o envelhecimento de uma liga de alumínio Al-10,3 \%at. Si como função do tempo de envelhecimento. Análise comparativa do ajuste dos dados experimentais aos modelos JMAK e Austin-Rickett (STARINK,1997).

O modelo mais usado para descrever a cinética de precipitação em aços maraging é o JMAK. Sinha et al. (1998) e Vasudevan et al. (1990) estudaram a cinética de precipitação em aços maraging T250 e C250. A figura 28 apresenta a aplicação do modelo JMAK linearizado para o aços maraging T250 (SINHA et al., 1998). 


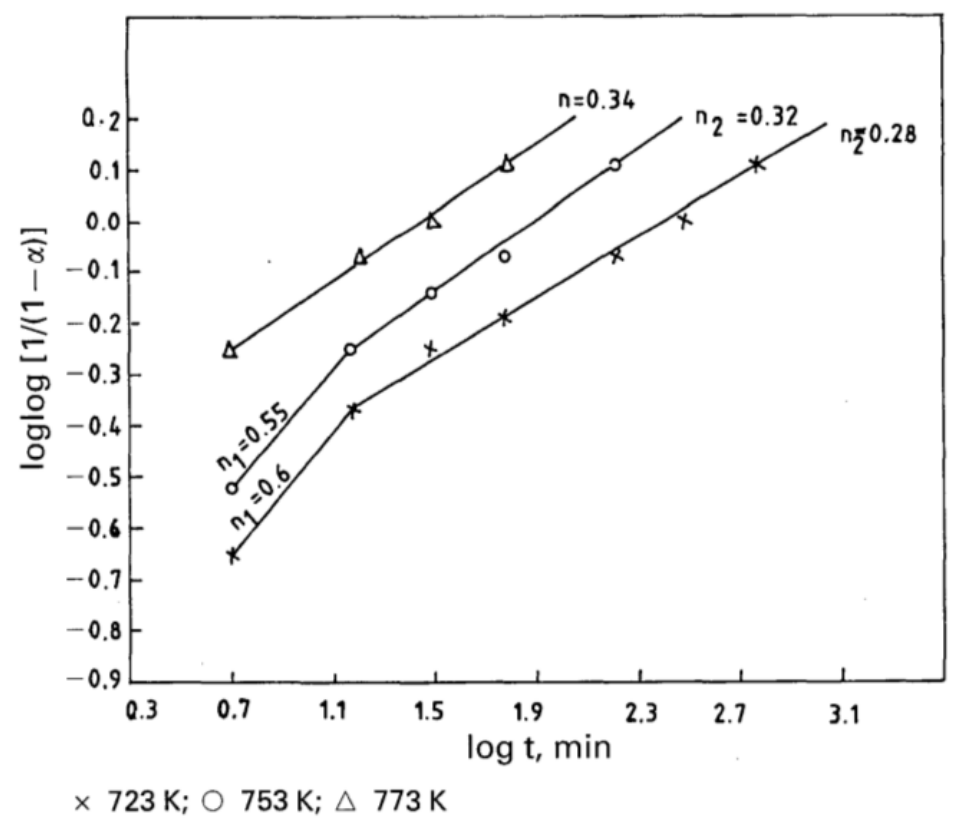

Figura 28: Aplicação do modelo JMAK linearizado aos dados de fração transformada de precipitação para um aço maraging T250 (SINHA et al.,1998).

Os valores da constante $\mathrm{n}$ de precipitação da equação JMAK para os aços maraging estão comumente entre 0,2 e 0,6 (VASUDEVAN et al, 1990; SINHA et al,1998). Vasudevan e coautores (1990) concluíram que valores de $n$ próximos a um 1/3 corresponderia à manifestação da unidimensional da equação para precipitação nas discordâncias que prevê 2/3 (vide tabela 7).

Todavia, quando são cotejados os valores da constante $n$ obtidos por Sinha et al. (1998) e Vasudevan et al. (1990) com as mudanças de morfologia dos precipitados já mencionadas na seção 2.3.3.1, nota-se uma discrepância entre o que ocorre em nível local na microestrutura e o previsto por meio da aplicação da equação JMAK.

Dessa maneira, foi realizada nessa tese uma análise comparativa da aplicação dos modelos JMAK e Austin-Rickett para a fração transformada da reação de precipitação em um aço maraging 350, apresentada no item 4.3.3.1.

Em virtude do pequeno espaçamento entre os precipitados formados durante as etapas iniciais de envelhecimento, supõe-se que o encontro dos campos difusivos (impingement) tenha uma influência na cinética de precipitação. Como não foram encontrados estudos comparativos desses modelos para o estudo de cinética de precipitação em aços maraging, a comparação entre os modelos JMAK e AustinRickett é oportuna. 
No item 2.4.1.3 é discutida a cinética de reversão da martensita em aços maraging.

\subsubsection{Cinética isotérmica de reversão da martensita}

Além dos estudos relativos à presença da austenita em nível local para variados tempos e temperatura de superenvelhecimento, conforme discutido na seção 2.3.3.2, o acompanhamento da cinética global da reversão da martensita é de fundamental importância devido à sua influência nas propriedades mecânicas e magnéticas (TAVARES et al., 2004; PARDAL et al., 2007; VISWANATHAN; DEY; SETHUMANDHAVAN, 2005).

Uma das maneiras de determinar a fração volumétrica em amostras superenvelhecidas é mediante os picos de difratograma de raios X (PARDAL et al., 2006). A figura 29 mostra um difratograma de amostras lixadas e não lixadas de um aço maraging 300 envelhecido a $600^{\circ} \mathrm{C}$ por 1 hora.

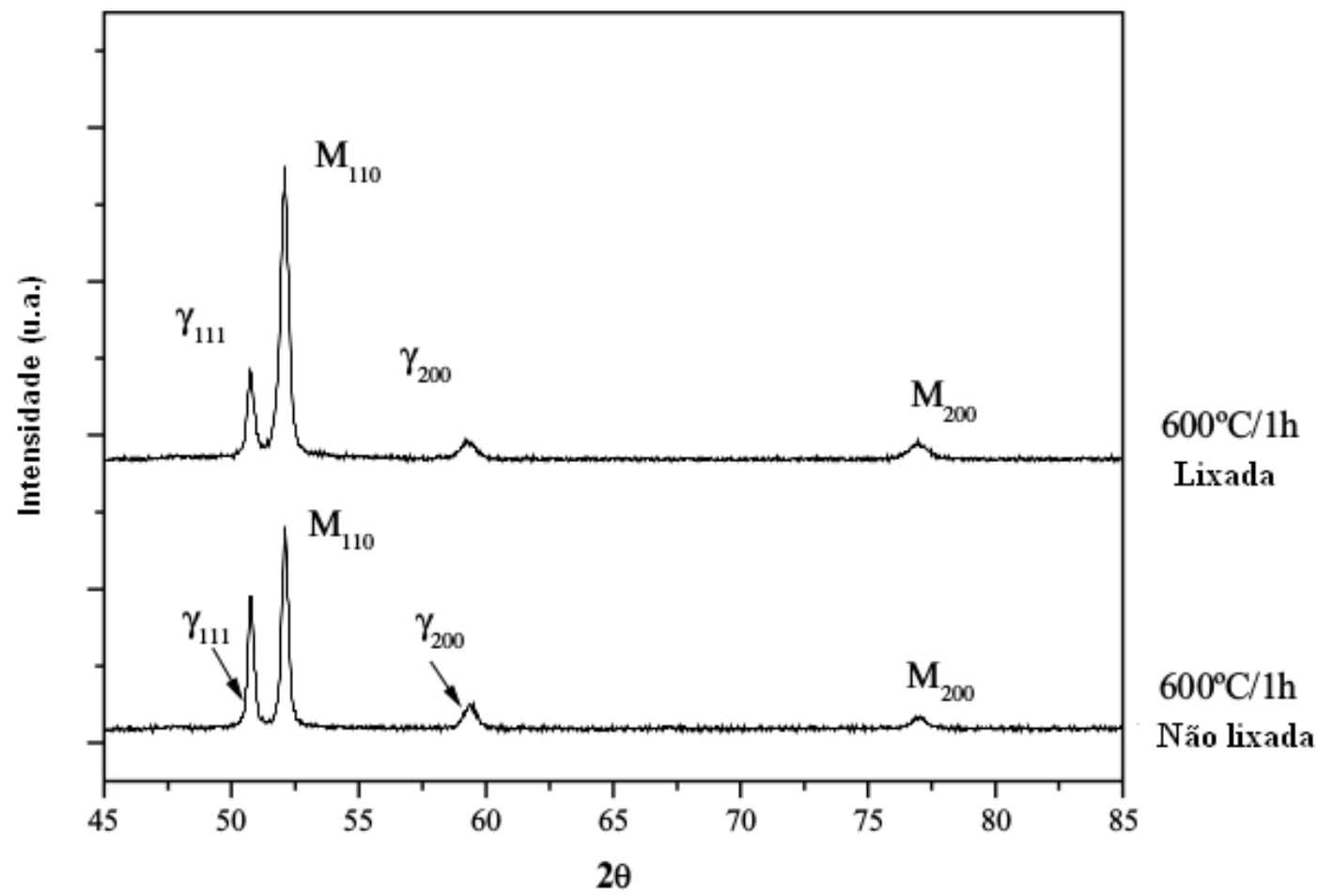

Figura 29: Difratograma de raios $X$ de amostras envelhecidas em $600{ }^{\circ} \mathrm{C}$ por 1 hora que foram lixadas e não lixadas de um aço maraging 300 obtido usando radiação CoKa (PARDAL et al.,2006). 
A figura 29 mostra que o controle da preparação da superfície é muito importante para a quantificação da proporção de austenita revertida, uma vez que a austenita pode transformar para a martensita devido à deformação plástica da amostra.

Com base na área dos picos dos difratograma de raios $\mathrm{X}$, é possível obter a fração volumétrica da austenita por meio da intensidade dos picos e da intensidade integrada deles (PARDAL et al, 2006).

Pardal e coautores (2006) mediram a influência do tempo e da temperatura de envelhecimento em um aço maraging 300, como apresentado na figura 30 . Eles observaram que a fração volumétrica da austenita tem um comportamento crescente com o tempo de envelhecimento para amostras tratadas em 560 e $600{ }^{\circ} \mathrm{C}$, enquanto para as amostras tratadas a $650{ }^{\circ} \mathrm{C}$ a fração volumétrica foi decrescente com 0 tempo de envelhecimento, o que foi atribuído ao empobrecimento em níquel.

Observa-se também que o valor estimado da fração volumétrica da austenita pode ser diferente de acordo com o método de cálculo usado. Se for considerado o fator de espalhamento da austenita igual ao da martensita, o valor obtido é um pouco maior do que aquele estimado quando se considera fatores de espalhamento diferentes da austenita e da martensita. $O$ fator de espalhamento diferente ocorre devido à diferença de composição química das fases.

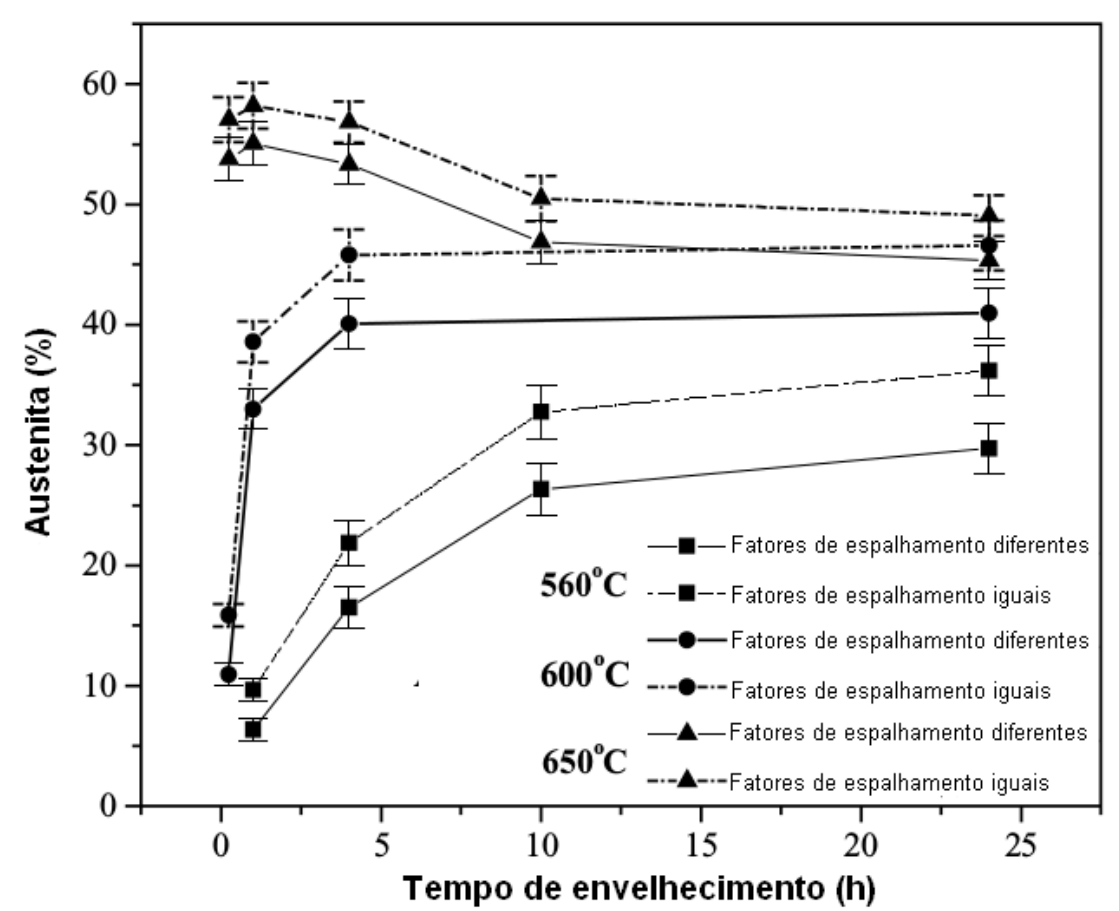

Figura 30: Evolução da fração volumétrica da austenita em função do tempo e da temperatura de envelhecimento para um aço maraging 300 (PARDAL et al.,2006). 
Com base no comportamento da fração volumétrica que converge assintoticamente a $30 \%$ e $40 \%$, respectivamente, para amostras envelhecidas a 560 e $600{ }^{\circ} \mathrm{C}$, considerando fatores de espalhamentos diferentes, Pardal e coautores (2006) propuseram a equação empírica $11^{4}$ :

$$
\gamma t=\gamma_{M A X} \cdot[1-\exp g \cdot t](11)
$$

$\mathrm{Na}$ equação acima, $\gamma(\mathrm{t})$ é a fração volumétrica em um dado tempo de envelhecimento $t$ em horas, $\bigvee_{\operatorname{MAX}}$ é a fração volumétrica máxima em uma dada temperatura e g é uma constante negativa.

A partir da equação 11 e dos dados de fração volumétrica da austenita com o tempo e a temperatura de envelhecimento para um aço maraging 300 , Pardal e coautores (2006) verificaram o ajuste do modelo empírico aos dados experimentais, conforme apresentado na figura 31 e na tabela 9.

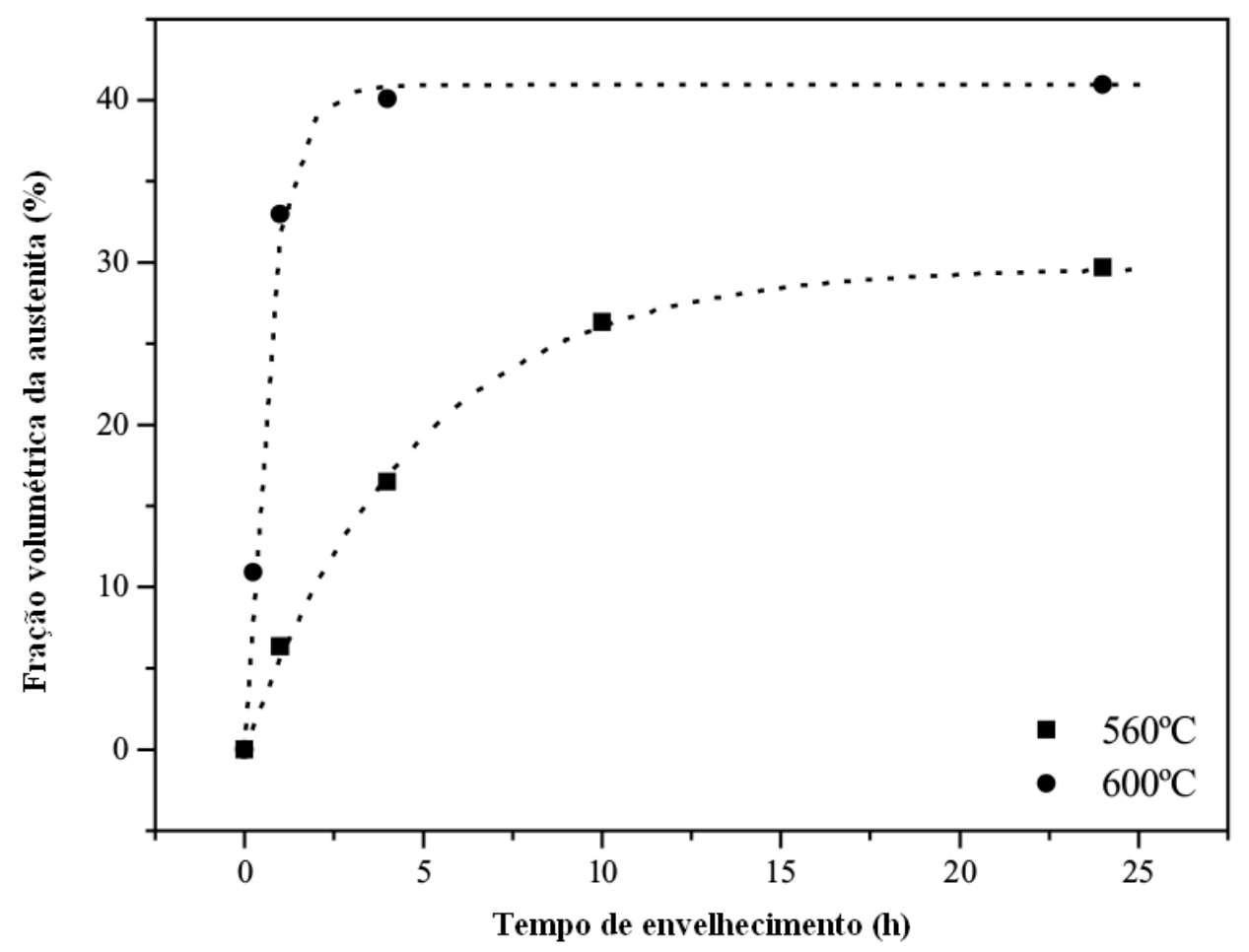

Figura 31: Comparação da curva do modelo empírico ajustado com os dados experimentais de fração volumétrica da austenita para amostras tratadas a 560 e $600{ }^{\circ} \mathrm{C}$ em um aço maraging 300 (PARDAL et al.,2006).

\footnotetext{
${ }^{4} \mathrm{~A}$ constante $\mathrm{g}$ refere-se à constante b no artigo original de Pardal e coautores (2006). A simbologia foi alterada a fim de padronizar o símbolo b para o vetor de Burgers ao longo dessa tese.
} 
Tabela 9: Valores das constantes $\mathrm{Y}_{\operatorname{MAX}}$ e $\mathrm{b}$ das curvas ajustadas do modelo empírico de Pardal et al. (2006) para 560 e $600{ }^{\circ} \mathrm{C}$ em um aço maraging 300. O valor do coeficiente de correlação R também é apresentado.

\begin{tabular}{cccc}
\hline Temperatura $\left({ }^{\circ} \mathrm{C}\right)$ & $\mathrm{g}$ & $\mathrm{V}_{\operatorname{MAX}}(\%)$ & $\mathrm{R}$ \\
\hline 560 & $-0,21$ & 29,9 & 0,99 \\
600 & $-1,49$ & 40,8 & 0,99 \\
\hline
\end{tabular}

A figura 31 e a tabela 9 mostram que o modelo empírico proposto por Pardal e coautores (2006) se ajusta bem aos dados experimentais de fração volumétrica da austenita obtidas de amostras tratadas a 560 e $600{ }^{\circ} \mathrm{C}$. Pode-se demonstrar que a relação sugerida por Pardal et al. (2006) pode ser obtida da equação JMAK com a constante $\mathrm{n}$ de Avrami igual 1. De acordo com a tabela 8, apresentada na seção 2.4.1.2, esse valor está relacionado com a nucleação de fases em contornos de grão, o que está consistente com a formação de austenita revertida inter-ripas em contornos de ripas e contornos de grão da martensita geralmente observada em aços maraging, conforme discutido no item 2.3.3.2.

Outra forma de detecção da presença de austenita em amostra superenvelhecidas é por meio da alteração das propriedades magnéticas, pois a austenita é uma fase paramagnética, em que os domínios magnéticos se alinham paralelamente somente quando um campo magnético é aplicado, enquanto a martensita é ferromagnética, na qual há orientação espontânea dos domínios magnéticos.

As propriedades magnéticas geralmente são mensuradas por meio de curvas de histerese obtidas com o auxílio de magnetômetro, cujo tipo mais usado em aços maraging é o magnetômetro de amostra vibrante. A obtenção da curva de histerese ocorre pela medição da variação da magnetização da amostra em função do campo magnético aplicado, como o exemplo apresentado na figura 32. 


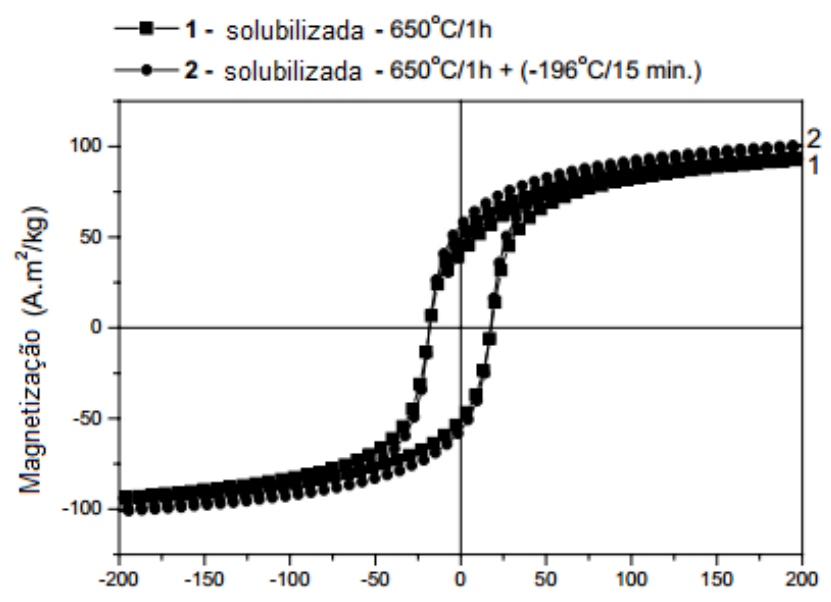

(a)

Campo aplicado (Oe)

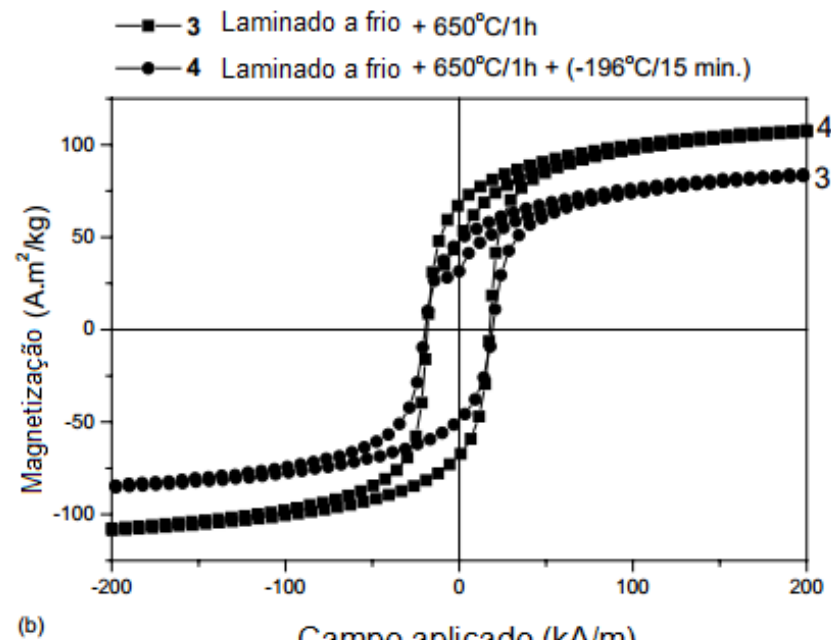

(b) Campo aplicado $(\mathrm{kA} / \mathrm{m})$

Figura 32: Curvas de histerese magnética de amostras antes e depois da imersão em nitrogênio líquido por $15 \mathrm{~min}$ : (a) amostra solubilizada e envelhecida a $650^{\circ} \mathrm{C}$ por $1 \mathrm{~h}$; (b) amostra solubilizada, laminada a frio e envelhecida por $1 \mathrm{~h}$ em um aço maraging 350 (TAVARES et al., 2004a).

A figura 32 mostra que as curvas de histerese são sensíveis à condição de tratamento térmico das amostras e, consequentemente, à microestrutura das amostras (TAVARES et al., 2004a). As propriedades magnéticas mais estudadas em curvas de histerese são o campo coercivo e a saturação magnética. $O$ campo coercivo é o campo magnético que deve ser aplicado para anular a magnetização da amostra, enquanto a saturação magnética é o valor máximo que a magnetização se torna constante com o campo magnético aplicado (TAKEUCHI, 2010).

Diversos estudos mostraram que a presença de austenita revertida formada em variadas condições de tratamento térmico influencia os valores de campo coercivo $\mathrm{H}_{\mathrm{C}}$ e a saturação magnética $\mathrm{m}_{\mathrm{s}}$ nos aços maraging (BELYAKOV; 
NIKOL'SKAYA; RYZHAK, 1968; HABIBY; UL HAQ; KHAN, 1992; AHMED et al., 1994b; TAVARES et al., 2004a, 2004b; PARDAL et al., 2007).

A figura 33 apresenta a relação entre a saturação magnética e a proporção de austenita.

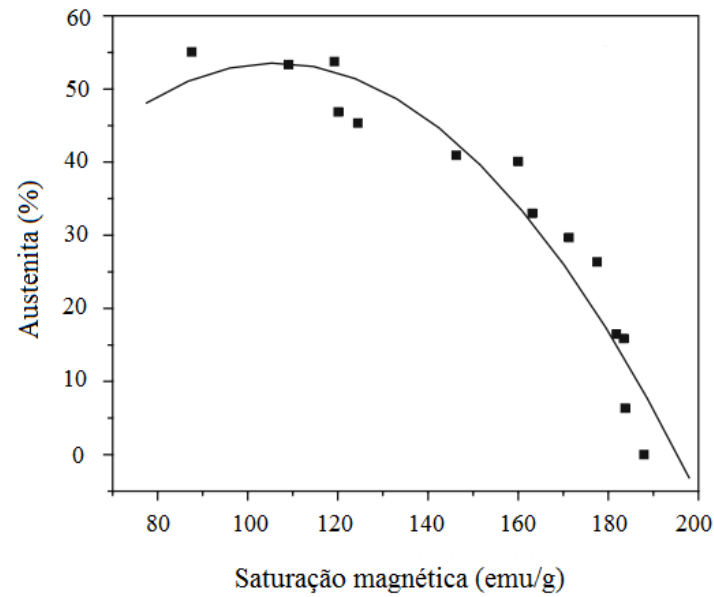

(a)

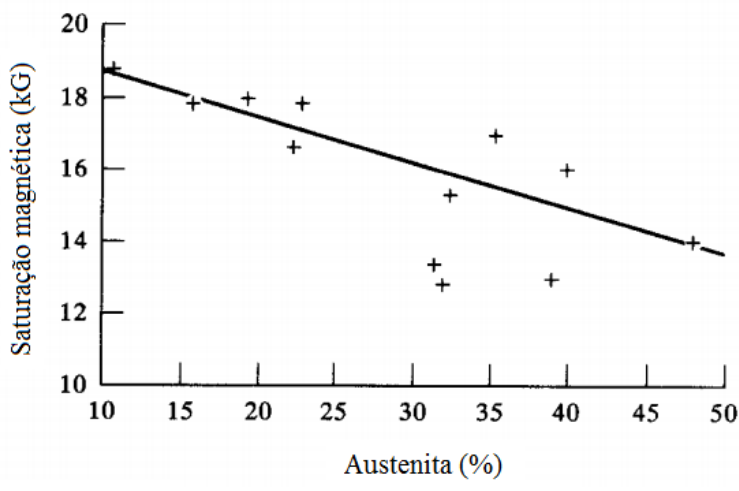

(b)

Figura 33: Relação entre a fração volumétrica da austenita e a saturação magnética em (a) um aço maraging 300 e (b) um aço maraging 350 (AHMED et al.,1994; PARDAL et al., 2007).

A figura 33 mostra que a saturação magnética nos aços maraging 300 e 350 tem um comportamento decrescente com a porcentagem de austenita. Já a figura 34 apresenta a relação entre o campo coercivo $\mathrm{H}_{\mathrm{C}}$ e a fração volumétrica da austenita.

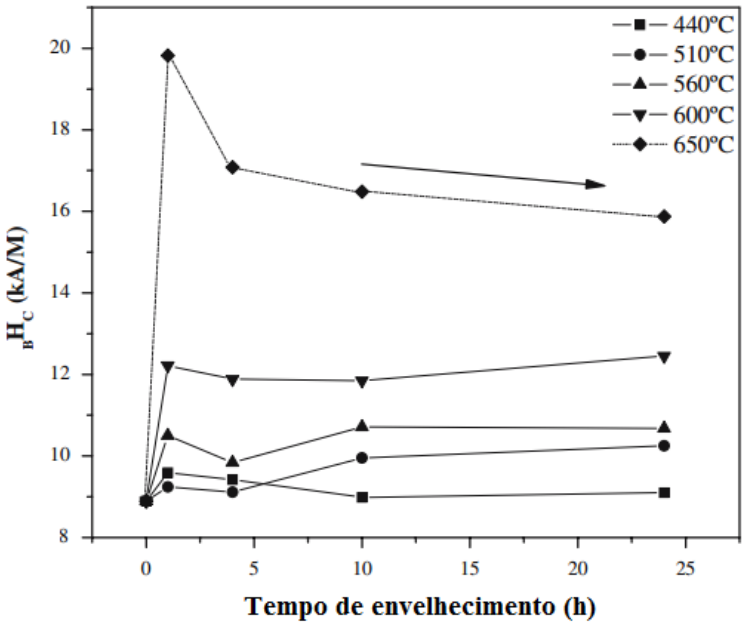

(a)

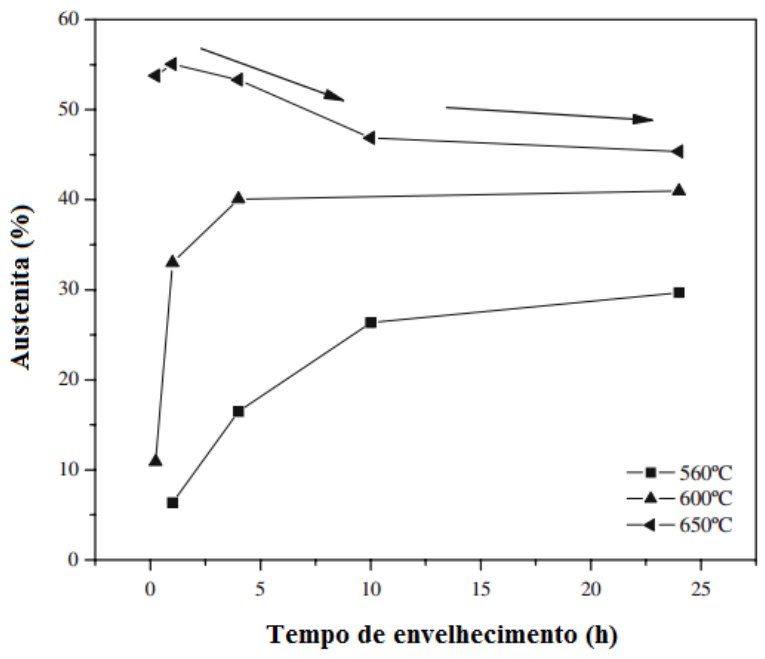

(b)

Figura 34: Variação do campo coercivo $\mathrm{H}_{\mathrm{C}}$ (a) e da fração volumétrica da austenita (b) em função do tempo de envelhecimento um aço maraging 300 (PARDAL et al., 2007). 
A figura 34 mostra também que tanto o campo coercivo Hc quanto a fração volumétrica aumentam com o incremento da temperatura de envelhecimento. Uma análise comparativa do comportamento da figura 34a e da figura 34b sugere que há uma relação entre o aumento do campo coercivo e a proporção de austenita para o aço maraging 300 (PARDAL et al., 2007), o que também foi observado por Tavares et al. (2004a) e Ahmed (1994) em aços maraging 350.

Habiby et al. (1992b) também analisaram a variação da corrente parasita ou corrente de Foucault (eddy current) e a fração volumétrica de austenita com o aumento da temperatura de envelhecimento. A proporção de austenita revertida foi determinada com o auxílio de difração de raios $X$. Já a corrente parasita ou corrente de Foucault foram determinadas em um instrumento Foester Defectoscop S-2.830, que apresenta o mesmo princípio físico de funcionamento do ferritoscópio usado nessa tese, descrito na seção $\underline{3.3 .4}$.

No instrumento de medida usado por Habiby et al. (1992b), as correntes parasitas são causadas devido a um campo magnético gerado por uma bobina indutora. O fluxo de corrente parasita induzido é influenciado por propriedades magnéticas e elétricas da amostra. Esse fluxo tem uma relação com a fração volumétrica de fases presentes na amostra. Dessa maneira, se a proporção volumétrica das fases mudar devido a algum tratamento térmico nas amostras, alterações nas correntes parasita podem ser correlacionadas com essas mudanças microestruturais.

A figura 35 apresenta a variação da quantidade de austenita revertida e da corrente parasita em função da temperatura de envelhecimento em um aço maraging 350. Essa figura mostra que a corrente parasita tem um decréscimo com o aumento da proporção de austenita. A relação direta entre essas duas medidas foi verificada na figura 36 . 


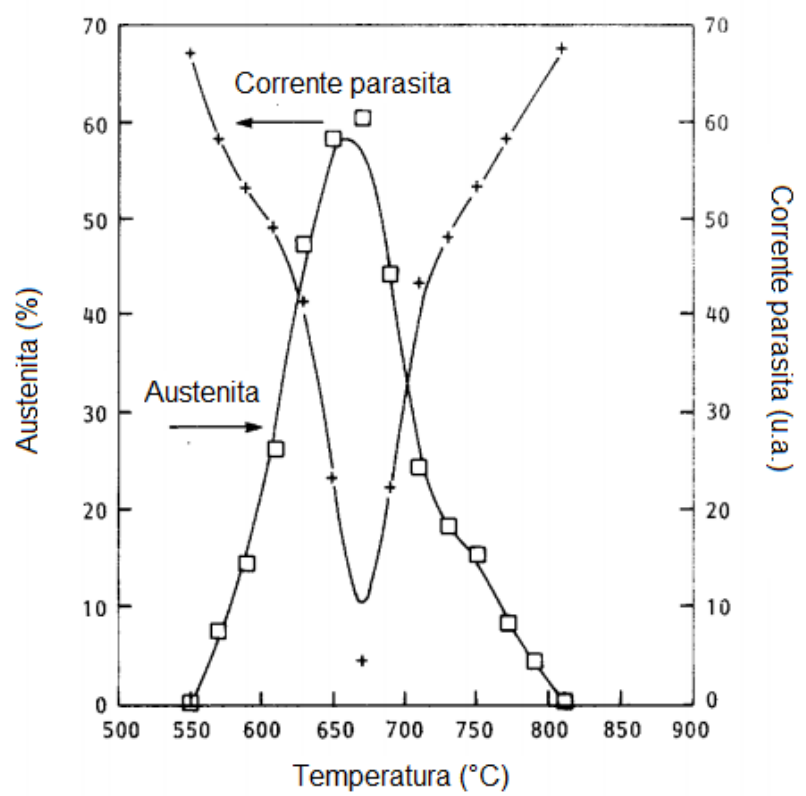

Figura 35: Variação da fração volumétrica da austenita e da corrente parasita em função da temperatura de envelhecimento em um aço maraging 350 (HABIBY et al..,1992b).

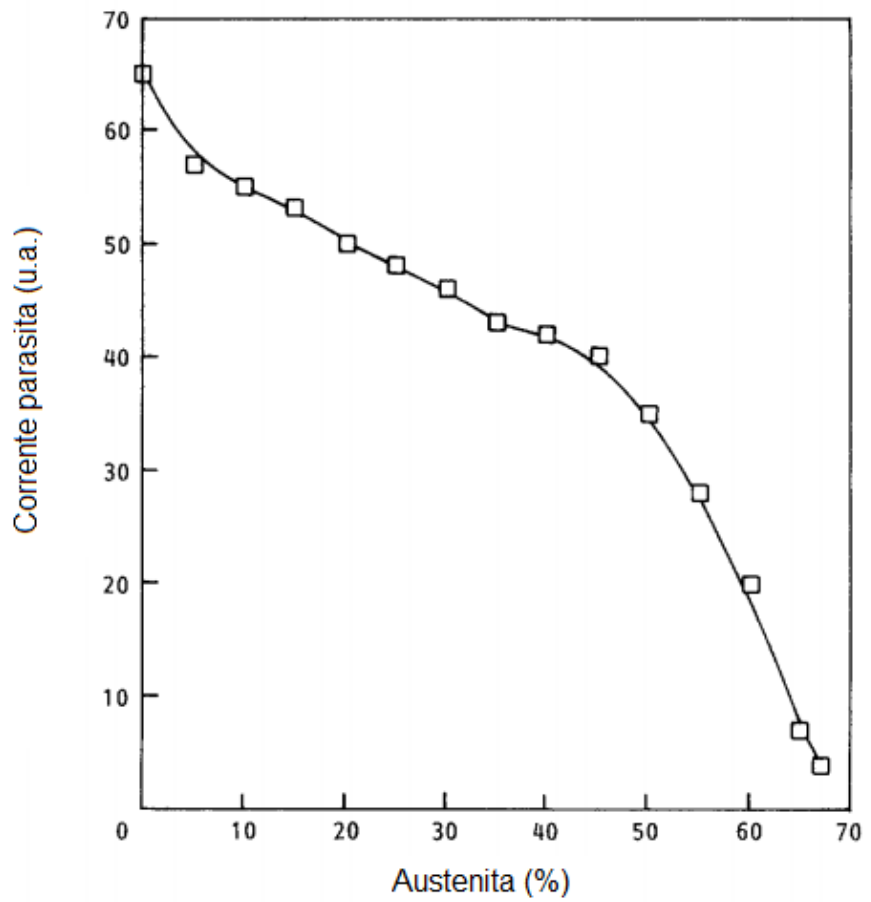

Figura 36: Relação entre a fração volumétrica da austenita e a corrente parasita em um aço maraging 350 (HABIBY et al..,1992b).

De acordo com Habiby e coautores (1992b), na figura 36 a variação da corrente parasita com a fração da austenita tem duas regiões distintas que se comportam de maneira linear. A primeira região situa-se entre 5\% e 40\% de fração volumétrica da austenita e a segunda região localiza-se acima de 40\%. 
Nessa tese será realizado um estudo similar ao feito por Habiby e coautores (1992b) para a cinética de reversão da austenita na seção $\underline{4.3 .2}$, usando um ferristocópio. No próximo item são discutidos os estudos de cinética não-isotérmica de precipitação e reversão da martensita.

\subsubsection{Estudos de cinética não-isotérmica de precipitação e reversão da martensita}

A cinética não-isotérmica das transformações de aços maraging também é um assunto abordado desde a década de 60 e passou a ser abordado com maior frequência desde a década de 90 por diversos autores. No item 2.4.2.1, é discutido o uso de medidas físicas para o acompanhamento da cinética de precipitação de compostos intermetálicos e da reversão da martensita em aços maraging.

\subsubsection{Uso de medidas físicas para o estudo da cinética não-isotérmica de precipitação e de reversão da martensita}

O acompanhamento da cinética não-isotérmica de precipitação e de reversão em aços maraging geralmente é realizado por meio de mudanças em propriedades físicas que essas transformações de fase proporcionam. Na dilatometria, as transformações de fase acarretam mudanças na variação do comprimento das amostras durante o aquecimento, enquanto na calorimetria exploratória diferencial é medida a variação do fluxo de calor devido às transformações de fase quando as amostras são submetidas a uma taxa de aquecimento (GOLDBERG; O'CONNOR,1967; VISWANATHAN; KUTTY; GANGULY, 1993; KAPOOR; KUMAR; BATRA, 2003; GUO; SHA, 2004; KAPOOR; BATRA, 2004; CARVALHO et al., 2013). Além da dilatometria e da calorimetria exploratória diferencial, as medidas realizadas por resistividade elétrica e por magnetização também permitem a detecção de transformações de fase em amostras aquecidas a uma taxa de aquecimento (KIMURA et al., 1975; TAVARES et al., 2003; 2004b)

Tavares et al. (2003) analisaram a variação da magnetização em função da temperatura a uma taxa de aquecimento constante usando análise termomagnética, conforme mostrado na figura 37. Pode-se observar duas regiões de mudança da magnetização. A primeira em que há uma queda da magnetização entre 685 e 800 
${ }^{\circ} \mathrm{C}$ durante o aquecimento devido à reversão da martensita e a segunda no qual há um aumento da magnetização devido à transformação martensítica no resfriamento. Todavia não foi observada uma mudança significativa da magnetização na região de ocorrência da precipitação.

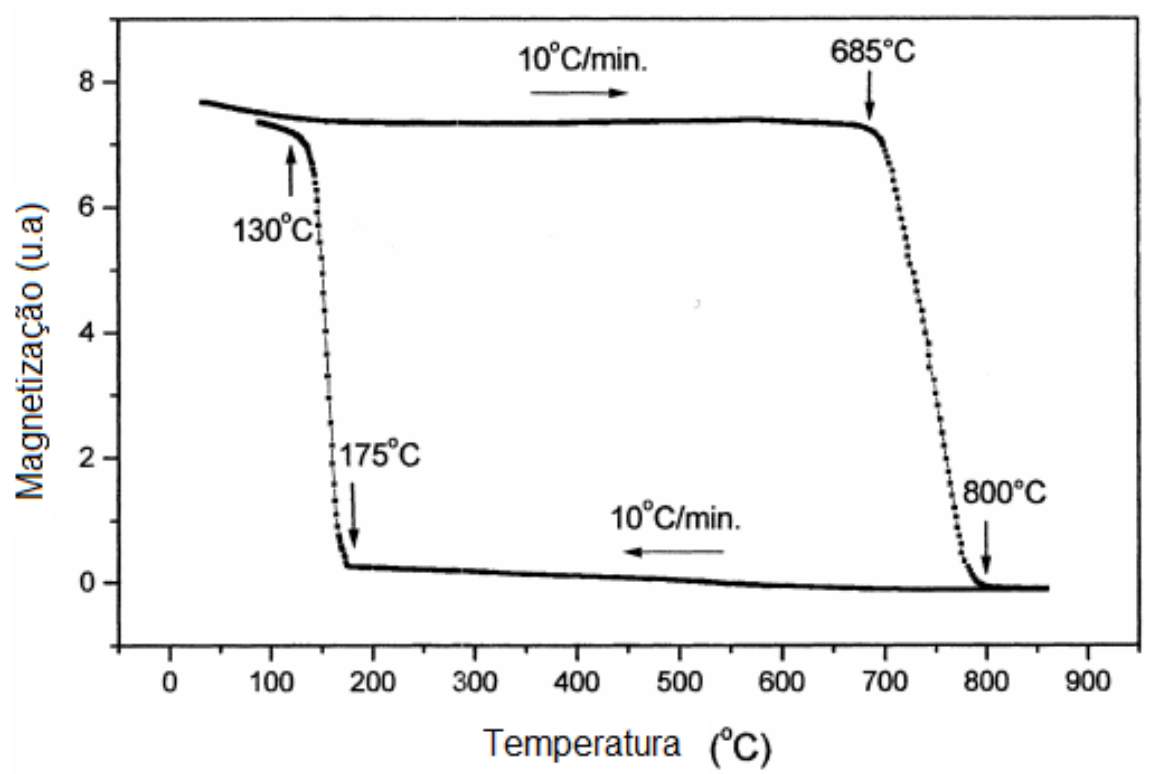

Figura 37: Variação da magnetização com o aumento da temperatura para uma taxa de aquecimento e resfriamento de $10^{\circ} \mathrm{C} / \mathrm{min}$ em um aço maraging 350 (TAVARES et al..,1993).

A figura 38 mostra também que o comportamento da variação do tamanho da amostra na dilatometria, com relação ao seu tamanho durante o ciclo de aquecimento e resfriamento, permite a identificação de três transformações de fase: a precipitação de compostos intermetálicos, reversão da martensita e a transformação martensítica (CARVALHO et al., 2013). 


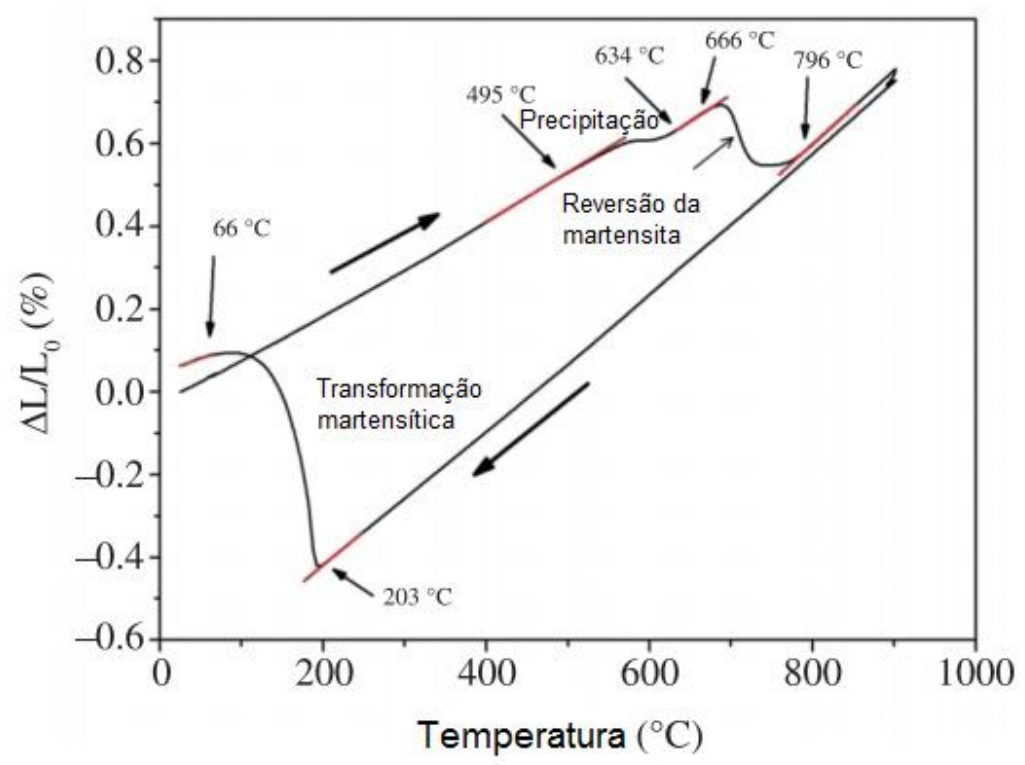

Figura 38: Variação do comprimento da amostra com relação ao seu tamanho inicial para o ciclo de aquecimento e resfriamento de $10^{\circ} \mathrm{C} / \mathrm{s}$ em um aço maraging 350 (CARVALHO et al..,2013).

Além da obtenção das temperaturas de início e de fim das transformações por desvio da linearidade da variação do comprimento da amostra com a temperatura, a dilatometria permite também outras informações da precipitação de compostos intermetálicos e da reversão da martensita por meio da derivada da variação do comprimento da amostra em função da temperatura, como apresentado na figura 39.

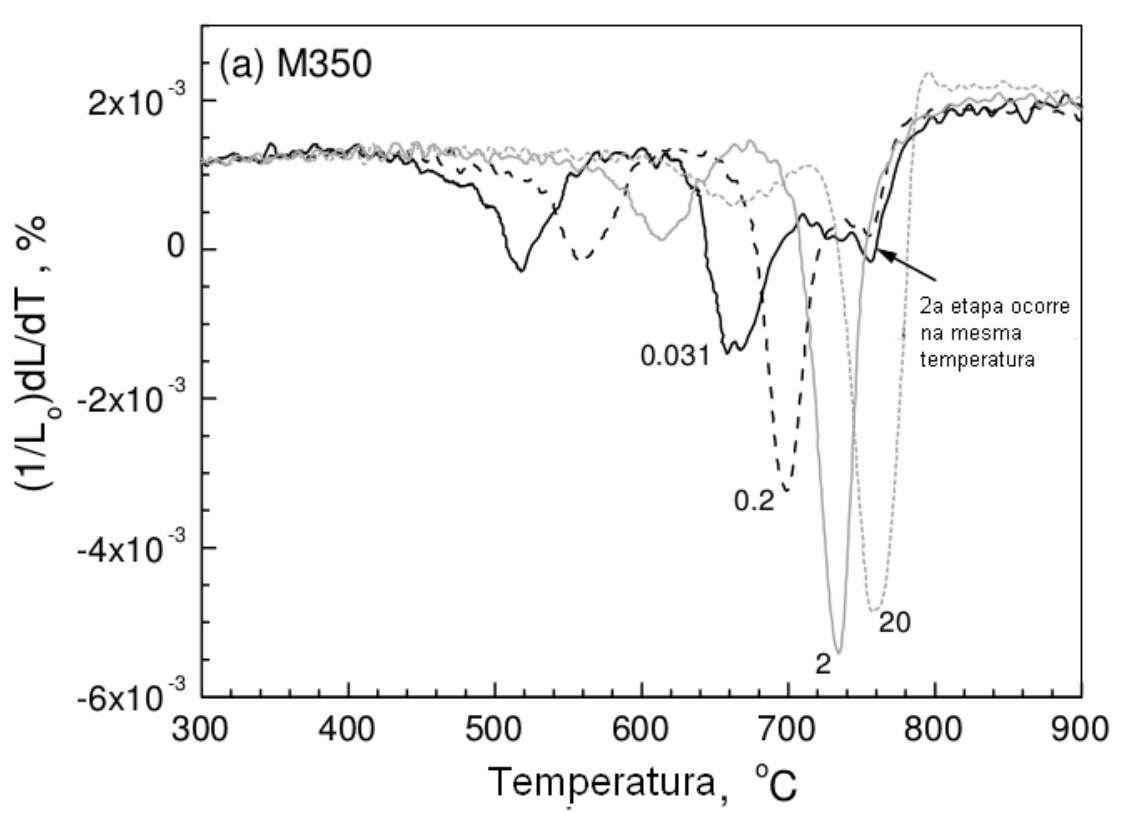

Figura 39: Variação da derivada do comprimento da amostra durante o experimento de dilatometria com relação à temperatura para diversas taxas de aquecimento em um aço maraging 350 (KAPOOR; KUMAR; BATRA, 2003). 
A figura 39 mostra a ocorrência da precipitação de compostos intermetálicos no primeiro intervalo de temperatura, no qual a derivada é negativa, enquanto a segunda região de contração mais intensa corresponde a reversão da martensita. Observa-se também que a reversão da martensita apresenta duas etapas, o que sugere a ocorrência de dois mecanismos de reversão da martensita (KAPOOR, R.; KUMAR, L.; BATRA, 2003).

Além da identificação das transformações de fase, as temperaturas que correspondem à máxima contração do comprimento da amostra referem-se às máximas taxas de transformação. Essas temperaturas são fundamentais para a estimativa da energia de ativação por meio do método de Kissinger, como será visto na próxima seção (item 2.4.2.2).

Estudos de transformações de fase durante o aquecimento podem ser feitos também com o uso do DSC. A figura 40 mostra a variação do fluxo de calor devido à ocorrência da precipitação de compostos intermetálicos e de reversão da martensita (GUO; SHA, 2004).

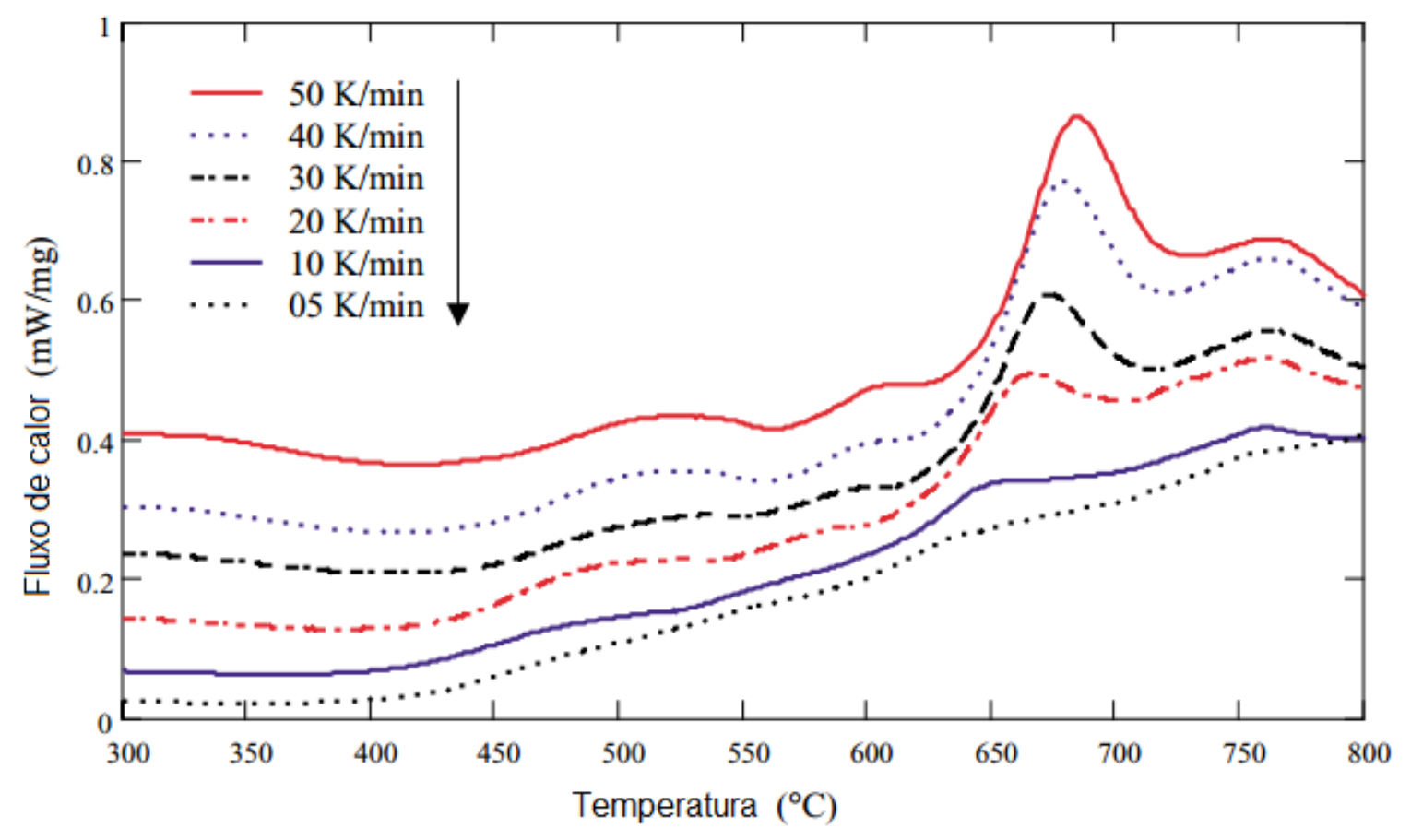

Figura 40: Variação do fluxo de calor com aumento da temperatura no DSC para diversas taxas de aquecimento em um aço maraging 250 (GUO; SHA, 2004). 
Guo e Sha (2004) sumarizaram as possíveis transformações de fase pesquisadas por outros autores durante o aquecimento contínuo em aços maraging, conforme apresentado na tabela 10.

Tabela 10: Interpretação dos resultados de DSC em uma curva de DSC para uma taxa de aquecimento de $50^{\circ} \mathrm{C} / \mathrm{min}$ (GUO; SHA, 2004).

\begin{tabular}{|c|c|c|c|}
\hline Região & $\begin{array}{l}\text { Características } \\
\text { do DSC }\end{array}$ & $\begin{array}{c}\text { Faixa de } \\
\text { temperatura }\left({ }^{\circ} \mathrm{C}\right)\end{array}$ & Possíveis transformações de fase \\
\hline I & Exotérmica & $310-510$ & $\begin{array}{l}\text { - Recuperação da martensita } \\
\text { - Formação de precipitados de carbonetos } \\
\text { (endurecimento menor) } \\
\text { - Formação de precipitados coerentes }\end{array}$ \\
\hline II & Exotérmica & $535-603$ & $\begin{array}{l}\text { - Formação dos principais precipitados } \\
\text { endurecedores }\end{array}$ \\
\hline III & Endotérmica & $635-730$ & - Reversão da martensita por difusão \\
\hline IV & Endotérmica & $730-800$ & $\begin{array}{l}\text { - Transformação da martensita para a austenita } \\
\text { por cisalhamento } \\
\text { - Recristalização ou dissolução de precipitados }\end{array}$ \\
\hline
\end{tabular}

A tabela 10 mostra que são possíveis dois picos endotérmicos e dois picos exotérmicos. O primeiro pico exotérmico pode corresponder à recuperação da martensita, à formação de precipitados de carbonetos e à formação de precipitados coerentes (GUO; SHA, 2004). Como visto na seção 2.3.3.1, os precipitados coerentes são formados em temperaturas mais baixas do que os precipitados endurecedores principais dos aços maraging (TEWARI et al., 2000). O segundo pico exotérmico refere-se à formação dos principais precipitados endurecedores. Já os picos endotérmicos são relacionados as etapas de reversão da martensita que podem ocorrer tanto por difusão como por cisalhamento (GUO; SHA, 2004).

A figura 41 mostra os picos exotérmicos e endotérmicos durante 0 aquecimento contínuo em um aço maraging 250. 


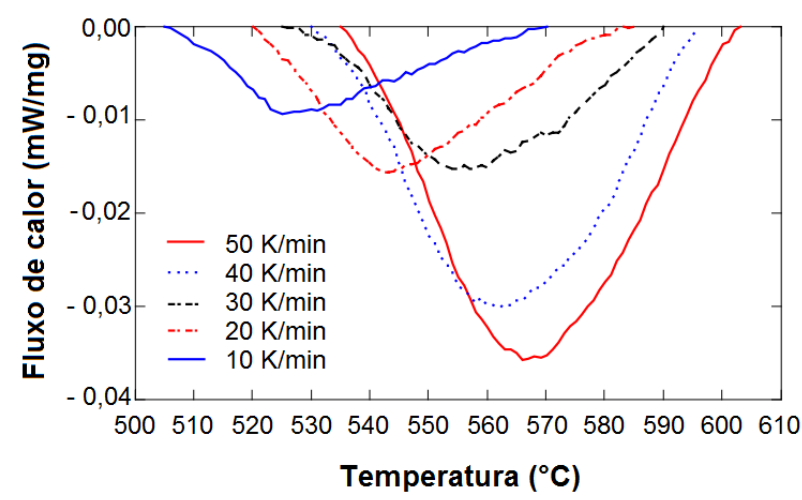

(a)

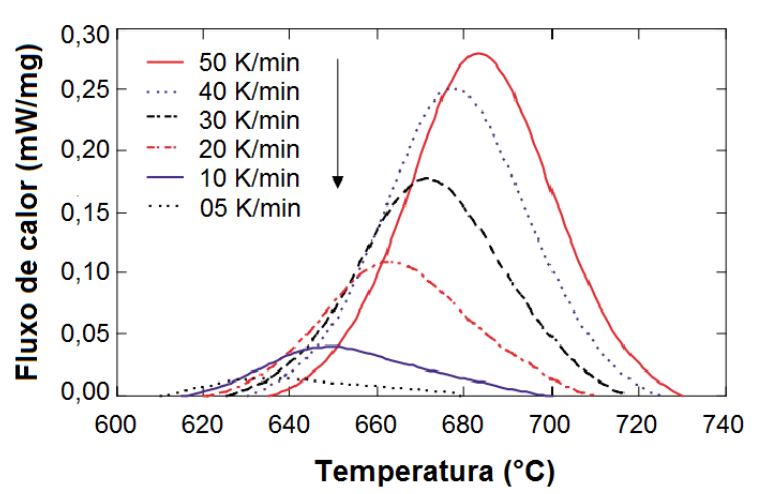

(b)

Figura 41: Variação do fluxo de calor com aumento da temperatura no DSC para diversas taxas de aquecimento em um aço maraging 250 (GUO; SHA, 2004).

O pico exotérmico mostrado na figura 41a ocorre em virtude da precipitação dos compostos intermetálicos, enquanto o pico endotérmico apresentado na figura 41 b ocorre devido à reversão da martensita. Além disso, observa-se também que as temperaturas de transformação aumentam com o incremento da taxa de aquecimento, o que indica que ambos os processos são termicamente ativados (GUO; SHA, 2004).

Com as temperaturas de transformações de fase obtidas por experimentos realizados em taxa de aquecimento constante, como a dilatometria e DSC, é possível esquematizar um diagrama $\mathrm{CHT}$. Conhecido em inglês por continuous heating transformation diagram, o diagrama $\mathrm{CHT}$ é uma representação que mostra a sequência das transformações de fase durante o aquecimento contínuo, no qual são representadas as temperaturas de início e de término de cada transformação durante o aquecimento da amostra. Na figura 42 é apresentado um exemplo de um diagrama $\mathrm{CHT}$ para um aço maraging 350 , obtido por meio de dilatometria. (KAPOOR; BATRA, 2004). 


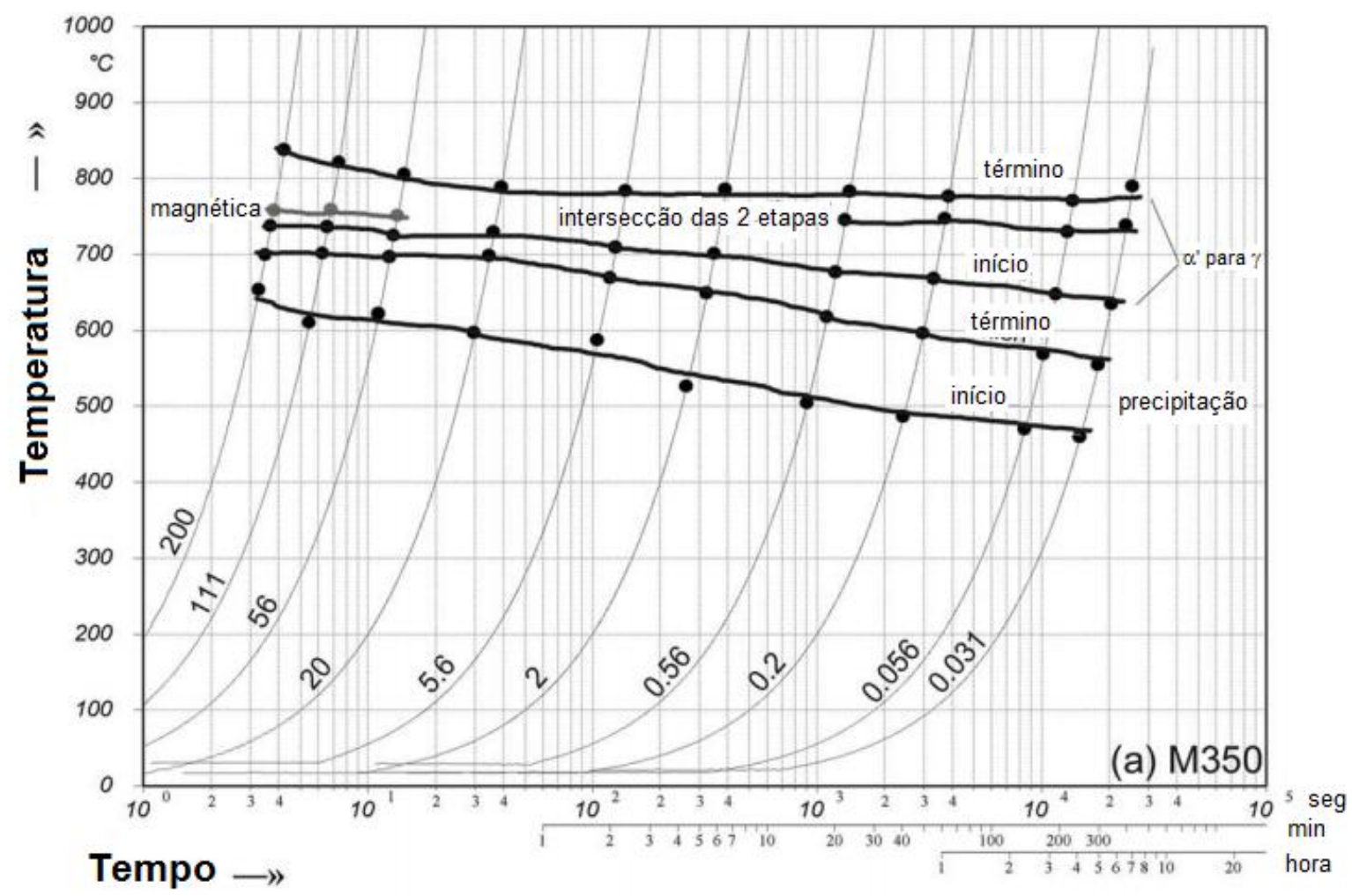

Figura 42: Variação do fluxo de calor com aumento da temperatura no DSC para diversas taxas de aquecimento em um aço maraging 350 (KAPOOR; BATRA, 2004).

A figura 42 mostra que a precipitação ocorre antes da reversão da martensita. A reversão da martensita pode acontecer em duas etapas, uma etapa em que a reversão da martensita é controlada por mecanismos difusivos, enquanto a segunda etapa ocorre com o predomínio de mecanismos de cisalhamento (KAPOOR; BATRA, 2004).

O próximo tópico discute como a energia de ativação das transformações de fase, como a precipitação e a reversão da martensita em aços maraging, pode ser obtida por meio do método de Kissinger.

\subsubsection{Análise cinética pelo método de Kissinger}

O método de Kissinger é um dos métodos das máximas taxas de transformação mais usados para a determinação de ativação de transformações de fase em materiais (STARINK, 2003). Esse método é também o mais utilizado em aços maraging (VISWANATHAN; KUTTY; GANGULY, 1993; GUO; SHA, 2004; KAPOOR; BATRA, 2004; CARVALHO et al., 2013). Além dele, há outros tipos de 
análises similares como, por exemplo, os métodos de Ozawa, de Boswell e de Starink para determinação da energia de ativação de transformação de fase, que não serão tratados nessa tese (BOSWELL, 1980; OZAWA, 1992; STARINK, 2003).

Em métodos de máxima taxa de transformações de fase, como a análise de Kissinger, as temperaturas em que ocorre a máxima taxa são usadas para a determinação da energia de ativação (STARINK, 2003). Nos experimentos de dilatometria, as máximas taxas de transformação ocorrem quando a taxa de variação do comprimento tem um ponto de mínimo ou um máximo local para uma dada temperatura, em uma taxa de aquecimento fixa, como já foi ilustrado na figura 39 localizada na seção anterior (KAPOOR; BATRA, 2004; CARVALHO et al., 2013). Já as máximas taxas de transformações, nos experimentos de DSC, acontecem quando o fluxo de calor tem um ponto de máximo para o caso do pico endotérmico ou um ponto de mínimo para o caso do pico exotérmico, como foi apresentado na figura 41 no item anterior (GUO; SHA, 2004).

A equação de Kissinger relaciona as temperaturas de máxima taxa de transformação, a taxa de aquecimento e a energia de ativação, como apresentado na equação 12 (KISSINGER, 1997; STARINK, 2003).

$$
\ln \frac{\beta}{T_{M}^{2}}=-\frac{E}{R T_{M}}+C
$$

Nas equações anteriores, $\beta$ é a taxa de aquecimento, $T_{M}$ a temperatura em que há a máxima taxa de transformação de fase, $E$ a energia de ativação, $R$ a constante universal dos gases e $\mathrm{C}$ uma constante arbitrária.

A figura 43 apresenta a aplicação do método de Kissinger para o estudo da precipitação e da reversão em aços maraging. 


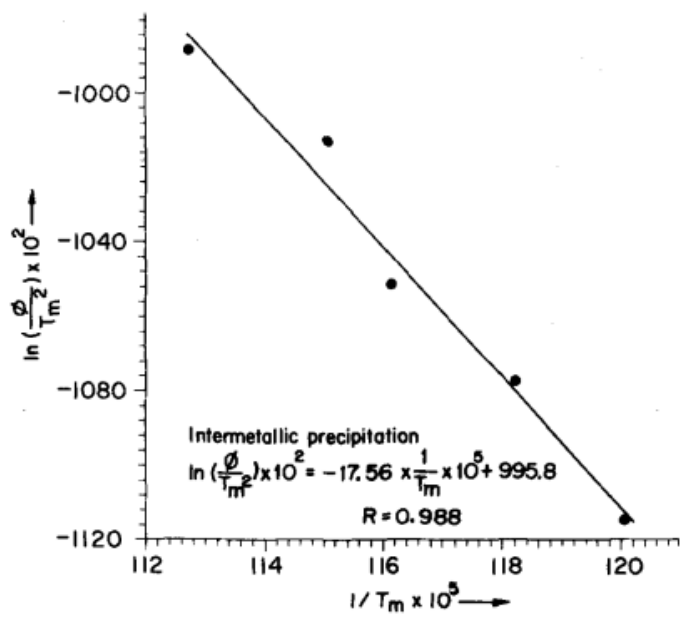

(a)

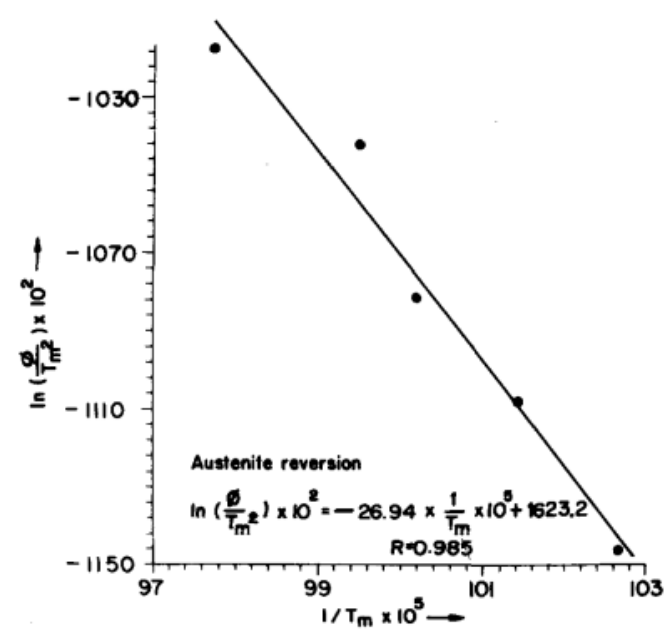

(b)

Figura 43: Método de Kissinger usado para a determinação da energia de ativação da precipitação (a) e da reversão da martensita (b) em um aço maraging 350 a partir de dados de dilatometria (VISWANATHAN; KUTTY; GANGULY, 1993).

$\mathrm{Na}$ figura 43, observa-se que o método de Kissinger se ajusta bem aos dados experimentais para a determinação da energia de ativação da precipitação e da reversão da martensita. A partir da inclinação da reta, pode-se estimar a energia de ativação dessas transformações de fase, conforme mostrado na equação 12 já apresentada.

Os valores da energia de ativação obtidos por diversos autores, por meio desse método para a precipitação e a reversão da martensita, foram discutidos em conjunto com os resultados dessa tese na seção $\underline{4.2 .2}$.

Mittemeijer (1992) mostrou que a obtenção da energia de ativação por meio do método de Kissinger para as máximas taxas de transformações de fase durante o aquecimento contínuo pode ter um pequeno erro associado. Starink (2003) sugeriu também que este erro está relacionado às pequenas variações da fração transformada na máxima taxa de transformação de fase. Todavia, de acordo com Starink (2003), o método de Kissinger tem um erro relativo de 1\%, sendo, portanto, o melhor método de máxima taxa de transformação conhecido atualmente.

Na próxima seção 2.5 são discutidos os mecanismos de endurecimento na martensita e o comportamento da curva de envelhecimento dos aços maraging. 


\subsection{MECANISMOS DE ENDURECIMENTO NA MARTENSITA E O COMPORTAMENTO DA CURVA DE ENVELHECIMENTO}

$\mathrm{O}$ endurecimento durante $\mathrm{O}$ envelhecimento nos aços maraging tem sido estudado por diversos pesquisadores (FLOREEN; DECKER, 1962; VISWANATHAN; DEY; ASUNDI, 1993; WILSON, 1997; SHA, 2000; GUO; SHA, 2002; PARDAL et al., 2005). Estes estudos mostraram que os aços maraging têm um comportamento típico de uma curva de envelhecimento com um único pico de dureza, como ilustrado na figura 44.

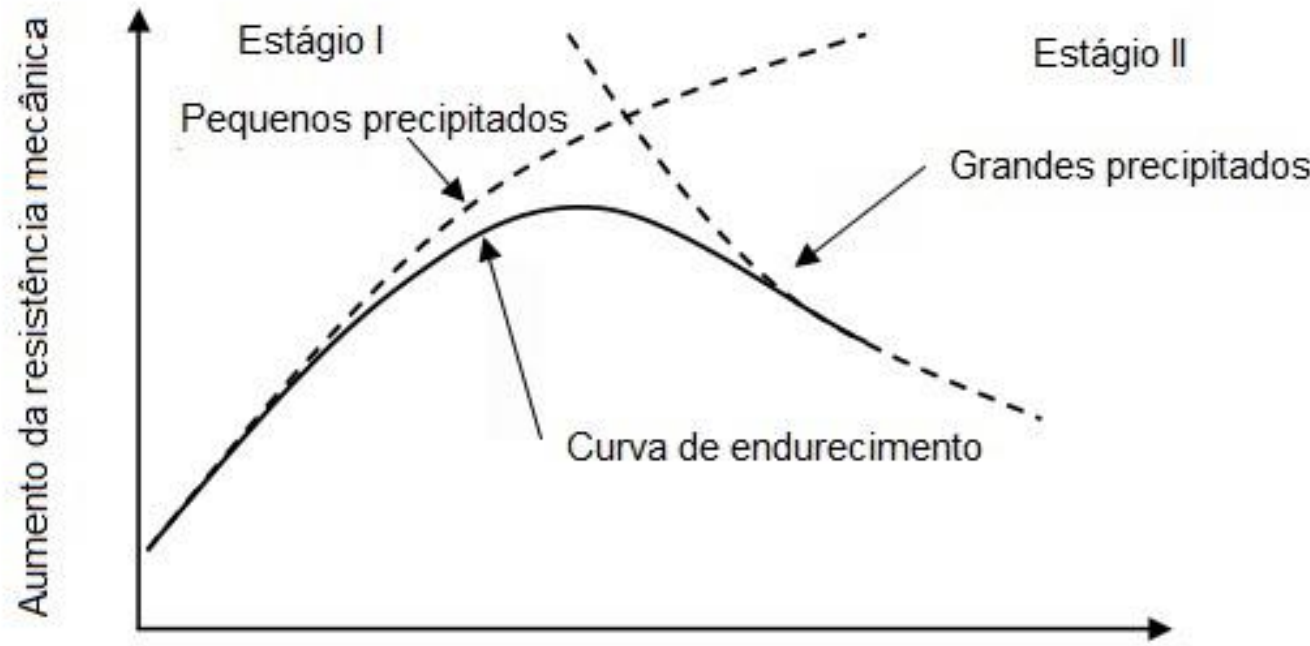

Tempo de envelhecimento

Figura 44: Curva de endurecimento em função do tempo de envelhecimento (GUO; SHA, 2002).

A figura 44 mostra que o comportamento de uma curva típica de envelhecimento apresenta dois estágios. Uma etapa de endurecimento decorrente do cisalhamento de pequenos precipitados coerentes e ordenados em relação à matriz, enquanto o amolecimento é devido a uma mudança no mecanismo de endurecimento por precipitação em virtude da formação de precipitados grossos (WILSON, 1997; MARTIN, 1998; SHA, 2000; GUO; SHA, 2002; PARDAL et al., 2005). Além do amolecimento devido ao engrossamento dos precipitados, a reversão da martensita durante o superenvelhecimento também leva a um decréscimo da microdureza (VISWANATHAM; DEY; SETHUMANDHAVAN, 2005; PARDAL et al., 2005, 2006). 
Diversos mecanismos podem atuar no endurecimento devido ao cisalhamento de precipitados. No endurecimento "químico" (chemical strengthening), o aumento de resistência ocorre devido à energia necessária para criar uma interface precipitado-matriz quando o precipitado é cisalhado pela discordância; enquanto endurecimento causado por falha de empilhamento (stacking-fault strengthening) é decorrente da diferença entre a energia de falha de empilhamento do precipitado e da matriz, quando eles tiverem estrutura cristalina cúbica de face centrada ou hexagonal compacta. O mecanismo de endurecimento devido ao módulo elástico é decorrente da diferença entre o módulo de elasticidade da matriz e o precipitado. Já o endurecimento por coerência (coherency strengthening) ocorre como um resultado das distorções elásticas ao redor de um precipitado que não se ajusta perfeitamente com a matriz. Por fim, o endurecimento por ordenamento (order strengthening) é devido ao trabalho requerido para criar um contorno de antifase no caso das discordâncias passando através dos precipitados que têm um ordenamento com a matriz (MARTIN, 1998; GLADMAN, 1999; GUO; SHA, 2002).

A tensão crítica de cisalhamento (CRSS) é a tensão necessária para cisalhar um precipitado, o que pode ocorrer mediante os mecanismos de ordenamento (equação 13) e de coerência (equação 14). A equação 13 mostra que o endurecimento por cisalhamento, decorrente do mecanismo de ordenamento, depende do raio $r$ e da fração volumétrica do precipitado $V_{V}$ (MARTIN, 1998; GUO; SHA, 2002) ${ }^{5}$.

$$
\tau_{c}=\frac{\gamma_{a p b}}{2 b^{2}} \quad{\frac{3 \pi^{2} \gamma_{a p b} V_{V} \cdot r}{32 T_{1}}}^{1 / 2}-V_{V}
$$

Nos quais, $\tau_{c}$, a tensão crítica de cisalhamento (CRSS); $\gamma_{a p b}$, energia do contorno de antifase; $T_{1}$, tensão de linha da discordância; $b$, o módulo do vetor de Burgers; $V_{V}$, fração volumétrica do precipitado.

\footnotetext{
${ }^{5} \mathrm{~A}$ constante $V_{V}$ refere-se à constante $f$ nos trabalhos de Martin (1998) e Guo e Sha (2002). A simbologia foi alterada como o objetivo de padronizar o símbolo f para a fração transformada ao longo dessa tese.
} 
Já a equação 14 evidencia que o endurecimento por cisalhamento devido ao mecanismo de coerência depende do raio $r$ e da fração volumétrica do precipitado V $_{\mathrm{V}}$ (MARTIN, 1998; GUO; SHA, 2002).

$$
\tau_{c}=4,1 G \varepsilon^{3 / 2} V_{V}{ }^{1 / 2} r / b^{1 / 2}(14)
$$

Nos quais, $\varepsilon$, distorção da matriz; $G$, uma constante.

Em ambos os mecanismos, quando a fração volumétrica e o raio do precipitado crescem, também aumenta a tensão crítica de cisalhamento necessária para cortar o precipitado, o que está de acordo com o comportamento do primeiro estágio da curva de envelhecimento mostrada na figura 44 (MARTIN, 1998; GUO; SHA, 2002).

A figura 45 ilustra como ocorre o endurecimento por cisalhamento de precipitados quando uma discordância passa através deles (GLADMAN,1999).

Antes

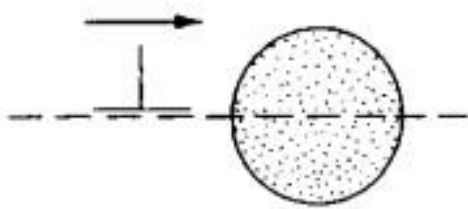

Depois

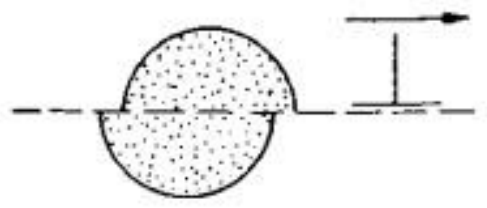

Figura 45: Movimentação das discordâncias através do cisalhamento de precipitados (GLADMAN,1999).

A figura 46 mostra o endurecimento por precipitação incoerente pelo qual o endurecimento ocorre pela tensão de linha necessária para a formação de anéis de discordâncias por meio do mecanismo de Orowan (GLADMAN,1999). 
(a) Situação inicial

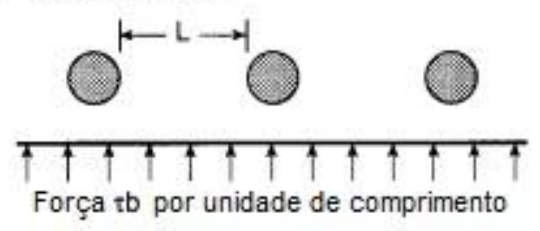

(b) Situação sub-critica

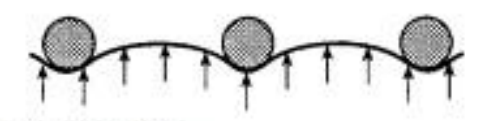

(c) Situação crîtica

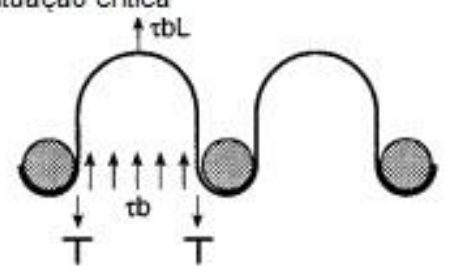

(d) Situação final

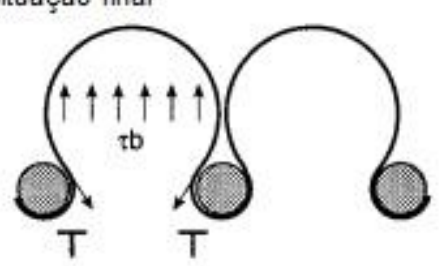

Figura 46: Formação dos anéis de discordâncias pela passagem das discordâncias em precipitados incoerentes por meio do mecanismo de Orowan (GLADMAN,1999).

O mecanismo de endurecimento de Orowan ocorre de forma predominante no segundo estágio da curva de endurecimento apresentada na figura 44. A tensão crítica TC para o mecanismo de Orowan é dada por (MARTIN,1998):

$$
\tau_{c}=\frac{\mu b}{\Lambda}=\frac{3}{2 \pi}^{1 / 2} \frac{\mu b}{r}^{1 / 2} V_{V}^{1 / 2}
$$

Nas equações anteriores, $\mu$ é o módulo de cisalhamento da matriz e $\Lambda$ é o espaçamento médio dos precipitados.

A partir da equação 15 pode-se concluir que o aumento do raio $r$ diminui a tensão crítica $T_{C}$, o que elucida o comportamento do segundo estágio da curva de envelhecimento (GUO; SHA, 2002). Para precipitados mais grossos, torna-se mais difícil eles serem cisalhados pela passagem de discordâncias, pois os precipitados comportam-se como obstáculos impenetráveis (MARTIN, 1998).

Com base nos mecanismos de endurecimento expostos, Wilson (1997) propôs dois modelos para descrever os dois estágios do comportamento da curva de 
envelhecimento. A partir da suposição do mecanismo de endurecimento, devido ao cisalhamento de precipitados por discordâncias no primeiro estágio da curva de envelhecimento, Wilson (1997) e Guo e Sha (2002) deduziram uma expressão que relaciona a microdureza com o tempo de envelhecimento, como mostrado na equação 16.

$$
\Delta \mathrm{H}=(\mathrm{kt})^{m}(16)
$$

Nos quais, $\Delta \mathrm{H}$ é a variação da dureza com relação ao estado solubilizado, $\mathrm{m}$ e k são constantes dependentes da temperatura. Na dedução da equação 16 , Wilson (1997) e Guo e Sha (2002) utilizaram a equação JMAK e a relação parabólica de Zener para o crescimento dos precipitados. Vale ressaltar que Floreen e Decker (1962) também propuseram uma equação similar à equação 16 para a variação da dureza com o tempo de envelhecimento por meio do uso de uma abordagem empírica.

Pardal e coautores (2005) aplicaram a equação 16 aos dados experimentais de microdureza, como função d o tempo para um aço maraging 300 na região referente ao primeiro estágio da curva de envelhecimento, já mencionado na figura 44. Pode-se observar que o modelo se ajusta bem aos dados experimentais para amostras envelhecidas $440,480,510$ e $560^{\circ} \mathrm{C}$, como apresentado na figura 47.

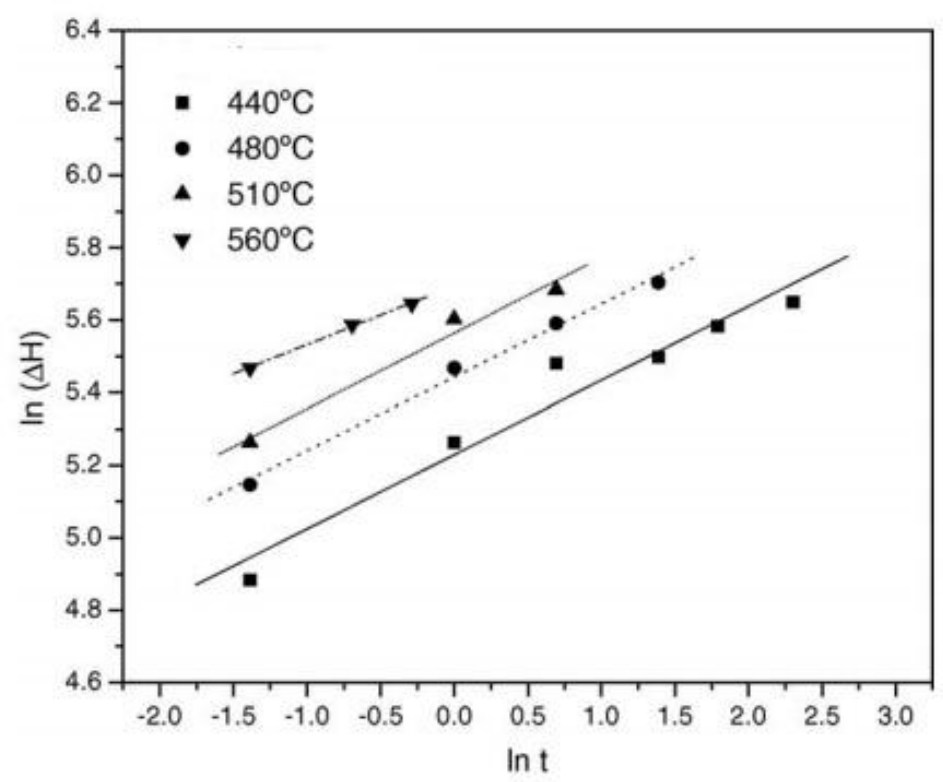

Figura 47: Ajuste do modelo da precipitação em estágios iniciais aos dados experimentais da curva de envelhecimento para um aço maraging 300 (PARDAL et al.,2005). 
Além da equação do primeiro estágio, Wilson (1997) também propôs uma expressão para o amolecimento durante o superenvelhecimento em virtude da ocorrência do mecanismo de Orowan e da presença de precipitados mais grossos, descrita pela seguinte equação:

$$
\Delta \mathrm{H}^{-3}=\Delta \mathrm{H}_{0}^{-3}+\mathrm{M} .\left(\mathrm{t}-\mathrm{t}_{P}\right)(17)
$$

Nos quais, $\Delta \mathrm{H}$ é a diferença entre a dureza da amostra envelhecida e a solubilizada, $\mathrm{M}$ é uma constante dependente da temperatura, $t_{P}$ é o tempo do pico de dureza e $\Delta \mathrm{H}_{0}$ é a variação da dureza no tempo de início do engrossamento tp.

Pardal e coautores (2005) também aplicaram o modelo da equação 17 aos dados experimentais de microdureza para amostras superenvelhecidas em um aço maraging 300 , como mostra a figura 48. Pode-se observar que o modelo se ajusta bem aos dados experimentais para amostras tratadas a $560{ }^{\circ} \mathrm{C}$, porém o mesmo não ocorre com os dados para amostras envelhecidas a $600^{\circ} \mathrm{C}$.

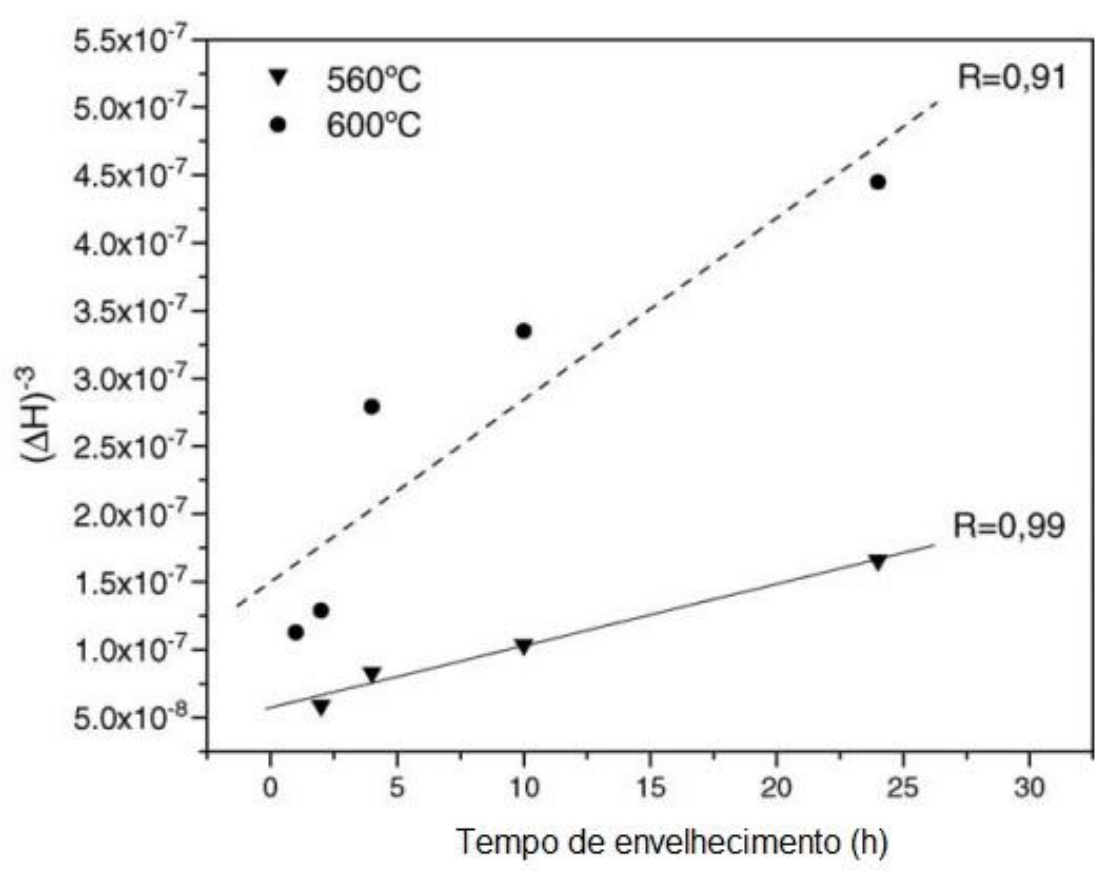

Figura 48: Ajuste do modelo da curva de envelhecimento para o amolecimento devido ao engrossamento dos precipitados em um aço maraging 300 (PARDAL et al.,2005).

A menor aderência dos dados de dureza das amostras tratadas a $600{ }^{\circ} \mathrm{C}$ ao modelo de amolecimento proposto por Wilson (1996) levou Pardal et al. (2005) a 
proporem um modelo empírico para descrever a mudança na dureza com o tempo de envelhecimento durante o superenvelhecimento:

$$
H=H_{1} \cdot t^{p}(18)
$$

No qual $\mathrm{H}$ é o valor de dureza, t é o tempo de envelhecimento, $\mathrm{H}_{1}$ é o valor de dureza em $t=1 \mathrm{~h}$ e $\mathrm{p}$ é uma constante exponencial. A Figura 49 mostra o ajuste do modelo de Pardal et al. (2005) aos resultados experimentais do aço maraging 300. Pode-se observar que o modelo empírico se ajusta bem ao comportamento dos dados experimentais.

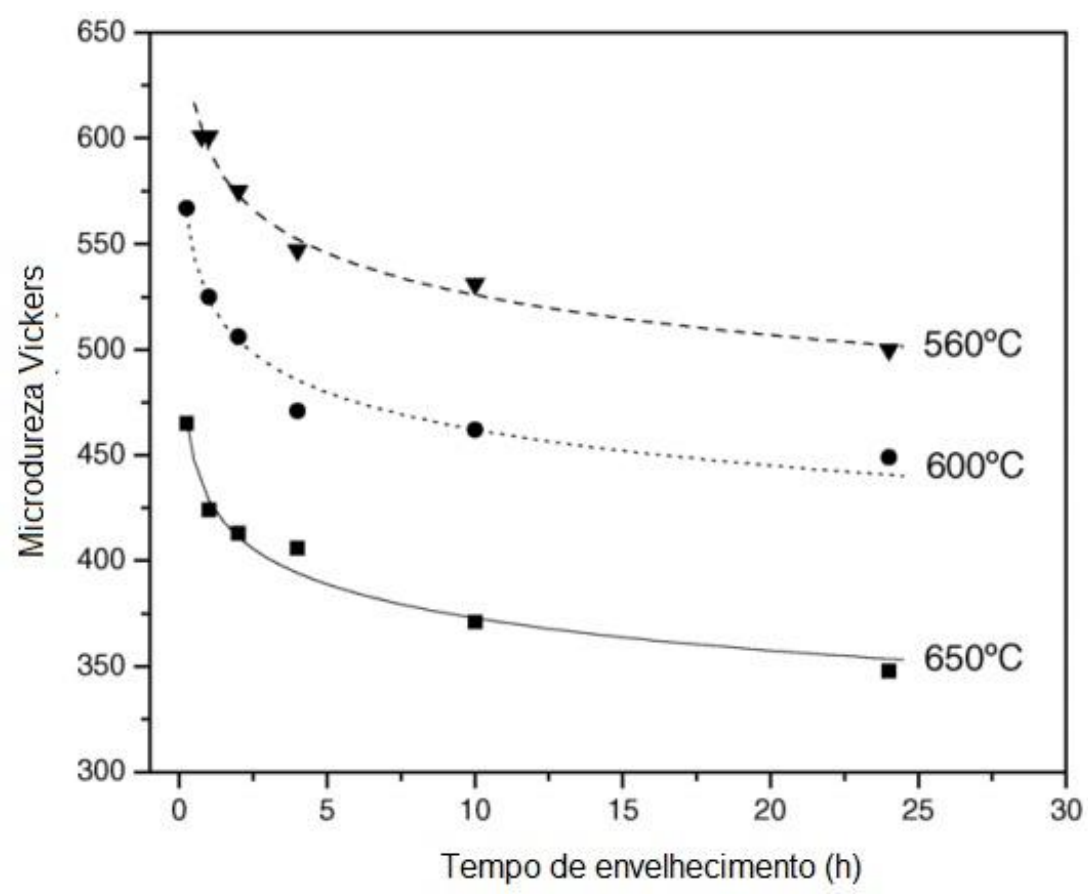

Figura 49: Ajuste do modelo empírico de Pardal e coautores (2005) aos dados de microdureza Vickers em amostras superenvelhecidas em um aço maraging 300 (PARDAL et al.,2005).

Uma análise similar à apresentada nessa seção dos mecanismos de endurecimento na curva de envelhecimento foi realizada no aço maraging 350B, como apresentado na seção $\underline{\text { 4.3.3.2.2. }}$.

Na próxima seção são descritos os materiais e métodos usados nessa tese. 


\section{MATERIAIS E MÉTODOS}

\subsection{MATERIAIS}

Neste trabalho foram analisadas uma barra de aço maraging 300 e duas barras de aço maraging 350, fornecidas pelo Centro Tecnológico da Marinha em São Paulo (CTMSP) ${ }^{6}$. Os materiais foram produzidos por fusão em forno de indução a vácuo (VIM) e, em seguida, por refusão em forno a arco (VAR). Posteriormente, as barras fornecidas foram conformadas mecanicamente por forjamento a quente, seguida por solubilização a $820^{\circ} \mathrm{C}$ por 1 hora por $25 \mathrm{~mm}$ de espessura, durante a fabricação.

As barras tinham formas cilíndricas com diâmetro de 98,5 m para a barra $300 \mathrm{~A}$ e de $139,5 \mathrm{~mm}$ para as barras 350B e 350C. A partir dessas barras, o CTMSP obteve discos com espessura de 10 a $13 \mathrm{~mm}$. Na tabela 11 são apresentadas as composições químicas das três barras.

Tabela 11: Composição química (\% em massa) das barras pesquisadas.

\begin{tabular}{cccc}
\hline Elemento & $\begin{array}{c}\text { Maraging } 300 \\
\text { barra A }\end{array}$ & $\begin{array}{c}\text { Maraging } 350 \\
\text { barra B }\end{array}$ & $\begin{array}{c}\text { Maraging } 350 \\
\text { barra C }\end{array}$ \\
\hline $\mathrm{Ni}$ & 18,69 & 18,16 & 17,79 \\
$\mathrm{Co}$ & 8,99 & 11,92 & 11,85 \\
$\mathrm{Mo}$ & 5,01 & 4,81 & 4,83 \\
$\mathrm{Ti}$ & 0,80 & 1,22 & 1,46 \\
$\mathrm{Al}$ & 0,086 & 0,074 & 0,088 \\
$\mathrm{Cr}$ & 0,013 & 0,024 & 0,045 \\
$\mathrm{Si}$ & 0,015 & 0,020 & 0,035 \\
$\mathrm{Mn}$ & 0,019 & 0,029 & 0,021 \\
$\mathrm{P}^{*}$ & 26 & 19 & 28 \\
$\mathrm{~S}^{*}$ & 30 & 30 & 25 \\
$\mathrm{~B}^{*}$ & 4 & 3 & 10 \\
$\mathrm{Zr}^{*}$ & 10 & 10 & 10 \\
$\mathrm{Ca}^{*}$ & $<2$ & $<2$ & $<2$ \\
$\mathrm{C}^{*}$ & 10 & 30 & 25 \\
$\mathrm{O}^{*}$ & 9 & 8 & 9 \\
$\mathrm{~N}^{*}$ & 1,5 & 2,0 & 7 \\
$\mathrm{H}^{*}$ & 0,7 & 0,5 & 0,8 \\
\hline${ }^{*}$ & & &
\end{tabular}

\footnotetext{
${ }^{*}$ teores em ppm
}

${ }^{6}$ Doravante, a nomenclatura do aço maraging 300 barra A será abreviada como maraging $300 \mathrm{~A}$, enquanto as duas barras de aço maraging 350 serão identificadas como 350B e 350C. 


\subsection{TRATAMENTOS TÉRMICOS}

Os tratamentos térmicos de envelhecimento realizados tiveram como objetivo o estudo das cinéticas de precipitação e de reversão da martensita, bem como a análise do comportamento da curva de envelhecimento entre 440 e $600{ }^{\circ} \mathrm{C}$, realizados apenas para as amostras do aço maraging 350B. Os tempos de envelhecimento usados para amostras tratadas a 520,560 e $600{ }^{\circ} \mathrm{C}$ foram de $6 \mathrm{~min}$, $12 \mathrm{~min}, 18 \mathrm{~min}, 24 \mathrm{~min}, 30 \mathrm{~min}, 45 \mathrm{~min}, 1 \mathrm{~h}, 2 \mathrm{~h}, 4 \mathrm{~h}, 6 \mathrm{~h}, 8 \mathrm{~h}, 10 \mathrm{~h}, 14 \mathrm{~h}$ e $18 \mathrm{~h}$.

As amostras da barra $350 \mathrm{~B}$, tratadas a 440 e $480^{\circ} \mathrm{C}$, entretanto, tiveram faixas de tempos de envelhecimento alteradas, pois o pico de microdureza e 0 superenvelhecimento ocorrem em tempos mais prolongados em relação às temperaturas 520,560 e $600{ }^{\circ} \mathrm{C}$. Dessa maneira, o tempo de envelhecimento para as amostras tratadas a $440^{\circ} \mathrm{C}$ foi estendido até 66 horas, enquanto as amostras envelhecidas a $480^{\circ} \mathrm{C}$ foram envelhecidas até 22 horas.

Os tratamentos térmicos de envelhecimento foram realizados em um forno tipo mufla da marca Grion, instalado no Departamento de Engenharia Metalúrgica e de Materiais da Universidade de São Paulo.

No próximo item, são descritas as principais técnicas de análise microestrutural usadas neste trabalho.

\subsection{TÉCNICAS DE ANÁLISE MICROESTRUTURAL}

A caracterização microestrutural das amostras no estado como recebido e tratadas termicamente envolveu o uso de diversas técnicas complementares, como microscopia ótica (MO), microscopia eletrônica de varredura (MEV) com espectroscopia por dispersão de energia de raios $X$ (EDS), microdureza Vickers, difração de raios $X(D R X)$ e ferritoscopia. Já a calorimetria exploratória diferencial (DSC) foi usada para estudar as transformações de fase, precipitação de compostos intermetálicos e reversão da martensita, por meio de experimentos com taxa de aquecimento constante. $O$ organograma mostrado na figura 50 mostra de forma esquemática a estratégia experimental utilizada, os experimentos realizados e as técnicas experimentais usadas nesta tese. 


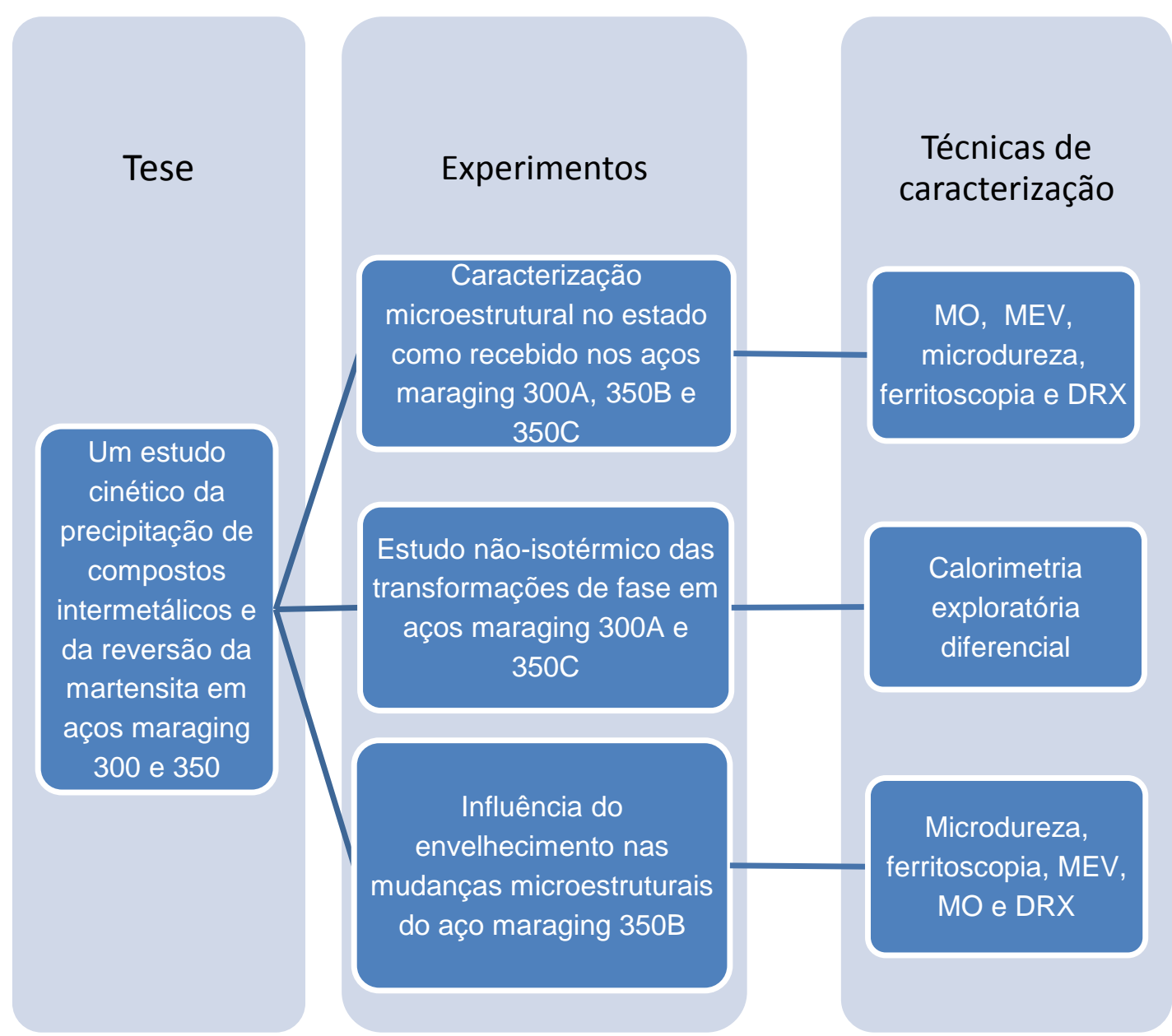

Figura 50: Organograma dos experimentos realizados e das técnicas utilizadas na tese.

A figura 50 ilustra as técnicas escolhidas para analisar diversos fenômenos nos aços maraging 300 e 350. A microscopia óptica (MO) e a microscopia eletrônica de varredura (MEV) foram usadas para observação da microestrutura de amostras no estado como recebido e envelhecidas entre 440 e $600{ }^{\circ} \mathrm{C}$; a microdureza foi empregada para o estudo da cinética de precipitação e do comportamento da curva de envelhecimento. A difração de raios $X(D R X)$ foi empregada na detecção de austenita; a ferritoscopia usada para verificar a influência do tratamento térmico nas propriedades magnéticas e nas mudanças microestruturais, enquanto a calorimetria exploratória diferencial (DSC) foi utilizada para estudar a cinética não-isotérmica da precipitação de compostos intermetálicos e da reversão da martensita. Os tópicos que se seguem detalham esse conjunto de técnicas empregadas no presente trabalho. 


\subsubsection{Microscopias óptica e eletrônica de varredura}

As amostras para observação, tanto no microscópio óptico quanto no microscópio eletrônico de varredura, foram cortadas e embutidas em baquelite em torno de $170{ }^{\circ} \mathrm{C}$. Posteriormente, foram desbastadas com lixas de carbeto de silício com diferentes granulometrias: 180, 220, 400, 600 e 1200 \#. Em seguida, o polimento mecânico foi feito com pasta de diamante de 3 e $1 \mu \mathrm{m}$.

Os reagentes metalográficos empregados para revelar a microestrutura das amostras são mostrados na tabela 12 .

Tabela 12: Reagentes utilizados nas barras pesquisadas (FAROOQ et al., 1987).

\begin{tabular}{|c|c|c|c|}
\hline Reagente & Composição Química & Tempo de ataque & Finalidade \\
\hline Vilella & $\begin{array}{l}\text { Ácido pícrico }(1 \mathrm{~g})+\mathrm{HCl}(5 \\
\mathrm{ml})+ \text { metanol }(95 \%)\end{array}$ & $\begin{array}{l}3 \text { a } 10 \text { min sob } \\
\text { imersão }\end{array}$ & $\begin{array}{l}\text { Visualizar a microestrutura } \\
\text { martensítica do estado } \\
\text { solubilizado no microscópio } \\
\text { óptico }\end{array}$ \\
\hline Marble & $\begin{array}{l}\mathrm{CuSO}_{4}(10 \mathrm{~g})+\mathrm{HCl}(50 \mathrm{ml}) \\
\text { + água destilada }(50 \mathrm{ml})\end{array}$ & $\begin{array}{l}\text { Cerca de } 20 \\
\text { segundos sob } \\
\text { imersão }\end{array}$ & $\begin{array}{l}\text { Visualizar a austenita revertida } \\
\text { durante o superenvelhecimento } \\
\text { no microscópio óptico e no } \\
\text { MEV }\end{array}$ \\
\hline Nital 2\% & $\mathrm{HNO}_{3}(2 \%)$ em metanol & $\begin{array}{l}20 \text { segundos a } 1 \\
\text { minuto sob imersão }\end{array}$ & $\begin{array}{l}\text { Visualizar a austenita revertida } \\
\text { durante o superenvelhecimento } \\
\text { no MEV }\end{array}$ \\
\hline Nital 4\% & $\mathrm{HNO}_{3}(4 \%)$ em metanol & $\begin{array}{l}3 \text { a } 10 \text { min sob } \\
\text { imersão }\end{array}$ & $\begin{array}{l}\text { Visualizar a microestrutura } \\
\text { martensítica do estado } \\
\text { solubilizado no microscópio } \\
\text { óptico }\end{array}$ \\
\hline
\end{tabular}

A observação da microestrutura das amostras no estado como recebido e tratadas termicamente foi realizada com um microscópio óptico Olympus BX60M, com aumento máximo de 1000X. Utilizou-se também o microscópio eletrônico de varredura (MEV) FEI Quanta 450 FEG, com detectores de elétrons secundários, retroespalhados e espectrômetro EDS de raios X. Ambos equipamentos estão instalados no Departamento de Engenharia Metalúrgica e de Materiais da Escola Politécnica da USP.

No item 3.3.2 é detalhado o procedimento usado para a caracterização de difração de raios $X$. 


\subsubsection{Difração de raios $X$}

O objetivo dos ensaios de difração de raios $X$ foi quantificar a presença de austenita em amostras no estado como recebido e envelhecidas. Os ensaios foram realizados em amostras com as dimensões $1,5 \mathrm{~cm} \times 1,5 \mathrm{~cm} \times 0,3 \mathrm{~cm}$, polidas com pasta de diamante de 3 e $1 \mu \mathrm{m}$ para minimizar o efeito da deformação na transformação de austenita revertida em martensita induzida. As determinações por meio de difração de raios $X$ foram realizadas no Laboratório de Caracterização Tecnológica do Departamento de Engenharia de Minas e de Petróleo da Escola Politécnica da USP.

$\mathrm{Na}$ técnica de difração de raios $X$, a amostra é bombardeada com um feixe incidente monocromático de raios $\mathrm{X}$. A detecção do feixe difratado, resultante da interferência construtiva da interação do raio $X$ com os planos cristalinos, é dada por picos característicos de acordo com a estrutura cristalina do material analisado (CULLITY, 1978). Esses picos satisfazem a lei de Bragg dada por:

$$
n \lambda=2 d_{h k l} \operatorname{sen} \theta(19)
$$

Onde $\lambda$ é o comprimento de onda dos raios $X$; $d_{h k l}$, a distância interplanar dos planos cristalinos; $\theta$, o ângulo formado entre o feixe incidente e o plano cristalino; $\mathrm{n}, \mathrm{a}$ ordem da reflexão.

A determinação dos ângulos em que a difração ocorre permite a determinação dos espaçamentos dos diversos planos cristalinos e, portanto, da estrutura cristalina das fases presentes no sólido. A comparação dos valores de $d_{\mathrm{hkl}}$ com os valores tabulados para diversas substâncias pode ser usada para identificar as fases presentes na amostra.

Os cálculos da intensidade integrada dos picos de difração também foram utilizados para estimar a fração volumétrica de fases presentes nos materiais (CULLITY, 1978). Nessa tese, foi aplicado o mesmo método usado por Pardal et al. (2006) para determinar a fração volumétrica para um aço maraging 300 , considerando apenas por simplicidade fatores de espalhamento e composições químicas iguais nas fases. A fração volumétrica foi obtida a partir da média dos valores estimados por meio dos picos $\alpha^{\prime}(200), \alpha^{\prime}(211), \alpha^{\prime}(220), y(200), y(220)$, $\gamma(311)$ e $\gamma(222)$. Além do método de intensidade integrada, o método de Rietveld foi 
usado para estimar a fração volumétrica da austenita e os parâmetros de rede da austenita e da martensita para amostras superenvelhecidas. Esse método baseia-se no ajuste dos difratogramas do padrão simulado de difração em relação ao padrão experimental, o que é feito por meio do método de mínimos quadrados (LOPES, 2011). Esse ajuste foi realizado mediante o uso do software GSAS.

A varredura foi efetuada com passo de $0,02^{\circ}$ no intervalo de $2 \theta$ entre 40 e $100^{\circ}$. Tal intervalo foi estimado por comparação com as fichas JCPDS da austenita e ferrita (mesma estrutura cristalina da martensita), possibilitando a detecção de diversos picos da austenita e da martensita. Ademais, as amostras foram submetidas à rotação (spinner) durante o ensaio para uma melhor estatística dos grãos por medida no difratograma de raios $X$, sendo a radiação empregada na análise de CuKa com $\lambda=1,5405 \AA$. A partir de tais considerações, foram obtidos os difratogramas de amostras no estado como recebido e das amostras superenvelhecidas entre 520 e $600{ }^{\circ} \mathrm{C}$. Os picos do difratograma de raios $\mathrm{X}$ foram usados tanto na estimativa da fração volumétrica quanto na determinação do parâmetro de rede da martensita e da austenita.

\subsubsection{Microdureza}

As medidas de microdureza têm sido usadas tanto para a avaliação da cinética de precipitação de amostras envelhecidas quanto para o estudo das mudanças de mecanismo de endurecimento durante o envelhecimento em aços maraging (GUO, SHA, 2002; PARDAL et al., 2006; SHA, 2000; WILSON, 1996; VISWANATHAN, DEY, ASUNDI,1993a; FLOREEN, DECKER, 1962; SINHA et al., 1998). Além disso, essas medidas também permitem inferir a influência do tratamento térmico nas mudanças no limite de escoamento, uma vez que a relação entre o valor de microdureza e o limite de escoamento em aços é dada aproximadamente por (SOUZA, 1982):

$$
H V \approx 3 . \sigma_{e}(20)
$$


Em que HV é o valor de microdureza Vickers em $\mathrm{kgf} / \mathrm{mm}^{2}$ e $\sigma_{e}$ é o limite de escoamento em MPa.

Neste trabalho foi adotada a dureza Vickers com carga de $1 \mathrm{kgf}$, com marcas de impressão adequadas para a leitura de microdureza dos estados solubilizado (300 a $400 \mathrm{kgf} / \mathrm{mm}^{2}$ ) e no pico de dureza do estado envelhecido (650 a 750 $\mathrm{kgf} / \mathrm{mm}^{2}$ ). Todas as amostras foram submetidas ao polimento mecânico mínimo em pasta de diamante de $3 \mu \mathrm{m}$, visando remover a camada superficial encruada após o processo de lixamento. O número de medidas foi fixado em 15 para cada amostra e com tempo de aplicação de carga de $20 \mathrm{~s}$. O valor da dureza Vickers é dado pela seguinte expressão (PADILHA, AMBROZIO FILHO, 1985; SOUZA, 1982):

$$
H V=\frac{1,8544 \cdot L}{d^{2}}
$$

Onde $\mathrm{L}$ é a carga aplicada e $\mathrm{d}$ a média das diagonais da impressão. As medidas de microdureza das amostras nos estados como recebido e envelhecido foram realizadas em um microdurômetro da marca Zwick, instalado no Departamento de Engenharia Metalúrgica e de Materiais.

\subsubsection{Ferritoscopia}

O ferritoscópio é um instrumento muito usado para avaliar a proporção de fases ferromagnéticas, especialmente em aços inoxidáveis austeníticos, duplex e superduplex (MARTORANO; TAVARES; PADILHA, 2012; MARÉCHAL, 2011; AGUIAR, 2013). Esse instrumento permite, por exemplo, determinar a quantidade de ferrita delta em aços inoxidáveis austeníticos (MARTORANO; TAVARES; PADILHA, 2012). Além da medição da presença da ferrita delta em aços inoxidáveis austeníticos, o uso de medidas ferromagnéticas possibilita também acompanhar a transformação da austenita y (paramagnética) para a martensita a' (ferromagnética), por meio de processos de conformação (MARÉCHAL, 2011; AGUIAR, 2013). Neste trabalho, essa técnica será usada para observar o efeito do tratamento de envelhecimento na cinética de reversão da martensita.

O princípio de funcionamento do ferritoscópio é descrito pela figura 51. 


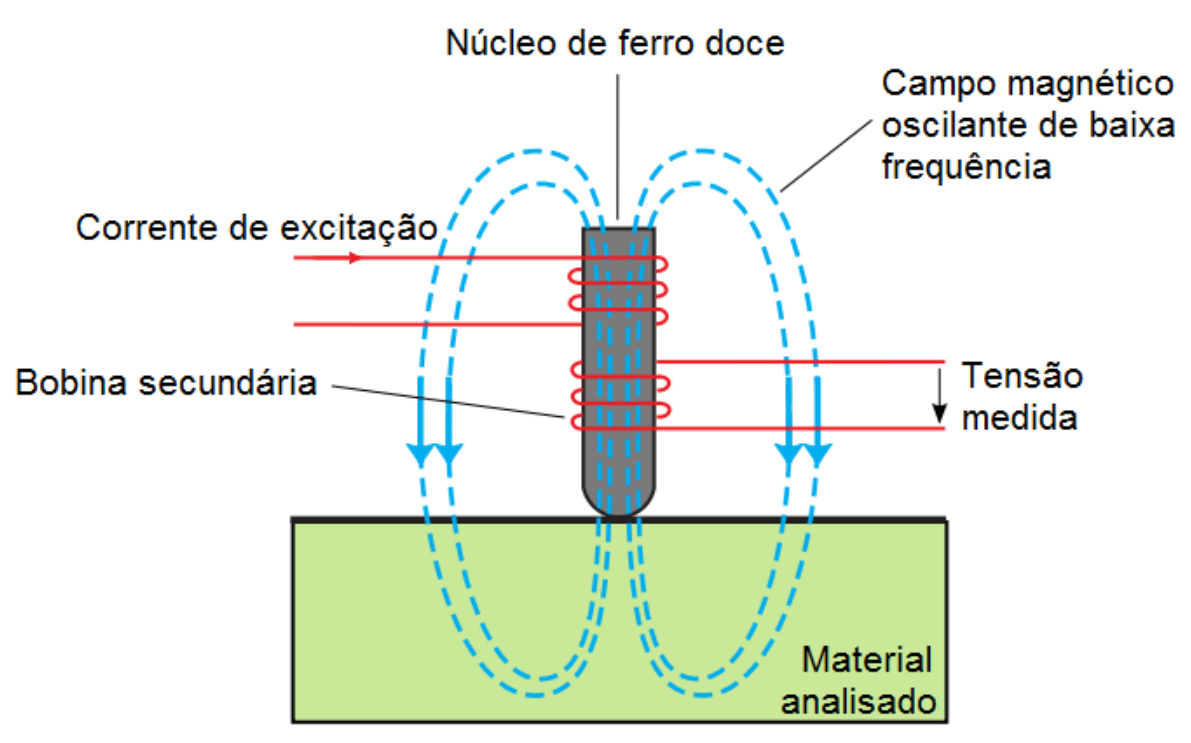

Figura 51: Desenho esquemático da medida de indução magnética realizada por um ferritoscópio (MARÉCHAL, 2011).

A figura 51 ilustra a geração de um campo magnético oscilante de baixa frequência por uma corrente de excitação da bobina primária, que circunda o núcleo de ferro doce da sonda. A bobina secundária tem uma corrente induzida devido ao campo magnético gerado pela bobina primária. Quando a sonda é colocada em contato com a amostra ferromagnética, o campo magnético é alterado, o que leva à mudança no valor da corrente induzida na bobina secundária (MARÉCHAL, 2011; AGUIAR, 2013).

Em geral, o valor da tensão medida na bobina secundária é proporcional à proporção de fases ferromagnéticas na amostra. A estimativa de fração volumétrica de fases ferromagnéticas em uma amostra depende da utilização de padrões e da obtenção de uma curva de calibração da medida obtida como função de valores de fração volumétrica, mensurados a partir de outras técnicas, como a difração de raios $X$. Essa calibração é essencial, uma vez que mudanças de composição química podem alterar os valores de permeabilidade magnética da amostra (MARÉCHAL, 2011; AGUIAR, 2013).

Neste trabalho foram realizadas medidas ferromagnéticas em amostras do aço maraging $350 \mathrm{~B}$ envelhecidas entre 480 e $600^{\circ} \mathrm{C}$, para os tempos de tratamento térmico já descritos na seção 3.2. Cada amostra foi medida 10 vezes com a sonda do ferritoscópio. O instrumento usado neste trabalho foi um ferritoscópio portátil da marca Helmut Fischer modelo MP 3B. 


\subsubsection{Calorimetria exploratória diferencial}

A calorimetria exploratória diferencial (DSC) é uma técnica tradicionalmente usada para o estudo da cinética de transformações de fase. Ela permite a obtenção de parâmetros cinéticos como as temperaturas de transformação, a energia de ativação aparente e as frações transformadas. Tais parâmetros podem ser comparados com os modelos previstos, a partir dos quais são inferidos possíveis mecanismos das transformações.

Por exemplo, um estudo cinético realizado por Guo e Sha (2004) possibilitou a detecção da precipitação de compostos intermetálicos e da reversão da martensita em um aço maraging 250 e, por consequência, a obtenção das temperaturas de início e de fim de transformação, a energia de ativação aparente e a fração transformada das transformações mencionadas.

A DSC é uma técnica na qual é medida uma variação de entalpia entre uma amostra a ser estudada e outra amostra de referência durante o aquecimento e/ou resfriamento. Elas são submetidas a ciclos térmicos controlados por um programa pré-definido. Na DSC com fluxo de calor, a amostra de referência e a amostra a ser analisada são colocadas em seus respectivos suportes de amostra. Estas, por sua vez, são fixadas em um disco de platina com boa condução térmica. O fluxo de calor principal da câmara térmica para as amostras ocorre por meio do disco mencionado. Durante o experimento, as temperaturas dos materiais de referência e das amostras a serem testadas são medidas simultaneamente. Caso uma diferença de temperatura seja detectada entre a amostra analisada e a amostra de referência, o fluxo de calor gerado pela transformação de fase pode ser estimado (BERNAL et al.; 2002, GUO; SHA, 2004).

Neste trabalho, as amostras foram primeiramente cortadas com as dimensões $3,5 \mathrm{~mm} \times 3,5 \mathrm{~mm} \times 1,0 \mathrm{~mm}$ - as mesmas do trabalho elaborado por Guo e Sha (2004) para um aço maraging 250. Esses cortes foram realizados em uma cortadeira de precisão Accutom 50 da Struers, através de um disco de carboneto de silício com espessura de $0,5 \mathrm{~mm}$, cujo avanço de corte foi de $0,020 \mathrm{~mm} / \mathrm{s}$.

O equipamento Netzsch STA F3 Jupiter teve a sua sensitividade calibrada usando amostras padrão de In, $\mathrm{Zn}, \mathrm{Al}, \mathrm{Ag}$ e Au antes do início das medidas para as 
amostras de aço maraging $300 \mathrm{~A}$ e $350 \mathrm{C}$. Todos os experimentos foram realizados com o fluxo de hélio após a aplicação do vácuo para evitar a oxidação das amostras.

Essas amostras de aços maraging 300A e 350C foram aquecidas de 20 até $900{ }^{\circ} \mathrm{C}$ usando as taxas de aquecimento de $10,20,30,40$ e $50{ }^{\circ} \mathrm{C} / \mathrm{min}$ e, posteriormente, resfriadas até a temperatura ambiente. Esses ensaios foram duplicados para assegurar a reprodutibilidade dos experimentos. Os dados relativos aos experimentos foram armazenados e analisados no item $\underline{4.2}$. 


\section{RESULTADOS E DISCUSSÃO}

Os resultados obtidos nessa tese foram agrupados e serão apresentados e discutidos em três seções principais: a caracterização microestrutural no estado como recebido dos aços maraging 300A, 350B e 350C (4.1); a análise cinética da precipitação de compostos intermetálicos e da reversão da martensita nos aços maraging 300A e 350C por meio do uso do DSC (4.2) e, por fim, a análise das mudanças microestruturais após o tratamento de envelhecimento para o aço maraging $350 \mathrm{~B}(4.3)$.

\subsection{CARACTERIZAÇÃO MICROESTRUTURAL NO ESTADO COMO RECEBIDO}

A caracterização da microestrutura no estado como recebido nos aços maraging 300A, 350B e 350C envolveu o uso de uma variedade de técnicas experimentais, como a microscopia óptica, difração de raios $X$ e microdureza Vickers.

Nas figuras 52, 53 e 54 são apresentadas as micrografias da microestrutura no estado como recebido dos aços maraging 300A, 350B e 350C, obtidas pelo uso do reagente Villela e do $4 \%$ Nital e observadas por meio do uso do microscópio óptico.
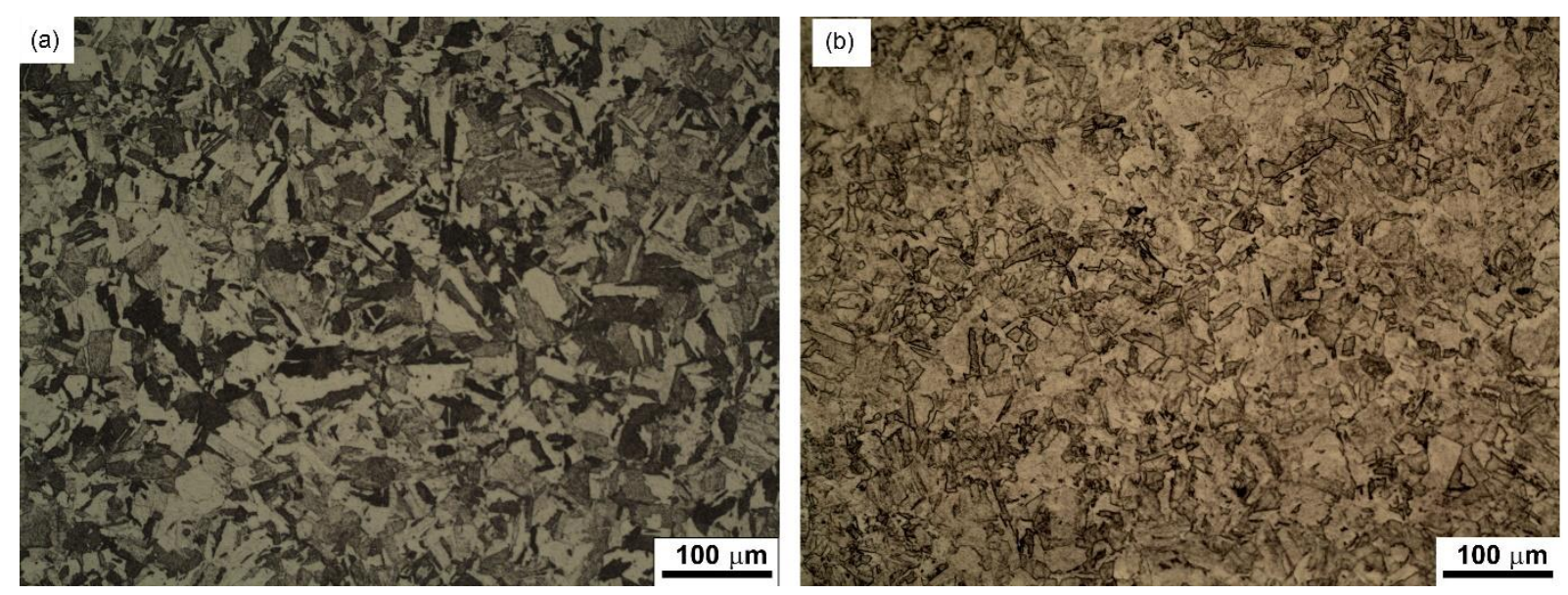

Figura 52: Micrografia obtida com microscopia óptica e revelada pelo uso dos reagentes Vilella (a) e $4 \%$ Nital (b) para o aço maraging 300A no estado como recebido. 

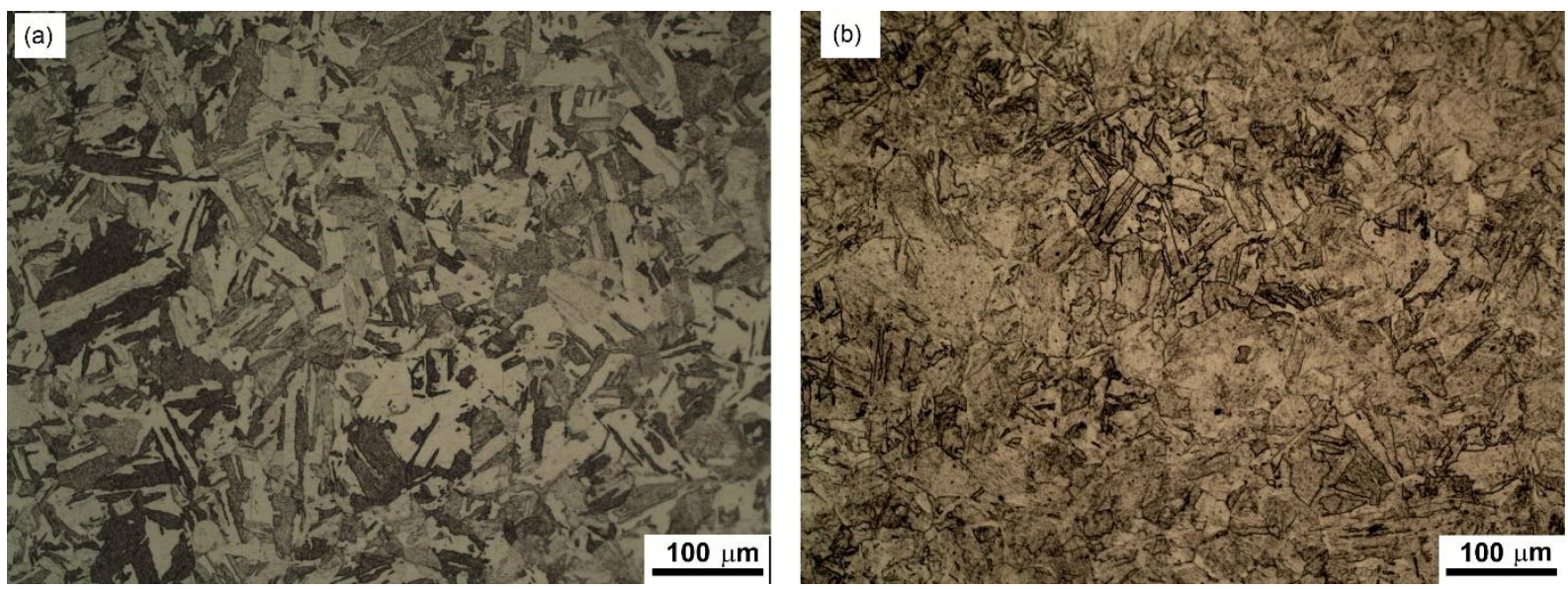

Figura 53: Micrografia obtida com microscopia óptica e revelada pelo uso dos reagentes Vilella (a) e $4 \%$ Nital (b) para o aço maraging 350B no estado como recebido.
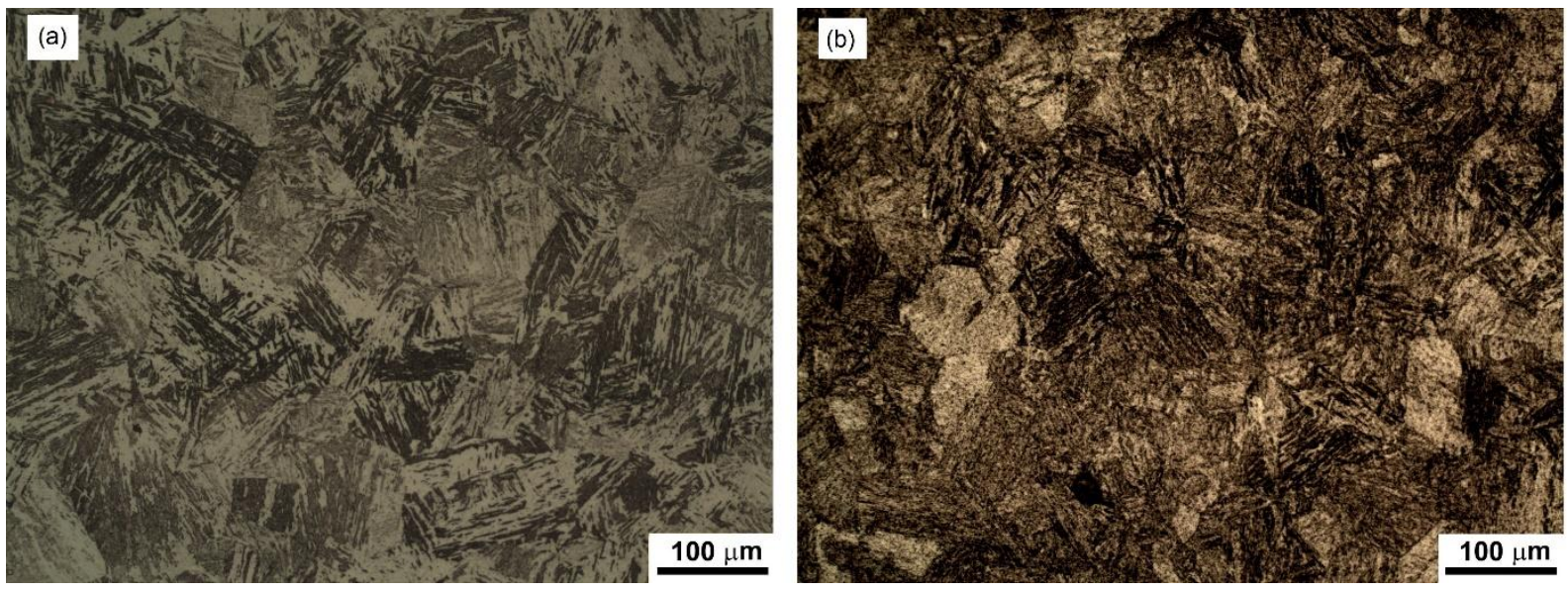

Figura 54: Micrografia obtida com microscopia óptica e revelada pelo uso dos reagentes Vilella (a) e $4 \%$ Nital (b) para o aço maraging $350 \mathrm{C}$ no estado como recebido.

$\mathrm{O}$ ataque químico das amostras dos aços maraging 300A, 350B e 350C, no estado como recebido com os reagentes Villela e $4 \%$ Nital, revelou que a microestrutura é martensítica. O Vilella revelou os blocos e os contornos de pacote da microestrutura martensítica das barras 300A e 350B, mas não revelou as ripas desta microestrutura. Além dos blocos e contornos de pacote, os contornos de grão também foram revelados parcialmente na barra 350B. No caso da barra 350C, o reagente Villela evidenciou somente as ripas e parcialmente os contornos de pacote da estrutura martensítica. Já o reagente $4 \%$ Nital revelou parcialmente os blocos e contornos de pacote da microestrutura martensítica das corridas 300A e 350B, enquanto 0 ataque com $4 \%$ Nital evidenciou a ripas da microestrutura martensítica da corrida $350 \mathrm{C}$. 
$\mathrm{Na}$ figura 55 são apresentados os valores médios da microdureza Vickers para diversas regiões dos discos de aços maraging 300A, 350B e 350C no estado como recebido.

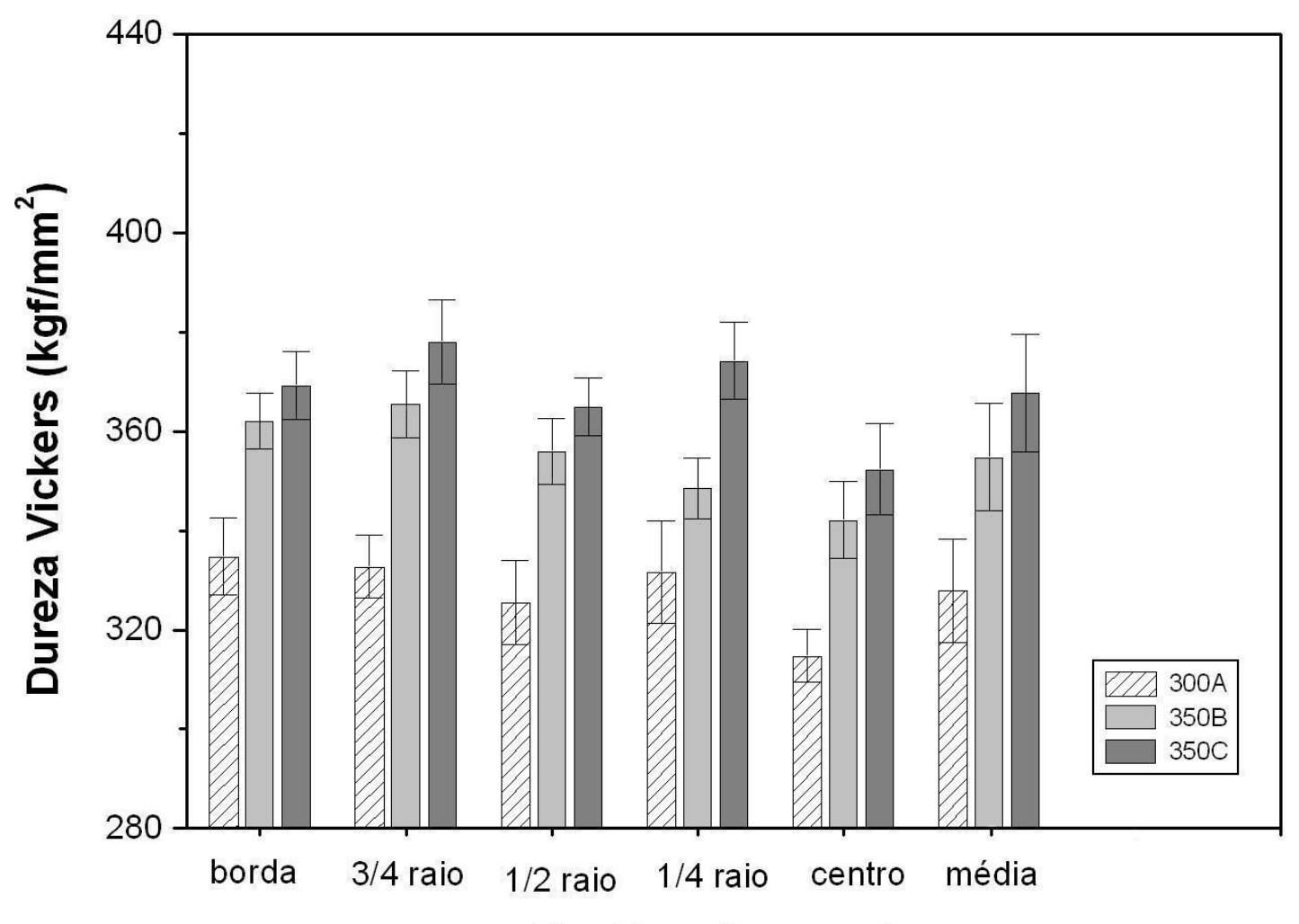

Regiões da amostra

Figura 55: Valores médios das medidas de microdureza, usando carga de $1 \mathrm{kgf}$, para diversas regiões dos discos de aços maraging 300A, 350B e 350C no estado como recebido.

Embora os valores de microdureza Vickers sejam compatíveis entre si em duas barras de erro, a figura 55 mostra que os valores de microdureza do aço maraging 300 são sistematicamente menores em relação àqueles medidos para os aços maraging 350B e 350C, o que pode indicar um discreto endurecimento devido aos maiores teores de cobalto no aço maraging 350.

Além da comparação entre as barras, o gráfico também mostra que as diversas regiões de cada barra apresentam valores compatíveis entre si em uma barra de erro, indicando que há uma homogeneidade dos valores de microdureza em cada barra.

$\mathrm{Na}$ figura 56, são apresentados os difratogramas de raios $X$ de amostras dos aços maraging 300A, 350B e 350C no estado como recebido. 


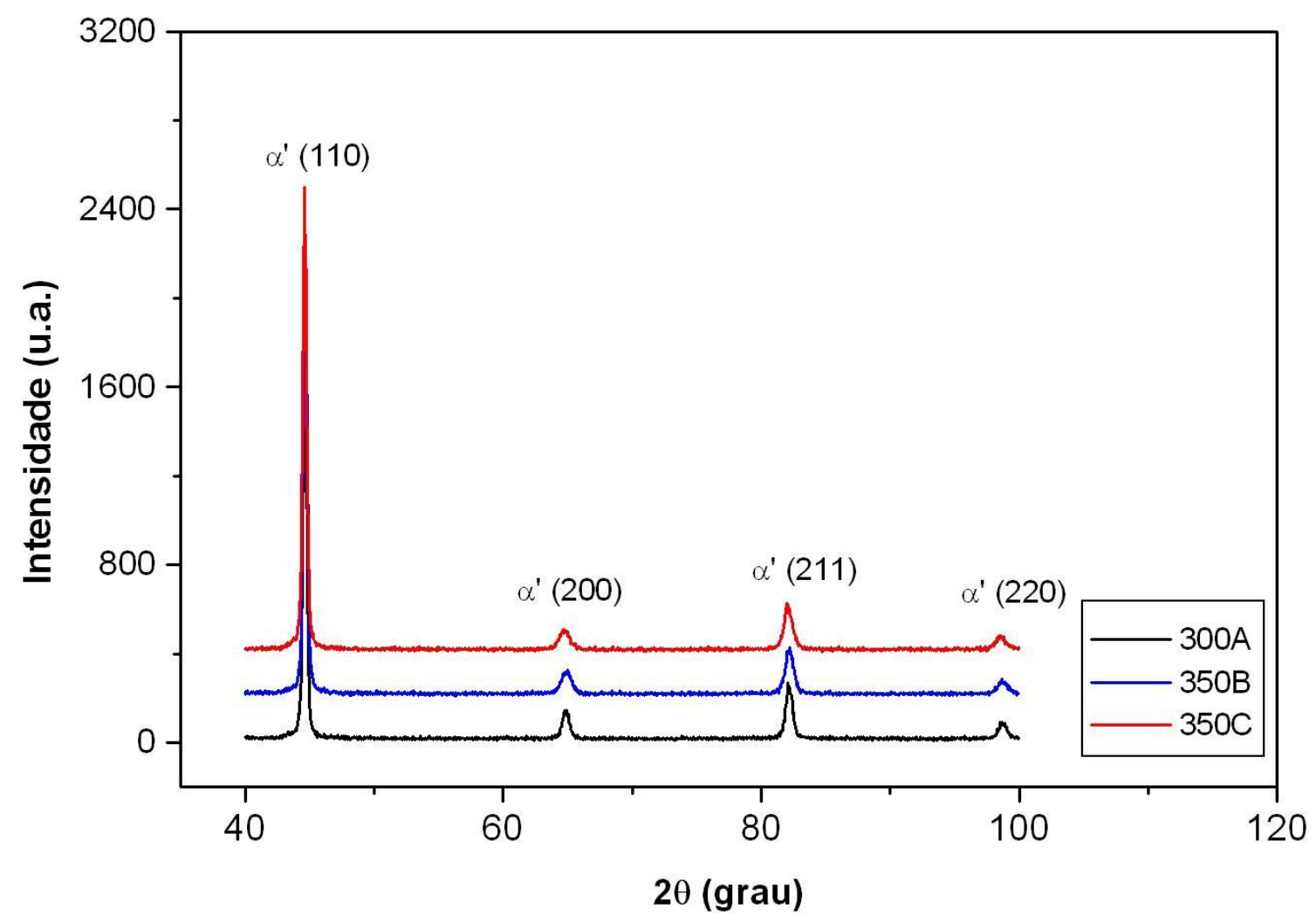

Figura 56: Difratograma de raios $X$ das barras pesquisadas no estado como recebido usando radiação CuKa.

$\mathrm{Na}$ figura 56 , os difratogramas de raios $\mathrm{X}$ mostram que os aços maraging pesquisados têm uma estrutura totalmente martensítica ou uma proporção de austenita retida muito baixa no estado como recebido. Com base nos difratogramas apresentados, os picos de intensidade foram identificados e, posteriormente, o valor do espaçamento interplanar foi estimado por meio da Lei de Bragg (CULLITY, 1978). Nas tabelas 13, 14 e 15 são apresentadas as grandezas que foram utilizadas para a estimativa do parâmetro de rede da martensita para os aços maraging pesquisados.

Tabela 13: Cálculos para a estimativa do parâmetro de rede do aço maraging 300A no estado como recebido.

\begin{tabular}{cccccc}
\hline $\begin{array}{c}\text { Plano } \\
\text { (hkl) }\end{array}$ & $2 \theta$ (graus) & $d_{\text {hkl }}(\AA)$ & $a(\AA)$ & $\operatorname{Cos}^{2} \theta$ & Intensidade $(\%)$ \\
\hline 110 & $44,61 \pm 0,01$ & $2,0295 \pm 0,0003$ & $2,8701 \pm 0,0005$ & $0,8559 \pm 0,0027$ & 100 \\
200 & $64,91 \pm 0,01$ & $1,43542 \pm 0,0003$ & $2,8708 \pm 0,0005$ & $0,712 \pm 0,005$ & 6,8 \\
211 & $82,11 \pm 0,01$ & $1,17279 \pm 0,0003$ & $2,8727 \pm 0,0005$ & $0,569 \pm 0,007$ & 11,8 \\
220 & $98,64 \pm 0,01$ & $1,0157 \pm 0,0003$ & $2,8729 \pm 0,0005$ & $0,425 \pm 0,009$ & 4,1 \\
\hline
\end{tabular}


Tabela 14: Cálculos para a estimativa do parâmetro de rede do aço maraging 350B no estado como recebido.

\begin{tabular}{cccccc}
\hline $\begin{array}{c}\text { Plano } \\
\text { (hkl) }\end{array}$ & $2 \theta$ (graus) & $\mathrm{d}_{\text {hkl }}(\AA)$ & $\mathrm{a}(\AA)$ & $\operatorname{Cos}^{2} \theta$ & Intensidade (\%) \\
\hline$(110)$ & $44,68 \pm 0,01$ & $2,0266 \pm 0,0003$ & $2,8659 \pm 0,0005$ & $0,8555 \pm 0,0027$ & 100 \\
$(200)$ & $64,91 \pm 0,01$ & $1,43543 \pm 0,0003$ & $2,8708 \pm 0,0005$ & $0,712 \pm 0,005$ & 7,5 \\
$(211)$ & $82,15 \pm 0,01$ & $1,17239 \pm 0,0003$ & $2,8717 \pm 0,0005$ & $0,568 \pm 0,007$ & 11,7 \\
$(220)$ & $98,62 \pm 0,01$ & $1,01589 \pm 0,0003$ & $2,8733 \pm 0,0005$ & $0,425 \pm 0,009$ & 4,6 \\
\hline
\end{tabular}

Tabela 15: Cálculos para estimativa do parâmetro de rede do aço maraging 350C no estado como recebido.

\begin{tabular}{cccccc}
\hline $\begin{array}{c}\text { Plano } \\
\text { (hkl) }\end{array}$ & $2 \theta$ (graus) & $d_{\text {hkl }}(\AA)$ & $a(\AA ̊)$ & $\operatorname{Cos}^{2} \theta$ & Intensidade (\%) \\
\hline$(110)$ & $44,59 \pm 0,01$ & $2,0302 \pm 0,0003$ & $2,8711 \pm 0,0005$ & $0,8560 \pm 0,0027$ & 100 \\
$(200)$ & $64,72 \pm 0,01$ & $1,43912 \pm 0,0003$ & $2,8782 \pm 0,0005$ & $0,713 \pm 0,005$ & 5,1 \\
$(211)$ & $81,99 \pm 0,01$ & $1,17419 \pm 0,0003$ & $2,8761 \pm 0,0005$ & $0,570 \pm 0,007$ & 10,7 \\
$(220)$ & $98,55 \pm 0,01$ & $1,01641 \pm 0,0003$ & $2,8748 \pm 0,0005$ & $0,426 \pm 0,009$ & 4,0 \\
\hline
\end{tabular}

Uma estimativa do parâmetro de rede da estrutura martensítica pode ser obtida por diferentes métodos. Nesse trabalho, os valores do parâmetro de rede foram determinados pelo último pico do difratograma de raios $X$ e o método de extrapolação usando a função $\cos ^{2} \theta$, conforme mostrado na figura 57 .

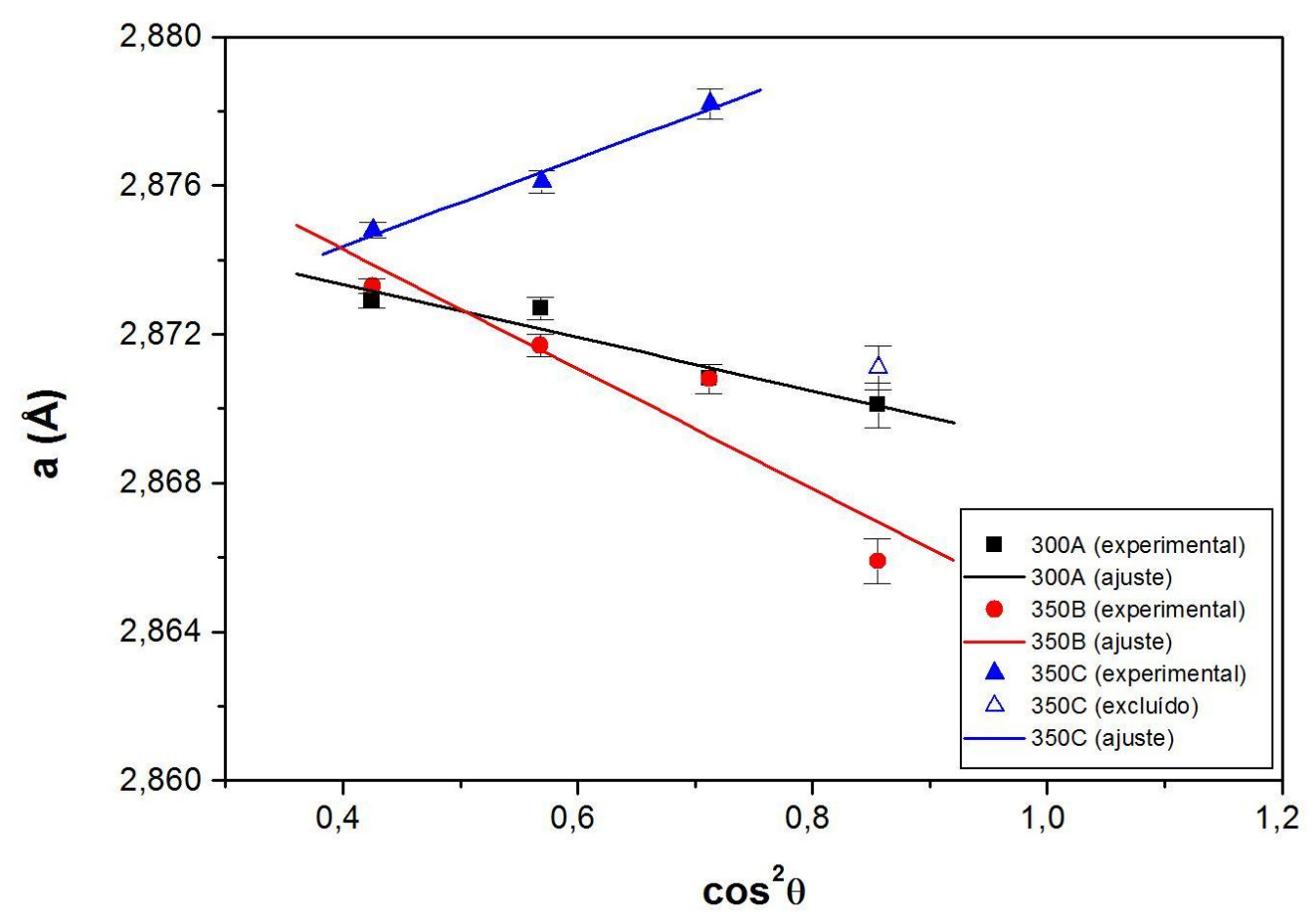

Figura 57: Extrapolação do parâmetro de rede da martensita usando regressão linear como função de $\cos ^{2} \theta$ para os aços maraging pesquisados no estado como recebido. 
Na figura 57, observa-se que o parâmetro de rede como função do $\cos ^{2} \Theta$ segue o comportamento linear para os aços maraging 300A, 350B e 350C. Vale ressaltar que foi excluído um dos pontos do ajuste linear para a barra 350C. Já na figura 58 são apresentados os valores dos parâmetros de rede estimados pelo método de extrapolação e pelo último pico do difratograma de raios $\mathrm{X}$, comparando com os valores obtidos por estudos anteriores (BALL,1984; HABIBY et. al.,1996).

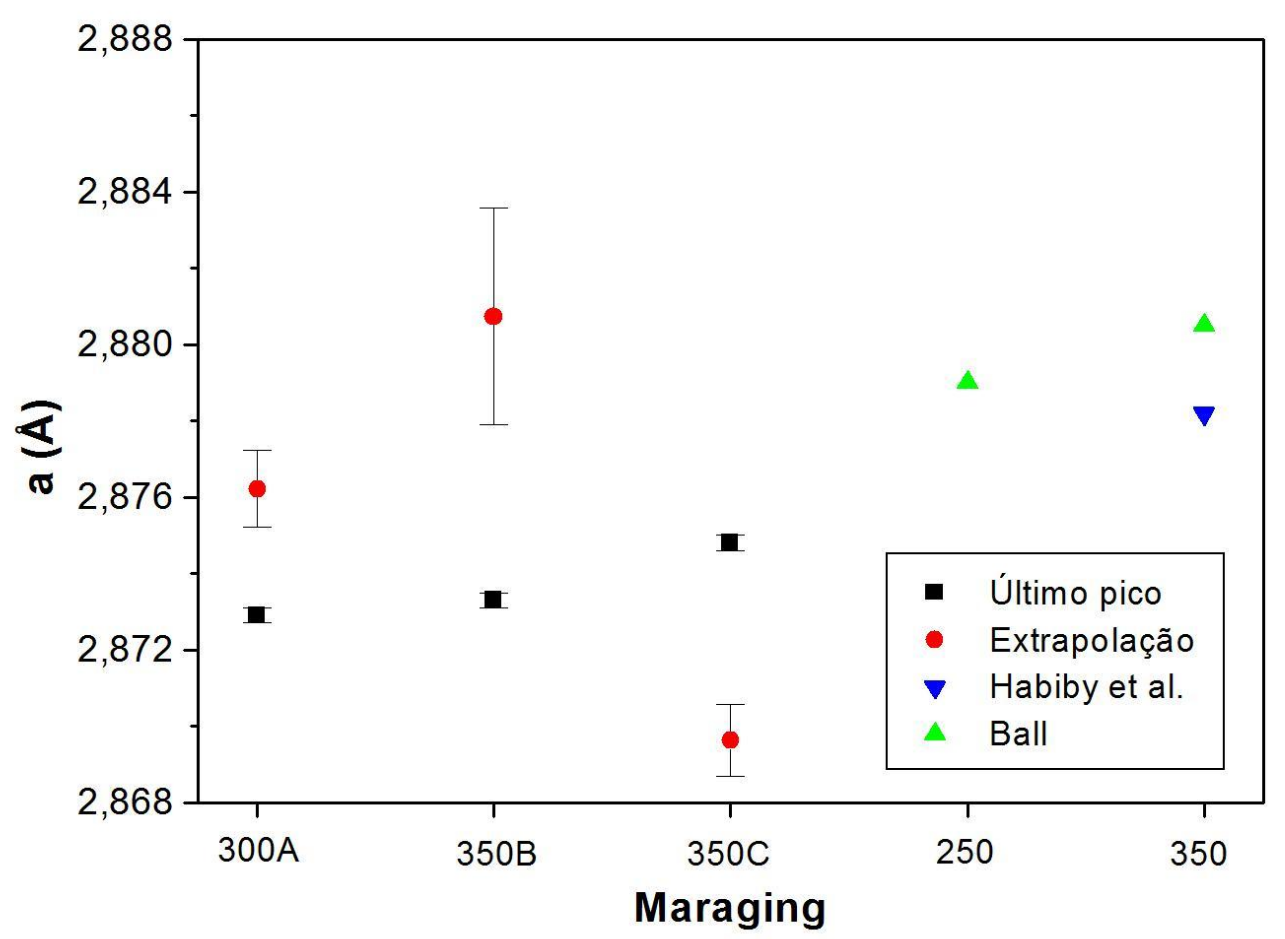

Figura 58: Comparação dos valores do parâmetro de rede estimados com os valores de Habiby e de Ball (BALL,1984; HABIBY et. al.,1996).

Se de um lado, os valores dos parâmetros de rede estimados pelo método de extrapolação estão compatíveis entre si em três barras de erro, nos materiais pesquisados devido ao grande erro desse método; por outro lado, os valores estimados pelo último pico indicam que maiores teores de cobalto e de molibdênio influenciam no parâmetro de rede da microestrutura martensítica das séries $300 \mathrm{e}$ 350 , no estado como recebido. Além disso, os valores obtidos estão mais próximos do estimado por Habiby et al. (1996) para um aço maraging 350, enquanto os valores de Ball estão mais distantes. Contudo, os valores estimados por Ball também sugerem que os parâmetros de rede do maraging 250 e 350 são ligeiramente diferentes, indicando que a composição química influencia nessa grandeza (BALL,1984; HABIBY et. al.,1996). 


\subsection{ANÁLISE CINÉTICA DA PRECIPITAÇÃO DE COMPOSTOS INTERMETÁLICOS E DA REVERSÃO DA MARTENSITA NOS AÇOS MARAGING 300A E 350C COM O DSC}

Os resultados dos experimentos do DSC foram subdivididos em duas partes. A primeira é referente à obtenção das temperaturas de transformação durante o aquecimento e de diagramas $\mathrm{CHT}$ para os aços maraging 300A e 350C. A segunda parte consiste na estimativa da energia de ativação usando as temperaturas de máxima taxa de transformação usando o método de Kissinger.

\subsubsection{Temperaturas de transformação e diagramas CHT}

Como mencionado nas seções 2.4 .2 e 3.3.5, o acompanhamento da variação do fluxo de calor com a temperatura em diversas taxas de aquecimento permite analisar a cinética de precipitação e de reversão da martensita em aços maraging. As figuras 59 e 60 apresentam o fluxo de calor ${ }^{7}$ em função da temperatura para diversas taxas de aquecimento em aços maraging 300A e 350C.

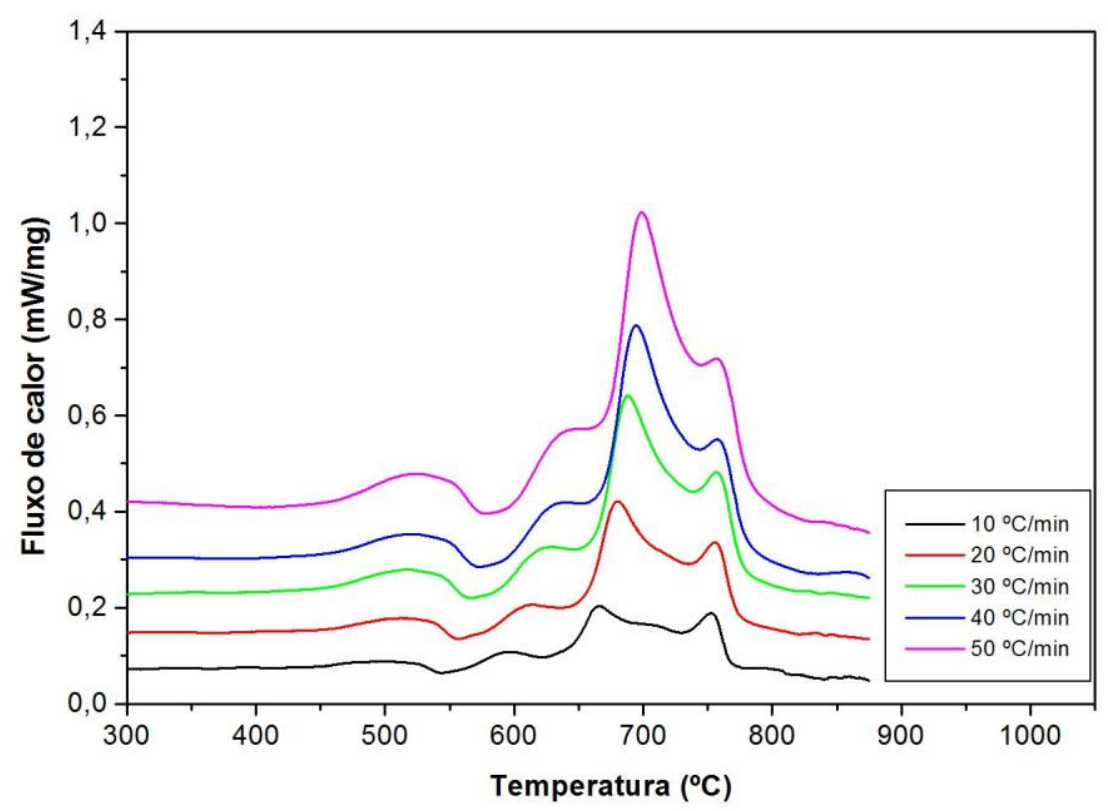

Figura 59: Variação do fluxo de calor em função da temperatura para diversas taxas de aquecimento no aço maraging $300 \mathrm{~A}$.

\footnotetext{
${ }^{7}$ Essa é a nomenclatura mais usada na teoria de análises térmicas é fluxo de calor. Todavia, o termo equivalente em fenômenos de transporte seria taxa de transferência de calor por unidade de massa. Nesse sentido, o fluxo de calor, em análises térmicas, tem um sentido diferente daquele tradicionalmente definido na teoria de fenômenos de transporte.
} 


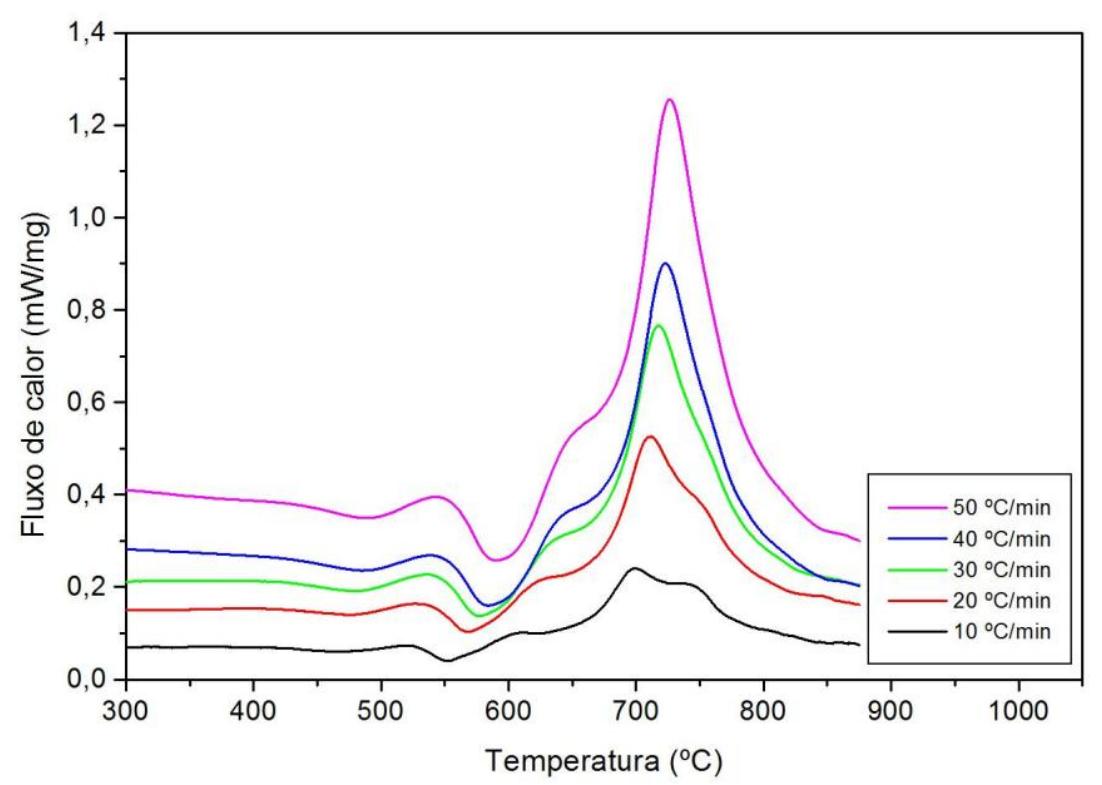

Figura 60: Variação do fluxo de calor em função da temperatura para diversas taxas de aquecimento no aço maraging $350 \mathrm{C}$.

Os dados de fluxo de calor mostrados nas figuras 59 e 60 evidenciam que os aços maraging possuem reações endotérmicas e exotérmicas durante 0 aquecimento, pois há variações do fluxo de calor medido que resulta no aparecimento de picos e vales. Para que as transformações de fase sejam analisadas de forma apropriada é necessário corrigir a linha de base do sinal de DSC. Tal procedimento também foi aplicado na análise de dados feita por Guo e coautores (2004) para um aço maraging 250.

As curvas de DSC dos aços maraging $300 \mathrm{~A}$ e $350 \mathrm{C}$ com a linha da base corrigida são apresentadas nas figuras 61 e 62. 


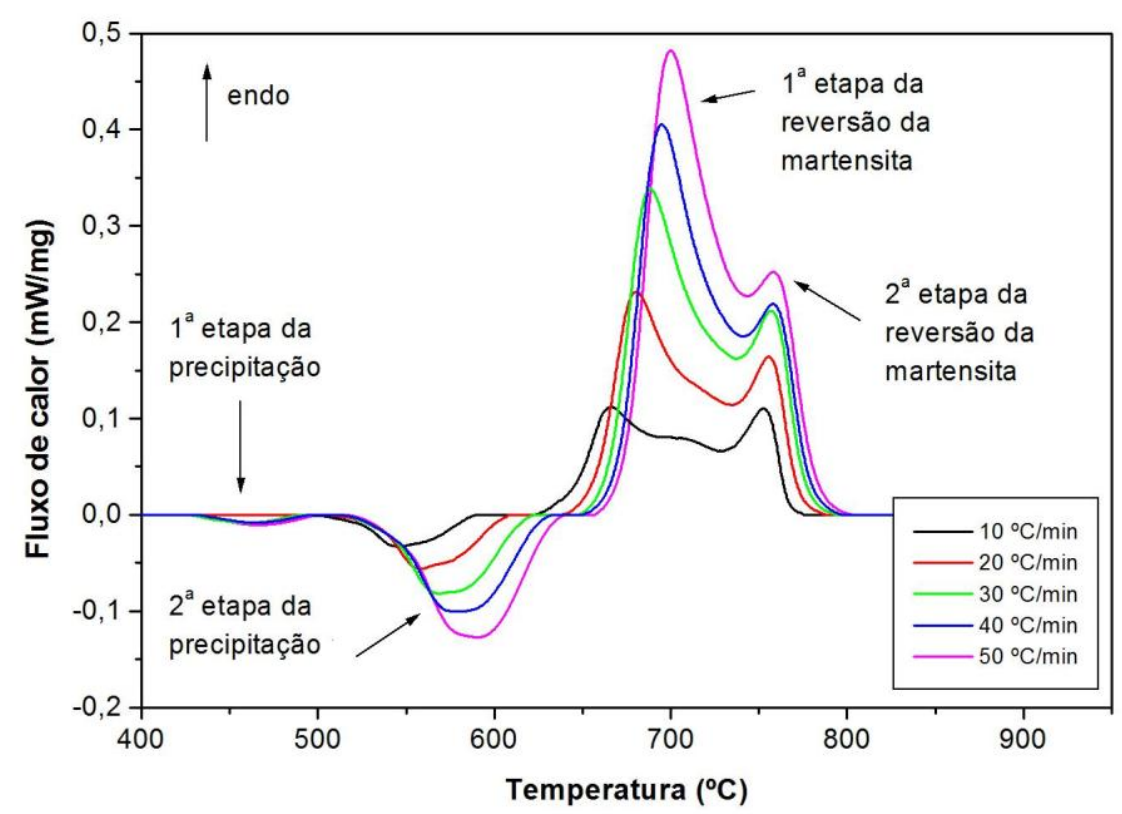

Figura 61: Variação do fluxo de calor corrigida em função da temperatura para diversas taxas de aquecimento no aço maraging $300 \mathrm{~A}$.

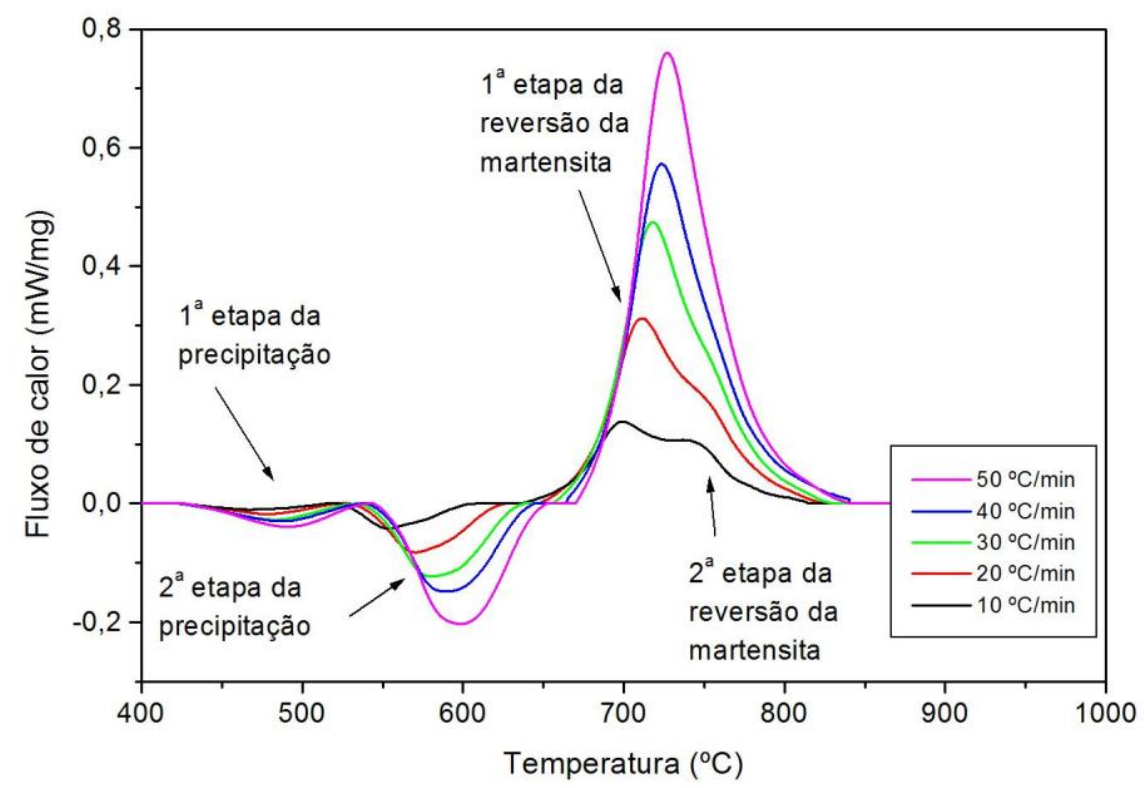

Figura 62: Variação do fluxo de calor corrigida em função da temperatura para diversas taxas de aquecimento no aço maraging 350C.

As figuras 61 e 62 mostram que tanto a precipitação de compostos intermetálicos quanto a reversão da martensita podem ocorrer em duas etapas. Estudos anteriores feitos por Carvalho e coautores (2013) e Kapoor e coautores (2003) mostraram a ocorrência de duas etapas para a reversão da martensita em aços maraging 300 e 350, o que foi atribuído à existência de dois mecanismos de transformação. Esses mecanismos são a reversão da martensita pela difusão de elementos de liga e a reversão da martensita para austenita por mecanismos de 
cisalhamento similares à transformação martensítica, ocorrida durante o resfriamento.

Carvalho e coautores (2013) também observaram em experimentos de dilatometria que a proporção dos elementos de liga nos aços maraging podem influenciar nessa divisão em duas etapas. Aços maraging que contenham maiores teores de cobalto, por exemplo o aço maraging 350 em relação ao aço maraging 300, possuem uma maior tendência de apresentar uma única etapa. Esse mesmo comportamento pode ser observado nas figuras 61 e 62 . O aço maraging 300A tem uma divisão em duas etapas para todas as taxas de aquecimento entre 10 e 50 ${ }^{\circ} \mathrm{C} /$ min, enquanto o aço maraging apresenta esse comportamento apenas para taxas de aquecimento de 10 a $30^{\circ} \mathrm{C} / \mathrm{min}$.

Guo e Sha (2004) também analisaram a ocorrência de transformações de fase durante o aquecimento para um aço maraging 250. Entretanto, eles analisaram a reversão da martensita apenas no intervalo entre 600 e $730^{\circ} \mathrm{C}$, o que não tornou possível a análise da reversão da martensita como um todo. Dessa maneira, o foco da análise deles foi o estudo da cinética de reversão pelo mecanismo de difusão. Carvalho et al. (2013) e Kapoor et al. (2003) observaram que a reversão da martensita pode ocorrer até temperaturas em torno de $800{ }^{\circ} \mathrm{C}$, o que evidencia a consistência dos resultados obtidos com estudos anteriores.

As figuras 61 e 62 mostram também que a reação de precipitação pode ocorrer em duas etapas nos aços maraging 300A e 350C. Estudos anteriores realizados por Kapoor et al. (2003) e Carvalho et al. (2013) não evidenciaram por meio de dilatometria a ocorrência de duas etapas de precipitação em aços maraging 300 e 350; possivelmente, em virtude da precipitação de compostos intermetálicos causar uma pequena distorção de até $0,08 \%$ na amostra, impossibilitando a detecção da precipitação em seus estágios iniciais. Guo e coautores (2004) também não detectaram a separação em dois estágios em experimentos com DSC para o aço maraging 250, o que ocorreu devido à menor concentração de cobalto no aço maraging 250 quando comparado aos aços maraging 300 e 350 .

As figuras 63 e 64 apresentam a influência da taxa de aquecimento nas temperaturas de precipitação e reversão da martensita nos aços maraging $300 \mathrm{~A} \mathrm{e}$ 350C. A figura 63 mostra que a temperatura de início de precipitação do estágio 1 $\left(\mathrm{P}_{\mathrm{S} 1}\right)$ é menor para o aço maraging $350 \mathrm{C}$ do que o aço maraging $300 \mathrm{~A}$ devido ao maior teor de cobalto que diminui a solubilidade do molibdênio (PETERS, 1968; 
CARVALHO, 2012). Já o início da segunda etapa da precipitação ocorre em temperaturas mais baixas para o aço maraging $300 \mathrm{~A}$, em relação àquelas verificadas para o aço maraging 350C. Sha et al. (1993a) observaram em um aço maraging 300 que o molibdênio tem uma difusão mais lenta do que o observado para o titânio. Vale ressaltar que não foi possível obter as temperaturas de transformação para a primeira etapa para o aço maraging 300, para a taxa de aquecimento 10 e $20{ }^{\circ} \mathrm{C} / \mathrm{min}$. A figura 63 mostra também que as temperaturas de transformações aumentam com a taxa de aquecimento devido à natureza difusional da reação de precipitação.

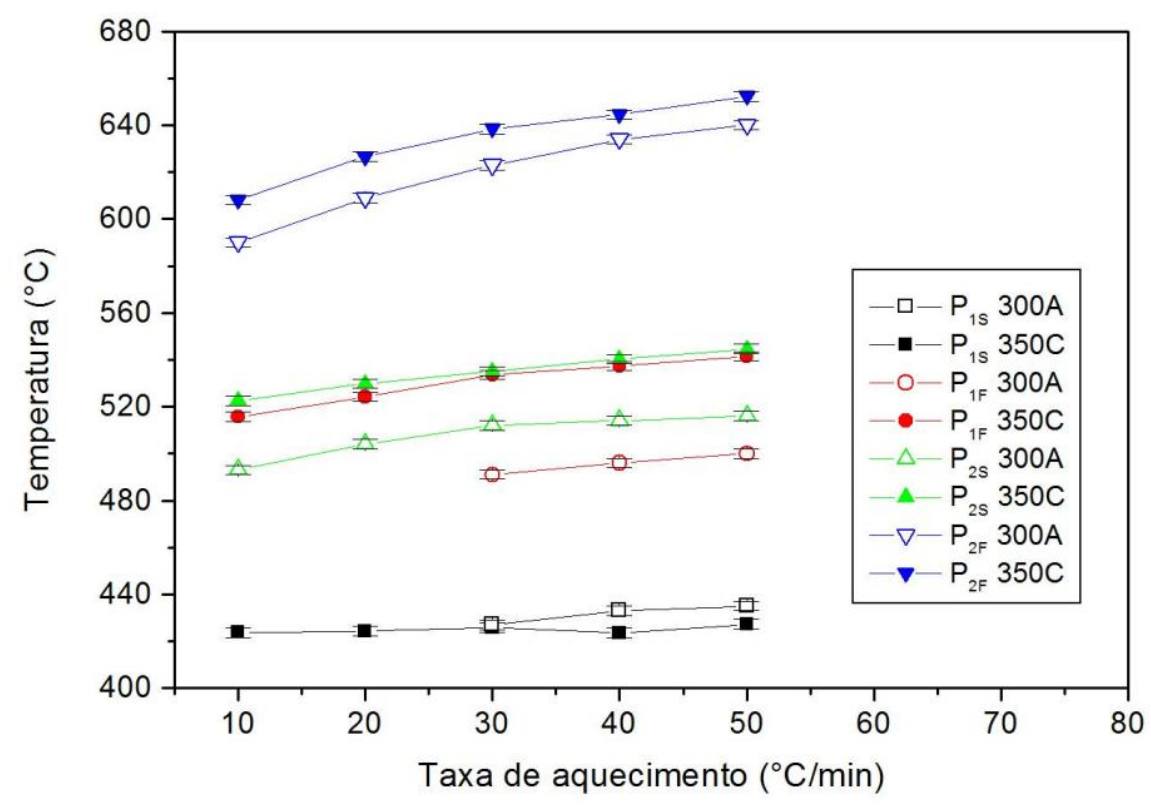

Figura 63: Variação das temperaturas de precipitação para diversas taxas de aquecimento nos aços maraging $300 \mathrm{~A}$ e $350 \mathrm{C}$.

A figura 64 apresenta as temperaturas de início e término da reversão da martensita para os aços maraging 300A e 350C em diversas taxas de aquecimento. 


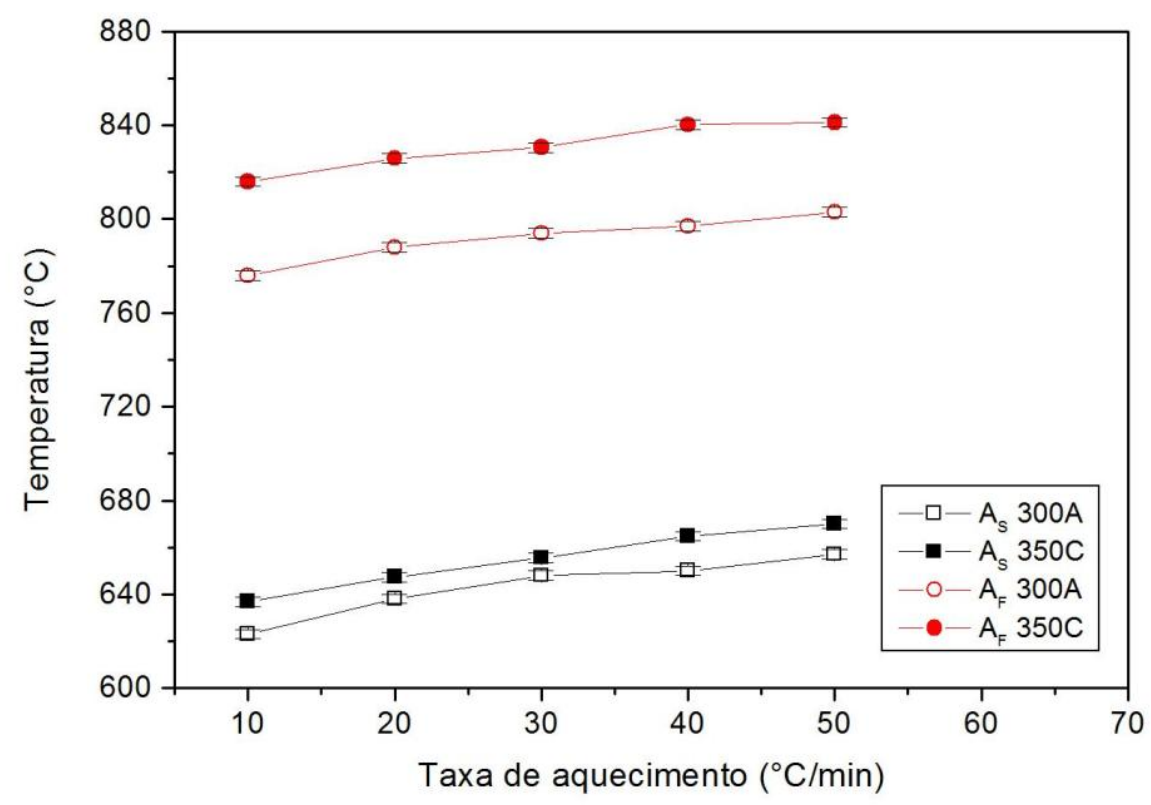

Figura 64: Variação das temperaturas de reversão da martensita para diversas taxas de aquecimento nos aços maraging $300 \mathrm{~A}$ e $350 \mathrm{C}$.

A figura 64 mostra que a temperatura apresenta comportamento crescente com o aumento da taxa de aquecimento. Além disso, a análise comparativa dos aços maraging 300A e 350C são influenciadas pelo teor dos elementos de liga. $\mathrm{O}$ cobalto tem o papel de retardar a reversão da martensita, o que explica as maiores temperaturas de reversão para o aço maraging $350 \mathrm{C}$ em relação ao aço maraging 300A. Peters (1968) observou que maiores teores de cobalto em ligas de aços maraging levam à formação de uma menor fração volumétrica de austenita.

Nas figuras 65 e 66 são apresentados os diagramas CHT dos aços maraging $300 \mathrm{~A}$ e $350 \mathrm{C}$ elaborados com base nas temperaturas de transformações de fase das figuras 63 e 64 . 


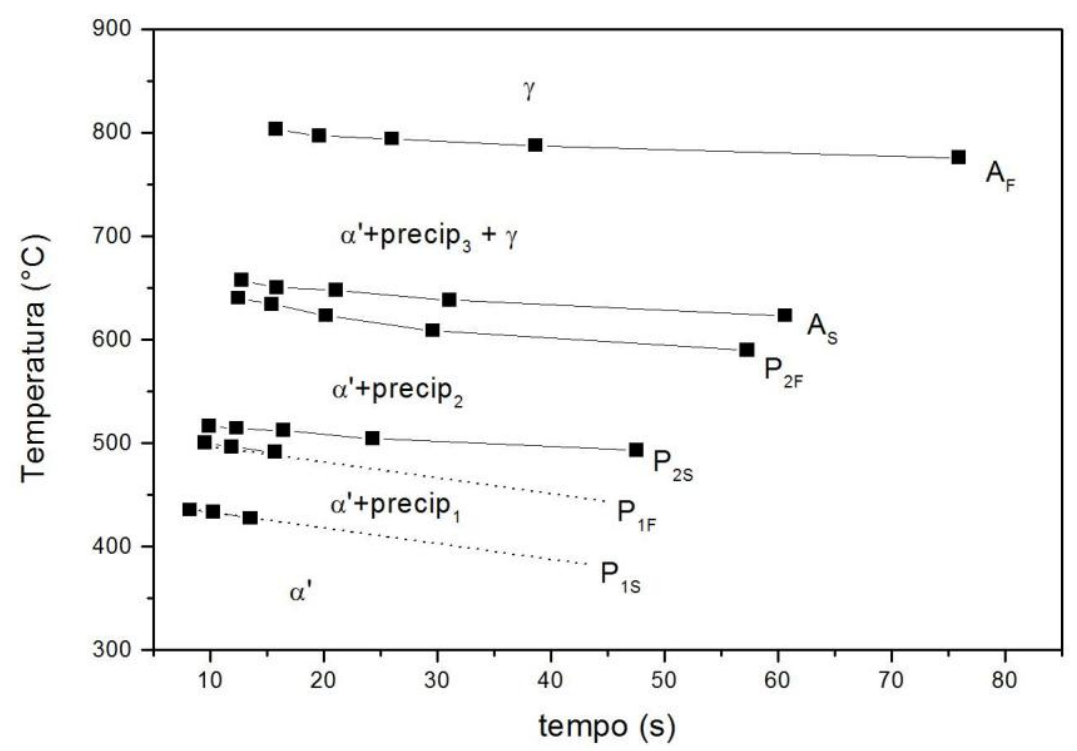

Figura 65: Diagrama CHT das transformações de fase no aço maraging 300A.

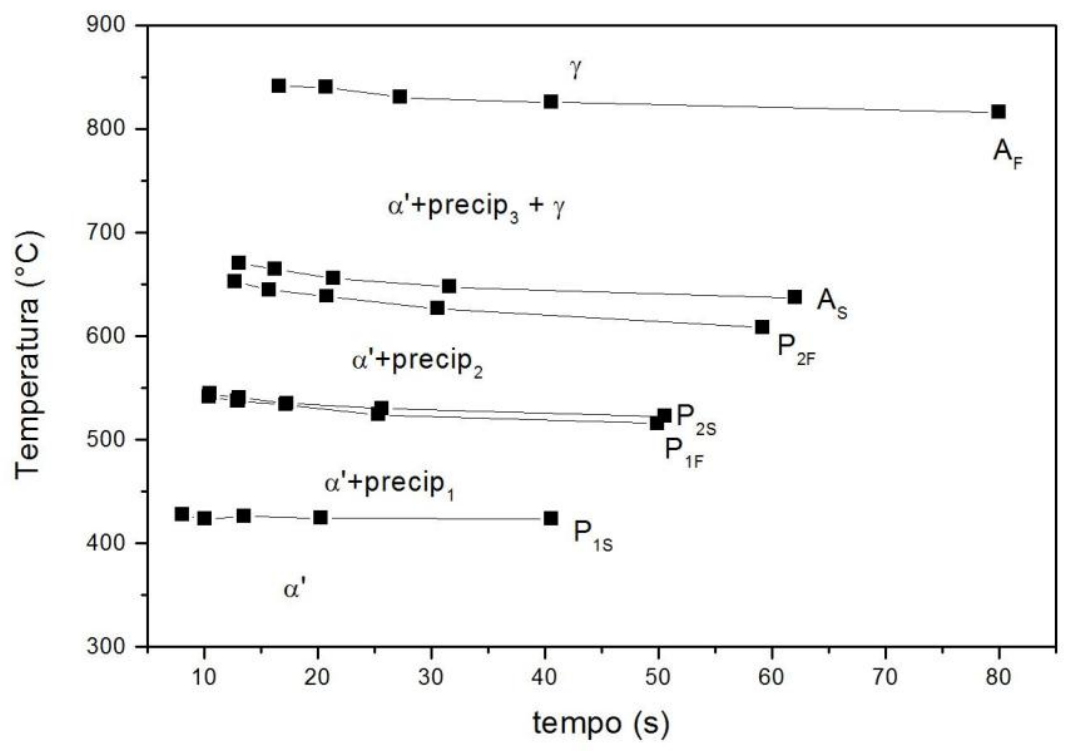

Figura 66: Diagrama CHT das transformações de fase no aço maraging 350C.

As figuras 65 e 66 ilustram como as transformações de fase ocorrem nos aços maraging 300A e 350C. Até a temperatura de $P_{1 s}$, a martensita a' está supersaturada em elementos de liga. Entre as temperaturas $P_{1 s}$ e $P_{1 F}$, há a formação dos primeiros precipitados na microestrutura martensítica. Já no intervalo entre $\mathrm{P}_{2 S}$ e $\mathrm{P}_{2 F}$ ocorre a formação de outros tipos de precipitados, denotado por precip2. Por fim, entre as temperaturas de reversão da martensita $A_{S}$ e $A_{F}$, há a reversão da martensita e formação de outros precipitados em relação àqueles presentes no intervalo $\mathrm{P}_{2 S}$ e $\mathrm{P}_{2 F}$, denotado por precip3. Por fim, antes que a 
martensita seja totalmente transformada em austenita, há a dissolução dos precipitados tipo 3 e, em seguida, a reversão da martensita é completada.

\subsubsection{Análise cinética por meio do método de Kissinger pela máxima taxa de transformação}

As temperaturas de pico das transformações de fase obtidas por meio das máximas taxas de fluxo de calor são apresentadas na tabela 16. Essas temperaturas serão usadas no método de Kissinger para os aços maraging 300A e 350 mais adiante.

Tabela 16: Temperaturas de pico para a precipitação e a reversão da martensita para os aços maraging 300A e 350C em função da taxa de aquecimento. ${ }^{8}$

\begin{tabular}{cccccc}
\hline $\begin{array}{c}\text { Série do aço } \\
\text { maraging }\end{array}$ & $\begin{array}{c}\text { Taxa de aquecimento } \\
\left({ }^{\circ} \mathrm{C} / \mathrm{min}\right)\end{array}$ & $\mathrm{P}_{1 \operatorname{MAX}}\left({ }^{\circ} \mathrm{C}\right)$ & $\mathrm{P}_{2 \operatorname{MAX}}\left({ }^{\circ} \mathrm{C}\right)$ & $\mathrm{A}_{1 \mathrm{MAX}}\left({ }^{\circ} \mathrm{C}\right)$ & $\mathrm{A}_{2 \operatorname{MAX}}\left({ }^{\circ} \mathrm{C}\right)$ \\
\hline $300 \mathrm{~A}$ & 10 & - & 546,0 & 668,0 & 752,6 \\
$300 \mathrm{~A}$ & 20 & - & 559,4 & 680,3 & 755,0 \\
$300 \mathrm{~A}$ & 30 & 459,0 & 569,2 & 687,9 & 756,6 \\
$300 \mathrm{~A}$ & 40 & 464,5 & 579,2 & 694,4 & 757,3 \\
$300 \mathrm{~A}$ & 50 & 467,5 & 590,4 & 699,4 & 757,2 \\
\hline $350 \mathrm{C}$ & 10 & 466,6 & 553,3 & 700,0 & 745,3 \\
$350 \mathrm{C}$ & 20 & 479,7 & 570,9 & 712,1 & 753,1 \\
$350 \mathrm{C}$ & 30 & 481,9 & 580,6 & 718,1 & 760,2 \\
$350 \mathrm{C}$ & 40 & 486,3 & 589,1 & 723,6 & - \\
$350 \mathrm{C}$ & 50 & 489,3 & 599,1 & 727,0 & - \\
\hline
\end{tabular}

A tabela 16 mostra que a taxa de aquecimento tem uma influência nas temperaturas de pico da precipitação de compostos intermetálicos e da reversão da martensita. Guo e Sha (2004) também observaram que as temperaturas de pico dessas transformações de fase aumentam com o incremento da taxa de aquecimento para um aço maraging 250.

\footnotetext{
${ }^{8}$ A temperatura $\mathrm{P}_{1 \mathrm{MAX}}$ não pôde ser determinada devido ao pico de reação exotérmico não ser bem definido para o pico do primeiro estágio da precipitação no aço maraging $300 \mathrm{~A}$ para taxas de aquecimento menores que $30^{\circ} \mathrm{C} / \mathrm{min}$. Já a temperatura $A_{2 \text { MAX }}$ não pôde ser estimada para taxas de aquecimento maiores que $30^{\circ} \mathrm{C} / \mathrm{min}$, pois há uma sobreposição com a primeira etapa da reversão da martensita para o aço maraging $350 \mathrm{C}$.
} 
A partir das temperaturas de pico das transformações foi possível estimar a energia de ativação da precipitação de compostos intermetálicos e da reversão da martensita por meio da equação de Kissinger para os aços maraging 300A e 350.

As figuras 67 e 68 apresentam a variação de $\ln \left(T^{2} / \beta\right)$ em função de $1 / T$ para a obtenção das energias de ativação por meio do método de Kissinger para os aços maraging $300 \mathrm{~A}$ e $350 \mathrm{C}$.

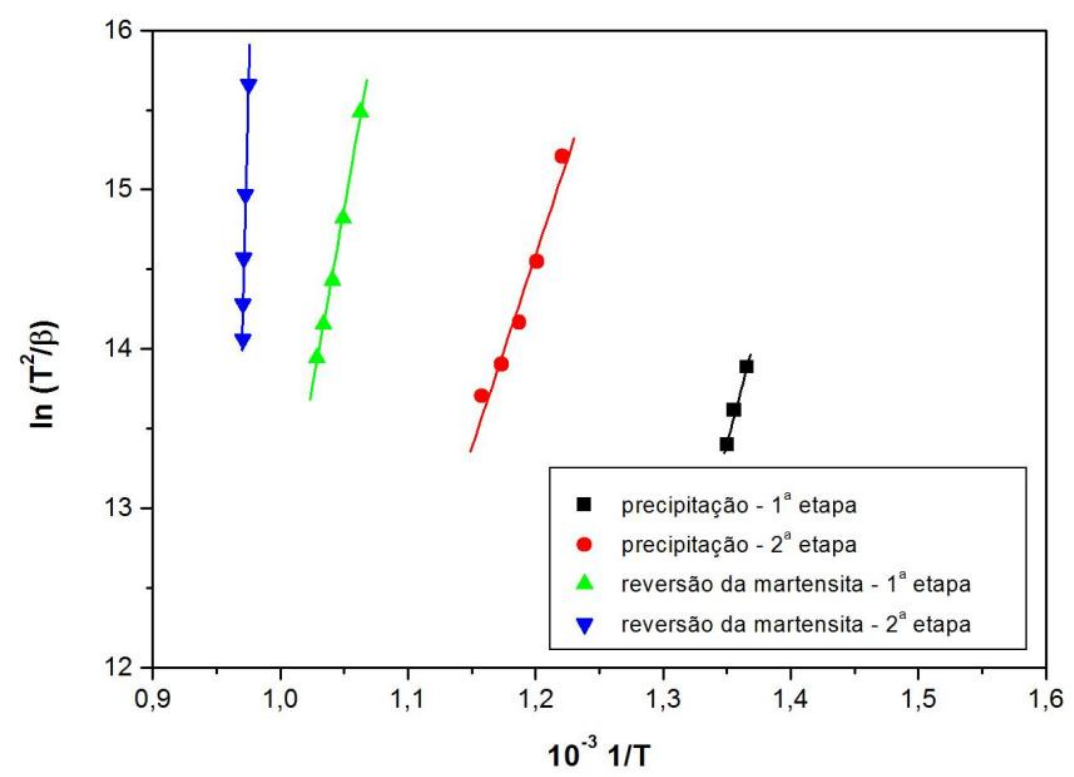

Figura 67: Variação de $\ln \left(T^{2} / \beta\right)$ em função de 1/T para a obtenção das energias de ativação da precipitação de compostos intermetálicos e da reversão da martensita por meio do método de Kissinger para o aço maraging 300A.

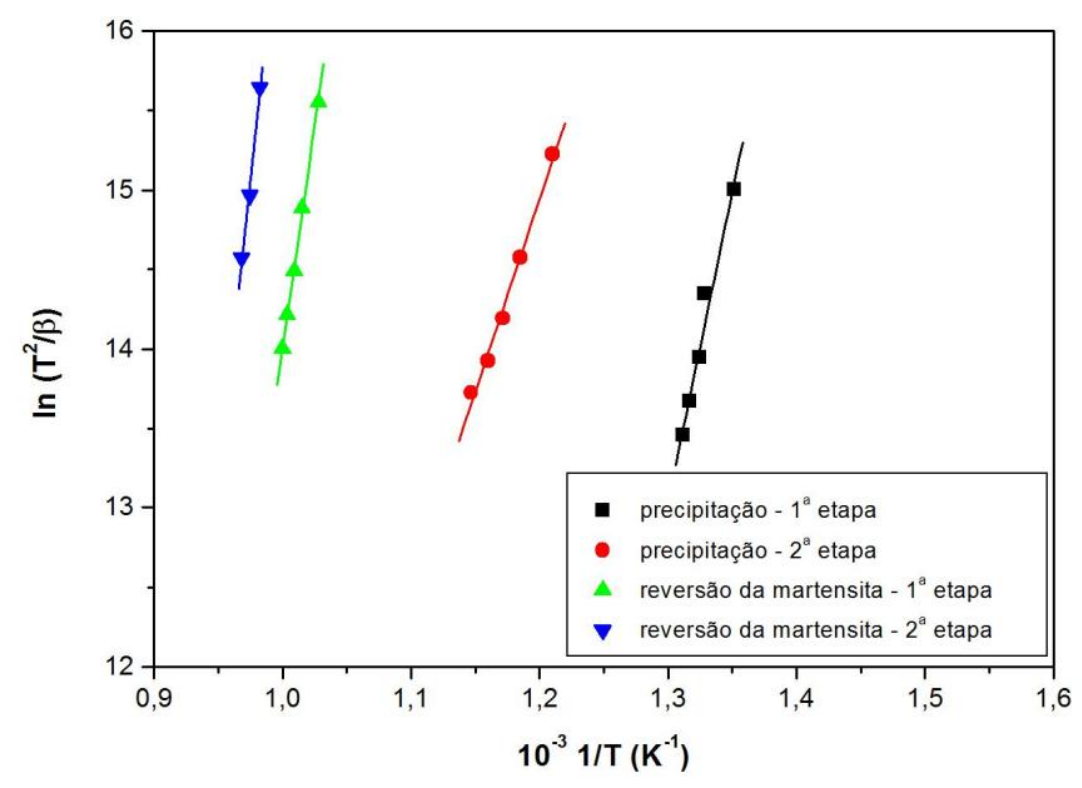

Figura 68: Variação de $\ln \left(T^{2} / \beta\right)$ em função de 1/T para a obtenção das energias de ativação da precipitação de compostos intermetálicos e da reversão da martensita por meio do método de Kissinger para o aço maraging 350C. 
A partir dos valores dos coeficientes angulares obtidos em cada reta foi possível estimar a energia de ativação de cada transformação de fase, como foi discutido na seção 2.4.2.2. Os valores obtidos foram comparados com os estimados por outros autores em trabalhos anteriores, conforme mostrado na tabela 17.

Tabela 17: Valores da energia de ativação obtidos para a reação de precipitação $E_{p}$ por meio da análise de Kissinger os aços maraging 300A e 350C em comparação com os estudos anteriores.

\begin{tabular}{|c|c|c|c|c|c|}
\hline Referência & $\begin{array}{c}\text { Série do aço } \\
\text { maraging }\end{array}$ & $\mathrm{E}_{\mathrm{p}}(\mathrm{kJ} / \mathrm{mol})$ & $\begin{array}{c}\text { Taxa de } \\
\text { aquecimento }\end{array}$ & $\mathrm{R}$ & $\begin{array}{l}\text { Técnica } \\
\text { usada }\end{array}$ \\
\hline Guo e Sha (2004) & 250 & 205,1 & 10 a $50 \mathrm{C} \% \mathrm{~min}$ & 0,993 & DSC \\
\hline Carvalho et al. (2013) & 300 & $272 \pm 18$ & 1 a $28 \mathrm{C} \% \mathrm{~s}$ & 0,998 & Dilatometria \\
\hline $\begin{array}{l}\text { Este trabalho - } \\
\text { Primeira etapa }\end{array}$ & 300 & $253 \pm 27$ & 10 a $50 \mathrm{C} \% \mathrm{~min}$ & 0,995 & DSC \\
\hline $\begin{array}{l}\text { Segunda etapa - } \\
\text { Este trabalho }\end{array}$ & 300 & $200 \pm 22$ & 10 a $50 \mathrm{C} \% \mathrm{~min}$ & 0,983 & DSC \\
\hline Carvalho et al. (2013) & 350 & $294 \pm 51$ & $1 \mathrm{a} 28 \mathrm{C} / \mathrm{s}$ & 0,985 & Dilatometria \\
\hline $\begin{array}{l}\text { Este trabalho - } \\
\text { primeira etapa }\end{array}$ & 350 & $322 \pm 34$ & 10 a $50 \mathrm{C} \% / \mathrm{min}$ & 0,984 & DSC \\
\hline $\begin{array}{l}\text { Este trabalho - } \\
\text { segunda etapa }\end{array}$ & 350 & $201 \pm 11$ & 10 a $50 \mathrm{C} \% / \mathrm{min}$ & 0,996 & DSC \\
\hline $\begin{array}{c}\text { Viswanathan et al. } \\
\qquad(1993 b)\end{array}$ & 350 & $145 \pm 4$ & 10 a $40 \mathrm{C} \% \mathrm{~min}$ & 0,988 & Dilatometria \\
\hline Kapoor e Batra (2004) & 350 & 265 & 0,2 a $200^{\circ} \mathrm{C} / \mathrm{s}$ & - & Dilatometria \\
\hline
\end{tabular}

A Tabela 17 evidencia que os valores de energia de ativação da precipitação divergem devido às diferentes faixas de taxas de aquecimento. Estudos anteriores mostraram que em baixas taxas de aquecimento, a redistribuição de soluto durante a precipitação atinge níveis suficientes para que o crescimento dos precipitados ocorra por meio do mecanismo de difusão ao longo das discordâncias (pipe diffusion); enquanto, em taxas mais altas de aquecimento, os valores de energias de ativação obtidas por Carvalho et al. (2013) e Kapoor e Batra (2004) são próximos das energias de ativação para difusão no volume de elementos de liga, como o titânio (272 kJ/mol) e o molibdênio (238 kJ/mol) na ferrita (similar à martensita). Isso sugere o predomínio do mecanismo da difusão de soluto no volume ao invés da difusão ao longo das discordâncias (VISWANATHAN; KUTTY; GANGULY, 1993; GUO; SHA, 2004; KAPOOR; BATRA, 2004; CARVALHO et al., 2013).

\footnotetext{
9 Foram analisados os aços maraging $300 \mathrm{~A}$ e $350 \mathrm{C}$. Os experimentos de dilatometria foram realizados por Carvalho e coutores (2013) analisaram os mesmos materiais.
} 
Estudos anteriores realizados por Kapoor e Batra (2004), Viswanathan et al. (1993b), Carvalho et al. (2013) e Guo e Sha (2004) observaram que a precipitação de compostos intermetálicos em aços maraging apresenta apenas uma única etapa em experimentos para diversas taxas de aquecimento. Todavia, os resultados dessa tese com os aços maraging 300A e 350C mostram a ocorrência de duas etapas durante a precipitação para taxas de aquecimento entre 10 e $50{ }^{\circ} \mathrm{C} / \mathrm{min}$. É importante ressaltar que a possibilidade da ocorrência de duas etapas de precipitação em experimentos não-isotérmicos já havia sido sugerida por Guo e Sha (2004), porém somente uma etapa de precipitação fora detectada.

Observa-se também que os valores de energia de ativação para a precipitação na primeira etapa estão próximos das energias de ativação de para a difusão de elementos de liga, como o níquel $(245,8 \mathrm{~kJ} / \mathrm{mol})$ e o molibdênio (238 $\mathrm{kJ} / \mathrm{mol}$ ) na ferrita, bem como daquelas energias de ativação para a precipitação determinadas por Carvalho et al. (2013) e Kapoor e Batra (2003), para taxas de aquecimento maiores que $1^{\circ} \mathrm{C} / \mathrm{s}$, o que indica a predominância do mecanismo de difusão de soluto no volume.

Já a segunda etapa da precipitação tem valores de ativação inferior à energia de ativação do molibdênio e do níquel na ferrita, o que indica a ocorrência do mecanismo de difusão ao longo das discordâncias. Experimentos isotérmicos realizados por Vasudevan e coautores (1990) indicaram que a precipitação inicial ocorre nas discordâncias, seguida por uma etapa de crescimento dos precipitados pelo mecanismo de difusão ao longo das discordâncias (pipe diffusion).

A tabela 18 apresenta os valores da energia de ativação da reversão da martensita obtidos com o método de Kissinger. 
Tabela 18: Valores de energia de ativação obtidos da reversão da martensita $E_{A}$ por meio da análise de Kissinger para os aços maraging 300A e 350C em comparação com os estudos anteriores.

\begin{tabular}{|c|c|c|c|c|c|}
\hline Referência & $\begin{array}{l}\text { Série do aço } \\
\text { maraging }\end{array}$ & $\mathrm{E}_{\mathrm{A}}(\mathrm{kJ} / \mathrm{mol})$ & $\begin{array}{c}\text { Taxa de } \\
\text { aquecimento }\end{array}$ & $\mathrm{R}$ & $\begin{array}{l}\text { Técnica } \\
\text { usada }\end{array}$ \\
\hline Guo e Sha (2004) & 250 & 342 & 10 a $50 \mathrm{C} \% \mathrm{~min}$ & - & DSC \\
\hline Carvalho et al. (2013) & 300 & $562 \pm 69$ & $1 \mathrm{a} 28 \mathrm{C} \% \mathrm{~s}$ & 0,993 & Dilatometria \\
\hline $\begin{array}{l}\text { Primeira etapa - } \\
\text { Este trabalho }\end{array}$ & 300 & $373 \pm 10$ & 10 a $50 \mathrm{C} \% \mathrm{~min}$ & 0,999 & DSC \\
\hline $\begin{array}{l}\text { Segunda etapa - } \\
\text { Este trabalho }\end{array}$ & 300 & $2720 \pm 38$ & 10 a $50 \mathrm{C} \% \mathrm{~min}$ & 0,981 & DSC \\
\hline Carvalho et al. (2013) & 350 & $646 \pm 8$ & 1 a $28 \mathrm{C} \% \mathrm{~s}$ & 1,000 & Dilatometria \\
\hline $\begin{array}{l}\text { Este trabalho - } \\
\text { primeira etapa }\end{array}$ & 350 & $465 \pm 8$ & 10 a $50 \mathrm{C} \% \mathrm{~min}$ & 0,999 & DSC \\
\hline $\begin{array}{l}\text { Este trabalho - } \\
\text { segunda etapa }\end{array}$ & 350 & $626 \pm 69$ & 10 a $50 \mathrm{C} \% \mathrm{~min}$ & 0,994 & DSC \\
\hline $\begin{array}{l}\text { Viswanathan et al. } \\
\qquad(1993 b)\end{array}$ & 350 & $224 \pm 4$ & 10 a $40 \mathrm{C} \% \mathrm{~min}$ & 0,985 & Dilatometria \\
\hline Kapoor e Batra (2004) & 350 & $\begin{array}{l}423 ; \beta<2 \mathrm{C} / \mathrm{s} \\
828 ; \beta>2 \mathrm{C} \% \mathrm{~s}\end{array}$ & 0,2 a $200^{\circ} \mathrm{C} / \mathrm{s}$ & - & Dilatometria \\
\hline
\end{tabular}

A Tabela 18 indica que há uma variação dos valores da energia de ativação da reversão da martensita com a taxa de aquecimento. A energia de ativação na primeira etapa é ligeiramente maior do que aquelas para a difusão do níquel (245,8 $\mathrm{kJ} / \mathrm{mol}$ ) e do molibdênio $(238 \mathrm{~kJ} / \mathrm{mol}$ ) na ferrita, enquanto a segunda etapa tem energia de ativação maior, indicando a ocorrência de outro mecanismo, por exemplo, a reversão da martensita por cisalhamento. Estudos anteriores realizados por Kapoor e Batra (2004), Viswanathan et al. (1993b), Carvalho et al. (2013) e Guo e Sha (2004) observaram que a energia de ativação da reversão da martensita é maior em altas taxas de aquecimento devido à menor influência do mecanismo de difusão do molibdênio e do níquel (menor redistribuição de elementos gamagênicos); já que o mecanismo de cisalhamento ocorre de forma mais expressiva em altas taxas de aquecimento.

Estudos isotérmicos realizados por Habiby e coautores (1996) para amostras tratadas de forma isócrona para diversas temperaturas indicaram que a fração volumétrica tem um comportamento crescente entre 550 e $650^{\circ} \mathrm{C}$, o que coincide com a diminuição do parâmetro de rede da martensita, sugerindo que o mecanismo

\footnotetext{
${ }^{10}$ Foram analisados os aços maraging $300 \mathrm{~A}$ e $350 \mathrm{C}$. Os experimentos de dilatometria realizados por Carvalho e coutores (2013) analisaram os mesmos materiais.
} 
de reversão da martensita por difusão ocorre de forma mais intensa nessa faixa de temperatura. Por outro lado, a fração volumétrica apresenta uma tendência decrescente a partir de $650^{\circ} \mathrm{C}$ e um aumento do parâmetro de rede da martensita, o que indica que há uma mudança de mecanismo de reversão da martensita. Dessa maneira, as observações realizadas por Habiby e coautores corroboram aquelas detectadas por dilatometria nos trabalhos de Kapoor e Batra (2004) e Carvalho et al. (2013).

No item 4.3 são avaliadas as mudanças microestruturais após 0 envelhecimento para o aço maraging 350B.

\subsection{AVALIAÇÂO DAS MUDANÇAS MICROESTRURAIS APÓS O ENVELHECIMENTO PARA O AÇO MARAGING 350B}

A análise das mudanças microestruturais das amostras envelhecidas para 0 aço maraging 350B foi agrupada em diversos tópicos. O item 4.3.1 analisa as mudanças microestruturais decorrentes do envelhecimento, especialmente a reversão da martensita. Já no item 4.3.2 foi investigada a influência de tratamentos térmicos entre 520 e $600{ }^{\circ} \mathrm{C}$ em medidas ferromagnéticas e de difração de raios $\mathrm{X}$, de amostras tratadas do aço maraging 350B. Por fim, no item 4.3.3 foram estudados a cinética de precipitação e o comportamento da curva de envelhecimento para 0 aço maraging 350B.

\subsubsection{Análise da microestrutura após o envelhecimento para o aço maraging 350B}

Nessa seção foi dada uma ênfase na caracterização de amostras superenvelhecidas, pois os precipitados formados em estágios iniciais do envelhecimento têm um tamanho da ordem de dezenas de nanômetros, cuja observação seria possível apenas em microscopia eletrônica de transmissão ou microscopia de campo iônico (SHA; CEREZO; SMITH, 1993d; VASUDEVAN; KIM; WAYMAN, 1990; VISWANATHAN; DEY; ASUNDI, 1993a; MOSHKA et al, 2015.

A figura 69 apresenta diversas micrografias obtidas com o reagente Marble que mostram a influência do tempo de envelhecimento para amostras tratadas termicamente a $600^{\circ} \mathrm{C}$. 


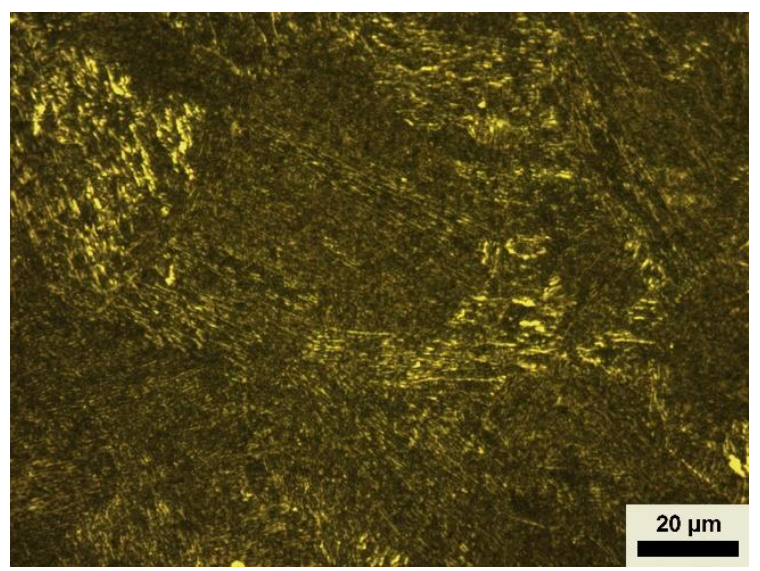

(a) $45 \mathrm{~min}$

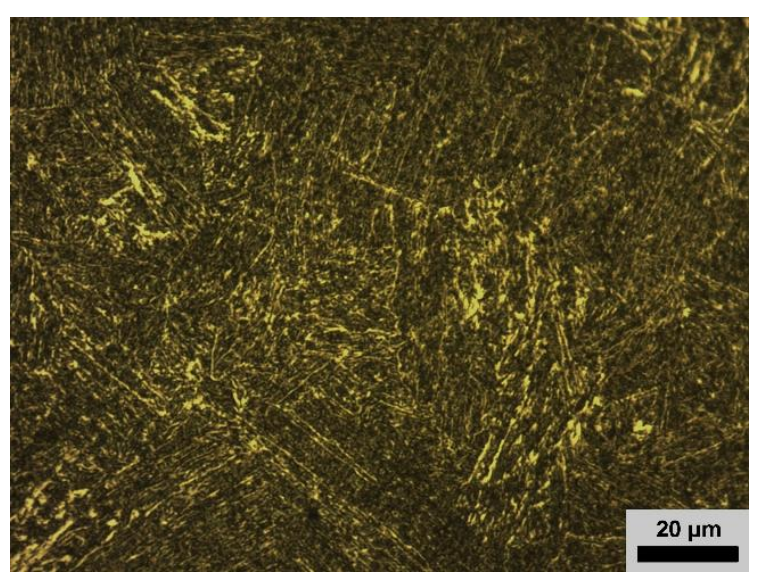

(c) $6 \mathrm{~h}$

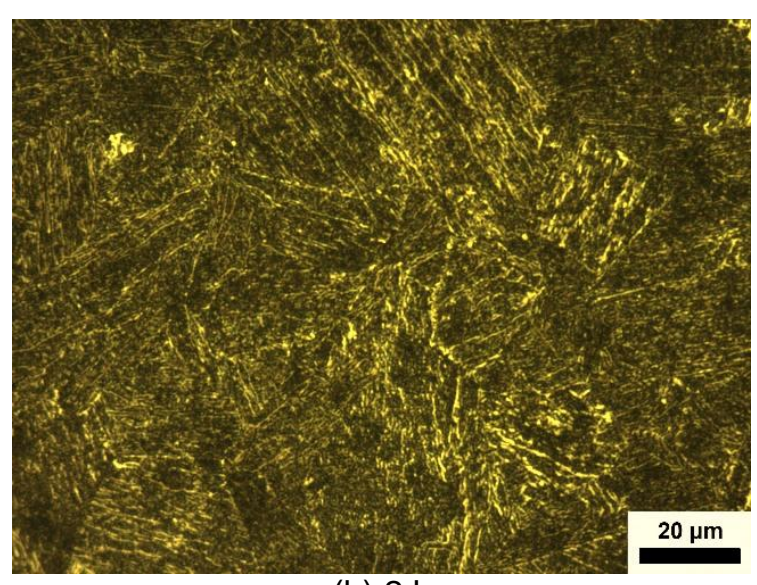

(b) $2 \mathrm{~h}$

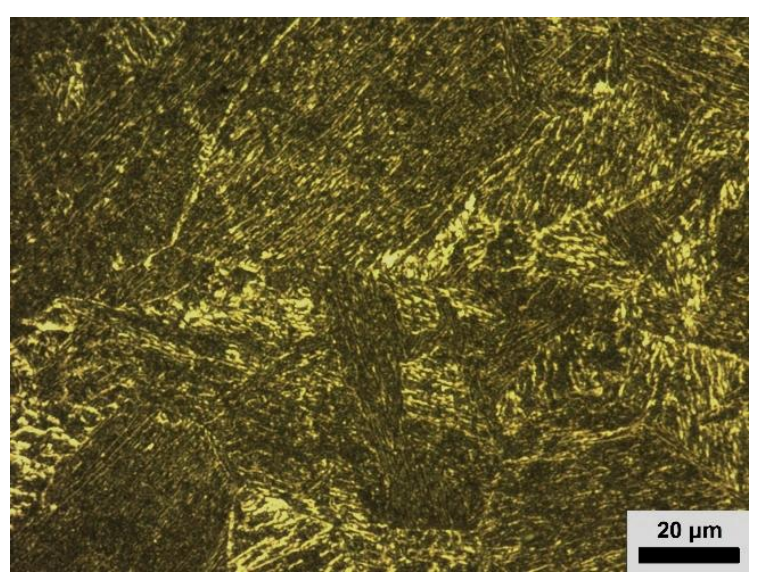

(d) $18 \mathrm{~h}$

Figura 69: Microestrutura do aço maraging 350B revelada pelo uso do reagente Marble e obtida por meio do microscópio óptico para amostras envelhecidas em $600{ }^{\circ} \mathrm{C}$ para $45 \mathrm{~min}$ (a), $2 \mathrm{~h} \mathrm{(b),} 6 \mathrm{~h} \mathrm{(c)} \mathrm{e}$ $18 \mathrm{~h}(\mathrm{~d})$.

$\mathrm{Na}$ figura 69, a austenita revertida consiste nas áreas mais claras da micrografia, enquanto as ripas da martensita são as áreas mais escuras. Dessa maneira, pode-se afirmar de forma qualitativa que há um aumento na fração volumétrica com o incremento do tempo de envelhecimento em amostras tratadas a $600{ }^{\circ} \mathrm{C}$, especialmente quando são comparadas as figuras 69b, 69c e 69d em relação à figura 69a (PARDAL et al., 2006).

Na figura 70 são apresentadas micrografias de amostras envelhecidas a 560 e $600^{\circ} \mathrm{C}$ reveladas com Marble e obtidas por imagens de elétrons secundários no microscópio eletrônico de varredura. 


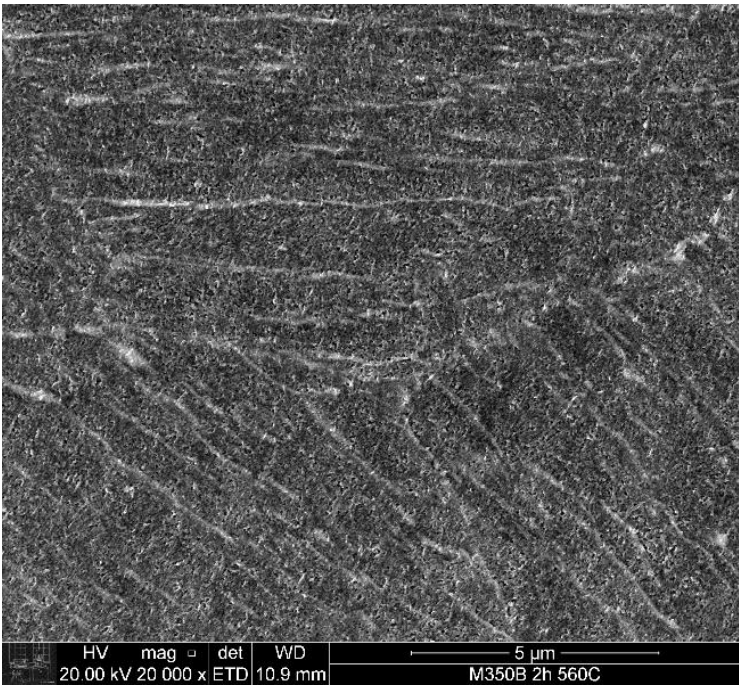

(a) $560^{\circ} \mathrm{C}$ por 2 horas

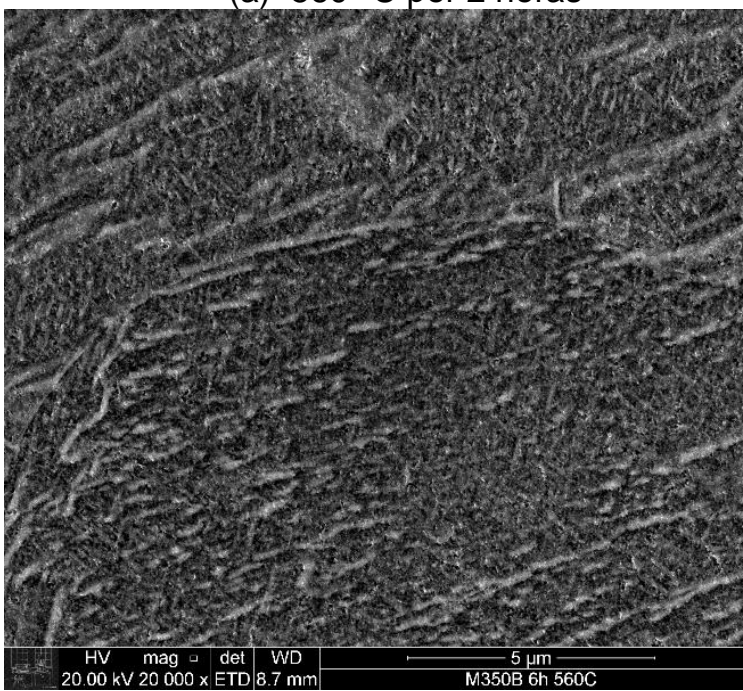

(b) $560^{\circ} \mathrm{C}$ por 6 horas

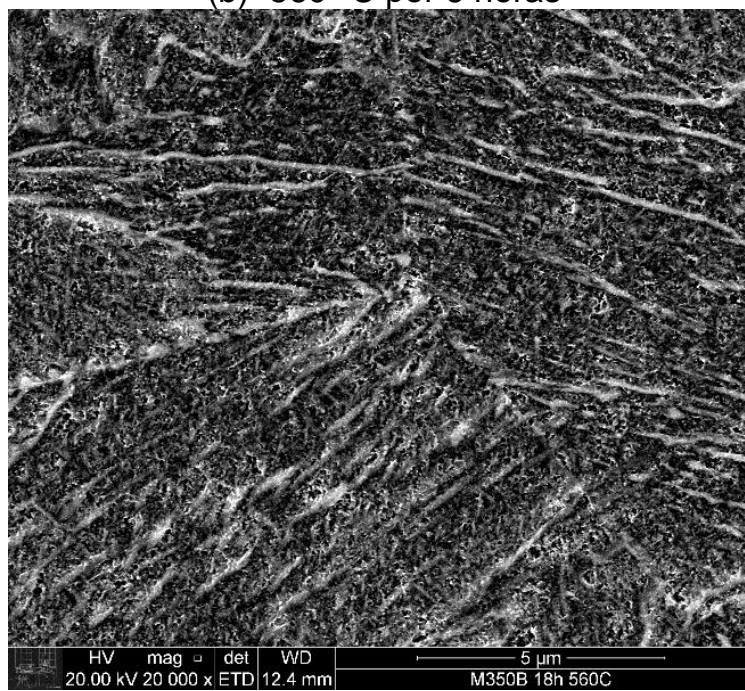

(e) $560^{\circ} \mathrm{C}$ por 18 horas

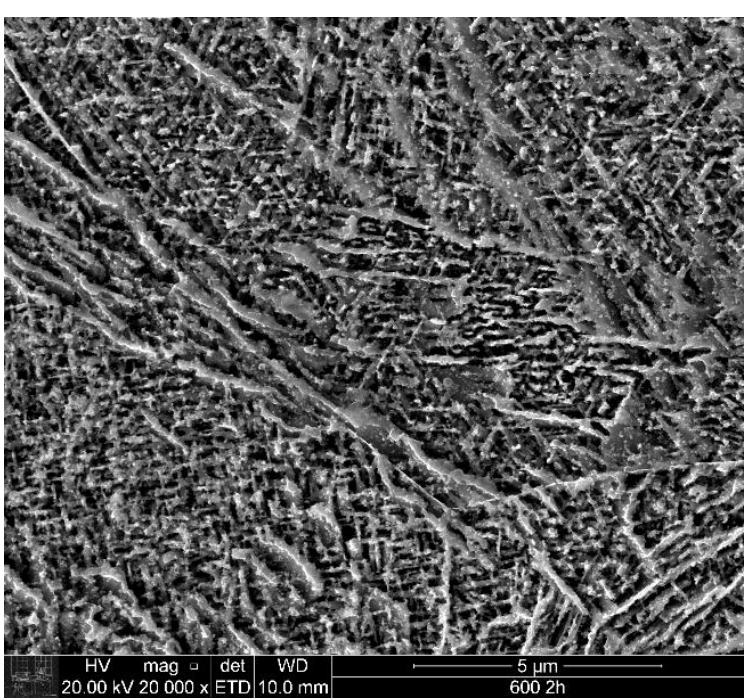

(b) $600^{\circ} \mathrm{C}$ por 2 horas

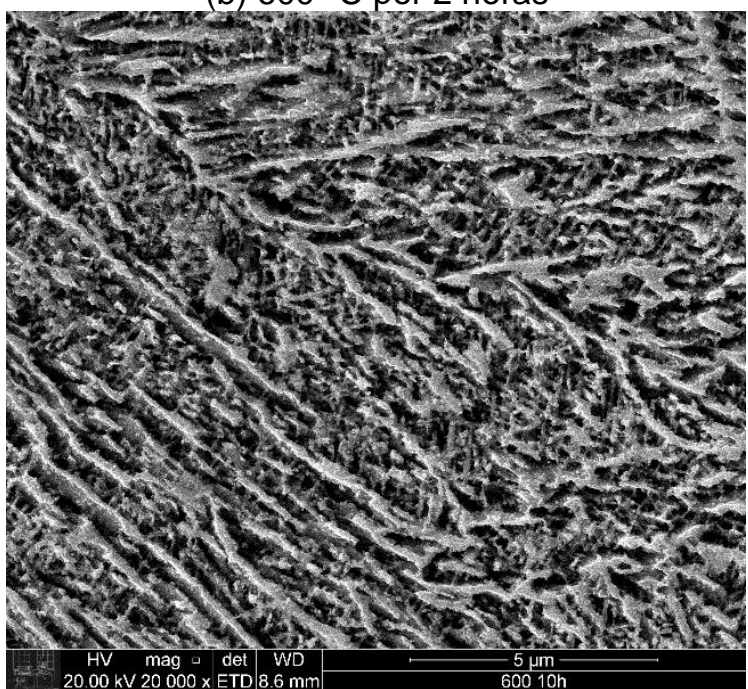

(c) $600^{\circ} \mathrm{C}$ por 6 horas

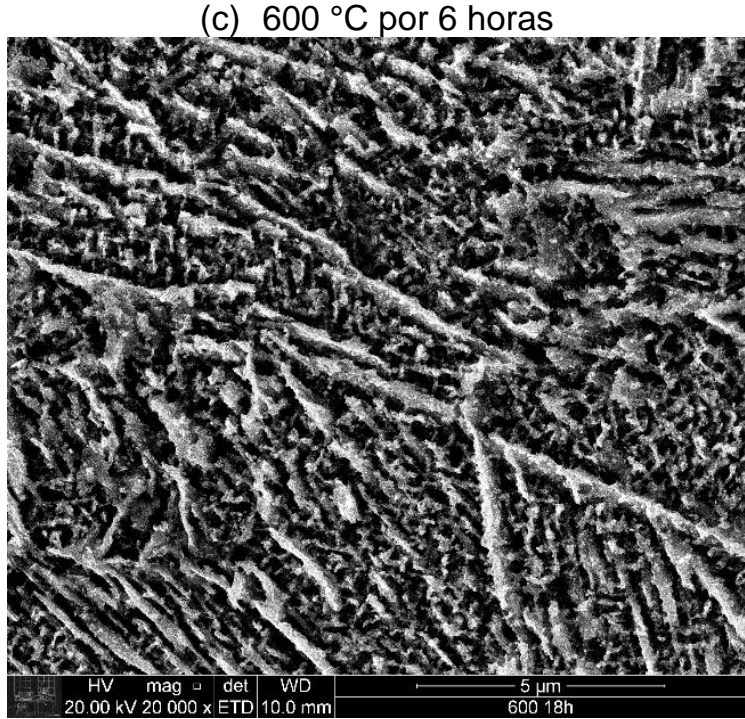

(f) $600{ }^{\circ} \mathrm{C}$ por 18 horas

Figura 70: Imagens por elétrons secundários da microestrutura do aço maraging 350B revelada pelo uso do reagente Marble em amostras envelhecidas a: $560{ }^{\circ} \mathrm{C}$ por 2 horas (a), $600{ }^{\circ} \mathrm{C}$ por 2 horas (b), $560^{\circ} \mathrm{C}$ por 6 horas (c), $600^{\circ} \mathrm{C}$ por 6 horas (d), $560^{\circ} \mathrm{C}$ por 18 horas (e) e $600^{\circ} \mathrm{C}$ por 18 horas (f). 
As figuras 70 (a-f) mostram também que a temperatura e o tempo de envelhecimento têm um efeito na cinética de austenita formada nos contornos de ripa da martensita e nos contornos de pacote da martensita. Um aumento da temperatura de $560{ }^{\circ} \mathrm{C}$ para $600^{\circ} \mathrm{C}$ acelera a taxa de difusão de elementos de liga, proporcionando maiores frações volumétricas para temperaturas de envelhecimento maiores. Além disso, os tempos mais prolongados de envelhecimento também levam a maiores frações volumétricas de austenita (PARDAL et al.,2006).

A figura 71 apresenta a microestrutura de uma amostra tratada a $520^{\circ} \mathrm{C}$ por 18 horas.

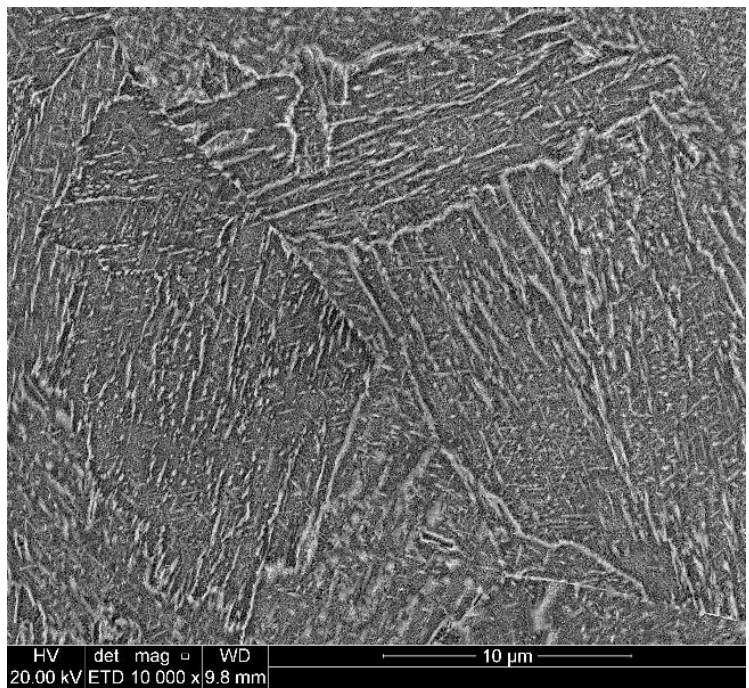

(a) imagem por elétrons secundários com aumento de $10000 \mathrm{X}$

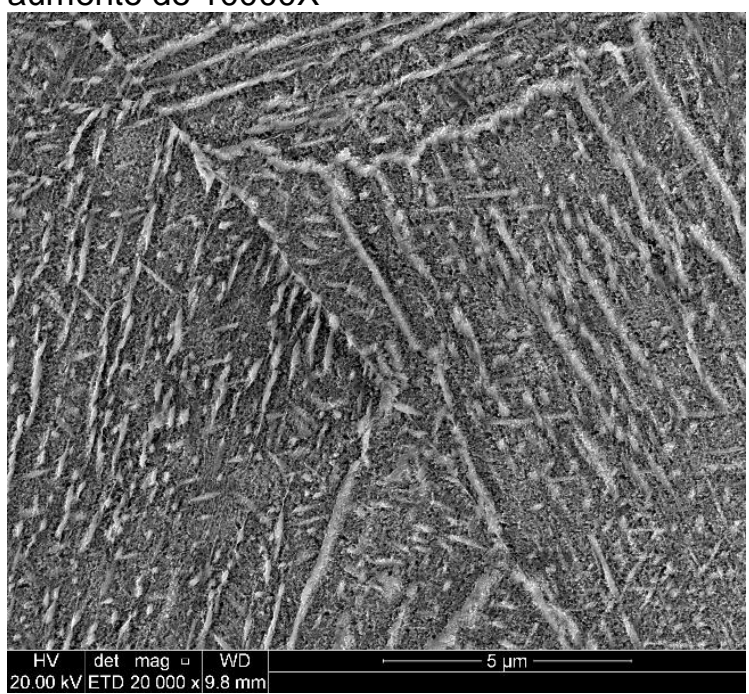

(c) imagem por elétrons secundários com aumento de $20000 \mathrm{X}$

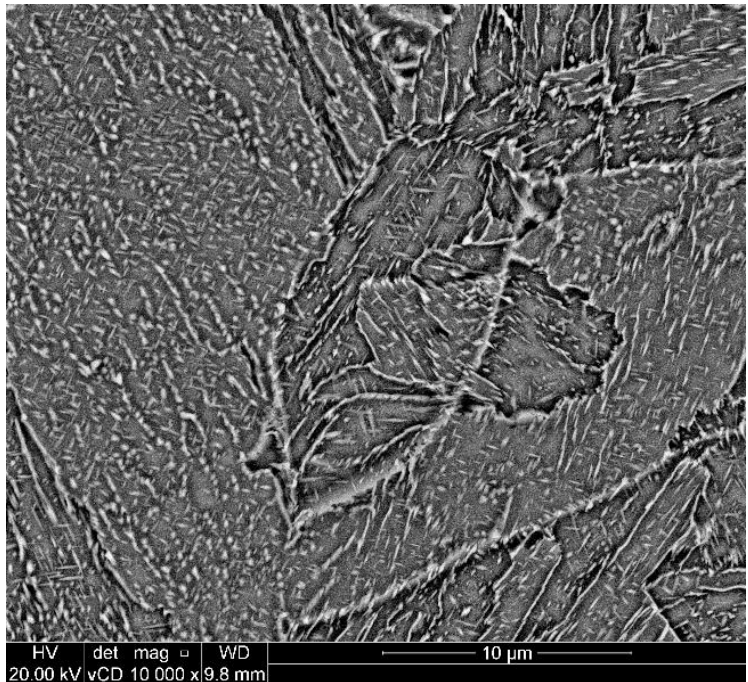

(b) imagem por elétrons retroespalhados com aumento de $10000 \mathrm{X}$

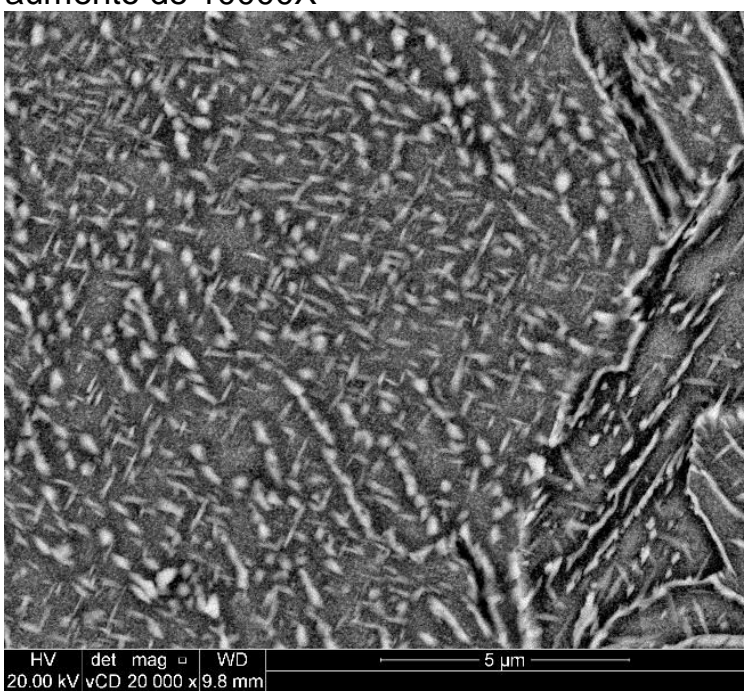

(d) imagem por elétrons retroespalhados com aumento de $20000 \mathrm{X}$

Figura 71: Micrografias da microestrutura do aço maraging 350B revelada pelo uso do reagente $2 \%$ Nital e obtida por microscopia eletrônica de varredura em uma amostra envelhecida a $520{ }^{\circ} \mathrm{C}$ por 18 horas. 
As imagens por elétrons secundários nas figuras 71a e 71c mostram uma diferença de profundidade resultante do ataque seletivo na austenita e na martensita causado pelo $2 \% \mathrm{Nital}$, enquanto as imagens por elétrons retroespalhados $71 \mathrm{~b} \mathrm{e}$ $71 \mathrm{~d}$ evidenciam as diferenças de composições química, no qual as regiões mais brilhantes representam um número atômico médio local maior do que a vizinhança. No caso dos aços maraging, as regiões mais brilhantes das imagens feitas por elétrons retroespalhados indicam principalmente a presença de molibdênio.

As micrografias relevadas por $2 \%$ Nital mostradas nas figuras $71 \mathrm{a}, 71 \mathrm{~b}, 71 \mathrm{c}$ e $71 \mathrm{~d}$ evidenciam que há a formação de austenita revertida nas regiões de contornos de ripas e de contornos de pacotes da martensita para amostras envelhecidas em $520^{\circ} \mathrm{C}$ por 18 horas. Além disso, no interior das ripas da martensita, pode ser vista a presença de fases com tamanho menor em relação à austenita, apresentando as morfologias elipsoidal, cilíndrica e esferoidal, o que poderia indicar a presença das fases $\mathrm{Ni}_{3} \mathrm{Ti}, \mathrm{Ni}_{3} \mathrm{Mo}$ e $\mathrm{Fe}_{2} \mathrm{Mo}$ (FAROOQUE et al., 1998; VISWANATHAN, DEY, ASUNDI, 1993a; VISWANATHAN, DEY, SETHUMANDHAVAN, 2005; MOSHKA et al., 2015). Dessa maneira, foram investigadas essas fases menores em imagens com tamanho maiores que 20000X, como apresentado nas figuras 72 e 73 .

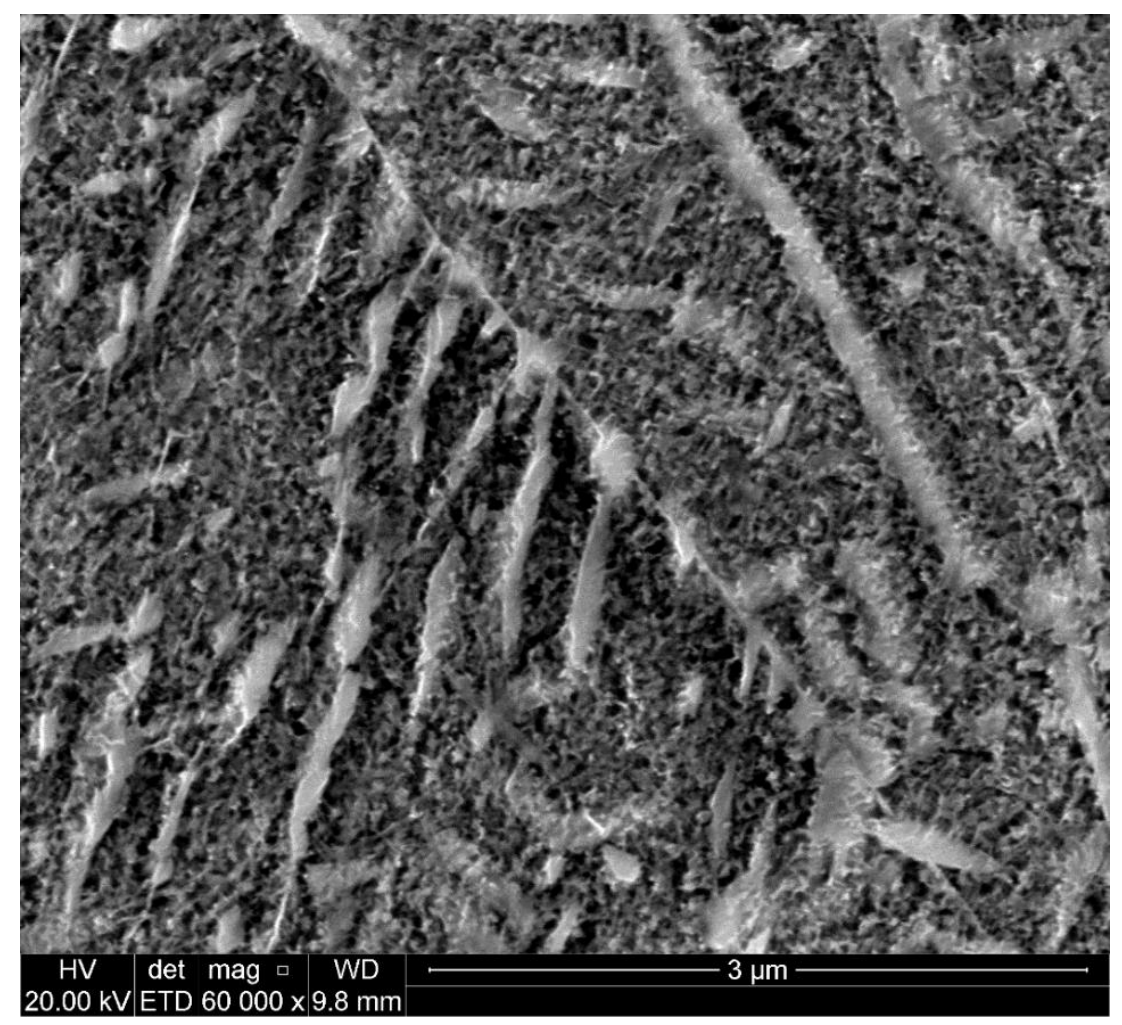

Figura 72: Imagem por elétrons secundários da microestrutura do aço maraging 350B revelada pelo uso do reagente $2 \%$ Nital em uma amostra envelhecida a $520{ }^{\circ} \mathrm{C}$ por 18 horas para um aumento de $60000 \mathrm{X}$. 


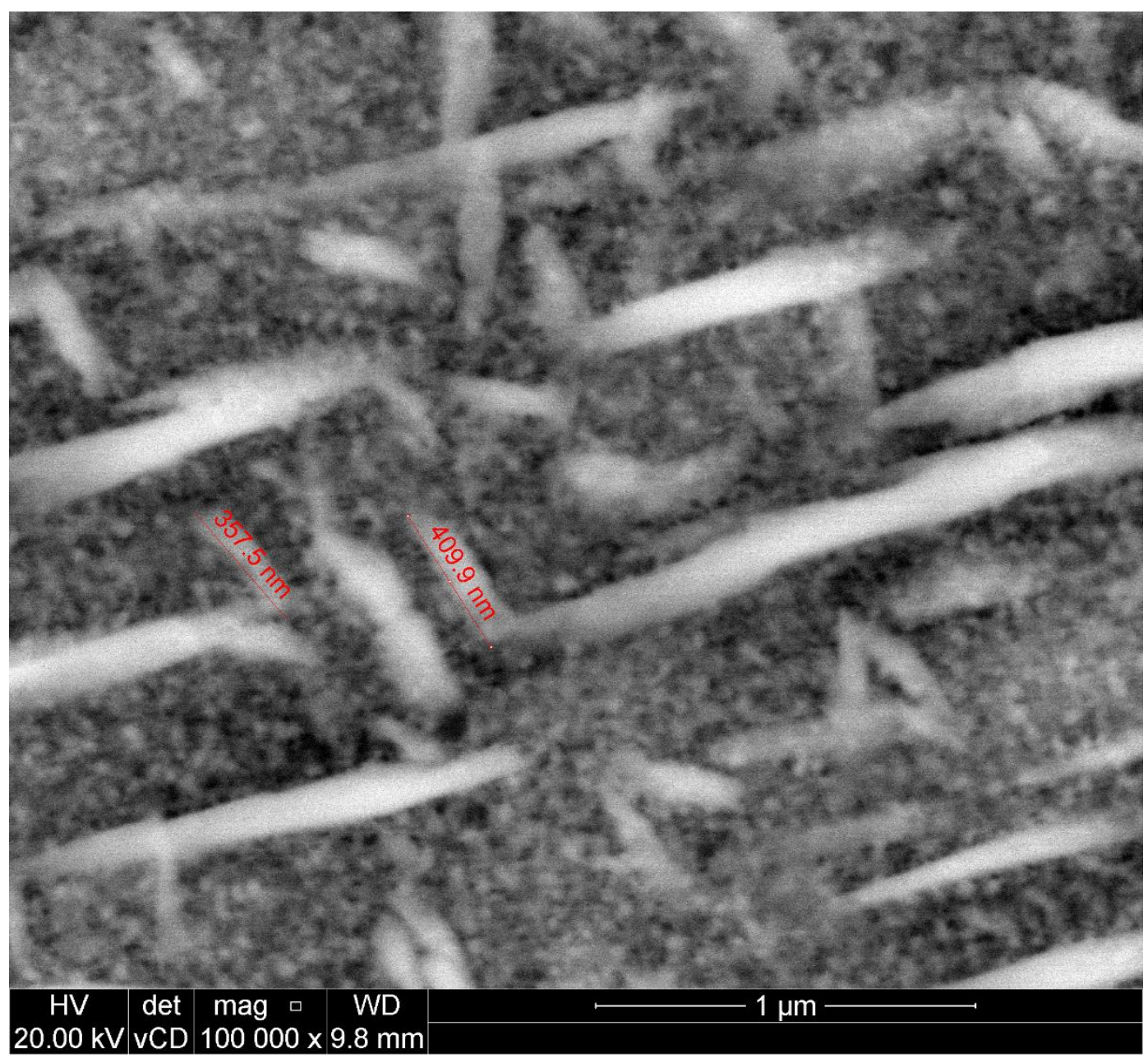

Figura 73: Imagem por elétrons retroespalhados da microestrutura do aço maraging 350B revelada pelo uso do reagente $2 \%$ Nital em uma amostra envelhecida a $520^{\circ} \mathrm{C}$ por 18 horas para um aumento de 100000X.

As figuras 72 e 73 mostram a presença da austenita inter-ripas alinhadas ao longo de uma direção bem definida, o que evidencia as relações de orientação entre a austenita e a martensita. Além disso, na figura 73 pode-se observar que há a presença de fases de tamanho nanométrico com morfologias elipsoidal e cilíndrica (FAROOQUE et al., 1998; VISWANATHAN, DEY, SETHUMANDHAVAN, 2005; MOSHKA et al., 2015).

A figura 74 apresenta micrografias de uma amostra envelhecida a $560{ }^{\circ} \mathrm{C}$ por 18 horas. 


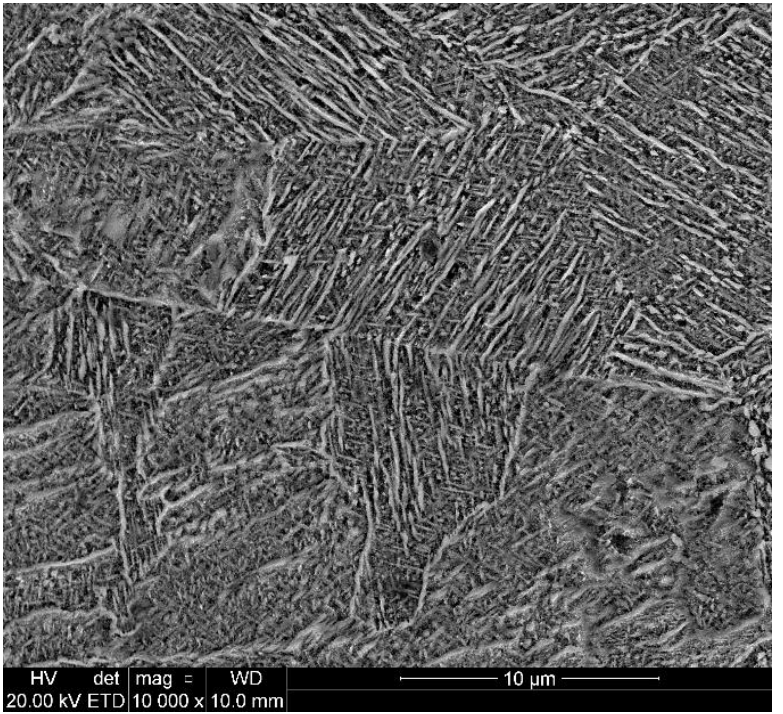

(a) imagem por elétrons secundários com aumento de $10000 \mathrm{X}$

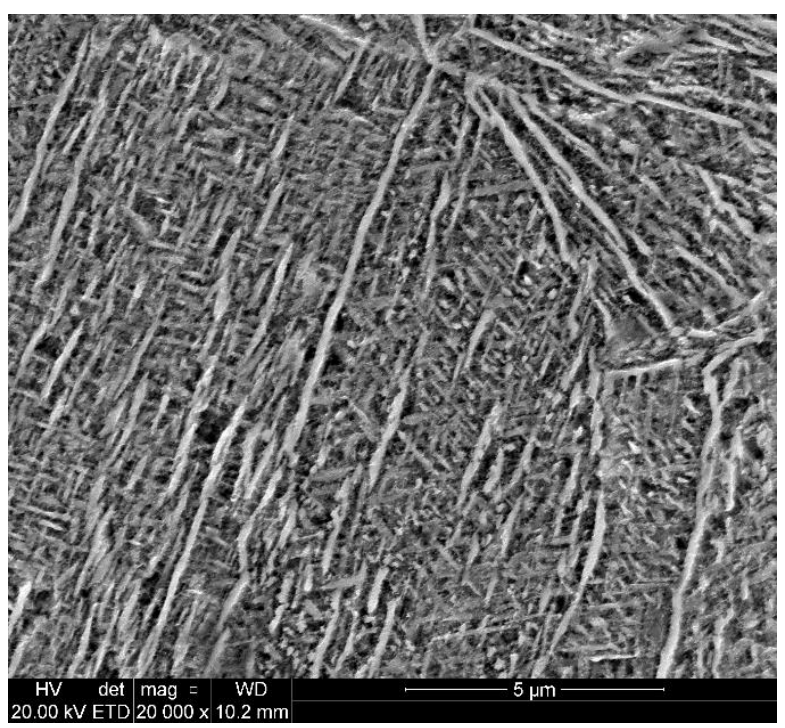

(c) imagem por elétrons secundários com aumento de $20000 \mathrm{X}$

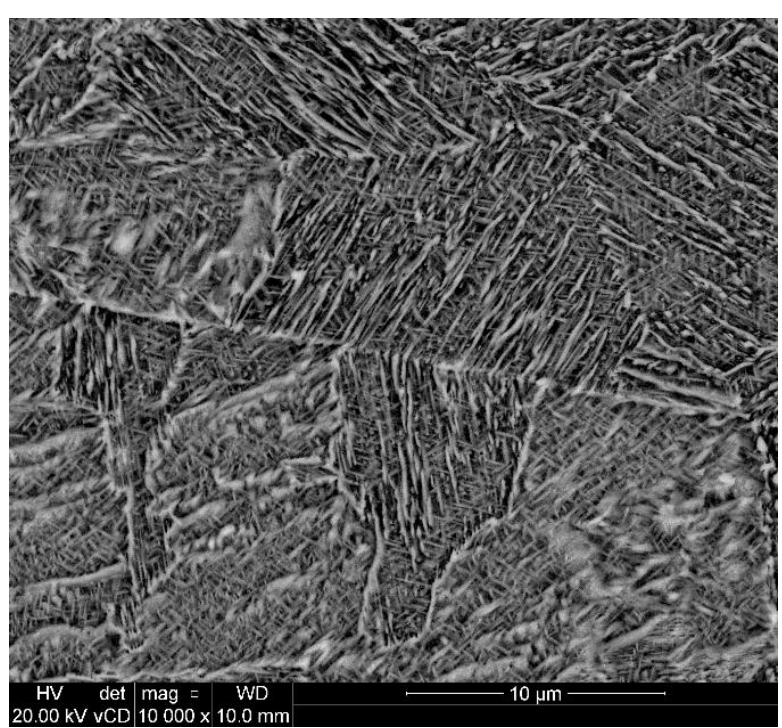

(b) imagem por elétrons retroespalhados com aumento de $10000 \mathrm{X}$

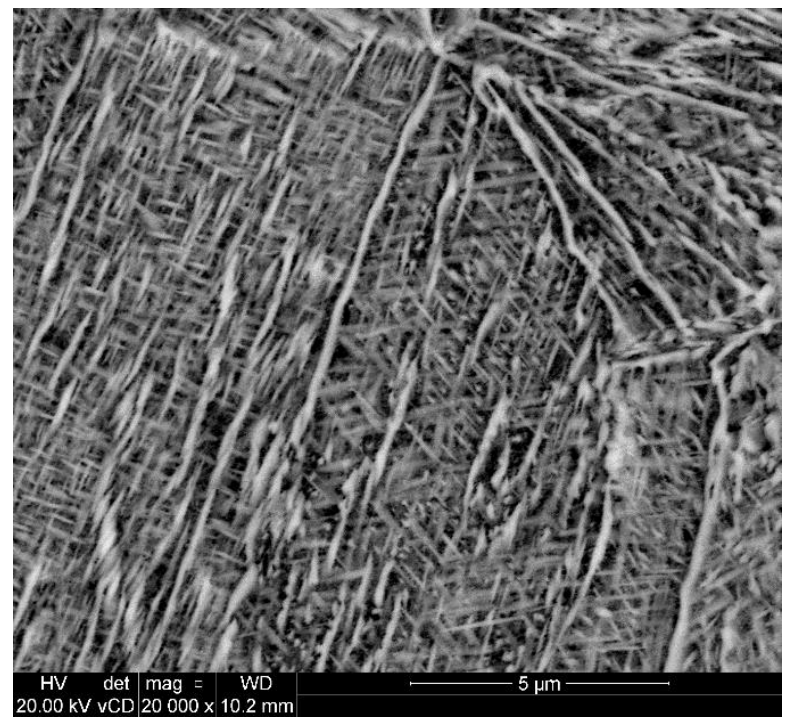

(d) imagem por elétrons retroespalhados com aumento de $20000 X$

Figura 74: Micrografias da microestrutura do aço maraging 350B revelada pelo uso do reagente $2 \%$ Nital e obtida por microscopia eletrônica de varredura em uma amostra tratada a $560{ }^{\circ} \mathrm{C}$ por 18 horas.

As figuras 74a, 74b, 74c e 74d evidenciam a formação de austenita inter-ripas a partir da reversão da martensita. Comparando-se as micrografias obtidas para a amostra tratada a $520{ }^{\circ} \mathrm{C}$ por 18 horas (vide figura 71) e a amostra envelhecida a $560{ }^{\circ} \mathrm{C}$ por 18 horas, observa-se que a austenita entre as ripas da martensita de amostras superenvelhecidas em $560{ }^{\circ} \mathrm{C}$ são mais espessas do que aquelas formadas em $520^{\circ} \mathrm{C}$. Além disso, as figuras $74 \mathrm{c}$ e $74 \mathrm{~d}$ mostram que há formação de agulhas de austenita do tipo Widmanstätten no interior das ripas da martensita, bem como a presença dos precipitados intermetálicos menores (VISWANATHAN, DEY, 
ASUNDI, 1993a; FAROOQUE et al., 1998; VISWANATHAN, DEY, SETHUMANDHAVAN, 2005).

$\mathrm{Na}$ figura 75 são apresentadas as micrografias obtidas por elétrons retroespalhados para diversos graus de aumento em uma amostra envelhecida a $600^{\circ} \mathrm{C}$ por 18 horas.

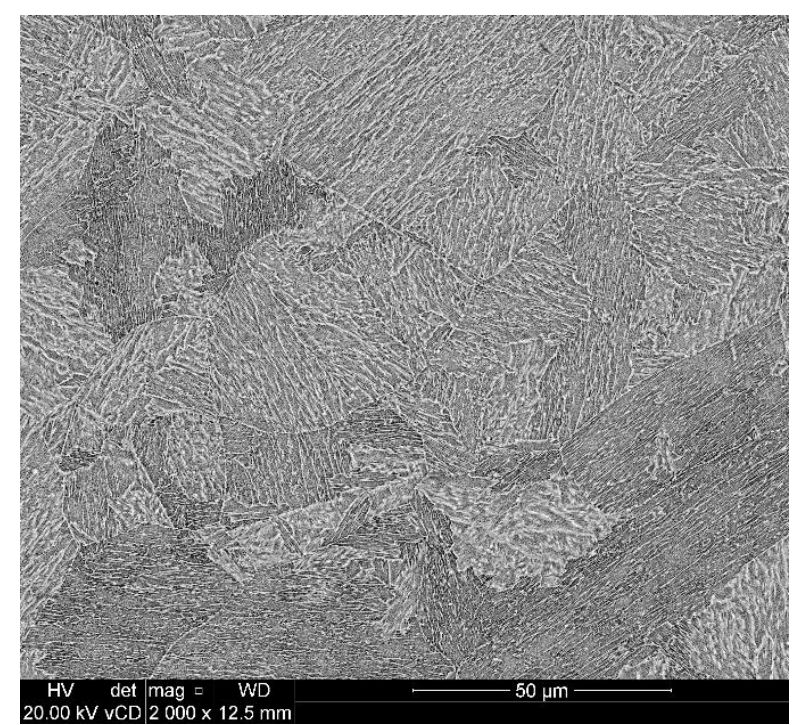

(a) imagem por elétrons retroespalhados com aumento de $2000 \mathrm{X}$

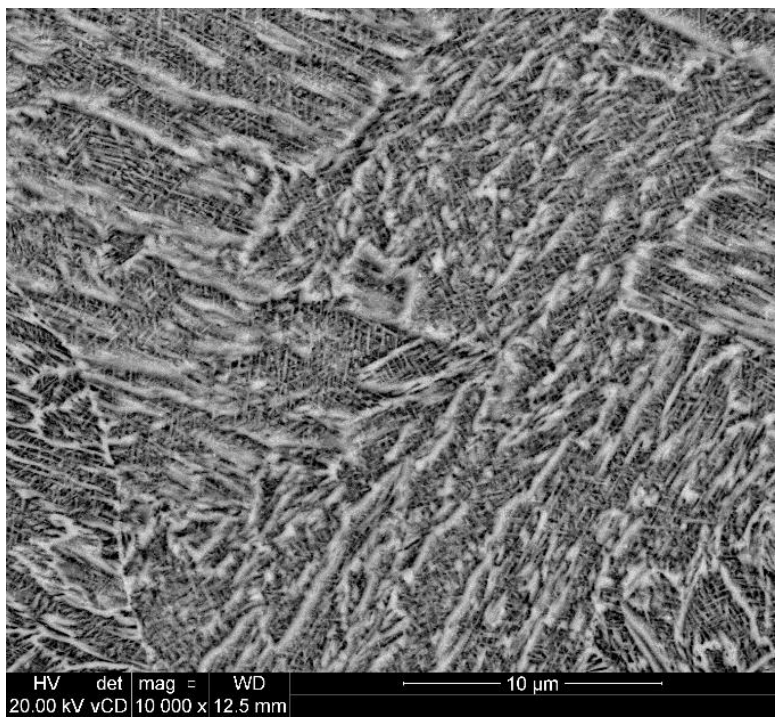

(c) imagem por elétrons retroespalhados com aumento de $10000 \mathrm{X}$

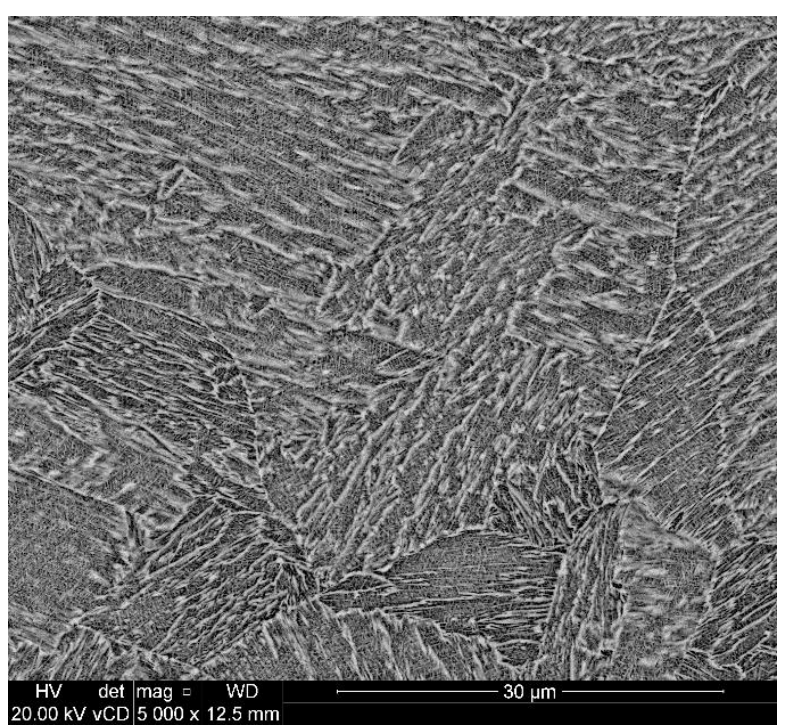

(b) imagem por elétrons retroespalhados com aumento de 5000X

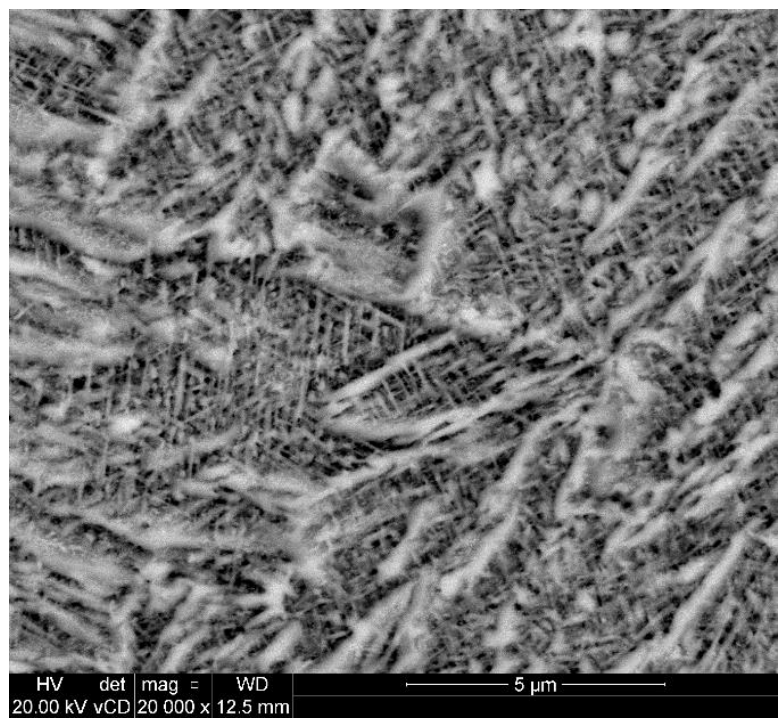

(d) imagem por elétrons retroespalhados com aumento de $20000 \mathrm{X}$

Figura 75: Micrografias da microestrutura do aço maraging 350B revelada pelo uso do reagente $2 \%$ Nital e obtida por microscopia eletrônica de varredura em uma amostra tratada a $600{ }^{\circ} \mathrm{C}$ por 18 horas.

As micrografias obtidas por meio de elétrons retroespalhados, nas figuras $75 a$ e 75b, mostram que a austenita revertida pode ser observada com menores aumentos em relação às demais. Já as figuras 75 c e $75 d$ evidenciam que austenita 
localizada entre as ripas da martensita são mais grossas do que aquelas formadas em 520 e $560{ }^{\circ} \mathrm{C}$ por 18 horas (vide figuras 71 e 74). Ademais, as figuras $74 \mathrm{c}$ e $74 \mathrm{~d}$ mostram que no interior das ripas da martensita são formadas agulhas de austenita do tipo Widmanstätten, bem como a presença de austenita globular entre as ripas da martensita (VISWANATHAN, DEY, ASUNDI, 1993a; FAROOQUE et al., 1998; VISWANATHAN, DEY, SETHUMANDHAVAN, 2005).

O item 4.3.2 discute as medidas ferromagnéticas e de difração de raios $X$ em amostras superenvelhecidas entre 520 e $600{ }^{\circ} \mathrm{C}$.

\subsubsection{Medidas ferromagnéticas e de difração de raios $X$ para 0 aço maraging $350 \mathrm{~B}$}

A figura 76 mostra o difratograma de raios $X$ para as amostras envelhecidas em 520,560 e $600{ }^{\circ} \mathrm{C}$ por 1 e 18 horas.

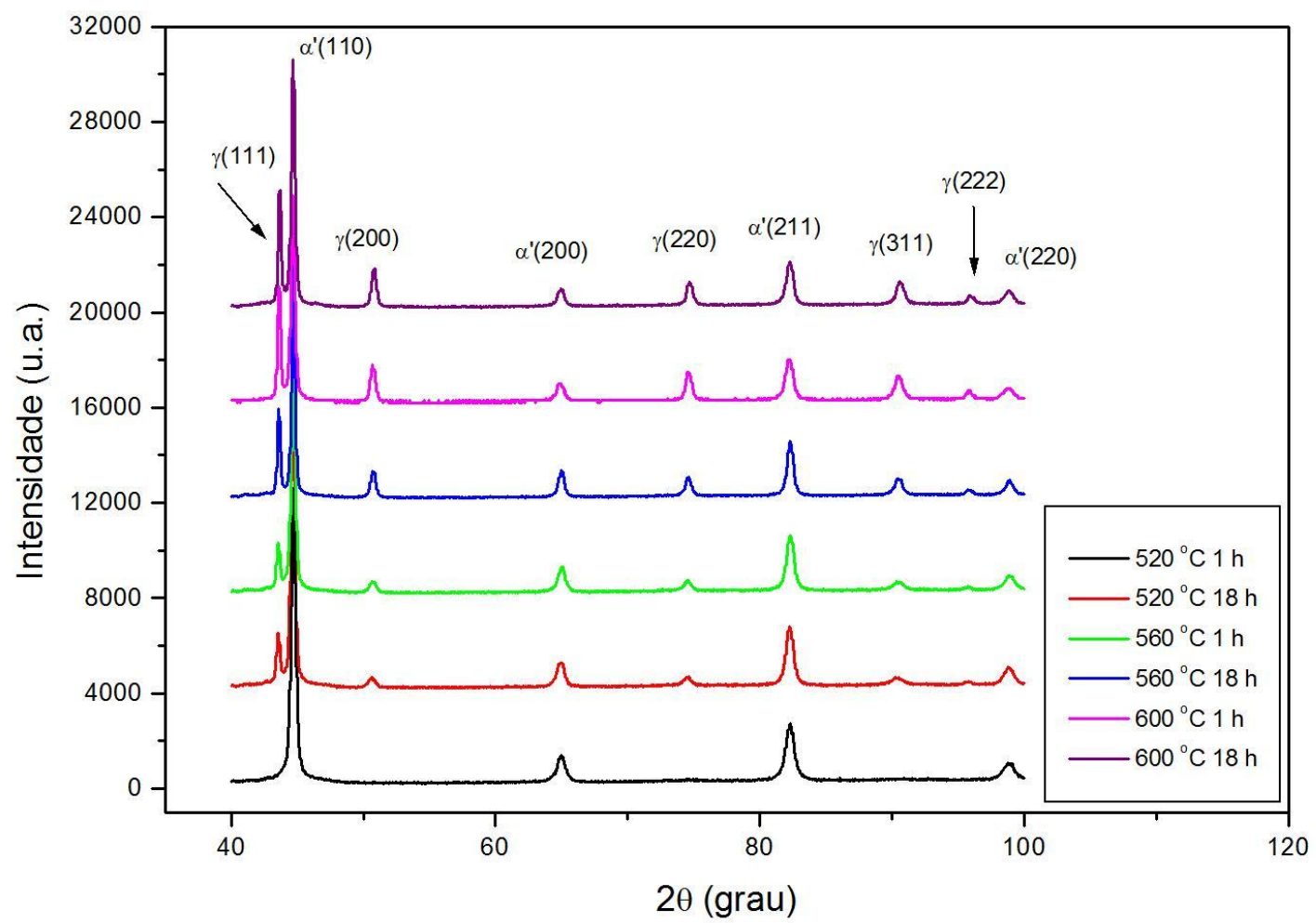

Figura 76: Difratograma de raios $X$ de amostras no estado como recebido e envelhecidas a 520, 560 e $600{ }^{\circ} \mathrm{C}$ por 1 e 18 horas para o aço maraging 350B.

O difratograma de raios $X$ apresentado na figura 76 mostra que conforme a temperatura e o tempo de envelhecimento aumentam há a formação de uma quantidade de austenita, o que pode ser visto comparando-se os picos relativos à 
austenita $\gamma(200), y(220), y(311)$ e $\gamma(222)$, em diversas condições de tratamento térmico.

Os valores da fração volumétrica da austenita, parâmetros de rede da austenita e da martensita calculados a partir do difratograma com base no método de intensidade intengrada e no método de Rietveld são apresentados na tabela 19.

Tabela 19: Valores da fração volumétrica da austenita, parâmetro de rede da austenita e da martensita do aço maraging 350B.

\begin{tabular}{|c|c|c|c|c|c|}
\hline $\begin{array}{l}\text { Tratamento } \\
\text { térmico }\end{array}$ & Método & $\begin{array}{c}\text { Fração } \\
\text { volumétrica } \\
\text { da austenita } \\
(\%)\end{array}$ & $\begin{array}{l}\text { Parâmetro de } \\
\text { rede da } \\
\text { austenita }(\AA)\end{array}$ & $\begin{array}{l}\text { Parâmetro de } \\
\text { rede da } \\
\text { martensita }(\AA)\end{array}$ & $\mathrm{Chi}^{2}$ \\
\hline \multirow{2}{*}{$520^{\circ} \mathrm{C}$ por $1 \mathrm{~h}$} & $\begin{array}{l}\text { Intensidade } \\
\text { integrada }\end{array}$ & $0,0 \pm 1,0$ & - & $2,8697 \pm 0,0005$ & - \\
\hline & Rietveld & $0,0 \pm 1,0$ & & $2,8755 \pm 0,0005$ & 3,2 \\
\hline \multirow{2}{*}{$520^{\circ} \mathrm{C}$ por $18 \mathrm{~h}$} & $\begin{array}{l}\text { Intensidade } \\
\text { integrada }\end{array}$ & $15,5 \pm 1,1$ & $3,5980 \pm 0,0005$ & $2,8697 \pm 0,0005$ & - \\
\hline & Rietveld & $14,0 \pm 1,0$ & $3,6051 \pm 0,0005$ & $2,8749 \pm 0,0005$ & 4,2 \\
\hline \multirow{2}{*}{$560^{\circ} \mathrm{C}$ por $1 \mathrm{~h}$} & $\begin{array}{l}\text { Intensidade } \\
\text { integrada }\end{array}$ & $16,3 \pm 1,1$ & $3,5995 \pm 0,0005$ & $2,8660 \pm 0,0005$ & - \\
\hline & Rietveld & $17,0 \pm 1,0$ & $3,6042 \pm 0,0005$ & $2,8732 \pm 0,0005$ & 4,6 \\
\hline \multirow{2}{*}{$560{ }^{\circ} \mathrm{C}$ por $18 \mathrm{~h}$} & $\begin{array}{l}\text { Intensidade } \\
\text { integrada }\end{array}$ & $31,3 \pm 1,3$ & $3,5973 \pm 0,0005$ & $2,8675 \pm 0,0005$ & - \\
\hline & Rietveld & $30,0 \pm 1,0$ & $3,6020 \pm 0,0005$ & $2,8731 \pm 0,0005$ & 3,8 \\
\hline \multirow{2}{*}{$600^{\circ} \mathrm{C}$ por $1 \mathrm{~h}$} & $\begin{array}{l}\text { Intensidade } \\
\text { integrada }\end{array}$ & $40,9 \pm 1,6$ & $3,5971 \pm 0,0005$ & $2,8707 \pm 0,0005$ & - \\
\hline & Rietveld & $36,0 \pm 1,0$ & $3,6041 \pm 0,0005$ & $2,8765 \pm 0,0005$ & 4,3 \\
\hline \multirow{2}{*}{$600{ }^{\circ} \mathrm{C}$ por $18 \mathrm{~h}$} & $\begin{array}{l}\text { Intensidade } \\
\text { integrada }\end{array}$ & $39,7 \pm 1,5$ & $3,5940 \pm 0,0005$ & $2,8694 \pm 0,0005$ & - \\
\hline & Rietveld & $34,0 \pm 1,0$ & $3,6002 \pm 0,0005$ & $2,8752 \pm 0,0005$ & 4,5 \\
\hline
\end{tabular}

A tabela 19 mostra que os valores da fração volumétrica estimada pela intensidade integrada e pelo método de Rietveld são compatíveis em uma barra de erro para as amostras tratadas a 520 e $560{ }^{\circ} \mathrm{C}$, porém aqueles calculados para as 
amostras envelhecidas a 600 são compatíveis em duas barras de erro. Além disso, os valores de parâmetro de rede da austenita e da martensita estimados pelos dois métodos são incompatíveis em três barras de erro.

$\mathrm{Na}$ tabela 19, observa-se que o parâmetro da austenita diminui com o aumento da temperatura de envelhecimento para tratamentos isócronos entre 520 e $560{ }^{\circ} \mathrm{C}$ por 1 hora e 18 horas no método de Rietveld e no método de intensidade integrada. Esse fato ocorre devido à mudança na composição química da austenita com a temperatura de envelhecimento, como foi observado por Pardal e coautores (2006) e por Li e Yin (1995), o que minimiza a distorção do parâmetro de rede. Além disso, Pardal e coautores (2006) também observaram o aumento da proporção de austenita em um aço maraging 300 devido ao aumento da temperatura e do tempo de envelhecimento.

Já o parâmetro de rede da martensita calculado apresentou uma diminuição com o aumento da temperatura de envelhecimento até $560{ }^{\circ} \mathrm{C}$, como visto na figura 78; o que foi também observado por Habiby e coautores (1996), em um aço maraging 350 para amostras tratadas até $650^{\circ} \mathrm{C}$, e por Pardal e coautores (2006) em um aço maraging 300 para amostra envelhecidas em 560 e $600{ }^{\circ} \mathrm{C}$. O decréscimo do parâmetro de rede é devido à precipitação de átomos substitucionais que estavam na rede cristalina supersaturada da martensita, diminuindo a distorção do parâmetro de rede (HABIBY et. al.,1996).

Além da influência das medidas de difração de raios $X$, as medidas magnéticas foram realizadas também para acompanhar a evolução da cinética de reversão da martensita como função do tempo e da temperatura de envelhecimento, como apresentado na figura 77. 


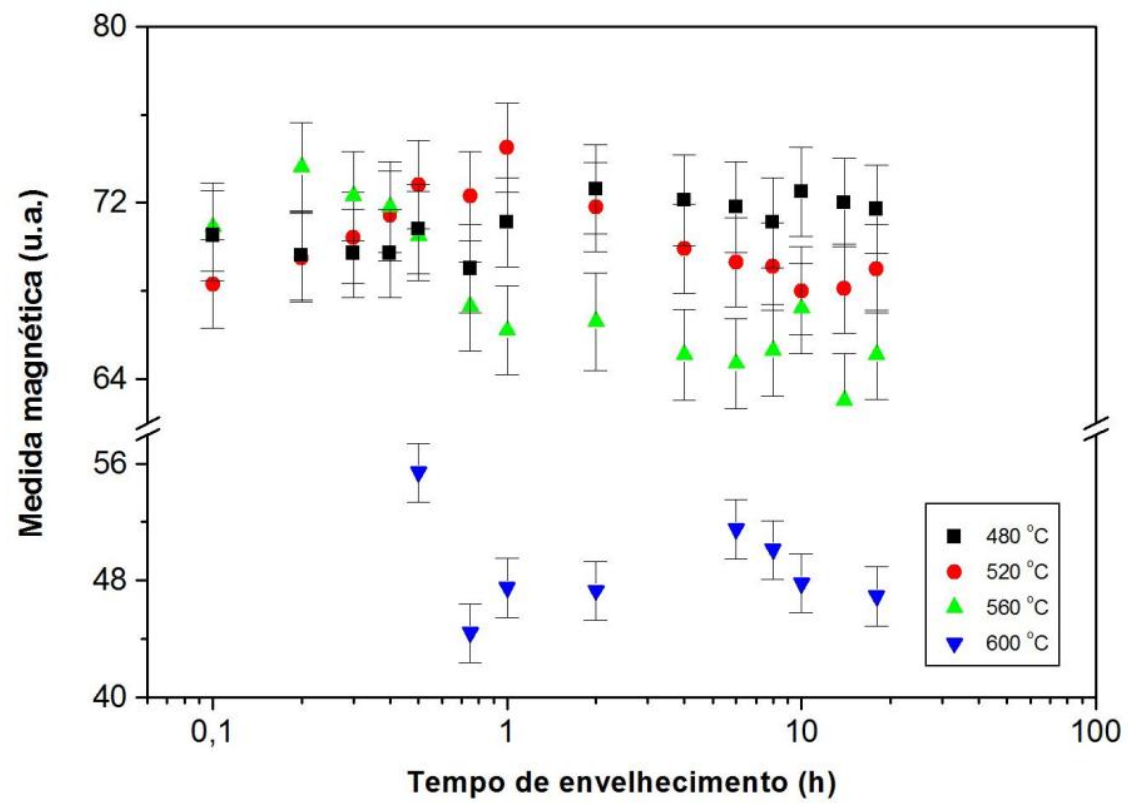

Figura 77: Variação das medidas magnéticas como função do tempo de envelhecimento para as temperaturas 520,560 e $600{ }^{\circ} \mathrm{C}$ no aço maraging $350 \mathrm{~B}$.

A figura 77 mostra que há um efeito significativo do tempo e da temperatura de envelhecimento nas medidas magnéticas realizadas com o ferritoscópio, o que pode indicar que a proporção de austenita aumenta, uma vez que a austenita é uma fase paramagnética. Dessa maneira, foi verificada a relação entre as medidas ferromagnéticas realizadas com o ferritoscópio e a fração volumétrica calculada pelo método de intensidade integrada para a difração de raios $X$ no aço maraging $350 B$, conforme apresentado na figura 78.

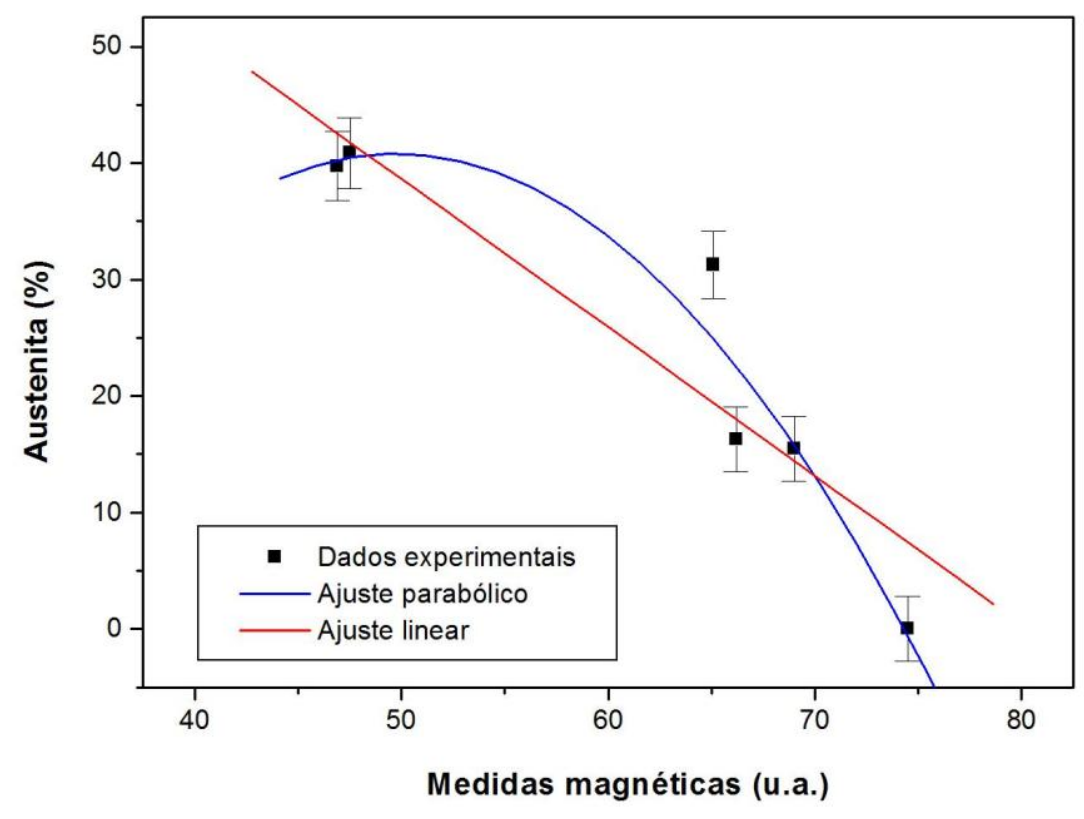

Figura 78: Relação entre medidas magnéticas feitas com o ferritoscópio e a fração volumétrica para o aço maraging 350B. 
Os valores dos coeficientes das regressões linear e polinomial de $2^{\circ}$ grau, bem como do coeficiente de determinação $R^{2}$, para ambos ajustes, são apresentados na tabela 20.

Tabela 20: Valores dos coeficientes das regressões linear e polinomial de $2^{\circ}$ grau das medidas magnéticas como função da fração volumétrica da austenita para o aço maraging 350B. ${ }^{11}$

\begin{tabular}{ccccc}
\hline Regressão & $\mathrm{A}$ & $\mathrm{B}$ & $\mathrm{C}$ & $\mathrm{R}^{2}$ \\
\hline $\begin{array}{c}\text { Linear } \\
\begin{array}{c}\text { Polinômio de } 2^{\circ} \\
\text { grau }\end{array}\end{array}$ & 102,26 & $-1,27$ & - & 0,81 \\
\hline
\end{tabular}

A tabela 20 mostra que 0 valor do coeficiente de determinação $R^{2}$ da regressão polinomial de $2^{\circ}$ grau é maior que a regressão linear, indicando que o ajuste polinomial de $2^{\circ}$ grau se ajusta melhor aos dados experimentais. Pardal et al. (2007) observaram também que um polinômio de $2^{\circ}$ grau se ajusta melhor aos dados experimentais de saturação magnética e de fração volumétrica, o que foi atribuído às mudanças de composição química da austenita e da martensita que também influenciam nas propriedades magnéticas.

Com base nos coeficientes do ajuste polinomial e nas medidas magnéticas, pode-se obter os valores da fração volumétrica da austenita como função do tempo de envelhecimento, como apresentado na figura 79.

${ }^{11}$ Os coeficientes do ajuste linear são representados na equação da seguinte maneira:

$$
y=A+B \cdot x
$$

Já os coeficientes do ajuste polinomial de $2^{\circ}$ grau na equação da seguinte forma:

$$
y=A+B \cdot x+C \cdot x^{2}
$$




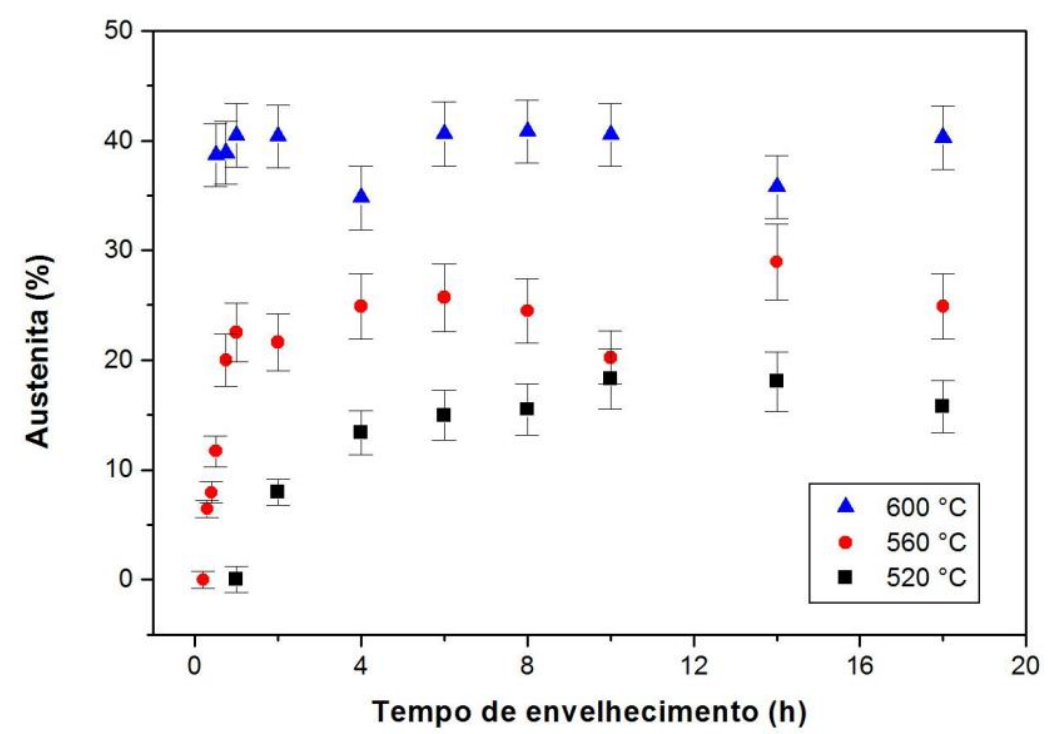

Figura 79: Variação da fração volumétrica da austenita como função do tempo e da temperatura de envelhecimento para o aço maraging 350B.

$\mathrm{Na}$ figura 79, observa-se que a cinética de reversão da austenita é fortemente influenciada pela temperatura de envelhecimento. Quanto maior a temperatura de envelhecimento, mais rapidamente a fração volumétrica alcança um patamar constante, o que pode ser notado quando se compara o comportamento da fração volumétrica da austenita como função do tempo de envelhecimento para 520, $560 \mathrm{e}$ $600{ }^{\circ} \mathrm{C}$. Esse comportamento assintótico também foi observado por Pardal e coautores (2006) em um aço maraging 300.

\subsubsection{Estudo da cinética de precipitação e do comportamento da curva de envelhecimento para $\mathrm{O}$ aço maraging $350 \mathrm{~B}^{12}$}

Como dito anteriormente, as medidas de dureza permitem tanto o estudo da cinética de precipitação quanto o estudo das mudanças de mecanismo de endurecimento durante o envelhecimento em aços maraging (GUO, SHA, 2002; PARDAL et al., 2005; SHA, 2000; WILSON, 1996; VISWANATHAN, DEY, ASUNDI,1993a; FLOREEN, DECKER, 1962; SINHA et al., 1998). Nesta tese, as

\footnotetext{
${ }^{12}$ Neste item, os aços maraging com cobalto serão precedidos pela letra $C$ da classificação de sua série. Por exemplo, um aço maraging 250 com cobalto como aço maraging C250. Já os aços maraging $250 \mathrm{sem}$ cobalto também serão precedidos pela letra $T$ e do número que classifica a sua série. Dessa forma, um aço maraging 250 sem cobalto será expresso como aço maraging T250. Esse tipo de classificação é comum junto aos fabricantes e à literatura científica. O objetivo dessa abreviação é tornar as tabelas mais concisas e claras ao leitor da tese.
} 
medidas de dureza foram usadas para avaliar o efeito da temperatura e do tempo de envelhecimento no comportamento da curva de envelhecimento e na cinética de precipitação no aço maraging 350B.

O ponto de partida para esses estudos no aço maraging 350B foi a medição da microdureza de amostras tratadas em diversos tempos de envelhecimento, entre 440 e $600^{\circ} \mathrm{C}$, conforme mostrado na figura 80 .

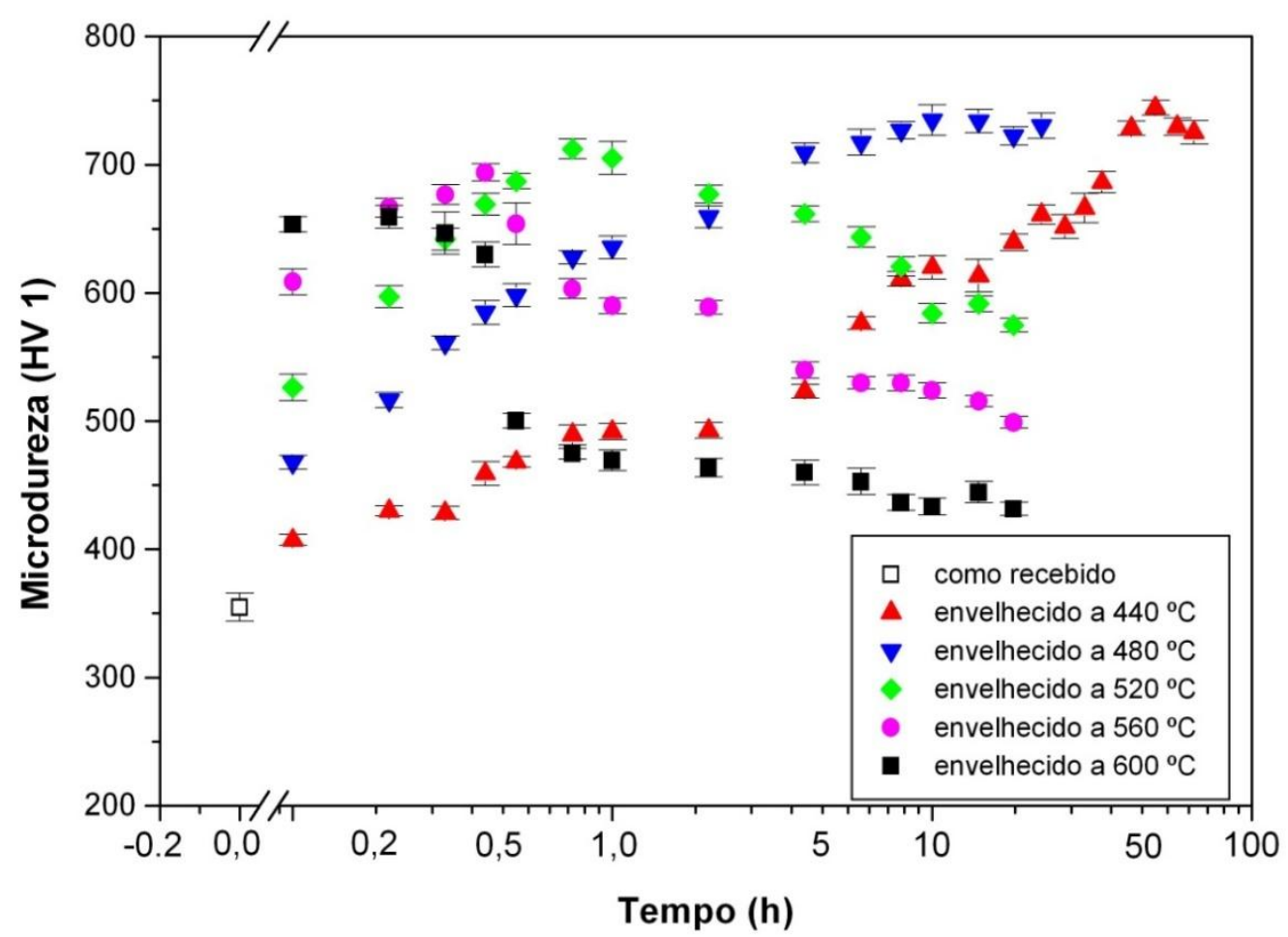

Figura 80: Variação da microdureza Vickers (carga 1kg) de amostras envelhecidas do aço maraging 350B como função do tempo em $440,480,520,560$ e $600^{\circ} \mathrm{C}$.

$\mathrm{Na}$ figura 80 , observa-se que a variação de microdureza das amostras segue o comportamento típico de uma curva de envelhecimento com um pico de dureza, uma etapa de endurecimento e outra de amolecimento (GUO, SHA, 2002; PARDAL et al., 2005; SHA, 2000; WILSON, 1996; VISWANATHAN, DEY, ASUNDI,1993a; FLOREEN, DECKER, 1962). Ademais, nota-se também que o tempo necessário para se alcançar o pico de dureza é progressivamente reduzido quando a temperatura de envelhecimento aumenta. Esse comportamento esperado é devido ao aumento na taxa de difusão dos átomos de soluto por meio da matriz, como resultado do aumento de temperatura (MARTIN, 1998). Pardal et al. (2005) e Viswanathan et al. (1993a) também observaram que este tempo segue uma relação 
do tipo Arrhenius em aços maraging, que será discutida com maior detalhe no item 4.3.3.1.

Observa-se também que o tempo de incubação é muito curto entre 440 e 600 ${ }^{\circ} \mathrm{C}$, uma vez que foi detectada uma variação na microdureza para tempo de envelhecimento de 6 min e $440^{\circ} \mathrm{C}$. Essa variação é maior para temperaturas mais altas devido à difusão de átomos de soluto da matriz. Peters e Cupp (1966) também observaram um aumento na dureza e uma diminuição da resistividade elétrica para tempos muito curtos de envelhecimento: no intervalo de 0,01 a $0,1 \mathrm{~h}$ para temperaturas entre 427 e $593^{\circ} \mathrm{C}\left(800\right.$ e $\left.1100^{\circ} \mathrm{F}\right)$, em um aço maraging C250.

Além da diminuição do tempo necessário para alcançar o pico de dureza com o aumento da temperatura, o valor máximo de dureza também é influenciado por essa variável. Nos experimentos, os valores mensurados do pico de dureza foram $744 \pm 6,734 \pm 12,712 \pm 8,694 \pm 7$ e $659 \pm 9 \mathrm{kgf} / \mathrm{mm}^{2}$, respectivamente, em 440 , $480,520,560$ e $600{ }^{\circ} \mathrm{C}$. A diminuição do valor máximo de dureza é devido à produção de precipitados maiores em temperaturas de envelhecimento mais altas. Além disto, como a solubilidade em geral diminui com a diminuição da temperatura, é razoável supor que a fração volumétrica de precipitados seja maior para as temperaturas de envelhecimento mais baixas. Consequentemente, para temperaturas de envelhecimento mais altas, os precipitados terão maior espaçamento entre si e serão menos eficientes na inibição da movimentação das discordâncias (MARTIN,1998).

A partir das medições de microdureza, mostradas na figura 46, foram realizados o estudo da cinética de precipitação, exposto no tópico 4.3.3.1, e a análise dos mecanismos de endurecimento ou amolecimento durante 0 envelhecimento, apresentada no tópico 4.3.3.2.

\subsubsection{Estudo da cinética de precipitação para o aço maraging 350B}

O estudo da cinética de precipitação no aço maraging 350B consistiu na análise dessa reação com o uso das equações Johnson-Mehl-Avrami-Kolmogorov (JMAK) e Austin-Rickett (AR). Além da comparação desses modelos, diversos métodos derivados do modelo de Arrhenius também foram utilizados para estimar a energia de ativação para a precipitação.

Como foi apresentado anteriormente no item 2.4.1, a obtenção da fração transformada é essencial para o estudo dos modelos JMAK e Austin-Rickett, que 
pode ser feito com base nos dados de microdureza de amostras envelhecidas apresentados na figura 45. Para cada temperatura fixa são usados os dados da microdureza no tempo de envelhecimento $t, \mathrm{H}_{t}$, o valor do pico de dureza $\mathrm{H}_{\text {MAX }}$ e o valor da dureza no estado solubilizado $\mathrm{H}_{0}$ que, no caso da amostra $350 \mathrm{~B}$, adotou-se a média de todas as regiões do disco (MITTEMEIJER, 1992; SINHA et al., 1998; STARINK, 1997).

A fração transformada como função do tempo e da temperatura de envelhecimento é apresentada na figura 81.

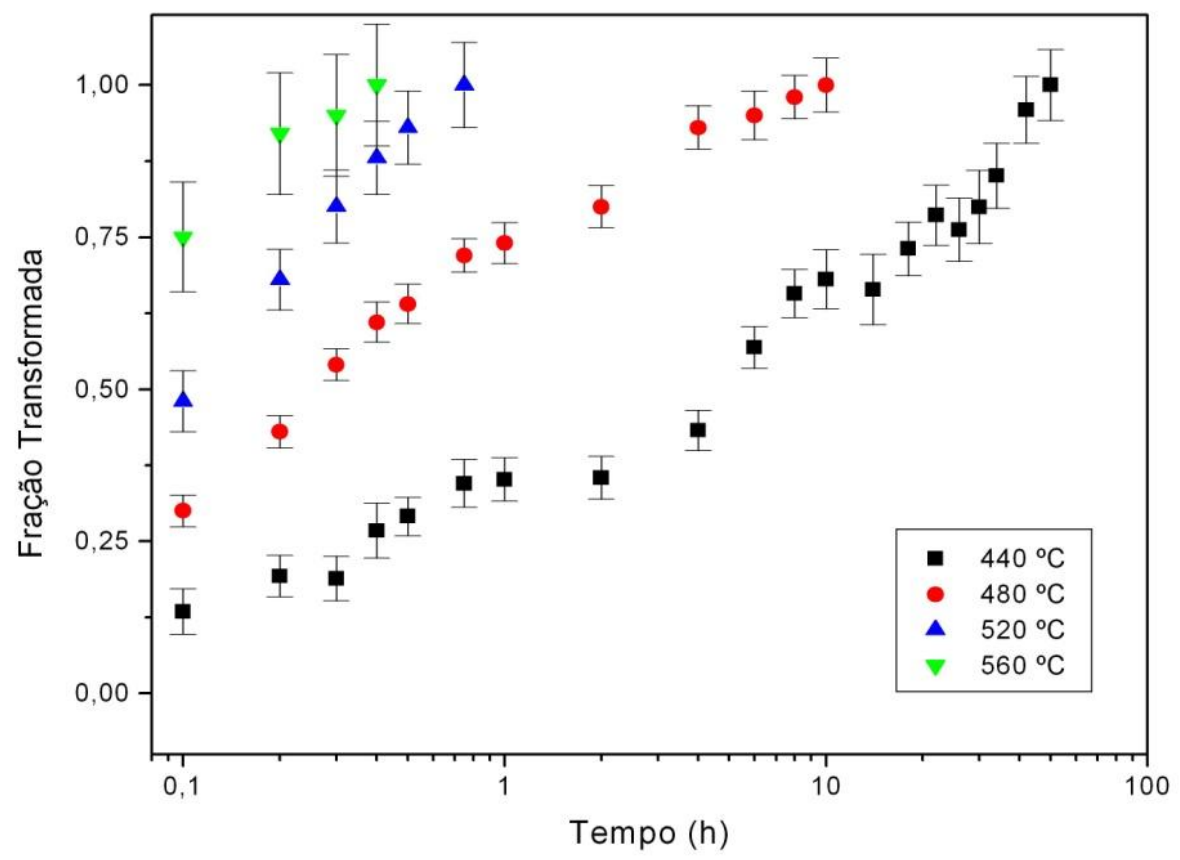

Figura 81: Fração transformada como função do tempo em 440, 480, 520 e $560{ }^{\circ} \mathrm{C}$ para o aço maraging $350 \mathrm{~B}$.

A figura 81 mostra que há uma aceleração da cinética de precipitação com o aumento da temperatura, de forma a indicar que a precipitação é termicamente ativada. Além disso, a figura 81 também evidencia que a precipitação tem um tempo de incubação muito baixo ou até mesmo inexistente para as temperaturas estudadas. Peters e Cupp (1966), Sinha et al. (1998) e Pardal et al. (2006) também observaram uma mudança significativa na microdureza para curtos períodos de tempo em diversas composições de aços maraging.

Com a obtenção dos dados de fração transformada, a cinética de precipitação foi estudada por meio do modelo JMAK. A partir da equação JMAK generalizada, apresentada no item 2.2.4.1, pôde-se deduzir a expressão linearizada para essa equação, descrita por: 


$$
G f=\ln \ln \frac{1}{1-f}=n \cdot \ln k+n \cdot \ln t(22)
$$

Nos quais $f$ é a fração transformada; $k$, a constante de velocidade cinética; $n$, a constante de Avrami; t, o tempo de envelhecimento e $G(f)$, uma função da fração transformada.

A partir da equação 12 foi realizada uma regressão linear dos dados de fração transformada com o modelo JMAK, conforme mostrado na figura 82.

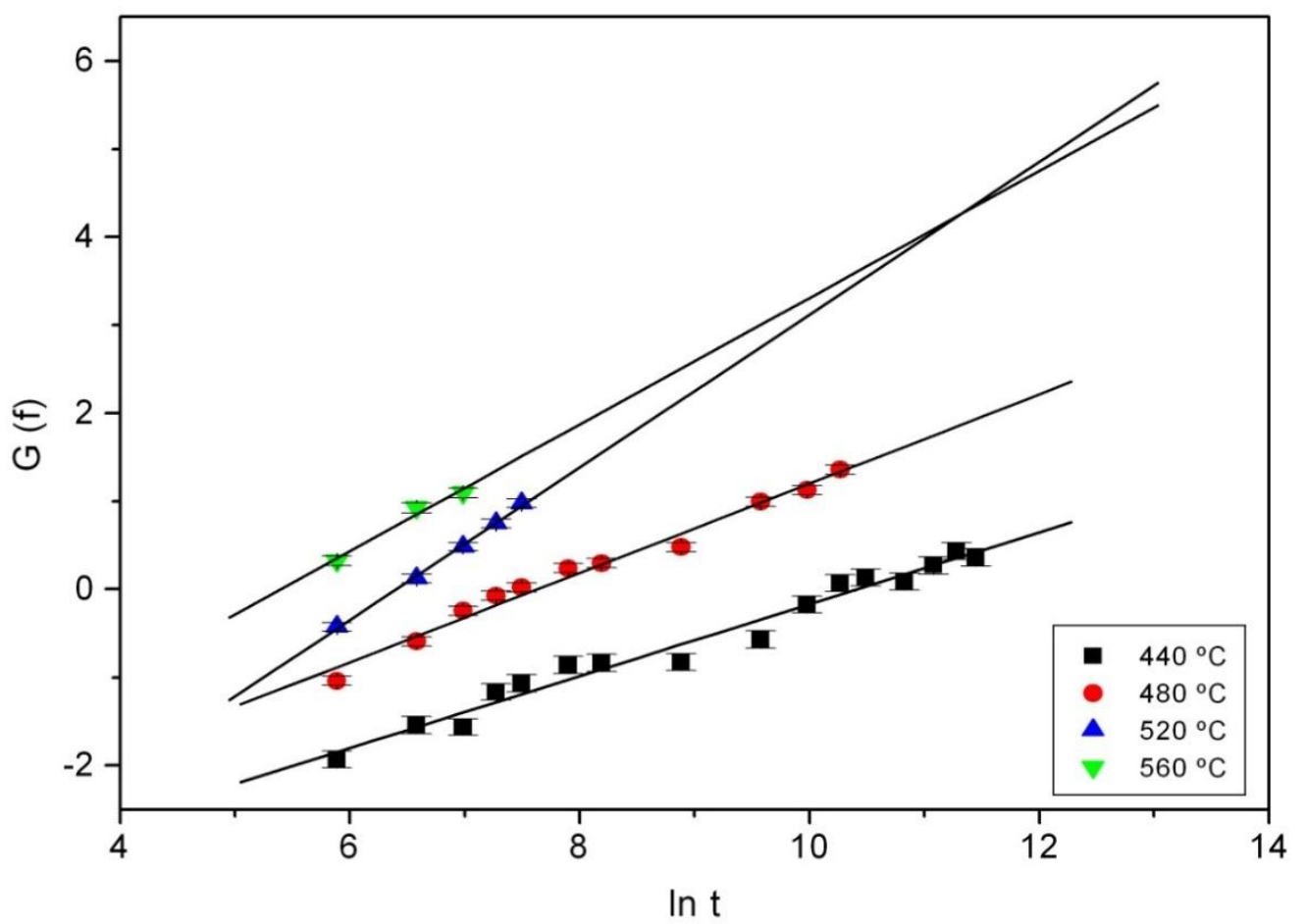

Figura 82: Regressão linear da equação JMAK linearizada a partir dos dados de fração transformada para o aço maraging $350 \mathrm{~B}$ nas temperaturas $440,480,520$ e $560^{\circ} \mathrm{C}$.

A figura 82 mostra que a regressão linear ajustou-se bem aos dados experimentais. Uma comparação dos valores das constantes da equação JMAK, obtidos nesta tese para cada temperatura com aqueles determinados por Vasudevan et al. (1990) e Sinha et al. (1998), é apresentada na tabela 21. 
Tabela 21: Valores das constantes da equação JMAK obtidas diversos autores e por regressão linear para o aço maraging 350B (VASUDEVAN et al, 1990; SINHA et al,1998).

\begin{tabular}{|c|c|c|c|c|}
\hline Referência & $\begin{array}{c}\text { Temperatura } \\
\left({ }^{\circ} \mathrm{C}\right)\end{array}$ & Faixa de tempo & $\begin{array}{c}\text { Constante de } \\
\text { Avrami n }\end{array}$ & $\begin{array}{c}\text { Técnica } \\
\text { experimental }\end{array}$ \\
\hline $\begin{array}{l}\text { Maraging T250 } \\
\text { (Vasudevan et al,,1990) }\end{array}$ & 427 & 0,017 a $100 h$ & 0,20 & Resistividade \\
\hline $\begin{array}{l}\text { Maraging T250 } \\
\text { (Sinha et al., 1998) }\end{array}$ & 450 & 5 a $15 \mathrm{~min}$ & 0,6 & Microdureza \\
\hline $\begin{array}{l}\text { Maraging T250 } \\
\text { (Sinha et al., 1998) }\end{array}$ & 450 & 15 a $600 \mathrm{~min}$ & 0,28 & Microdureza \\
\hline $\begin{array}{l}\text { Maraging C250 } \\
\text { (Vasudevan et al,,1990) }\end{array}$ & 427 & $0,017 \mathrm{~h}$ a $100 \mathrm{~h}$ & 0,39 & Resistividade \\
\hline $\begin{array}{l}\text { Maraging C350 } \\
\text { (Este trabalho) }\end{array}$ & 440 & $0,1 \mathrm{~h}$ a $50 \mathrm{~h}$ & $0,408 \pm 0,018$ & Microdureza \\
\hline $\begin{array}{l}\text { Maraging T250 } \\
\text { (Vasudevan et al,,1990) }\end{array}$ & 482 & $0,017 \mathrm{~h}$ a $100 \mathrm{~h}$ & 0,20 & Resistividade \\
\hline $\begin{array}{l}\text { Maraging T250 } \\
\text { (Sinha et al., 1998) }\end{array}$ & 480 & 5 a $15 \mathrm{~min}$ & 0,55 & Microdureza \\
\hline $\begin{array}{l}\text { Maraging T250 } \\
\text { (Sinha et al., 1998) }\end{array}$ & 480 & 15 a $180 \mathrm{~min}$ & 0,32 & Microdureza \\
\hline $\begin{array}{l}\text { Maraging T250 } \\
\text { (Sinha et al., 1998) }\end{array}$ & 500 & 5 a $60 \mathrm{~min}$ & 0,34 & Microdureza \\
\hline $\begin{array}{l}\text { Maraging C250 } \\
\text { (Vasudevan et al,,1990) }\end{array}$ & 482 & 0,017 a $50 h$ & 0,39 & Resistividade \\
\hline $\begin{array}{l}\text { Maraging C350 } \\
\text { (Este trabalho) }\end{array}$ & 480 & 0,1 a $10 \mathrm{~h}$ & $0,51 \pm 0,02$ & Microdureza \\
\hline $\begin{array}{l}\text { Maraging T250 } \\
\text { (Vasudevan et al,,1990) }\end{array}$ & 538 & 0,017 a $100 h$ & 0,21 & Resistividade \\
\hline $\begin{array}{l}\text { Maraging C250 } \\
\text { (Vasudevan et al,,1990) }\end{array}$ & 538 & 0,017 a $6 \mathrm{~h}$ & 0,45 & Resistividade \\
\hline $\begin{array}{l}\text { Maraging C350 } \\
\text { (Este trabalho) }\end{array}$ & 520 & 0,1 a $0,75 \mathrm{~h}$ & $0,867 \pm 0,023$ & Microdureza \\
\hline $\begin{array}{l}\text { Maraging C350 } \\
\text { (Este trabalho) }\end{array}$ & 560 & 0,1 a $0,4 \mathrm{~h}$ & $0,72 \pm 0,12$ & Microdureza \\
\hline
\end{tabular}

A tabela 21 mostra que os valores da constante $\mathrm{n}$ de Avrami podem variar de acordo com o material analisado, com a técnica experimental usada, bem como a temperatura e o tempo de envelhecimento aplicados nas amostras.

Sinha e coautores (1998) estudaram a cinética de precipitação em um aço maraging T250 por meio de medidas de microdureza Rockwell C. Eles verificaram 
que a constante $\mathrm{n}$ apresenta dois valores distintos para uma mesma temperatura em 450 e $480^{\circ} \mathrm{C}$, enquanto a estimativa de $\mathrm{n}$ apresenta um único valor em $500^{\circ} \mathrm{C}$. Esse comportamento de $\mathrm{n}$, nas temperaturas 450 e $480^{\circ} \mathrm{C}$, foi atribuído a dois estágios de precipitação. O primeiro estágio com valor de $n$ entre 0,55 e 0,60 seria uma etapa de pré-precipitação, enquanto o segundo estágio, com valor da constante de Avrami de 0,28 a 0,34 , seria uma etapa de precipitação. Além disso, Sinha e coautores (1998) também observaram que a constante $\mathrm{n}$ referente à etapa de precipitação aumenta com o incremento da temperatura em um aço maraging T250.

Vasudevan e coautores (1990) também estudaram de forma comparativa a cinética de precipitação em aços maraging T250 e C250. Eles observaram que a regressão linear feita a partir dos dados experimentais tem um único estágio para cada temperatura. Ademais, a constante $\mathrm{n}$ de Avrami determinada com base nessas regressões tem o valor de 0,39 para 427 e $482{ }^{\circ} \mathrm{C}$ de um aço maraging C250, enquanto a constante de Avrami é 0,45 para $538^{\circ} \mathrm{C}$. Dessa maneira, a constante de Avrami também aumentou em virtude do incremento da temperatura de envelhecimento para o aço maraging C250. Já a constante $\mathrm{n}$ manteve-se estável com valores entre 0,20 e 0,21 em 427, 482 e $538^{\circ} \mathrm{C}$ para o aço maraging T250.

Quando são comparados os valores das constantes $n$ determinados por Sinha et al. (1998) e Vasudevan et al. (1990) para o aço maraging T250, observa-se uma discrepância entre os valores obtidos. Sinha e coautores (1990) usaram medidas de microdureza para fazer a análise cinética JMAK, enquanto Vasudevan e coautores (1990) utilizaram medidas de resistividade elétrica para estudar a cinética do modelo mencionado. Essa diferença pode estar relacionada com o comportamento inicial das curvas de microdureza e resistividade. Vasudevan et al. (1990) observaram que em estágios iniciais da precipitação há uma variação mais discreta da resistividade do que aquela observada na microdureza Vickers. Por exemplo, quando mediram a resistividade numa amostra em estado como recebido obtiveram o valor de 0,64 $\mu \Omega$.m, já em outra, tratada a $538^{\circ} \mathrm{C}$ por $1 \mathrm{~min}(0,017 \mathrm{~h})$, obtiveram $0,61 \mu \Omega . \mathrm{m}$. Em relação à microdureza Vickers, as medidas no estado como recebido apresentaram o valor de $275 \mathrm{kgf} / \mathrm{mm}^{2}$; na amostra tratada a $538{ }^{\circ} \mathrm{C}$ por $1 \mathrm{~min}(0,017 \mathrm{~h}), 380$ $\mathrm{kg} / \mathrm{mm}^{2}$ (VASUDEVAN et al.,1990). Portanto, observa-se que a variação na microdureza Vickers foi de $38 \%$ e na resistividade foi de $4,7 \%$, o que evidencia um comportamento diferenciado dessas medidas quando comparadas entre si nos estágios iniciais de precipitação no aço maraging C250. 
Agnel e coautores (1977) fizeram também uma análise comparativa dos valores da constante $\mathrm{n}$ de Avrami obtidos por meio de resistividade e de microdureza para uma liga Fe-16,4Ni-8,2Mo. Nesse estudo, eles observaram certa discrepância nos valores da constante $\mathrm{n}$ a partir dessas medidas para amostras envelhecidas entre 431 e $473^{\circ} \mathrm{C}$, o que reforça o aspecto semiquantitativo de ambas as técnicas.

Os valores obtidos da constante $\mathrm{n}$ de Avrami para o aço maraging 350 $\mathrm{B}$ foram $0,408 \pm 0,018,0,507 \pm 0,0220,867 \pm 0,023,0,72 \pm 0,12$, respectivamente, para 440 , 480, 520 e $560^{\circ} \mathrm{C}$. Dessa maneira, observou-se que os valores da constante de Avrami para o aço maraging 350B aumentaram como função do incremento de temperatura entre 440 e $520{ }^{\circ} \mathrm{C}$ e permaneceram constantes para 520 e $560{ }^{\circ} \mathrm{C}$, quando considerados uma barra de erro. Além disso, os dados experimentais seguem o comportamento de uma única reta da equação JMAK linearizada para cada temperatura, o que sugere um único estágio da precipitação para cada temperatura.

Conforme visto anteriomente no item 2.2.4.1, Starink (1997) observou que o modelo JMAK apresenta fraca correlação com as mudanças microestruturais devido à precipitação em algumas ligas ferrosas e de alumínio. Dessa maneira, foi analisado também o modelo de Austin-Rickett que, na forma linearizada, é dado por:

$$
G f=\ln \frac{1}{1-1 / f}=n \cdot \ln k+n \cdot \ln t(23)
$$

A partir da equação mencionada foi feito um gráfico com base nos dados de fração transformada com a finalidade de comparar os resultados obtidos com os da equação JMAK, como apresentado na Figura 83. 


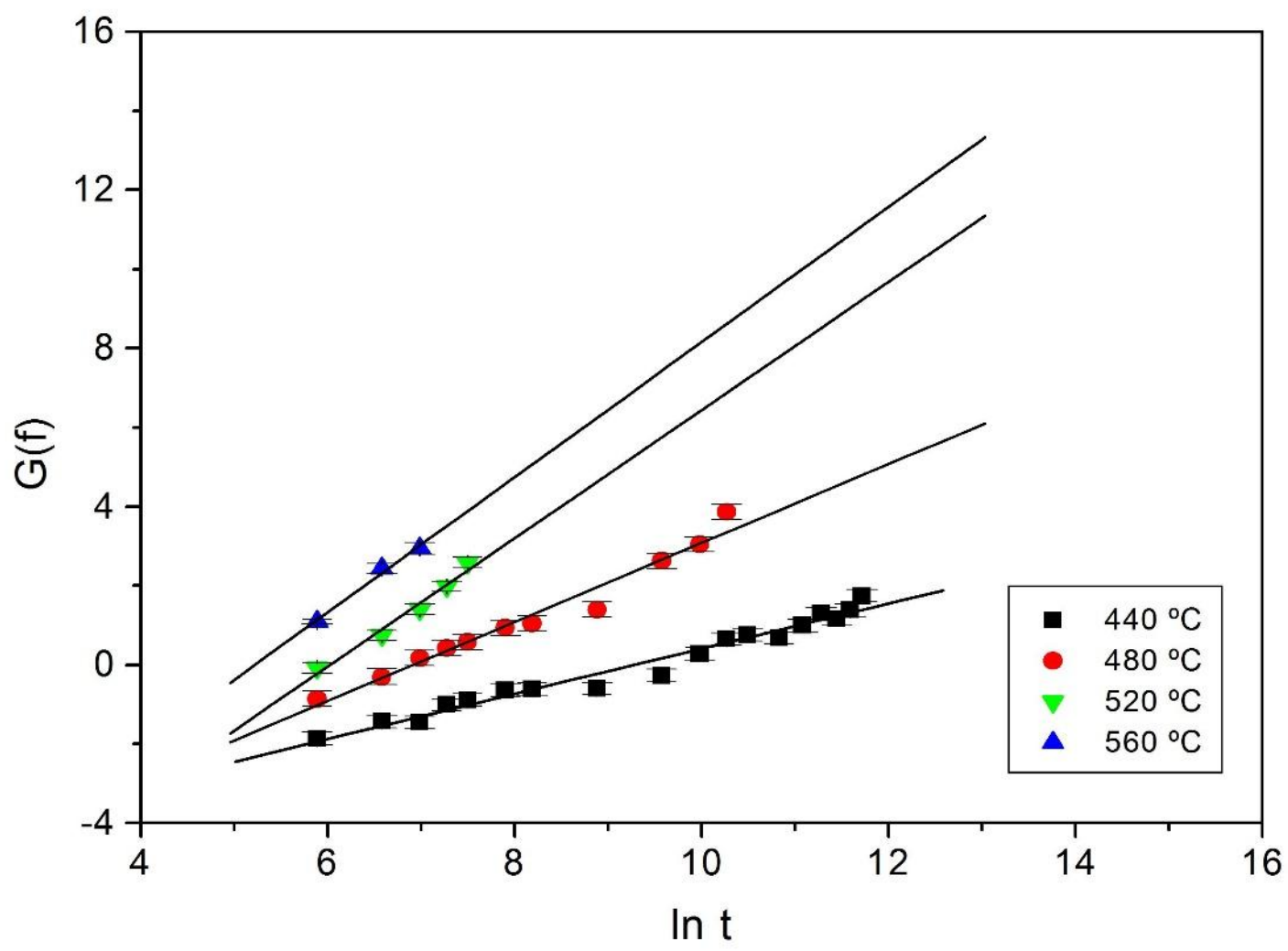

Figura 83: Regressão linear da equação Austin-Rickett linearizada a partir dos dados de fração transformada para o aço maraging $350 \mathrm{~B}$ nas temperaturas $440,480,520$ e $560^{\circ} \mathrm{C}$.

Uma análise comparativa das constantes $\mathrm{n}$ dos modelos Austin-Ricket $\mathrm{e}$ JMAK, obtidas a partir da regressão linear dos dados experimentais, é mostrada na Tabela 22, bem como as suas interpretações dessas constantes com base no trabalho de Rios e Padilha (2007), Starink (1997) e Christian (1975), apresentadas na seção 2.4.1. 
Tabela 22: Valores das constantes cinéticas $\mathrm{n}$ e In $\mathrm{k}$ para o modelo Austin-Rickett e o modelo JMAK para diversas temperaturas de envelhecimento no aço maraging $350 \mathrm{~B}$, bem como as suas possíveis interpretações com base nos trabalhos de Rios e Padilha (2007), Starink (1997) e Christian (1975).
$\mathrm{T}\left({ }^{\circ} \mathrm{C}\right)$ Modelo Constante $\mathrm{n}$
Ln k
$\mathrm{R} \quad$ Possíveis interpretações da constante $\mathrm{n}$

\begin{tabular}{|c|c|c|c|c|c|}
\hline \multirow[t]{2}{*}{440} & AR & $0,570 \pm 0,026$ & $-9,2 \pm 0,4$ & 0,984 & $\begin{array}{l}\text { Precipitação nas discordâncias em estágios } \\
\text { iniciais }(n=0,67) \text {. Também seria possível a } \\
\text { ocorrência do engrossamento de plaquetas } \\
\text { muito grandes, por exemplo, após o } \\
\text { encontro de arestas ou crescimento de } \\
\text { precipitados nos contornos de grão }(n=0,5)\end{array}$ \\
\hline & JMAK & $0,408 \pm 0,018$ & $-10,4 \pm 0,4$ & 0,987 & $\begin{array}{l}\text { Engrossamento de plaquetas muito } \\
\text { grandes, por exemplo, após o encontro de } \\
\text { arestas ou crescimento de precipitados nos } \\
\text { contornos de grão }(n=0,5)\end{array}$ \\
\hline \multirow{2}{*}{480} & $A R$ & $1,00 \pm 0,06$ & $-6,9 \pm 0,5$ & 0,994 & $\begin{array}{l}\text { Crescimento de cilindros longos finitos em } \\
\text { comparação com a distância de separação } \\
\text { entre eles com taxa de nucleação zero ( } \mathrm{n} \\
=1 \text { ) }\end{array}$ \\
\hline & JMAK & $0,507 \pm 0,022$ & $-7,6 \pm 0,4$ & 0,991 & $\begin{array}{l}\text { Engrossamento de plaquetas muito } \\
\text { grandes, por exemplo, após o encontro de } \\
\text { arestas ou crescimento de precipitados nos } \\
\text { contornos de grão }(n=0,5)\end{array}$ \\
\hline \multirow{2}{*}{520} & $A R$ & $1,62 \pm 0,15$ & $-6,0 \pm 0,6$ & 0,987 & $\begin{array}{l}\text { Crescimento de todos os precipitados, } \\
\text { crescendo a partir de pequenas dimensões } \\
\text { com taxa de nucleação igual a zero }(n=1,5) \\
\text { ou decrescente }(1,5<n<2,5)\end{array}$ \\
\hline & JMAK & $0,867 \pm 0,023$ & $-6,4 \pm 0,2$ & 0,999 & $\begin{array}{l}\text { Crescimento de cilindros longos finitos em } \\
\text { comparação com a distância de separação } \\
\text { entre eles com taxa de nucleação zero ( } \mathrm{n} \\
=1 \text { ) }\end{array}$ \\
\hline \multirow[b]{2}{*}{560} & AR & $1,71 \pm 0,19$ & $-5,2 \pm 0,7$ & 0,994 & $\begin{array}{l}\text { Crescimento de todos os precipitados, } \\
\text { crescendo a partir de pequenas dimensões } \\
\text { com taxa de nucleação igual a zero }(n=1,5) \\
\text { ou decrescente }(1,5<n<2,5)\end{array}$ \\
\hline & JMAK & $0,72 \pm 0,12$ & $-5,4 \pm 1,1$ & 0,987 & $\begin{array}{l}\text { Precipitação nas discordâncias em estágios } \\
\text { iniciais }(n=0,67) \text { ou crescimento de cilindros } \\
\text { longos finitos em comparação com a } \\
\text { distância de separação entre eles com taxa } \\
\text { de nucleação zero }(n=1)\end{array}$ \\
\hline
\end{tabular}

A tabela 22 mostra que tanto o modelo Austin-Rickett quanto o modelo JMAK apresentam uma boa correlação com os dados experimentais, porém os valores de $\mathrm{n}$, obtidos para cada temperatura em ambos os modelos, são incompatíveis entre si em três barras de erro. Contudo, os valores de In $\mathrm{k}$ obtidos pelos modelos JMAK e AR, para cada temperatura, são compatíveis entre si em duas barras de erro. Eles serão usados mais adiante a fim de estimar a energia de ativação para a reação de precipitação, por meio de expressões associadas à equação do tipo Arrhenius. 
A interpretação da constante $n$ para a equação Austin-Rickett é a mesma da utilizada para a equação JMAK e ambas possuem boa correlação com os dados (STARINK,1997). Assim, um critério para definir o modelo mais adequado para descrever a cinética da precipitação do aço maraging 350B seria a comparação das possíveis interpretações dos valores da constante $n$ do modelo JMAK e AR com estudos anteriores sobre a morfologia e a evolução microestrutural dos precipitados dos aços maraging durante o envelhecimento.

A interpretação das constantes $\mathrm{n}$ do modelo JMAK, a partir dos trabalhos de Rios e Padilha (2007), Starink (1997) e Christian (1975), sugere que a evolução microestrutural dos precipitados pode ter diversas etapas entre 440 e $560{ }^{\circ} \mathrm{C}$. Em 440 e $480^{\circ} \mathrm{C}$, poderia ocorrer tanto o engrossamento de plaquetas muito grandes após o encontro completo de arestas quanto o crescimento de precipitados nos contornos de grão. Enquanto para as temperaturas 520 e $560^{\circ} \mathrm{C}$, poderia acontecer o crescimento de cilindros longos finitos em comparação com a distância de separação entre eles com taxa de nucleação zero $(n=1)$. Além disso, há a possibilidade também da existência da precipitação nas discordâncias em estágios iniciais $(n=0,67)$ em $560^{\circ} \mathrm{C}$.

Já a interpretação da constante $n$ da equação Austin-Rickett, com base nos trabalhos mencionados, sugere também a ocorrência de diferentes estágios na evolução microestrutural dos precipitados durante o envelhecimento entre 440 e 560 ${ }^{\circ} \mathrm{C}$. Em $440{ }^{\circ} \mathrm{C}$, os possíveis mecanismos predominantes seriam a precipitação em discordâncias nos estágios iniciais $(n=0,67)$ ou também a ocorrência do engrossamento de plaquetas muito grandes; por exemplo, após o encontro de arestas ou crescimento de precipitados nos contornos de grão $(n=0,5)$. Além disso, um dos estágios da precipitação em $480{ }^{\circ} \mathrm{C}$ poderia ser o crescimento de cilindros longos finitos em comparação com a distância de separação entre eles, com taxa de nucleação zero $(n=1)$. Por fim, em 520 e $560{ }^{\circ} \mathrm{C}$, poderia haver o crescimento de todos os precipitados crescendo a partir de pequenas dimensões com taxa de nucleação igual a zero $(n=1,5)$ ou decrescente $(1,5<n<2,5)$.

A cinética local da microestrutura observada por diversos autores mostra que os precipitados dos aços maraging apresentam mudanças de morfologia durante o envelhecimento, conforme discutido na seção 2.3.3.1. Para temperaturas abaixo de $450{ }^{\circ} \mathrm{C}$, ocorre a precipitação nas discordâncias em estágios iniciais nos aços 
maraging. Essa reação propicia a formação das fases esferoidais $S, \omega$ e $X$ por meio de mecanismos de aglomeração e ordenamento (TEWARI et al., 2000; SERVANT; MAEDER; CIZERON, 1975; SHA; CEREZO; SMITH, 1993a, 1993c, 1993d). Enquanto em $480{ }^{\circ} \mathrm{C}$, há o crescimento dos precipitados elipsoidais $\mathrm{Ni}_{3} \mathrm{Ti}$ e cilíndricos $\mathrm{Ni}_{3} \mathrm{Mo}$ e a formação de precipitados esféricos $\mathrm{Fe}_{2} \mathrm{Mo}$ para amostras tratadas por um tempo prolongado (50 horas) (TEWARI et al., 2000; VASUDEVAN; KIM; WAYMAN, 1990).

Já em $510{ }^{\circ} \mathrm{C}$ ocorre a formação de aglomerados esféricos, que contêm titânio e molibdênio, em amostras tratadas por até 6 min. Nessa temperatura, há também a presença de precipitados esféricos $\mathrm{Fe}_{2} \mathrm{Mo}$ ou $\mathrm{Fe}_{7} \mathrm{Mo}_{6}$, precipitados elipsoidais $\mathrm{Ni}_{3} \mathrm{Ti}$ e precipitados $\mathrm{Ni}_{3} \mathrm{Mo}$ cilíndricos para tempos mais prolongados de envelhecimento (SHA; CEREZO; SMITH, 1993a, 1993d; MOSHKA et al., 2015; VISWANATHAN; DEY; ASUNDI, 1993a). Por fim, não foram encontrados estudos da morfologia dos precipitados em aços maraging em $560{ }^{\circ} \mathrm{C}$ entre $0,1 \mathrm{~h}$ e $0,4 \mathrm{~h}$. Todavia, uma análise microestrutural feita por Vasudevan et al. (1990) e Viswanathan et al. (1993a), em amostras de um aço maraging C250 superenvelhecida em $538^{\circ} \mathrm{C}$ por 50 horas e de um aço maraging C350 tratada em $575{ }^{\circ} \mathrm{C}$ por 8 horas, mostrou a presença de precipitados esféricos $\mathrm{Fe}_{2} \mathrm{Mo}$, precipitados cilíndricos $\mathrm{Ni}_{3} \mathrm{Ti}$ e austenita revertida, o que indica a presença dos mesmos precipitados observados em $510^{\circ} \mathrm{C}$.

Dessa forma, uma análise comparativa da evolução microestrutural dos precipitados com as interpretações dos dados da constante $n$, para as equações JMAK e Austin-Rickett, evidencia que a equação AR descreve com maior verossimilhança a cinética local dos precipitados dos aços maraging do que o modelo JMAK. A tabela 23 sumariza as interpretações da constante $\mathrm{n}$ do modelo Austin-Rickett, a partir das observações da evolução da morfologia dos precipitados dos aços maraging. 
Tabela 23: Intepretação da constante cinética n para o modelo Austin-Rickett no aço maraging 350B entre 440 e $560^{\circ} \mathrm{C}$, tendo como base a evolução microestrutural local dos precipitados analisada por outros autores.

\begin{tabular}{|c|c|c|c|}
\hline $\mathrm{T}\left({ }^{\circ} \mathrm{C}\right)$ & Constante $\mathrm{n}$ & $\begin{array}{l}\text { Intervalo de } \\
\text { tempo (h) }\end{array}$ & Interpretação da constante $\mathrm{n}$ de Austin-Rickett \\
\hline 440 & $0,570 \pm 0,026$ & 0,1 a 50 & $\begin{array}{l}\text { Precipitação nas discordâncias em estágios iniciais }(\mathrm{n}=0,67) \\
\text { com a formação de fases esferoidais } \mathrm{S} \text {, w e X, por meio de } \\
\text { mecanismos de aglomeração e ordenamento (TEWARI et al., } \\
\text { 2000; SERVANT; MAEDER; CIZERON, 1975; SHA; } \\
\text { CEREZO; SMITH, 1993a, 1993c, 1993d; STARINK,1997). }\end{array}$ \\
\hline 480 & $1,00 \pm 0,06$ & 0,1 a 10 & $\begin{array}{l}\text { Crescimento de precipitados elipsoidais } \mathrm{Ni}_{3} \mathrm{Ti} \text { e precipitados } \\
\mathrm{Ni}_{3} \mathrm{Mo} \text { na forma de agulhas longas e finitas, em comparação } \\
\text { com a distância de separação entre eles com taxa de } \\
\text { nucleação zero }(\mathrm{n}=1 \text { ) (TEWARI et al., 2000; VASUDEVAN; } \\
\text { KIM; WAYMAN,1990; STARINK,1997) }\end{array}$ \\
\hline 520 & $1,62 \pm 0,15$ & 0,1 a 0,75 & $\begin{array}{l}\text { Crescimento de precipitados esféricos } \mathrm{Fe}_{2} \mathrm{Mo} \text { ou } \mathrm{Fe}_{7} \mathrm{Mo}_{6} \text {, } \\
\text { precipitados elipsoidais } \mathrm{Ni}_{3} \mathrm{Ti} \text { e precipitados } \mathrm{Ni}_{3} \mathrm{Mo} \text { na forma } \\
\text { de agulhas a partir de pequenos aglomerados contendo } \\
\text { níquel, titânio e molibdênio, com taxa de nucleação igual a } \\
\text { zero }(\mathrm{n}=1,5) \text { ou decrescente }(1,5<\mathrm{n}<2,5)(\mathrm{SHA} \text {; CEREZO; } \\
\text { SMITH, 1993a, 1993d; MOSHKA et al., 2015; } \\
\text { VISWANATHAN; DEY; ASUNDI, 1993a; STARINK,1997). }\end{array}$ \\
\hline 560 & $1,71 \pm 0,19$ & 0,1 a 0,4 & $\begin{array}{l}\text { Crescimento de precipitados esféricos } \mathrm{Fe}_{2} \mathrm{Mo} \text { ou } \mathrm{Fe}_{7} \mathrm{Mo}_{6} \text {, } \\
\text { precipitados elipsoidais } \mathrm{Ni}_{3} \mathrm{Ti} \text { e precipitados } \mathrm{Ni}_{3} \mathrm{Mo} \text { na forma } \\
\text { de agulhas a partir de pequenos aglomerados contendo } \\
\text { níquel, titânio e molibdênio com taxa de nucleação igual a } \\
\text { zero }(n=1,5) \text { ou decrescente }(1,5<\mathrm{n}<2,5)(\mathrm{SHA} \text {; CEREZO; } \\
\text { SMITH, 1993a, 1993d; MOSHKA et al., 2015; } \\
\text { VISWANATHAN; DEY; ASUNDI, 1993a; STARINK,1997). }\end{array}$ \\
\hline
\end{tabular}

Além da análise cinética por meio das equações JMAK e Austin-Rickett, os dados de microdureza permitem também a avaliação da energia de ativação para a precipitação, conforme visto na seção 2.2.4.1, que geralmente é feita por equações associadas ao modelo de Arrhenius. A expressão linearizada que relaciona o tempo para atingir o pico de dureza ou uma dada fração transformada fixa de transformação, como resultado do envelhecimento, segue uma relação do tipo Arrhenius (VISWANATHAN, DEY, ASUNDI,1993a; PARDAL et. al. 2006):

$$
\ln t=\frac{Q}{R T}+\ln t_{0}(24)
$$

$\mathrm{Na}$ qual $\mathrm{Q}$ é a energia de ativação para a precipitação, $\mathrm{R}$ é a constante universal dos gases, t e T são, respectivamente, o tempo e a temperatura, nos quais ocorrem o pico de dureza durante o envelhecimento. 
Além dessa abordagem, a energia de ativação pode ser também obtida por meio das constantes cinéticas $k$ das equações JMAK e Austin-Rickett, que segue da mesma forma uma relação do tipo Arrhenius. Na forma linearizada, a equação da constante $k$ é dada por (RIOS; PADILHA, 2007; CHRISTIAN, 1975; STARINK, 1997):

$$
\ln k=-\frac{E}{R T}+\ln k_{0}(25)
$$

Em que E é a energia de ativação para a precipitação. Nas figuras 84 e 85 , são mostradas as regressões lineares das equações 24 e 25 por meio do uso de dados experimentais de microdureza.

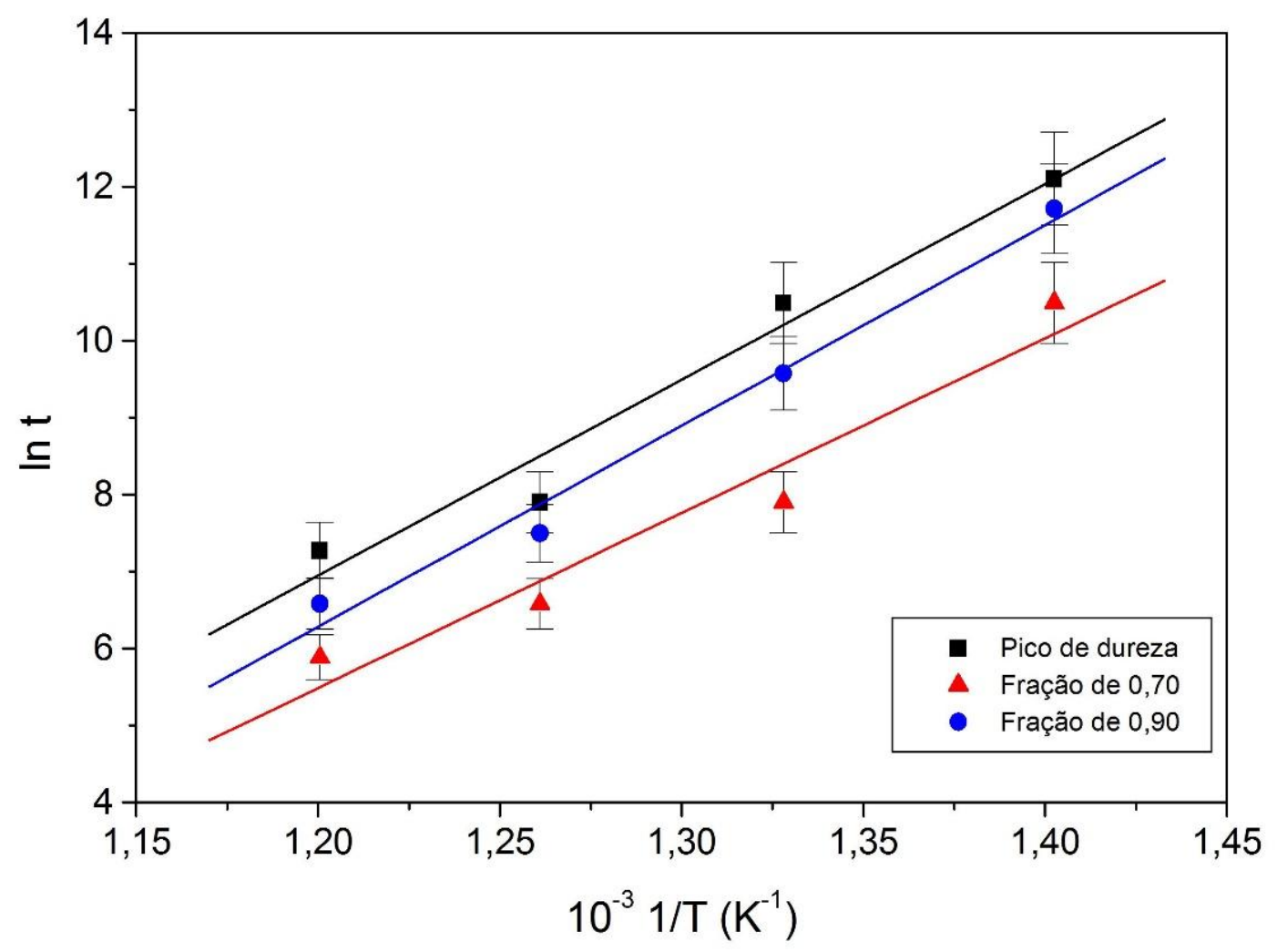

Figura 84: In t como função de 1/T para a estimar a energia de ativação por meio do método do tempo necessário para alcançar o pico de dureza, bem como o tempo para atingir uma determinada fração transformada de 0,70 ou 0,90 para o aço maraging 350B. 


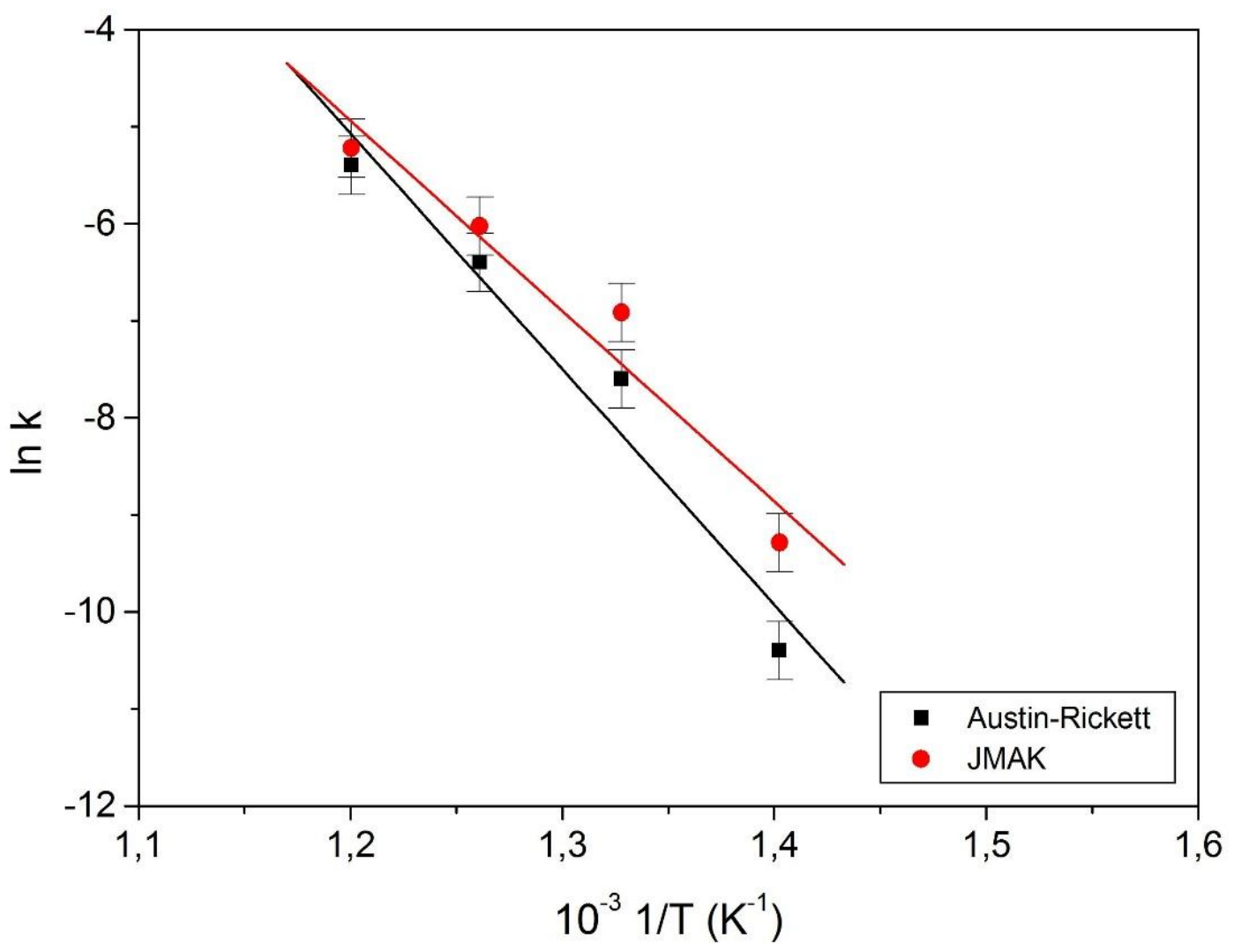

Figura 85: In k como função de 1/T para os modelos Austin-Rickett e JMAK no aço maraging 350B.

A tabela 24 sumariza os valores da energia de ativação aparente, obtidos por diversos autores, assim como o valor estimado para o aço maraging 350B. 
Tabela 24: Comparação dos valores de energia de ativação aparente obtido pelo pico de dureza, bem como pelos modelos JMAK e Austin-Rickett.

\begin{tabular}{|c|c|c|c|c|}
\hline Referência & Método & $\begin{array}{l}\text { Energia } \\
(\mathrm{kJ} / \mathrm{mol})\end{array}$ & $\mathrm{R}$ & Técnica usada \\
\hline $\begin{array}{l}\text { Maraging C250 e T250 } \\
\text { (Vasudevan et al.,1990) * }\end{array}$ & $\begin{array}{c}\text { Tempo para atingir a fração } \\
\text { transformada } 0,25\end{array}$ & 101 & - & Resistividade \\
\hline $\begin{array}{l}\text { Maraging C250 e T250 } \\
\text { (Vasudevan et al.,1990) * }\end{array}$ & $\begin{array}{c}\text { Tempo para atingir a fração } \\
\text { transformada } 0,50\end{array}$ & 130 & - & Resistividade \\
\hline $\begin{array}{c}\text { Maraging T250 } \\
\text { (Sinha et al., 1998) }\end{array}$ & $\begin{array}{c}\text { Tempo para atingir a fração } \\
\text { transformada } 0,50\end{array}$ & 108 & - & Microdureza \\
\hline $\begin{array}{l}\text { Maraging C250 e T250 } \\
\text { (Vasudevan et al.,1990) * }\end{array}$ & $\begin{array}{c}\text { Tempo para atingir a fração } \\
\text { transformada } 0,75\end{array}$ & 181 & - & Resistividade \\
\hline $\begin{array}{c}\text { Maraging T250 } \\
\text { (Sinha et al.,1998) * }\end{array}$ & $\begin{array}{c}\text { Tempo para atingir a fração } \\
\text { transformada } 0,80\end{array}$ & 116 & - & Microdureza \\
\hline $\begin{array}{c}\text { Maraging C250 } \\
\text { (Zhang et al., 1997) }\end{array}$ & $\begin{array}{l}\text { Tempo para alcançar o pico } \\
\text { de dureza }\end{array}$ & 85,8 & - & Microdureza \\
\hline $\begin{array}{l}\text { Maraging C300 } \\
\text { (Pardal et al., 2005) }\end{array}$ & $\begin{array}{c}\text { Tempo para alcançar o pico } \\
\text { de dureza }\end{array}$ & 132 & - & Microdureza \\
\hline $\begin{array}{l}\text { Maraging C350 } \\
\text { (Este trabalho) }\end{array}$ & $\begin{array}{c}\text { Tempo para atingir a fração } \\
\text { transformada } 0,70\end{array}$ & $188 \pm 31$ & 0,974 & Microdureza \\
\hline $\begin{array}{l}\text { Maraging C350 } \\
\text { (Este trabalho) }\end{array}$ & $\begin{array}{c}\text { Tempo para atingir a fração } \\
\text { transformada } 0,90\end{array}$ & $217 \pm 19$ & 0,992 & Microdureza \\
\hline $\begin{array}{l}\text { Maraging C350 } \\
\text { (Este trabalho) }\end{array}$ & $\begin{array}{c}\text { Tempo para alcançar o pico } \\
\text { de dureza }\end{array}$ & $211 \pm 29$ & 0,982 & Microdureza \\
\hline $\begin{array}{c}\text { Maraging C350 } \\
\text { (Viswanathan et al., } \\
\text { 1993a) }\end{array}$ & $\begin{array}{l}\text { Tempo para alcançar o pico } \\
\text { de dureza }\end{array}$ & $164 \pm 4$ & - & Microdureza \\
\hline $\begin{array}{l}\text { Maraging C350 } \\
\text { (Este trabalho) }\end{array}$ & Modelo JMAK & $202 \pm 31$ & $-0,977$ & Microdureza \\
\hline $\begin{array}{l}\text { Maraging C350 } \\
\text { (Este trabalho) }\end{array}$ & Modelo Austin-Rickett & $163 \pm 28$ & $-0,972$ & Microdureza \\
\hline
\end{tabular}

* De acordo com Vasudevan, os valores das energias de ativação aparente foram idênticos para os aços maraging C250 e T250.

Vasudevan et al. (1990) observaram por meio de medidas de resistividade que a energia de ativação aparente para a precipitação, para um aço maraging 250 com cobalto (C250) e outro aço maraging 250 sem cobalto (T250), aumenta com o 
incremento da fração transformada para os valores $0,25,0,50$ e 0,75 . Sinha et al. (1998) também observaram, por meio de medidas de dureza, um aumento da energia de ativação aparente quando a fração transformada é incrementada de 0,50 para 0,80 para um aço maraging 250 sem cobalto. Os valores obtidos para o aço maraging 350 com cobalto nessa tese mostram também um aumento da energia de ativação aparente com o acréscimo da fração transformada de 0,70 para 0.90 , porém os valores são compatíveis em uma barra de erro.

Além de serem classificadas conforme o seu valor de limite de resistência mecânica no estado envelhecido, as séries C250, C300 e C350 também têm teores crescentes de cobalto e titânio (INCO, 1979). Uma comparação dos valores de energia de ativação aparente para a precipitação, obtidos nessa tese, com aqueles estimados por outros autores, mostra que a energia de ativação segue a mesma ordem crescente do valor do limite de resistência, o que sugere uma influência da composição química na cinética de precipitação (ZHANG et al., 1997; PARDAL et al., 2005; VISWANATHAN et al., 1993a).

De acordo com Pardal e coautores (2005), esse aumento da energia de ativação é decorrente do incremento da razão dos teores de titânio e molibdênio (Ti/Mo) que propicia um endurecimento por precipitação maior, porém aumenta a energia de ativação para a precipitação. Além do aumento da razão Ti/Mo, o incremento da razão do cobalto e molibdênio ( $\mathrm{Co} / \mathrm{Mo})$ é também outro fator que acarreta maior endurecimento por precipitação e uma energia de ativação aparente mais elevada, uma vez que o cobalto diminui a solubilidade do molibdênio em aços maraging (DECKER et al., 1962; FLOREEN; SPEICH, 1964; PETERS; CUPP, 1966). Ademais, Sha e coautores (1993a) observam que a difusão do molibdênio é mais lenta do que a do titânio em tempos curtos de envelhecimento, para um aço maraging C300. Dessa forma, maiores teores de cobalto devem ter um efeito superior ao do titânio para explicar o aumento da energia de ativação nos aços maraging.

O valor de energia de ativação aparente obtido nessa tese, por meio do tempo para atingir o pico de microdureza, também é superior àqueles obtidos por Pardal et al. (2005), para o aço maraging C300, e por Zhang et al. (1997) para o aço maraging C250. Tal resultado encontra-se consistente com aqueles obtidos por Viswanathan et al. (1993a) para o aço maraging 350. A energia estimada nessa tese e em Viswanathan et al. (1993a) são compatíveis entre si quando considerados duas 
barras de erro. Além disso, os valores estimados da energia aparente, a partir do tempo de envelhecimento necessário para alcançar o pico de dureza ou uma fração transformada fixa, bem como os valores obtidos por meio das constantes cinéticas $\mathrm{k}$ das equações JMAK e Austin-Rickett, são compatíveis entre si em uma barra de erro.

Os valores da energia de ativação aparente para a precipitação para as diversas séries de aços maraging mencionadas, bem como o maraging $350 \mathrm{com}$ cobalto pesquisado nessa tese, estão abaixo dos valores da energia de ativação para a difusão do molibdênio $(238 \mathrm{~kJ} / \mathrm{mol})$ e o titânio na ferrita $(272 \mathrm{~kJ} / \mathrm{mol})$. Contudo, os valores obtidos são compatíveis apenas em três barras de erro com a energia de ativação do molibdênio. Os valores de energia de ativação abaixo da energia da difusão de molibdênio e titânio são comumente atribuídos à presença de uma alta densidade de discordâncias na martensita que facilitam a nucleação de precipitados, bem como ao mecanismo de difusão ao longo das discordâncias. Este último também conhecido como pipe diffusion, que aumenta a taxa de difusão de elementos da liga (VASUDEVAN et al., 1990; VISWANATHAN et al., 1993a).

No próximo item (4.3.3.2), será analisado o comportamento da curva de envelhecimento durante o tratamento térmico de envelhecimento no aço maraging 350B.

\subsubsection{Estudo do comportamento da curva de envelhecimento}

Como foi visto na seção 2.5 .2 e na figura 82, a variação da microdureza com o tempo de envelhecimento isotérmico pode apresentar dois comportamentos distintos durante o envelhecimento para cada temperatura em aços maraging. Uma etapa de endurecimento relacionada com a formação de fases coerentes com a matriz e outra etapa de amolecimento, também conhecida como superenvelhecimento, na qual ocorrem o engrossamento de precipitados e a reversão da martensita (GUO, SHA, 2002; PARDAL et al., 2005; SHA, 2000; WILSON, 1996; FLOREEN, DECKER, 1962; PETERS; CUPP, 1966).

A equação comumente usada para o estudo da etapa de endurecimento em ligas ferro-níquel endurecíveis por precipitação é aquela mostrada na seção 2.5.2, na qual há a suposição de que o mecanismo de endurecimento ocorre por 
cisalhamento de precipitados coerentes com a matriz e a fração transformada da precipitação siga o modelo JMAK.

A expressão linearizada da equação proposta por Wilson (1997) é descrita por:

$$
\ln \Delta H=m \cdot \ln k+m \cdot \ln (t)
$$

$\mathrm{Na}$ qual $\Delta \mathrm{H}$ é a variação da dureza com relação ao estado solubilizado, $\mathrm{m}$ e $\mathrm{k}$ são constantes dependentes da temperatura. As constantes $\mathrm{K}$ e $\mathrm{m}$ são estimadas pelo ajuste da equação 16 aos dados experimentais apresentados na figura 80 . A regressão linear dos dados é mostrada na Figura 86, enquanto os valores das constantes $\mathrm{K}$ e m, para diferentes temperaturas e faixas de tempo, são mostrados na Tabela 25.

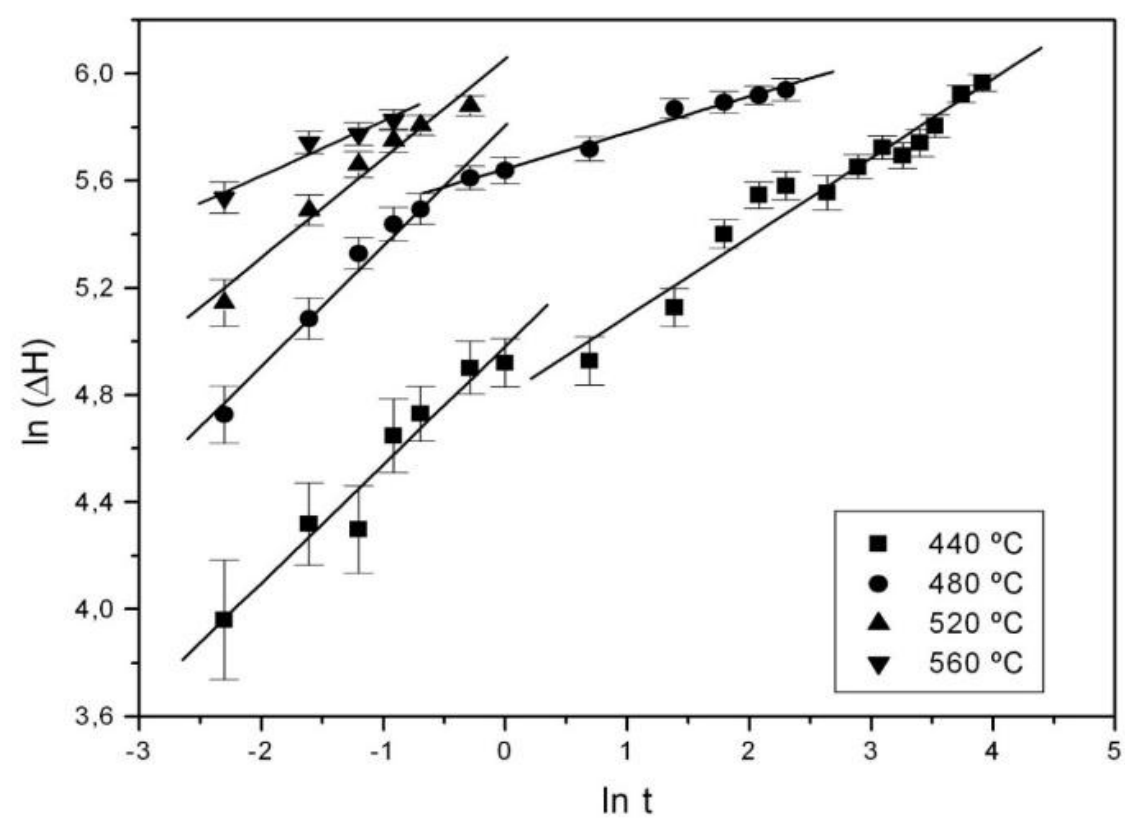

Figura 86: Ajuste do modelo de endurecimento baseado no mecanismo de cisalhamento de precipitados aos pontos experimentais para as amostras envelhecidas em $440,480,520$ e $560{ }^{\circ} \mathrm{C}$. 
Tabela 25: Valores das constantes $\mathrm{m}$ e $\mathrm{K}$ para o modelo de endurecimento baseado no mecanismo de cisalhamento de precipitados obtidos no presente trabalho para o aço maraging 350B e daqueles apresentados por Pardal et al. (2005) e Sha (2000) (aço maraging 300). O coeficiente de ajuste R também é dado.

\begin{tabular}{|c|c|c|c|c|c|}
\hline Referência & $\begin{array}{c}\text { Temperatura } \\
\left({ }^{\circ} \mathrm{C}\right)\end{array}$ & $\begin{array}{l}\text { Faixa de tempo } \\
\text { (h) }\end{array}$ & M & $\mathrm{K}\left(\mathrm{h}^{-1}\right)$ & $\mathrm{R}$ \\
\hline Pardal e coautores (2005) & 440 & $0,25 \mathrm{~h}-10,0$ & $0,20 \pm 0,02$ & $1,3 \times 10^{11}$ & 0,97 \\
\hline Este trabalho & 440 & $0,1-1,0$ & $0,44 \pm 0,05$ & $7,8 \times 10^{4}$ & 0,97 \\
\hline Este trabalho & 440 & $2,0-50,0$ & $0,29 \pm 0,02$ & $1,1 \times 10^{7}$ & 0,97 \\
\hline Pardal e coautores (2005) & 480 & $0,25-2,0$ & $0,20 \pm 0,01$ & $5,0 \times 10^{11}$ & 0,99 \\
\hline Este trabalho & 480 & $0,1-0,75$ & $0,49 \pm 0,03$ & $1,5 \times 10^{5}$ & 0,99 \\
\hline Este trabalho & 480 & $0,75-10,0$ & $0,14 \pm 0,01$ & $1,4 \times 10^{18}$ & 0,99 \\
\hline Pardal e coautores (2005) & 510 & $0,25-2,0$ & $0,21 \pm 0,02$ & $3,9 \times 10^{11}$ & 0,99 \\
\hline Sha (2000) & 510 & $0,04-0,42^{\star *}$ & 0,29 & $3,1 \times 10^{8}$ & $0,95^{\star}$ \\
\hline Este trabalho & 520 & $0,1-1,0$ & $0,37 \pm 0,03$ & $1,2 \times 10^{7}$ & 0,98 \\
\hline Pardal e coautores (2005) & 560 & $0,25-0,75$ & $0,16 \pm 0,01$ & $1,7 \times 10^{15}$ & 0,99 \\
\hline Este trabalho & 560 & $0,1-0,4$ & $0,21 \pm 0,03$ & $5,6 \times 10^{12}$ & 0,99 \\
\hline
\end{tabular}

Uma análise visual da Figura 88 e do coeficiente de correlação $R$, na Tabela 25, mostram que o modelo baseado no mecanismo de endurecimento por cisalhamento de precipitados tem um melhor ajuste para 480, 520 e $560{ }^{\circ} \mathrm{C}$ do que em $440 \stackrel{\circ}{\circ}$. Além disso, foi observado na Figura 88 que o endurecimento decorrente da precipitação em 440 e $480 \stackrel{\circ}{\mathrm{C}}$ apresenta dois estágios. Os valores de m obtidos nesse trabalho no primeiro estágio e no segundo estágio foram, respectivamente, $0,49 \pm 0,03$ e $0,14 \pm 0,01$. Enquanto as estimativas de $m$ foi $0,44 \pm 0,05$ na primeira etapa e 0,29 $\pm 0,02$ na segunda etapa para $440 \stackrel{\circ}{C}$.

Essas duas etapas podem ocorrer em virtude da formação de diferentes fases intermetálicas em diversos tempos de exposição durante o envelhecimento (TEWARI et al., 2000). Outra hipótese aventada é a mudança do mecanismo de 
crescimento dos precipitados controlado pela interface em estágio iniciais de precipitação para o crescimento controlado por difusão em estágios mais adiantados dessa transformação de fase (GUO; SHA, 2002). Pardal et al. (2005) sugeriram também que este comportamento poderia ocorrer em um aço maraging 300 a 440 ${ }^{\circ} \mathrm{C}$, em que o parâmetro $\mathrm{m}$, para o primeiro e o segundo estágios, foi de $0,29 \pm 0,01$ e $0,12 \pm 0,01$, respectivamente.

A tabela 25 mostra também que os valores de $\mathrm{K}$ e $\mathrm{m}$ apresentados por Sha (2000), para descrever o envelhecimento do aço maraging 300 em $520{ }^{\circ} \mathrm{C}$, estão mais próximos do que aqueles sugeridos por Pardal et al. (2005). Além disto, as constantes $\mathrm{m}$ obtidas para $\mathrm{O}$ aço maraging $350 \mathrm{~B}$ são superiores àquelas obtidas por Pardal et al. (2005) e Sha (2000) para o aço maraging 300, quando são comparadas as mesmas temperaturas e faixas de tempo de envelhecimento. De forma geral, observa-se que valores $m>0,25$ ocorrem para tempos de envelhecimento mais curtos do que aproximadamente $1 \mathrm{~h}$ em 440,480 e $520 \stackrel{\circ}{\circ}$. Enquanto $\mathrm{m}<0,25$ foi verificado para tempos de envelhecimento maiores que $1 \mathrm{~h}$ em 440,480 e $520 \stackrel{\circ}{\circ}$, assim como para tempos entre 0,1 e 0,4 para $560 \stackrel{\circ}{\circ}$.

Como foi visto no item 2.5.2, Wilson (1996) também propôs uma equação para o superenvelhecimento baseado no mecanismo de Orowan. A expressão linearizada da equação dessa equação é expressa por:

$$
\Delta H^{-3}=\left(\Delta H_{0}^{-3}-M . t_{0}\right)+M . t(27)
$$

Em que $\Delta \mathrm{H}$ é a diferença entre a dureza da amostra envelhecida e a solubilizada, $\mathrm{M}$ é uma constante dependente da temperatura, $\mathrm{t}_{0}$ é o tempo do pico de dureza enquanto $\Delta \mathrm{H}_{0}$ é a variação da dureza no tempo de início do engrossamento $t_{0}$. A figura 87 mostra as curvas ajustadas com os resultados experimentais do $\Delta H^{-3}$ como função do tempo de envelhecimento em 520,560 e $600 \stackrel{\circ}{\circ}$. Na tabela 26 , os coeficientes $\mathrm{M}$ e $\Delta \mathrm{H}_{0}$ obtidos por meio do ajuste nesse trabalho (aço maraging 350 ) são também comparados com aqueles apresentados por Pardal et al. (2005), para um aço maraging 300, e por Carvalho et al. (2015), para o aço maraging $350^{13}$.

\footnotetext{
${ }^{13} \mathrm{O}$ estudo de Carvalho et al. (2015) refere-se a um trabalho apresentado pelo autor desta tese para o aço maraging 350B no TMS 2015:144th Anual Meeting and Exhibition. Contudo, o intervalo de tempo aplicado nesse estudo é diferente da versão final da tese.
} 


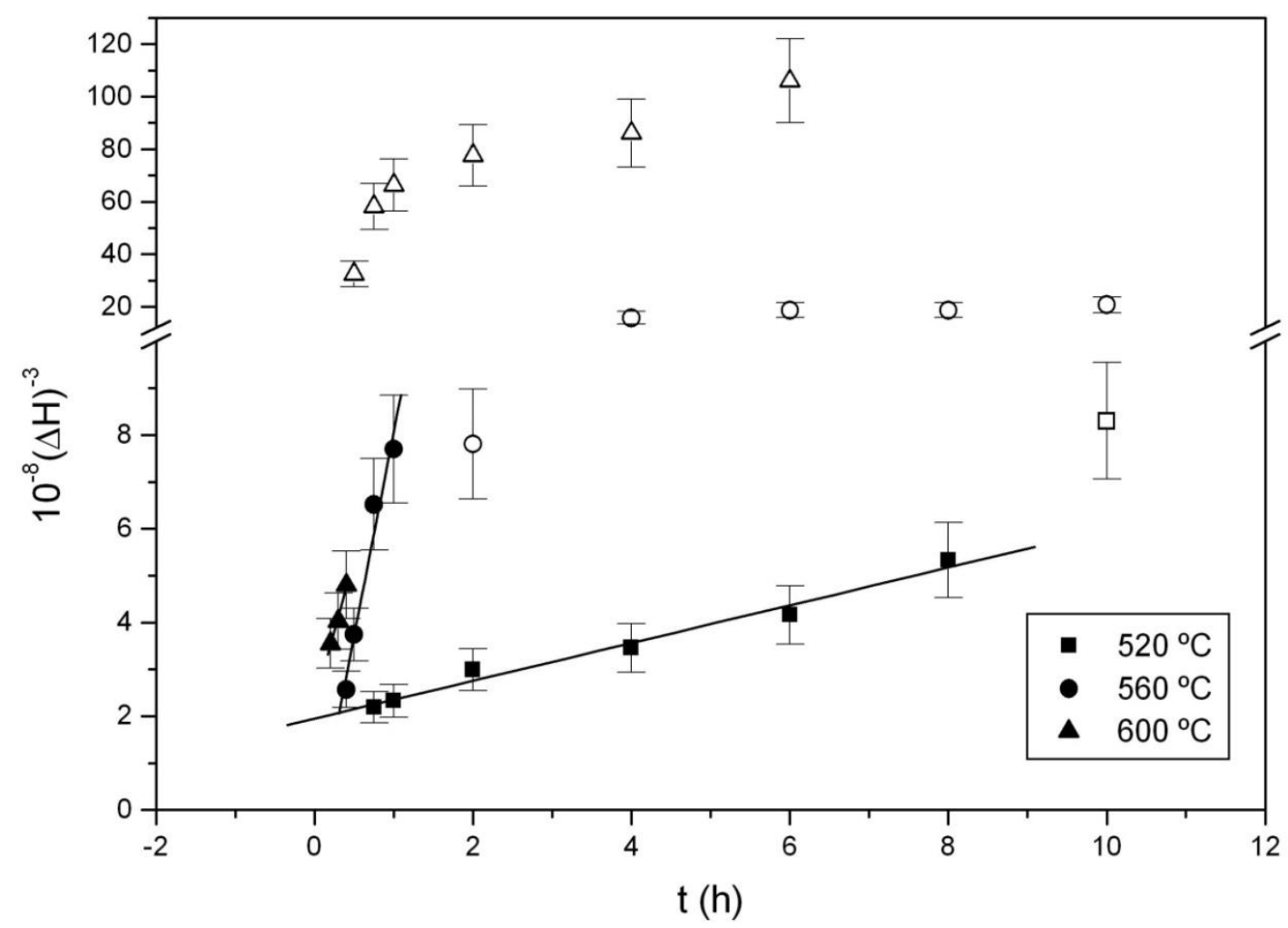

Figura 87: Ajuste do modelo baseado no mecanismo de Orowan aos dados experimentais, $\Delta \mathrm{H}^{-3}$ como função do tempo, para o amolecimento durante o superenvelhecimento a 520,560 e $600{ }^{\circ} \mathrm{C}$ para o aço maraging 350B. Os pontos abertos não foram usados no ajuste.

Tabela 26: Comparação dos valores de $\Delta \mathrm{H}_{0}$, $\mathrm{t}_{0}$, e $\mathrm{M}$ do modelo de amolecimento baseado no mecanismo de Orowan obtido no presente trabalho (aço maraging 350B) e aqueles apresentados por Pardal et al. (2005) em um aço maraging 300 e Carvalho et al. (2015) no aço maraging 350B em 520, 560 e $600{ }^{\circ} \mathrm{C}$. O coeficiente de ajuste R também é dado.

\begin{tabular}{|c|c|c|c|c|c|c|}
\hline Referência & $\begin{array}{c}\text { Temperatura } \\
\left({ }^{\circ} \mathrm{C}\right)\end{array}$ & $\begin{array}{l}\text { Faixa de } \\
\text { tempo (h) }\end{array}$ & $\mathrm{M}$ & $\Delta \mathrm{H}_{0}$ & $\mathrm{t}_{0}(\mathrm{~h})$ & $\mathrm{R}$ \\
\hline $\begin{array}{c}\text { Maraging 350B } \\
\text { (Carvalho et al.,2015) }\end{array}$ & 520 & $0,75-18$ & $4,32 \times 10^{-9}$ & $344 \pm 20^{*}$ & 0,75 & 0,96 \\
\hline $\begin{array}{l}\text { Maraging 350B } \\
\text { (Este trabalho) }\end{array}$ & 520 & $0,75-8,0$ & $4,03 \times 10^{-9}$ & $349 \pm 6^{*}$ & 0,75 & 0,99 \\
\hline $\begin{array}{c}\text { Maraging C300 } \\
\text { (Pardal et al.,2005) }\end{array}$ & 560 & $4-24$ & $4,57 \times 10^{-9}$ & 253 & - & 0,99 \\
\hline $\begin{array}{c}\text { Maraging 350B } \\
\text { (Carvalho et al.,2015) }\end{array}$ & 560 & $0,4-18$ & $1,55 \times 10^{-8}$ & $255 \pm 16^{*}$ & 0,4 & 0,97 \\
\hline $\begin{array}{l}\text { Maraging 350B } \\
\text { (Este trabalho) }\end{array}$ & 560 & $0,4-1,0$ & $8,7 \times 10^{-8}$ & $327 \pm 37^{*}$ & 0,4 & 0,98 \\
\hline $\begin{array}{c}\text { Maraging C300 } \\
\text { (Pardal et al.,2005) }\end{array}$ & 600 & $2-24$ & $1,30 \times 10^{-8}$ & 184 & - & 0,91 \\
\hline $\begin{array}{c}\text { Maraging 350B } \\
\text { (Carvalho et al.,2015) }\end{array}$ & 600 & $0,2-18$ & $9,61 \times 10^{-8}$ & $120 \pm 11^{*}$ & 0,2 & 0,87 \\
\hline $\begin{array}{l}\text { Maraging 350B } \\
\text { (Este trabalho) }\end{array}$ & 600 & $0,2-0,4$ & $6,2 \times 10^{-8}$ & $306 \pm 9^{*}$ & 0,2 & 0,99 \\
\hline
\end{tabular}

A diferença obtida diretamente a partir dos valores experimentais de microdureza no estado como recebido e no pico de dureza foram $357 \pm 13,339 \pm 13$ e $304 \pm 15$, respectivamente, para $520^{\circ} \mathrm{C}, 560^{\circ} \mathrm{C}$ e $600^{\circ} \mathrm{C}$. 
Pardal et al. (2005) aplicaram o modelo baseado no mecanismo de Orowan para um aço maraging C300 em 560 e $600{ }^{\circ} \mathrm{C}$ para tempos de envelhecimento de até 24 horas. Já Carvalho et al. (2015) usaram o mesmo modelo no aço maraging 350B em 520, 560 e $600{ }^{\circ} \mathrm{C}$ para amostras envelhecidas até 18 horas. Observa-se em ambos os trabalhos que o coeficiente de correlação $\mathrm{R}$ diminui com o incremento da temperatura de tratamento térmico. Além disso, uma comparação de $\Delta \mathrm{H}_{0}$ obtida diretamente a partir dos dados experimentais com aqueles valores determinados pela regressão linear no trabalho de Carvalho et al. (2015) mostra que eles são discrepantes. Essa divergência se dá em virtude da ocorrência da reversão da martensita, que é mais expressiva quando a temperatura de envelhecimento aumenta (PARDAL et al., 2005; PARDAL et al., 2006). Dessa maneira, o amolecimento decorrente do superenvelhecimento dos aços maraging não está associado somente ao engrossamento de precipitados, mas também se associa à reversão da martensita (PETERS; CUPP, 1966; VISWANATHAN; DEY; SETHUMANDHAVAN, 2005; PARDAL et al., 2005).

Outro possível efeito seria o processo de recuperação em que há uma queda da dureza associada à eliminação de defeitos cristalinos. Miner e coautores (1966) fizeram medidas de atrito interno para verificar o efeito do tratamento térmico nessa grandeza. Eles observaram que os processos de recuperação, no qual há uma queda do atrito interno, são predominantes em tempos curtos de tratamento térmico em ligas Ni-Co-Mo-Ti menos supersaturadas que o aço maraging 250; enquanto a precipitação leva a um aumento do atrito interno (MINER; JACKSON; GIBBONS, 1966). Entretanto, a recuperação geralmente não é observada em aços maraging comerciais 250, 300 e 350, pois essas ligas têm maiores teores de elementos de ligas, o que resulta em uma precipitação significativa mesmo para curtos tempos de envelhecimento. Dessa maneira, a precipitação tem um maior efeito do que a recuperação para as ligas comerciais de aços maraging em tempos curtos de envelhecimento, porém a eliminação de defeitos cristalinos durante 0 envelhecimento não deve ser desconsiderada.

A análise do modelo baseado no mecanismo de Orowan nessa tese restringiu ainda mais o intervalo quando comparado com o trabalho apresentado por Carvalho et. (2015). Para a definição do intervalo de tempo usado no ajuste linear, usou-se dois critérios. O primeiro foi a maximização do valor de $R$, enquanto o segundo foi a observação do comportamento dos pontos experimentais ao redor da reta ajustada, 
nos quais fez-se uso de uma análise estatística de resíduos reduzidos para avaliar a qualidade da regressão linear.

Ao ser empregada a metodologia mencionada, a regressão linear obtida nessa tese, em 520, 560 e $600{ }^{\circ} \mathrm{C}$ para o aço maraging 350B, teve o coeficiente de correlação $\mathrm{R}$ aumentado para valores entre 0,98 e 0,99. Todavia, o intervalo de tempo dos dados experimentais que seguem o modelo também foi diminuído. Observa-se que esse intervalo é mais reduzido quanto maior for a temperatura de tratamento térmico. Tal fato pode indicar que as amostras com frações volumétricas de austenita não desprezíveis não seguem o modelo derivado do mecanismo de Orowan. Além disso, uma comparação de $\Delta \mathrm{H}_{0}$, obtida diretamente a partir dos dados experimentais, com aqueles valores determinados pela regressão linear mostra que eles são compatíveis em uma barra de erro para cada temperatura.

O intervalo mais restrito da validade da equação relacionada ao mecanismo de Orowan em função do aumento de temperatura está associado à aceleração da cinética de reversão da martensita, especialmente em temperaturas de envelhecimento a partir de $560^{\circ} \mathrm{C}$, conforme foi verificado por Pardal et al. (2005) em um aço maraging C300.

Como Pardal et al. (2005) não conseguiram separar o efeito do amolecimento causado pela reversão da martensita, eles propuseram um modelo empírico para descrever a mudança na dureza durante o superenvelhecimento. Essa expressão na forma linearizada é dada por:

$$
\ln H=\ln H_{1}+p \cdot \ln t(28)
$$

Em que $\mathrm{H}$ é o valor de dureza, t é o tempo de envelhecimento, $\mathrm{H}_{1}$ é o valor de dureza em $t=1$ h e $p$ é uma constante exponencial.

A Figura 88 mostra o ajuste do modelo de Pardal et al. (2005) aos resultados experimentais do aço maraging 350, enquanto a Tabela 27 apresenta a comparação das constantes de ajuste $\mathrm{H}_{1}$ e $\mathrm{p}$, obtidas para o aço maraging 350B, com aquelas mensuradas por um aço maraging $\mathrm{C} 300$. 


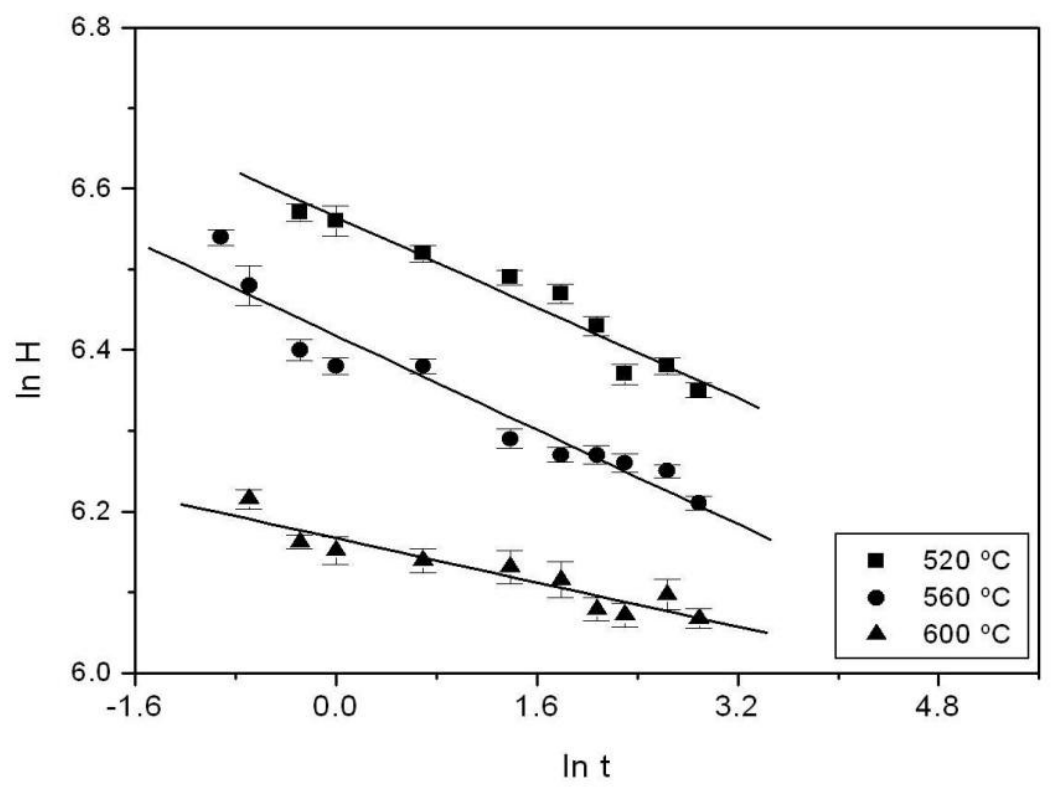

Figura 88: In $\mathrm{H}$ em função de In t para a equação de Pardal linearizada para 520,560 e $600{ }^{\circ} \mathrm{C}$.

Tabela 27: Comparação de $\mathrm{H}_{1}$ e $\mathrm{p}$ do modelo de Pardal et al. para a para diferentes aços maraging em $520,560,600$ e $650{ }^{\circ} \mathrm{C}$.

\begin{tabular}{ccccc}
\hline Referência & Temperatura $\left({ }^{\circ} \mathrm{C}\right)$ & $\mathrm{P}$ & $\mathrm{H}_{1}$ & $\mathrm{R}$ \\
\hline $\begin{array}{c}\text { Maraging 350B } \\
\text { (Este trabalho) }\end{array}$ & 520 & $-0,070$ & $710 \pm 9$ & 0,97 \\
\hline $\begin{array}{c}\text { Maraging C300 } \\
\text { (Pardal et al., 2005) }\end{array}$ & 560 & $-0,053$ & 594,3 & 0,99 \\
$\begin{array}{c}\text { Maraging 350B } \\
\text { (Este trabalho) }\end{array}$ & 560 & $-0,073$ & $613 \pm 7$ & 0,96 \\
\hline $\begin{array}{c}\text { Maraging C300 } \\
\text { (Pardal et al., 2005) }\end{array}$ & 600 & $-0,054$ & 523,3 & 0,99 \\
$\begin{array}{c}\text { Maraging 350B } \\
\text { (Este trabalho) }\end{array}$ & 600 & $-0,034$ & $476 \pm 4$ & 0,94 \\
\hline $\begin{array}{c}\text { Maraging C300 } \\
\text { (Pardal et al., 2005) }\end{array}$ & 650 & $-0,061$ & 428,8 & 0,99 \\
\hline
\end{tabular}

A tabela 27 mostra que o modelo proposto por Pardal et al. (2005) tem um bom ajuste em 520, 560 e $600 \stackrel{\circ}{\circ}$ para o aço maraging C300. Entretanto, a regressão linear dessa equação tem um coeficiente de correlação $\mathrm{R}$ decrescente com a temperatura para o aço maraging 350B. 
A figura 89 mostra que há uma relação linear da microdureza Vickers como da fração volumétrica da austenita para amostras superenvelhecidas em 520, 560 e $600^{\circ} \mathrm{C}$, tratadas por 1 e 18 horas para cada temperatura.

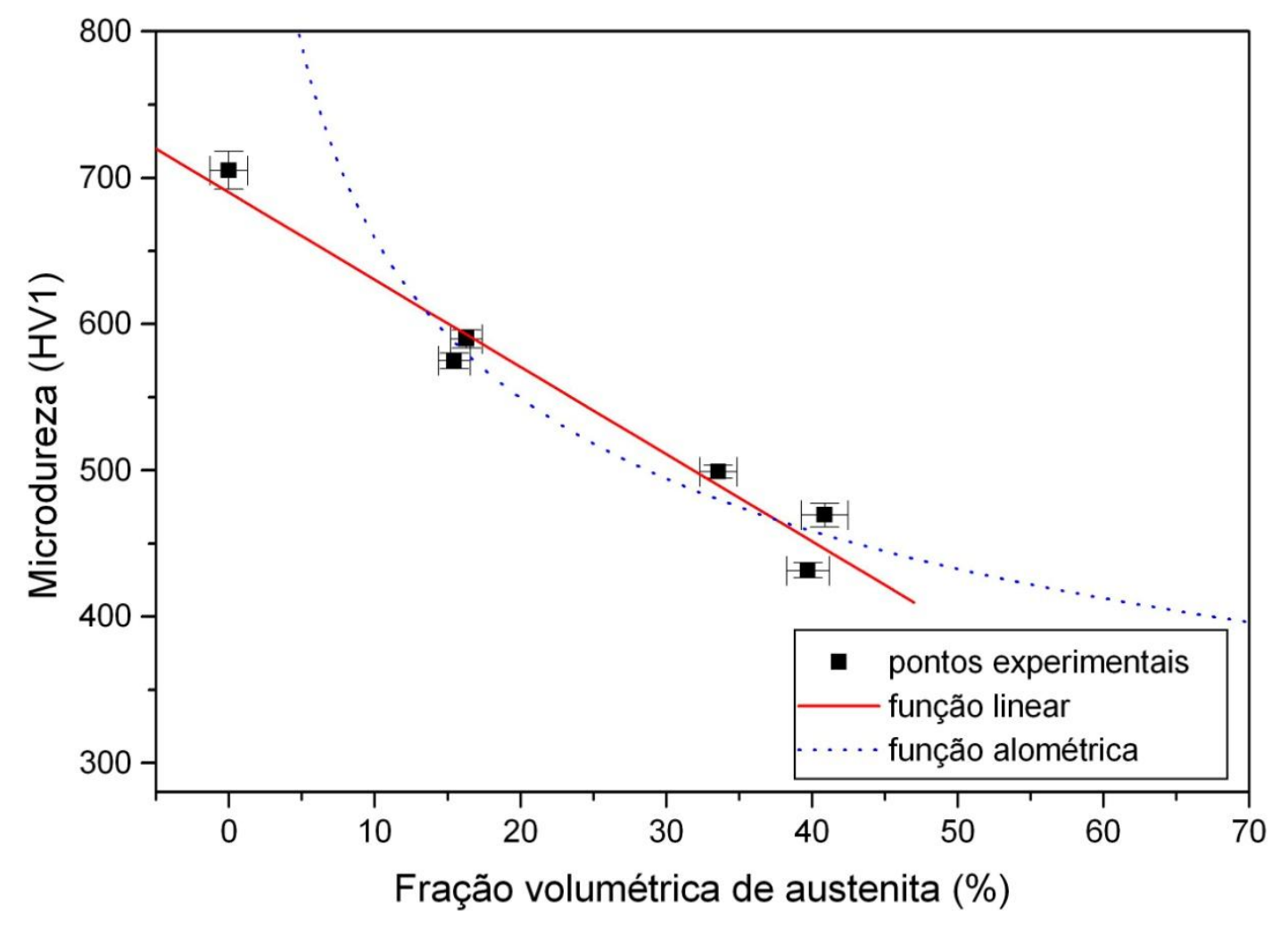

Figura 89: Dureza como função da fração volumétrica de austenita para o aço maraging 350B. 


\section{CONCLUSÕES}

Os experimentos e análises realizados nessa tese com os aços maraging 300 e 350 permitiram as seguintes conclusões:

a) Os experimentos não-isotérmicos de DSC com os aços maraging $300 \mathrm{e}$ 350 evidenciaram que a precipitação ocorre em duas etapas. A primeira relacionada à difusão de soluto no volume com energia de ativação próxima da difusão do níquel e do molibdênio na ferrita, enquanto a segunda acontece por meio da difusão de soluto ao longo das discordâncias com energia de ativação menor que da difusão do níquel e do molibdênio na ferrita. Observou-se também que a reversão da martensita pode ocorrer em duas etapas. A primeira etapa foi associada à difusão de soluto, enquanto a segunda foi relacionada ao mecanismo de cisalhamento.

b) A análise cinética da precipitação de compostos intermetálicos e da reversão por meio de experimentos não-isotérmicos com calorimetria exploratória diferencial (DSC) permitiu concluir que tanto a reação de precipitação de compostos intermetálicos como a reversão ocorrem em duas etapas.

c) As observações microestruturais com o auxílio de microscopia óptica e de microscopia eletrônica de varredura evidenciaram que a austenita revertida formada nas regiões de interface, como os contornos de grão, contornos de pacote e contornos de ripas da estrutura martensítica para temperaturas a partir de $520{ }^{\circ} \mathrm{C}$, enquanto a austenita revertida encontrada no interior das ripas da martensita, é formada a partir de 560 ${ }^{\circ} \mathrm{C}$.

d) O estudo da cinética de precipitação e do comportamento da curva de envelhecimento em um aço maraging 350 (350B) para tratamentos isotérmicos entre 440 e $600{ }^{\circ} \mathrm{C}$ mostrou que as medidas de microdureza podem ser muito úteis para estudos dessa natureza em aços maraging.

e) A análise cinética da precipitação realizada por meio do ajuste dos dados experimentais aos modelos JMAK e Austin-Rickett mostrou que eles se ajustam bem a esses modelos com coeficiente de correlação próximo de 
1. Entretanto, a interpretação dos valores de $n$ obtidos pela equação Austin-Rickett mostrou que eles têm maior concordância com as mudanças microestruturais observadas nos aços maraging em estudos anteriores do que aqueles estimados por meio da equação JMAK.

f) A intepretação das constantes $n$, usando a equação Austin-Rickett, permitiram estabelecer diversas etapas para a precipitação. Na primeira ocorre a precipitação nas discordâncias para $440{ }^{\circ} \mathrm{C}$, seguida pelo crescimento de cilindros longos e finitos em comparação com a distância de separação deles para $480{ }^{\circ} \mathrm{C}$ e, por fim, o crescimento de precipitados partindo de dimensões pequenas com taxa de nucleação zero para $520 \mathrm{e}$ $560^{\circ} \mathrm{C}$.

g) Já o estudo do comportamento da curva de envelhecimento para diversos tempos entre 440 e $600^{\circ} \mathrm{C}$ em um aço maraging 350 (350B) mostrou que esse material apresenta uma etapa de endurecimento e outra de amolecimento. Essa etapa de endurecimento, comumente atribuída à formação de fases intermetálicas coerentes e semicoerentes, pode subdividir-se em dois estágios para temperatura de envelhecimento de 440 e $480{ }^{\circ} \mathrm{C}$ ou apresentar um único estágio para 520 e $560{ }^{\circ} \mathrm{C}$. Já a etapa de amolecimento é associada não somente ao mecanismo clássico de superenvelhecimento em que a queda na resistência mecânica ocorre em virtude da perda de coerência e engrossamento de precipitados, mas também como uma consequência da formação de austenita revertida, a partir da martensita, especialmente para temperaturas entre 520 e $600 \stackrel{\circ}{\circ}$. 


\section{SUGESTÕES PARA TRABALHOS FUTUROS}

A partir dos resultados obtidos nessa tese, sugere-se a realização dos seguintes trabalhos futuros:

- Estudar as mudanças de tamanho, morfologia e relações de orientação com a matriz dos precipitados com auxílio de microscopia eletrônica de transmissão para amostras tratadas em diversas temperaturas e tempos de envelhecimento a fim de confirmar as mudanças dessas fases sugeridas pela interpretação das equações cinéticas de Austin-Rickett e JMAK.

- Obter a fração transformada da precipitação e da reversão da martensita por meio da análise dos picos exotérmicos e endotérmicos detectados com o auxílio de calorimetria exploratória diferencial e, em seguida, realizar a análise cinética JMAK e determinar as constantes cinéticas.

- Verificar se a energia de ativação varia em função da fração transformada para a precipitação e a reversão da martensita. A energia de ativação será obtida a partir de métodos cinéticos isofracionários, os quais usarão os dados de calorimetria exploratória diferencial já obtidos nessa tese. 


\section{REFERÊNCIAS}

AGUIAR, D. J. M. Estudo da formação e reversão de martensita induzida por deformação na austenita de dois aços inoxidáveis dúplex. $147 \mathrm{p}$. Tese (doutorado) - Escola Politécnica da Universidade de São Paulo, São Paulo, 2013.

AGNEL, A.; HEDIN, F.; MAEDER, G.; SERVANT, C.; LACOMBE, P. Etude par diffusion des rayons $X$ aux petits angles des zones formees dans les alliages $\mathrm{Fe}$ 16,4Ni-8,2Mo et Fe-15,4Ni-10,2Mo. Acta Metallurgica, v. 25, p. 1445-1457, 1977.

AHMED, M. et al. An in situ study of phase transformation in maraging steel. In: WILSON, R. K. (Org.). Maraging steels: recent developments and applications. Warrendale: TMS, 1988. p. 269-282.

AHMED, M.; NASIM, I.; HUSAIN, S. W. Influence of nickel and molybdenum on the phase stability and mechanical properties of maraging steels. Journal of Materials Engineering and Performance, v. 3, p. 248-254, 1994 a.

AHMED, M. et al. Magnetic properties of maraging steel in relation to deformation and structural phase transformations. Acta Metallurgica et Materialia, v. 42, p. 631$638,1994 b$.

ASSUNÇÃO, F. C. R. (Org.). Materiais avançados 2010-2022. Brasília: Centro de Gestão e Estudos Estratégicos, 2010. 360p.

ATSMON, N.; ROSEN, A. Reverted austenite in maraging steel. Metallography, v. 14, p. 163-167, 1981.

AVADHANI, G. S. Optimization of process parameters for the manufacturing of rocket casing: a study using processing maps. Journal of Materials Engineering and Performance, v. 12, p. 609-622, December 2003.

AVRAMI, M. Kinetics of phase change. I General theory. The Journal of Chemical Physics, v. 7, p. 1103-1112, 1939.

AVRAMI, M. Kinetics of phase change. II transformation-time relations for random distribution of nuclei. The Journal of Chemical Physics, v. 8, p. 212-224, 1940.

AVRAMI, M. Granulation, phase change, and microstructure kinetics of phase change. III. The Journal of Chemical Physics, v. 9, p. 177-184, 1941.

BALL, C. J. An X-ray investigation of austenite reversion in maraging steels. Australian Atomic Energy Commission, April 1984a. First edition. 32p.

BALL, C. J. X-ray powder diffraction patterns of titanium carbosulfide and t titanium sulfide. Metal Science, v. 18, p. 577-579, 1984b.

BERNAL, C. et al. Influência de alguns parâmetros experimentais nos resultados de análises calorimétricas diferenciais - DSC. Química Nova, v. 25, p. 849-855, 2002. 
BELYAKOV, L. N.; NIKOL'SKAYA, V. L.; RYZHAK, S. S. The $\alpha \rightarrow y$ transformation in maraging steel N18K9M5T. Metal Science and Heat Treatment, v. 10, p. 438-442, 1968.

BONISZEWSKI, T.; BONISZEWSKI, E. Inclusions in 18\% Ni-Co-Mo maraging steel, Journal of the Iron Steel Institute, v. 204, p. 360-365, April 1966.

BOSWELL, P. G. On the calculation of activation energies using a modified Kissinger method. Journal of Thermal Analysis, v. 18, p. 353-358, 1980.

BOUZID, N.; SERVANT, C.; LYON, O. Anomalous small-angle- X-ray scattering from a maraging alloy during martensite unmixing. Philosophical Magazine B, v. 57, p. 343-359, 1988.

CAIRNS, R. L.; NOVAK, C. J. The effect of reactive metal additions on grain boundary embrittlement in $18 \mathrm{Ni} 200$ maraging steel. Metallurgical Transactions B, v. 2, p. 1837-1846, July 1971 .

CARVALHO, L. G. Estudo dilatométrico das transformações de fase em aços maraging M300 e M350. 125 p. Dissertação (mestrado) - Escola Politécnica da Universidade de São Paulo, São Paulo, 2012.

CARVALHO, L. G.; ANDRADE, M. S.; PADILHA, A. F. A dilatometric study of the phase transformations in 300 and 350 maraging steels during continuous heating rates. Materials Research, v. 16, n. 4, p. 740-744, 2013.

CARVALHO, L. G.; PLAUT, R. L., MARTORANO, M. A.; PADILHA, A. F. Study of Age Hardening Behavior in a 350 Grade Maraging Steel. Characterization of Minerals, Metals, and Materials, p. 3-10, 2015.

CHRISTIAN, J. W. Transformations in metals and alloys. In: Part I: Equilibrium and general kinetic theory, Oxford: 2nd edition, Pergamon press. 1975, p.1-20.

CTMSP. São Paulo. Ciclo do combustível nuclear. Disponível em: $<$ https://www.mar.mil.br/ctmsp/ciclo combustivel.html>. Acesso em 6 fev. 2014.

CULLITY, B. D. Elements of x-ray diffraction. Reading: Addison-Wesley Publishing Company, 2nd edition, 1978. 555 p.

DECKER, R. F. Notes on the development of maraging steels. Source book on maraging steels, ASM, p. xi-xv, 1979.

DECKER, R. F.; EASH, J. T.; GOLDMAN, A. J. 18\% nickel maraging steel. Transactions of ASM, v. 55, p. 58-76, 1962.

DECKER, R. F.; FLOREEN, S. Maraging steels - the first 30 years. In: WILSON, R. K. (Org.). Maraging steels: recent developments and applications. Warrendale: TMS, 1988. p. 1-38.

DESALVO, R. et al. Study of quality factor and hysteresis associated with the stateof-the-art passive seismic isolation system for Gravitational Wave Interferometric Detectors. Nuclear Instruments And Methods In Physics Research Section A: 
Accelerators, Spectrometers, Detectors and Associated Equipment, v. 538, p.526-537, fev. 2005.

FAROOQ, M.; UL HAQ, A.; HASHMI, F. H. KHAN, A.Q. Microscopic determination of austenite in $18 \% \mathrm{Ni}$ maraging steel. Metallography, v.20, p.377-383, 1987.

FAROOQUE, M.; AYUB, H.; UL HAQ, A.; KHAN, A. Q. The formation of reverted austenite in $18 \% \mathrm{Ni} 350$ grade maraging steel. Journal of Materials Science, v. 33, p. 2927-2930, 1998.

FIGUEIREDO, E. Q. Análise da usinagem por furação em um aço maraging $\mathbf{3 0 0}$ homogeneizado e envelhecido. 2015. $124 \mathrm{f}$. Tese (Doutorado) - Curso de Mestrado em Ciências e Tecnologias Aeroespaciais, Instituto Tecnológico da Aeronáutica, São José dos Campos, 2015.

FLOREEN, S; DECKER, R. F. Heat treatment of $18 \% \mathrm{Ni}$ maraging steel. Transaction of the American Society for Metals, v. 55, p. 58-76, 1962.

FLOREEN, S.; SPEICH, G.R. Some observations on the strength and toughness of maraging steels. ASM Transactions Quarterly, v. 57, p. 714-726, 1964.

FLOREEN, S. The physical metallurgy of maraging steels. Metallurgical Reviews, v. 13, p. 115-128, 1968.

FLOREEN, S.; HAYDEN, H. W. Some observations of void growth during the tensite deformation of a high strength steel. Scripta Metallurgica, v.4, p. 87-94, 1970.

FLOREEN, S. Maraging Steels. Metals Handbook, ASM, v. 1, 9th Edition, p. 445452, 1978.

FLOREEN, S.; BAYER, A. M. Development and commercialization of cobalt-free maraging steels. In: WILSON, R. K. (Org.). Maraging steels: recent developments and applications. Warrendale: TMS, 1988. p. 39-54.

GARRISON Jr., W. M. Martensitic non-stainless steels: high strength and high alloy. Encyclopedia of Materials: Science and Technology, v.6, p. 5197-5203, 2008.

GERMERAAD, D. P. Impact of aerospace of technology on future ocean systems. In: SPACE CONGRESS, 7., 1970, Cocoa Beach. The Space Congress Proceedings. Cocoa Beach: Canaveral Council of Technical Societies, 1970. p. $6.65-6.82$.

GLADMAN, T. Precipitation hardening in metals. Materials Science and Technology, v. 15, p. 30-36, 1999.

GLASER, A. Characteristics of the gas ultracentrifuge for uranium enrichment and their relevance for nuclear weapon proliferation. Science and Global Security, v. 16, p.1-25, 2008.

GOLDBERG, A.; O'CONNOR, D. G. Influence of heating rate on transformations in an 18 per cent nickel maraging steel. Nature, v. 14, p. 170-171, 1967. 
GUIMARÃES, L. S. Estratégias de implementação e efeitos de arraste dos grandes programas de desenvolvimento tecnológico nacionais: experiências do programa nuclear da Marinha do Brasil. Pesquisa Naval, n¹6, p. 129-146, Outubro 2003.

GUO, Z; SHA, W. Quantification of precipitation hardening and evolution of precipitates. Materials Transactions, v. 43, p. 1273-1282, 2002.

GUO, Z.; SHA, W.; LI, D. Quantification of phase transformation kinetics of 18 wt. $\%$ $\mathrm{Ni}$ C250 maraging steel. Materials Science and Engineering A, v. 373, p. 10-20, 2004.

HABIBY, F.; UL HAQ, A.; KHAN, A. Q. Influence of austenite on the coercive force, electrical resistivity and hardness of $18 \%$ Ni maraging steels. Materials \& Design, v. 13, p. 259-264, 1992a.

HABIBY et al. Austenite determination by eddy current measurements in a maraging steel. NDT \& E International, v. 25, p.145-146, $1992 b$.

HABIBY, F. et al. Lattice changes in the martensitic phase due to ageing in $18 \mathrm{wt} \%$ nickel maraging steel grade 350. Journal of Materials Science, v. 31, p. 305-309, 1996.

HAMAKER, J. C.; BAYER, A. M. Applications des aciers maraging. Cobalt, v. 38, p. 3-12, Mars 1968.

HITACHI TECHNOLOGY 2010-2011. Hitachi. p. 69. Disponível em: <http://www.hitachi.com/rev/archive/2010/_icsFiles/afieldfile/2010/08/05/r2010_techn ology07_mt.pdf. Acessado em 01/02/2011 >. Acesso em 01 jun. 2013.

INCO. The 18 per cent nickel maraging steels: engineering properties. Source book on maraging steels, ASM, p. 351-377, 1979.

JOHNSON, W. C.; STEIN, D. F. A study of grain segregants in thermally embritted maraging steel. Metallurgical Transactions B, v. 5, p. 549-554, March 1974.

JOHNSON, W. A.; MEHL, Robert F. Reaction kinetics in processes of nucleation and growth. Transactions of AIME, v. 135, p. 396-415, 1939.

KALISH, D.; RACK, H. J. Thermal embrittlement of $18 \mathrm{Ni}(350)$ maraging steel. Metallurgical Transaction B, v. 2, p. 2665-2672, September 1971.

KANTAMANENI, K.; ALRASHED, I.; PHILLIPS, M. Cost vs. safety: a novel design for tornado proof homes. HBRC Journal, 2015.

KAPOOR, R.; BATRA, I. S. On the $\alpha^{\prime}$ to $y$ transformation in maraging (grade 350), $\mathrm{PH}$ 13-8 Mo and 17-4 PH steels. Materials Science and Engineering A, v.371, p. 324-334, 2004.

KAPOOR, R.; KUMAR, L.; BATRA, I. S. A dilatometric study of the continuous heating transformations in $18 \mathrm{wt} . \% \mathrm{Ni}$ maraging steel of grade 350 . Materials Science and Engineering A, v. 352, p. 318-324, 2003. 
KEMP, R. S. Gas centrifuge theory an development: a review of U.S. programs. Science and Global Security, v. 17, p. 1-19, 2009.

KIMURA, Y. et al. Relationship Between the Phase Transformations and the Magnetic, Physical and Mechanical Properties of 18 per cent Ni 350 Grade Maraging Steels. Tetsu-to-Hagane, v. 61, n. 11, p. 2617-2628, 1975.

KOLMOGOROV, A. N. On the statistical theory of metal solidification. Izvestija Akademii Nauk SSSR. Mathematical Series, v. 3, p. 355-359, 1937.

KRASS, A. S. Uranium enrichment and nuclear weapon proliferation. London: Taylor \& Francis, 1983. 296 p.

LECOMTE, J. B.; SERVANT, C.; CIZERON, G. J. A comparison of the structural evolution occurring during anisothermal or isothermal treatments in the case of nickel and manganese type maraging. Journal of Materials Science, v.20, p. 3339-3352, 1985.

LEE, E. S.; KIM, Y. G. A transformation kinetic model and its application to Cu-Zn-Al shape memory alloys-I. Isothermal conditions. Acta Metallurgica et Materialia, v. 38, p. 1669-1676, 1990.

LI, X.; YIN, Z. Mössbauer study of the aging behavior of $18 \mathrm{Ni}(350)$ maraging steel. Material Letters, v.24, p. 235-238, 1995a.

$\mathrm{LI}, \mathrm{X}$; Y YIN, Z. Reverted austenite during in $18 \mathrm{Ni}(350)$ maraging steel. Materials Letters, v. 24, p. 239-242, 1995b.

LOMBARDO, S. Caracterização mecânica e microestrutural de juntas soldadas a laser em aços maraging com posterior térmico e termoquímico de superfície a plasma. 2015. 193 f. Tese (Doutorado) - Curso de Doutorado em Engenharia Mecânica, Universidade Estadual Paulista "Júlio de Mesquita Neto", Guaratinguetá, 2015.

LOPES, D. A. Caracterização microestrutural de ligas do sistema U-Nb-Zr, no canto rico em urânio. 139 p. Dissertação (mestrado) - Escola Politécnica da Universidade de São Paulo, São Paulo, 2011.

LOWEY, S.; RHEINGANS, B.; MEKA, S. R.; MITTEMEIJER, E. J. Unusual martensite-formation kinetics in steels: observation of discontinuous rates. Acta Materialia, v. 64, p. 93-99, 2014.

MARTORANO, M. A.; TAVARES, C. F.; PADILHA, A. F. Predicting Delta Ferrite Content in Stainless Steel Castings. ISIJ International, v. 52, p. 1054-1065, 2012.

MARÉCHAL, D. Linkage between mechanical properties and phases in a $301 \mathrm{LN}$ austenitic stainless steel. 245 p. Tese (Doutorado) - Materials Engineering, University of British Columbia, Vancouver, 2011.

MARTIN, J. W. Precipitation hardening. Woburn: Butterworth-Heinemann, $2^{\text {nd }}$ Edition, 1998. 219p. 
MEYERS, M.; CHAWLA, K. Mechanical Behaviour of Materials. New York: Cambridge University Press, $2^{\text {nd }}$ Edition, 2009. 856p.

MINER, R. E.; JACKSON, J. K.; GIBBONS, D. F. Internal friction in 18 pct $\mathrm{Ni}$ maraging steels. Transactions of the Metallurgical Society of AIME, v. 236, p. 1565-1570, 1966.

MITTEMEIJER, E. J. Analysis of the kinetics of phase transformations. Journal of Materials Science, v. 27, p. 3977-3987, 1992.

MOSHKA, O. et al. Addressing the issue of precipitates in maraging steelsUnambiguous answer. Materials Science and Engineering A, v. 638, p. 232-239, 2015.

NES, E.; THOMAS, G. Precipitation of TiC in thermally embrittled maraging steels. Metallurgical Transactions A, v. 7, p. 967-975, July 1976.

OZAWA, T. Estimation of activation energy by isoconversion methods. Thermochimica Acta, v. 203, p. 159-165, 1992.

OLIVEIRA, F. L. G.; ANDRADE, M. S.; COTA, A. B. Kinetics of austenite formation during continuous heating in low carbon steel. Materials Characterization, v. 58, p. 256-261, 2007.

PADIAL, A. G. F. Transformações de fase e propriedades mecânicas de um aço maraging sem cobalto, 88 p. Dissertação (mestrado) - IPEN, São Paulo, 1994.

PADILHA, A. F; AMBROZIO FILHO, F. Técnicas de análise microestrutural. São Paulo: Hemus, $1^{\text {a }}$ edição, 1985. $190 p$

PADILHA, A. F. Materiais de engenharia: microestrutura e propriedades. São Paulo: Hemus, 1a edição, 1997. 349p.

PADILHA, A.F.; SICILIANO Jr, F.S. Encruamento, recristalização, crescimento de grão e textura. São Paulo: ABM: $3^{a}$ edição, 2005. 232p.

PALAU, José Carlos Fortes. Avaliação do processo de preparação de superfície de envelope motor foguete para aderência de isolante térmico em aços de ultra-alta-resistência. 2011. 163 f. Dissertação (Mestrado) - Curso de Mestrado Profissionalizante em Engenharia Mecânica, Universidade de Taubaté, Taubaté, 2011.

PARDAL, J. M.; TAVARES, S. S. M.; TERRA, V. F.; DA SILVA, M. R.; DOS SANTOS, D. R. Modelling of precipitation hardening during aging and overaging of $18 \mathrm{Ni}-\mathrm{Co}-\mathrm{Mo}-\mathrm{Ti}$ maraging steel 300. Journal of Alloy and Compounds, v. 393, p. 109-113, 2005.

PARDAL, J. M.; TAVARES, S. S. M.; FONSECA, M. P. C.; ABREU, H. F. G.; SILVA, J. J. M. Study of the austenite quantification by X-ray diffraction in the $18 \mathrm{Ni}-\mathrm{Co}-\mathrm{Mo}-\mathrm{Ti}$ maraging 300 steel. Journal of Materials Science, v. 41, p.2301-2307, 2006. 
PARDAL, J.M.; TAVARES, S. S. M.; FONSECA, M. C., da SILVA, M. R.; NETO, J. M., ABREU, H. F. G. Influence of temperature and aging time on hardness and magnetic properties of the maraging steel grade 300. Journal of Materials Science, v. 42 , p. $2276-2281,2007$.

PETERS, D. T. A Study of austenite reversion during aging of maraging steels. Transactions of ASM, v. 61, p. 62-74, 1968.

PETERS, D. T.; CUPP, C. R. The kinetics of aging reactions in 18 pct Ni maraging steels. Transactions of AIME, v. 236, p.1420-1429, 1966.

PINEDO, C. E. Nitretação por plasma para endurecimento superficial de aços ferramenta. Máquinas e Metais, v. 40, p.122-133, 2004.

PSIODA, J. A; LOW, J. R. The effect of microstructure and strength on the fracture toughness of an $18 \mathrm{Ni}, 300$ grade maraging steel. Nasa Technical Report, n. 6, August 1974. $48 \mathrm{p}$.

RAABE, D. et al. Designing ultrahigh strength with good ductibility by combining transformation induced plasticity and martensite aging. Advanced Engineering Materials, v.11, n. 7, p. 547-555, 2009.

RACK, H. J.; HOLLOWAY, P. H. Grain boundary precipitation in $18 \mathrm{Ni}$ maraging steels. Metallurgical Transactions A, v. 8, p. 1313-1315, August 1977.

RAJKUMAR, K. V. et al. Characterization of aging-induced microstructural changes in M250 maraging steel using magnetic parameters. Journal of Magnetism and Magnetic Materials, v. 312, n. 2, p. 359-365, 2007.

RAO, M. N. Progress in understanding the metallurgy of $18 \%$ nickel maraging steels. International Journal of Materials Research, v.11, p.1594-1607, 2006.

REZEK, J.; KLEIN, I. E.; YAHALOM, J. Structure and corrosion resistence of oxides grown on maraging steel in steam at elevated temperatures. Applied Surface Science, v. 108, p. 159-165, 1997a.

REZEK, J.; KLEIN, I. E.; YAHALOM, J. Electrochemical properties of protective coatings on maraging steel. Corrosion Science, v. 39, p. 385-397, 1997b.

RIOS, P. R.; PADILHA, A. F. Transformações de fase. 1. ed. São Paulo: Artliber Editora, 2007. 215 p.

SCHMIDT, M.; ROHRBACH, K. Maraging steels. In: VOLUME 1: Properties and Selection: Irons, Steels, and High-Performance Alloys. 10th ed. Materials Park: Asm International, 1990. p. 1225-1237. Electronic files 2005.

SCHMIDT, M.; ROHRBACH, K. Heat treating of maraging Steels. In: VOLUME 4: Heat Treating. 10th ed. Materials Park: Asm International, 1991. p. 528-548. Electronic files 2005. 
SERVANT, C.; MAEDER, G.; CIZERON, G. A small-angle x-ray scattering investigation of the zone formation of "maraging" type alloys. Metallurgical Transactions A, v.6, p. 981-990, 1975.

SERVANT, C.; LACOMBE, P. Structural transformations produced during tempering of Fe-Ni-Co-Mo. Journal of Materials Science, v.12, p. 1807-1826, 1977.

SHA, W.; CEREZO, A.; SMITH, G. D. W. Phase chemistry and precipitation reaction in maraging steels: Part I. Introduction and study of Co-containing C-300 steel. Metallurgical Transactions A, v.24, p. 1221-1232, June 1993a.

SHA, W.; CEREZO, A.; SMITH, G. D. W. Phase chemistry and precipitation reaction in maraging steels: Part II. Co-free T-300 steel. Metallurgical Transactions A, v.24, p. 1233-1239, June 1993b.

SHA, W.; CEREZO, A.; SMITH, G. D. W. Phase chemistry and precipitation reactions in maraging steels: Part III. Model alloys. Metallurgical Transactions A, v.24, p. 1241-1249, June 1993c.

SHA, W.; CEREZO, A.; SMITH, G. D. W. Phase chemistry and precipitation reactions in maraging steels: Part IV. Discussion and Conclusions. Metallurgical Transactions A, v.24, p. 1251-1256, June 1993d.

SHA, W. Quantification of age hardening in maraging steels and an Ni-base superalloy. Scripta Materialia, v. 42, p. 549-553, 2000.

SHA, W.; GUO, Z. Maraging steels: modeling of microstructure, properties and applications. Cambridge: Woodhead Publishing Limited $1^{\text {st }}$ edition, 2009. 203p.

SHA, W.; LI, Q.; WILSON, E. A. Precipitation, microstructure and mechanical properties of low nickel maraging steel. Materials Science and Technology, v. 27, p. 983-989, 2011.

SHETTY, K.; KUMAR; S.; RAO; P. R. Effect of ion nitriding on the microstructure and properties of maraging steel (grade 250). Surface and Coating Technology, v. 203, p.1530-1536, 2009.

SHMULEVITSH, M. et al. Elastic consideration of the precipitation in model alloys of maraging steels: theory and experimental validation. Journal of Materials Science, v. 50 , p. $4970-4979,2015$.

SILVA, O. L. P.; MARQUES, A. L. F. Enriquecimento de urânio no Brasil: desenvolvimento da tecnologia de ultracentrifugação. Economia e Energia, n. 54, p. 3-9, 2006.

SINHA, P. P.; THARIAN, K. T.; SREEKUMAR, K.; NAGARAJAN, K.V.; SARMA, D. S. Effect of aging on microstructure and mechanical properties of cobalt free $18 \% \mathrm{Ni}$ (250 grade) maraging steel. Materials Science and Technology, v. 14, p. 1-9, 1998.

SOUZA, S. A. Ensaios mecânicos de materiais metálicos. São Paulo: Edgard Blüncher, 5a edição, 1982. 286 p. 
SPITZIG, W. A.; CHILTON, J. M.; BARTON, C. J. Structure and strengthening mechanisms in $300-$ grade $18 \mathrm{Ni}-\mathrm{Co}-\mathrm{Mo}-\mathrm{Ti}$. Source book on maraging steels, ASM, p. 1-19, 1979.

STARINK, M. J. Kinetic equations for diffusion-controlled precipitation reactions. Journal of Materials Science, v. 32, p. 4061-4070, 1997.

STARINK, M. The determination of activation energy from linear heating rate experiments: a comparison of the accuracy of isoconversion methods. Thermochimica Acta, v. 404, p. 163-176,2003

TAKEUCHI, A. Y. Técnicas de medidas magnéticas. São Paulo: Editora Livraria da Física, 2010. 80p.

TAMURA, I.; TSUZAKI, K.; MAKI, T. Morphology of lath martensite formed from deformed austenite in $18 \% \mathrm{Ni}$ maraging steel. Journal de Physique, v. 43 , p. 551556, 1982.

TAVARES, S. S. M. et al. A thermomagnetic study of the martensite-austenite phase transition in the maraging 350 steel. Journal of Alloys and Compounds, v. 358, p. 152-156, 2003.

TAVARES, S.S.M. et al. Magnetic properties of a Ni-Co-Mo-Ti maraging 350 steel. Journal of Alloys and Compounds, v. 373, pp.304-311, 2004a.

TAVARES, S. S. M. et al. A magnetic study of the maraging 350 steel. Journal of Magnetism and Magnetic Materials, v. 272, p. 785-787, 2004b.

TEWARI, R., MAZUMDER, S., BATRA, I. S., DEY, G. K., BANERJEE, S. Precipitation in $18 \mathrm{wt} \% \mathrm{Ni}$ maraging steel of grade 350 . Acta Materialia, v. 48 , p. 1187-1200, 2000.

VASUDEVAN, V. K., KIM, S. J., WAYMAN, C. M. Precipitation reactions and strengthening behavior in $18 \mathrm{wt}$ pct nickel maraging steels. Metallurgical Transactions A, v.21, p. 2655-2668, 1990.

VISWANATHAN, U. K.; DEY, G. K.; ASUNDI, M. K. Precipitation hardening in 350 grade maraging steel. Metallurgical Transactions A, v. 24, p. 2429-2442, 1993a.

VISWANATHAN, U. K.; KUTTY, T. R. G.; GANGULY, C. Dilatometric technique for evaluation of the kinetics of solid-state transformation of maraging steel. Metallurgical Transactions A, v. 24, p. 2653-2656, $1993 \mathrm{~b}$.

VISWANATHAN, U. K.; DEY, G. K.; SETHUMANDHAVAN, V. Effects of austenite reversion during overageing on the mechanical properties of $18 \mathrm{Ni}(350)$ maraging steel. Materials Science and Engineering A, v. 398, p. 367-372, 2005.

VICENTE, A. A.; GIUSEPONE Jr, G. A.; PADILHA, A. F. Efeito do molibdênio no comportamento de oxidação a alta temperatura ao ar de aços maraging de ultra alta resistência mecânica. Anais do 55 Congresso Anual da ABM, p. 2035-2040, 2000. 
WILSON, E. A. Quantification of age hardening in an Fe-12Ni-6Mn alloy. Scripta Materialia, v. 36, p. 1179-1185, 1997.

WOOD, H. G.; GLASER, A.; KEMP, R. S. The gas centrifuge and nuclear weapons proliferation. Physics Today, v. 40, p.40-45, 2008.

ZETNER, M. D.; COLES, G. L.; TALBERT, R. J. Nuclear proliferation technology trends analysis. Pacific Northwest National Laboratory, September 2005. 106 p.

ZHANG, J. S.; LIU, X. J ; CUI, H. ; DUAN, X. J., SUN, Z. Q.; CHEN, G. L. Ageing behaviour of spray-deposited $18 \mathrm{Ni}$ (250) maraging steel+ 10 vol.\% Al 203 particulate-reinforced metal matrix composites. Materials Science and Engineering A, v. 225, 96-104, 1997. 